\author{
UNIVERSIDADE DE SÃO PAULO \\ ESCOLA DE ENGENHARIA DE SÃO CARLOS \\ DEPARTAMENTO DE ENGENHARIA DE ESTRUTURAS
}

LUIZ FERNANDO DE OLIVEIRA FRIEDEL

Análise de estruturas planas reforçadas com fibras ativas viscoelásticas e matriz com modelo constitutivo hiperelástico: aplicações gerais em engenharia e biomecânica 



\title{
Análise de estruturas planas reforçadas com fibras ativas viscoelásticas e matriz com modelo constitutivo hiperelástico: aplicações gerais em engenharia e biomecânica
}

\author{
VERSÃO CORRIGIDA \\ A versão original encontra-se na Escola de Engenharia de São Carlos
}

Dissertação apresentada ao Departamento de Engenharia de Estruturas da Escola de Engenharia de São Carlos, Universidade de São Paulo, como parte dos quesitos necessários para obtenção do título de Mestre em Engenharia Civil (Estruturas).

Orientador: Prof. Dr. Rodrigo Ribeiro Paccola 
AUTORIZO A REPRODUÇÃO TOTAL OU PARCIAL DESTE TRABALHO, POR QUALQUER MEIO CONVENCIONAL OU ELETRÔNICO, PARA FINS DE ESTUDO E PESQUISA, DESDE QUE CITADA A FONTE.

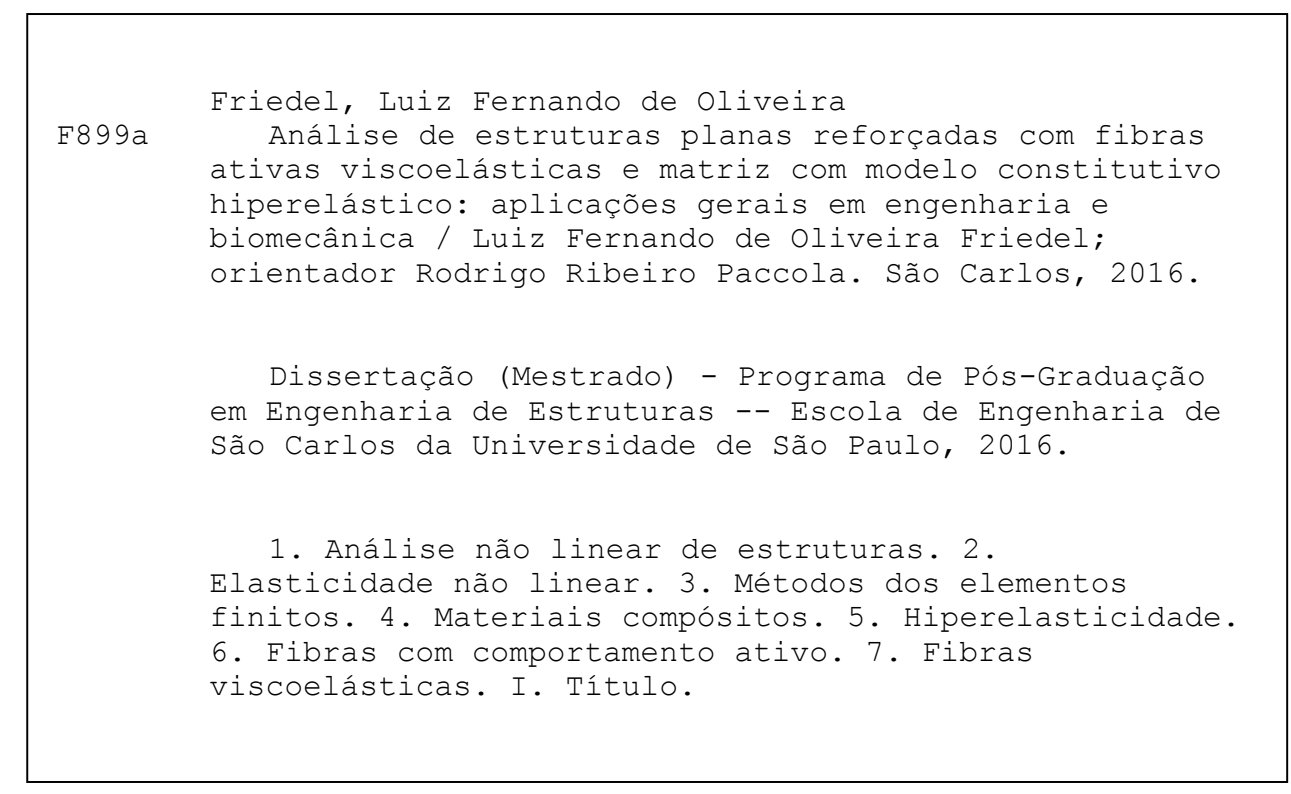




\section{FOLHA DE JULGAMENTO}

Candidato: Engenheiro LUIZ FERNANDO DE OLIVEIRA FRIEDEL.

Título da dissertação: "Análise de estruturas planas reforçadas com fibras ativas viscoelásticas e matriz com modelo constitutivo hiperelástico: aplicações gerais em engenharia e biomecânica".

Data da defesa: 15/03/2016

Comissão Julgadora:

Prof. Dr. Rodrigo Ribeiro Paccola (Orientador) (Escola de Engenharia de São Carlos/EESC)

Prof. Dr. João Paulo Pascon

(Escola de Engenharia de Lorena/EEL-USP)

Prof. Dr. Mariano Eduardo Moreno

(Universidade Federal de São Carlos/UFSCar)
Resultado:

APNVANO

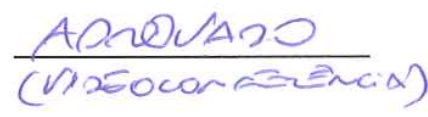

APROUADO

Coordenador do Programa de Pós-Graduação em Engenheira Civil (Engenharia de Estruturas):

Prof. Titular Humberto Breves Coda

Presidente da Comissão de Pós-Graduação:

Prof. Associado Paulo Sergio Lima Segantine 



\section{RESUMO}

FRIEDEL, L. F. O. Análise de estruturas planas reforçadas com fibras ativas viscoelásticas e matriz com modelo constitutivo hiperelástico: aplicações gerais em engenharia e biomecânica. 2016. 213p. Dissertação (Mestrado em Engenharia Civil (Estruturas)) - Escola de Engenharia de São Carlos, Universidade de São Paulo, São Carlos, 2016.

Neste trabalho apresenta-se uma formulação para modelagem não linear geométrica e não linear elástica de materiais compósitos através da imersão de elementos finitos de barra simples em elementos finitos triangulares do tipo chapa utilizando uma formulação inovadora do método dos elementos finitos baseada em posições. Essa formulação posicional utiliza funções de forma para aproximar grandezas definidas na Teoria da Elasticidade Não Linear e propõe que a energia específica de deformação e o potencial das cargas externas sejam escritos em função das posições nodais definidas a partir de uma função mudança de configuração. Assumindo as posições nodais valores atuais em cada nó, esse método considera naturalmente a não linearidade geométrica, ao passo que relações não lineares entre tensão e deformação podem ser consideradas através de uma teoria elástica não linear denominada hiperelasticidade que permite obter leis constitutivas linearizadas em formato variacional. Utilizando malhas independentes para os elementos de barras e chapa, a técnica para a imersão das barras adota funções de forma para escrever a posição de qualquer ponto de um elemento de barra em função dos nós dos elementos de chapa, não ocorrendo, portanto, nem o aumento do número de graus de liberdade nem a necessidade de que os nós dos elementos de barra coincidam com os nós dos elementos de chapa. Além disso, nesse trabalho propõe-se também uma formulação posicional para os elementos de barra simples que utiliza uma medida de deformação chamada de não linear de engenharia, a qual permite introduzir facilmente um comportamento tanto ativo quanto viscoso nos elementos de barra imersos. As formulações propostas são idealizadas para a modelagem de tecidos musculares, não estando, no entanto, limitadas somente a esse tipo de aplicação. Os quatro primeiro exemplos escolhidos são casos simples, alguns inclusive com soluções analíticas, e são destinados principalmente à validação das formulações apresentadas. Através da modelagem de uma estrutura formada por braço e antebraço, o quinto e último exemplo demonstra as potencialidades dos conceitos trabalhados e das formulações propostas durante este trabalho.

Palavras - chave: Análise não linear de estruturas. Elasticidade não linear. Métodos dos elementos finitos. Materiais compósitos. Hiperelasticidade. Fibras com comportamento ativo. Fibras viscoelásticas. 



\section{ABSTRACT}

FRIEDEL, L. F. O. Analysis of plane structures reinforced with active viscoelastic fibers and matrix with hyperelastic constitutive model: general applications in engineering and biomechanics. 2016. 213p. Dissertação (Mestrado em Engenharia Civil (Estruturas)) - Escola de Engenharia de São Carlos, Universidade de São Paulo, São Carlos, 2016.

This work presents a formulation for material and geometrical nonlinear analysis of composite materials by immersion of truss finite elements into triangular 2D solid ones using a novel formulation of the finite element method based on positions. This positional formulation uses the shape functions to approximate some quantities defined in the Nonlinear Theory of Elasticity and proposes to describe the specific strain energy and the potential of the external loads as function of nodal positions which are set from a deformation function. Because the nodal positions have current values in each node, this method naturally considers the geometric nonlinearities while the nonlinear relationships between stress and strain may be considered by a pure nonlinear elastic theory called hyperelasticity which allows to obtain linearized constitutive laws in its variational form. If independent meshes are used for the truss elements and for the $2 \mathrm{D}$ solid elements, the immersion technique of the trusses adopts shape functions to write the position of any point of a truss as a function of the nodal positions of the $2 \mathrm{D}$ solid elements, therefore there is neither an increase in the number of degrees of freedom nor the need that the nodes of the trusses elements coincide with the nodes of the 2D solid elements. Moreover, this work also proposes a positional formulation for the truss elements using a so called nonlinear engineering strain which allows to easily introduce both active and viscous behavior in the immersed truss elements. The proposed formulations are idealized for muscle tissue modeling, however they are not limited only to this type of application. The first 4 chosen examples are simple cases, some of them even with analytical solutions, mainly for validation purposes of the presented formulations. By modeling a structure formed by an arm and an forearm, the $5^{\text {th }}$ and last example shows the potentialities of the concepts and proposed formulations during this work.

Keywords: Nonlinear structural analysis. Nonlinear Elasticity. Finite element method. Composites. Hyperelasticity. Fibers with active behavior. Viscoelastic fibers. 



\section{KURZFASSUNG}

FRIEDEL, L. F. O. Analyse von zweidimensionalen strukturen mit aktiven viskoelastischen fasern verstärkt und matrix mit hyperelastischem materialmodell: allgemeine anwendungen im ingenieurwesen und in der biomechanik. 2016. 213p. Dissertação (Mestrado em Engenharia Civil (Estruturas)) - Escola de Engenharia de São Carlos, Universidade de São Paulo, São Carlos, 2016.

Durch das Einfügen von Stabelementen in zweidimensionale dreieckige Elemente wird in dieser Arbeit eine Ausarbeitung für die geometrische und materielle nichtlineare Modellierung von Verbundwerkstoffen vorgestellt, indem man eine auf Positionen basierende innovative Formulierung der Methoden der finiten Elemente benutzt. Diese positionelle Ausarbeitung benutzt Formfunktionen um die in der nichtlinearen Elastizitätstheorie definierten Mengen anzunähern und schlägt vor, die spezifische Deformationsenergie und das Potenzial der externen Kräfte als Funktion von der aus der Bewegungsfunktion definierten Positionen zu schreiben. Da die Knotenpositionen aktuelle Werte in jedem Knoten haben, enthält diese Methode die geometrische Nichtlinearität, wohingegen die nichtlinearen Beziehungen zwischen Dehnung und Spannung durch eine als Hyperelastizität bekannte nichtlineare elastische Theorie betrachtet werden können, welche den Erhalt von linearisierten konstitutiven Gleichungen in variierender Form ermöglicht. Benutzt man unabhängige Netze für die zweidimensionalen dreieckigen Elemente und die Stabelemente, schreibt die Technik für das Einfügen der Stabelemente die Positionen irgendwelcher Stabelementknoten als Funktion von zweidimensionalen Elementknoten, so dass sich weder der Freiheitsgrad des gesamten Systems erhöht, noch besteht die Notwendigkeit dass die Stabelementknoten in derselben Position wie die zweidimensionalen Elementknoten zusammenfallen. Außerdem wird in dieser Arbeit auch eine positionelle Formulierung für Stabelemente, die eine sogenannte ingenieurische nichtlineare Dehnung benutzt dargelegt, mit welcher sich sowohl ein aktives Verhalten als auch ein visköses Verhalten leicht in den eingefügten Stabelementen berücksichtigen lässt. Die vorgeschlagenen Formulierungen sind zunächst für die Modellierung von Muskelwerkstoffen entwickelt, sie sind aber nicht nur für solche Anwendungen geeignet. Die vier ersten ausgewählten Beispiele sind einfache Fälle, manche sogar mit analytischen Lösungen, und sind hauptsächlich nur für die Validierung der vorgestellten Ausarbeitung gedacht. Durch die Modellierung einer von Arm und Unterarm zusammengesetzten Struktur, bestätigt das fünfte und letzte Beispiel bestätigt die Potenzialität der während dieser Arbeit bearbeiteten Konzepte und vorgeschlagenen Formulierungen.

Schlüsselwörter: Nichtlineare Strukturanalyse. Nichtlineare Elastizität. Methode der finiten Elemente. Verbundwerkstoffe. Hyperelastizität. Faser mit aktivem Verhalten. Viskoelastiche Fasern. 



\section{LISTA DE ILUSTRAÇÕES}

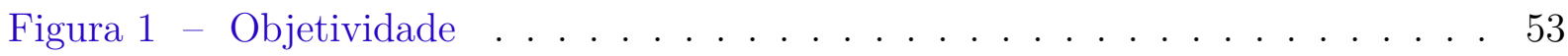

Figura 2 - Isotropia . . . . . . . . . . . . . . 58

Figura 3 - Formulação de um elemento finito posicional 2D . . . . . . . . . . . 69

Figura 4 - Carregamento distribuído nos lados do elemento finito de chapa . . . . 74

Figura 5 - Formulação de um elemento finito de barra simples posicional . . . . . 84

Figura 6 - Vetor tangente ao elemento finito de barra simples . . . . . . . . . 86

Figura 7 - Modelo viscoelástico ativo do elemento finito de barra simples . . . . . 94

Figura 8 - Espalhamento das forças internas do elemento finito de barra . . . . . . 97

Figura 9 - Espalhamento do hessiano do elemento finito de barra simples . . . . . 100

Figura 10 - Localização dos nós dos elementos finitos de barra simples . . . . . . . 104

Figura 11 - Propriedades musculares . . . . . . . . . . . . . . . . . . . 109

Figura 12 - Modelo de Hill . . . . . . . . . . . . . . . . . . . . . . . . . 109

Figura 13 - Modelo de Hill (1938) modificado . . . . . . . . . . . . . . . . 110

Figura 14 - Modelo para a fibra muscular . . . . . . . . . . . . . . . . . 112

Figura 15 - Modelo para o tecido muscular . . . . . . . . . . . . . . . 113

Figura 16 - Exemplo numérico 1 . . . . . . . . . . . . . . . . . . 122

Figura 17 - Modelo hiperelástico compressível de Yeoh sob deformação uniaxial . . 125

Figura 18 - Teste de convergência em tensões e deslocamentos . . . . . . . . . . . . 127

Figura 19 - Tensões e deslocamentos do modelo incompressível . . . . . . . . . . . 129

Figura 20 - Exemplo numérico $2 \ldots \ldots$. . . . . . . . . . . 130

Figura 21 - Estrutura de treliça na configuração deformada . . . . . . . . . . . . . 130

Figura 22 - Tensões viscosa e elástica no elemento de barra 1 . . . . . . . . . . 131

Figura 23 - Tensões elásticas nos elementos de barra . . . . . . . . . . . . . . . 132

Figura 24 - Deslocamentos dos nós 2 e $3 \ldots \ldots$. . . . . . . . . . . 132

Figura 25 - Deslocamentos dos nós 2 e $3 \ldots \ldots$. . . . . . . . . . . . . . . . . .

Figura 26 - Exemplo numérico $3 \ldots \ldots$. . . . . . . . . . . . 134

Figura 27 - Tensões e deslocamentos . . . . . . . . . . . . . . . . . 136

Figura 28 - Tensão nominal de engenharia nos elementos de barra simples . . . . . 137

Figura 29 - Exemplo numérico 4 . . . . . . . . . . . . . . . . . . . . . . 138

Figura 30 - Tensões e deslocamentos devido à contração das fibras . . . . . . . . . 139

Figura 31 - Tensões e deslocamentos nos elementos finitos de barra simples devido à contração das fibras . . . . . . . . . . . . . . . . . . . . 140 
Figura 32 - Deslocamento na direção x com procedimento iterativo de contração das fibras . . . . . . . . . . . . . . . . . . . . . . 142

Figura 33 - Tensões e deslocamentos com procedimento iterativo de alongamento das fibras . . . . . . . . . . . . . . . . . . . . . 142

Figura 34 - Tensão nominal de engenharia nos elementos de barra simples com procedimento iterativo de alongamento das fibras . . . . . . . . . . 143

Figura 35 - Deslocamentos com coeficiente de Poisson diferente de zero e devido à contração das fibras . . . . . . . . . . . . . . . . . . . . . . 143

Figura 36 - Barras paralelas e sujeitas a variação de temperatura . . . . . . . . . . 144

Figura 37 - Modelo de barras paralelas sujeitas a variação de temperatura . . . . . 146

Figura 38 - Tensões e deslocamentos devido ao encurtamento das fibras . . . . . . 146

Figura 39 - Tensão nominal de engenharia nos elementos de barra simples devido ao encurtamento das fibras . . . . . . . . . . . . . . . . . . . 147

Figura 40 - Exemplo numérico 5 . . . . . . . . . . . . . . . . . . . . 150

Figura 41 - Deslocamentos na direção x . . . . . . . . . . . . . . . . . . . . 151

Figura 42 - Deslocamentos na direção x . . . . . . . . . . . . . . . . . . . 152

Figura 43 - Tensões de Cauchy nas direções x e y . . . . . . . . . . . . . . . . . 152

Figura 44 - Deslocamentos na direção x . . . . . . . . . . . . . . . . . 153

Figura 45 - Deslocamentos nas direções x e y do nó 3031 . . . . . . . . . . . . . 154

Figura 46 - Deslocamentos na direção x devido a contração das fibras . . . . . . . . 156

Figura 47 - Deslocamento na direção x sem contração das fibras . . . . . . . . . . . 157

Figura 48 - Tensões nominais de engenharia nos elementos de barra simples devido a contração das fibras . . . . . . . . . . . . . . . . . . . . . . 158

Figura 49 - Deslocamentos na direção x devido a contração das fibras . . . . . . . . 158

Figura 50 - Deslocamento na direção x sem a contração das fibras . . . . . . . . . . 159

Figura 51 - Deslocamentos na direção x devido a contração das fibras . . . . . . . . 160

Figura 52 - Tensão nominal de engenharia nos elementos de barra simples sem a contração das fibras . . . . . . . . . . . . . . . . . . 160

Figura 53 - Tensões nominais de engenharia nos elementos de barra simples devido a contração das fibras . . . . . . . . . . . . . . . . . . . . . 161

Figura 54 - Deslocamentos na direção x devido à contração das fibras e aumento do módulo de elasticidade . . . . . . . . . . . . . . . . . . . . . . . 161

Figura 55 - Tensão nominal de engenharia nos elementos finitos de barra simples devido à contração das fibras e aumento do módulo de elasticidade . . 162 


\section{LISTA DE TABELAS}

Tabela 1 - Tempo de Processamento (em segundos) . . . . . . . . . . . . . 148

Tabela 2 - Ganhos obtidos com a paralelização . . . . . . . . . . . . . . . 148

Tabela 3 - Tempo de Processamento (em segundos) . . . . . . . . . . . . 155

Tabela 4 - Ganhos obtidos com a paralelização . . . . . . . . . . . . . . 155

Tabela 5 - Pontos e pesos de Hammer . . . . . . . . . . . . . . . 213 



\section{LISTA DE ABREVIATURAS E SIGLAS}

$\begin{array}{ll}\text { ARB } & \text { OpenMP Architecture Review Board } \\ \text { EESC } & \text { Escola de Engenharia de São Carlos } \\ \text { FORTRAN } & \text { Formula Translation } \\ \text { HUMOS } & \text { Human Model for Safety } \\ \text { OpenMP } & \text { Open Multi Processing } \\ \text { OpenMPI } & \text { Open Message Passing Interface } \\ \text { SET } & \text { São Carlos Estruturas } \\ \text { USP } & \text { Universidade de São Paulo }\end{array}$





\section{Letras Romanas Maiúsculas}
A, B
Tensor de $2^{\mathrm{a}}$ ordem qualquer
$\mathrm{C}$
Alongamento à direita de Cauchy-Green, Tensor de $2^{\mathrm{a}}$ ordem qualquer
$\mathbb{C}$
Tensor constitutivo
Div() Divergente com relação a configuração inicial indeformada
E Deformação de Green-Lagrange
$\mathbb{E} \quad$ Módulo de elasticidade
F $\quad$ Força interna, carga externa
$\mathbf{F}_{0} \quad$ Gradiente da função mudança de configuração inicial com relação ao elemento adimensional de referência
$\mathbf{F}_{1} \quad$ Gradiente da função mudança de configuração atual com relação ao elemento adimensional de referência
F $\quad$ Gradiente da função mudança de configuração
$\mathbf{F}_{i s o}, \mathbf{F}_{\text {vol }} \quad$ Parcelas isovolumétrica e volumétrica do gradiente da função mudança de configuração
G Módulo de elasticidade ao cisalhamento
$\operatorname{Grad}() \quad$ Gradiente com relação a configuração inicial indeformada
$H \quad$ Hessiano da estrutura
Grad() Gradiente com relação a configuração inicial indeformada
I Tensor identidade de $2^{\text {a }}$ ordem
$I_{1}, I_{2}, I_{3} \quad 1^{\mathrm{o}}, 2^{\mathrm{o}}$ e $3^{\mathrm{o}}$ invariante do alongamento à direita de Cauchy-Green
$\bar{I}_{1}, \bar{I}_{2}, \bar{I}_{3} \quad 1^{\circ}, 2^{\circ}$ e $3^{\circ}$ invariante a volume constante do alongamento à direita de Cauchy-Green 
Jacobiano do gradiente da função mudança de configuração

$\mathbf{P} \quad 1^{\circ}$ tensor de tensões de Piola-Kirchhoff

P Potencial das cargas externas

Q Movimento de rotação qualquer

R Parcela rotacional do alongamento à direita de Cauchy-Green ou à esquerda de Cauchy-Green

$2^{\text {o }}$ tensor de tensões de Piola-Kirchhoff

Área da secção transversal do elemento finito na configuração inicial indeformada

Força externa de superfície

Modulo do vetor tangente ao elemento finito de barra simples na configuração inicial indeformada

Modulo do vetor tangente ao elemento finito de barra simples na configuração atual deformada

U Energia de deformação

U Parcela de alongamento do alongamento à direita de Cauchy-Green, Campo de deslocamentos

$V \quad$ Volume na configuração inicial indeformada

X Posição na configuração inicial indeformada

Y Posição na configuração inicial indeformada

\section{Letras Romanas Minúsculas}

$\mathbf{a}_{0} \quad$ Direção do elemento finito de barra simples

a Parâmetro nodal para as funções de forma

b Alongamento à esquerda de Cauchy-Green, Forças de domínio

c Movimento de translação qualquer, Constante viscosa 


\begin{tabular}{|c|c|}
\hline$c_{10}, c_{20}, c_{20}$ & Constantes do modelo hiperelástico \\
\hline $\operatorname{det}()$ & Determinante de um tensor de $2^{\mathrm{a}}$ ordem \\
\hline $\operatorname{div}()$ & Divergente com relação a configuração atual deformada \\
\hline $\mathbf{e}_{i}, \mathbf{e}_{j}, \mathbf{e}_{k}$ & Componentes de uma base ortonormal qualquer do espaço tridimensional \\
\hline$e$ & Espessura do elemento de chapa \\
\hline$f$ & Função mudança de configuração, Movimento visto pelo observador A \\
\hline$f^{+}$ & Movimento visto pelo observador B \\
\hline$g$ & Função resposta do material, Vetor de desbalanceamento \\
\hline $\operatorname{grad}()$ & Gradiente com relação a configuração atual deformada \\
\hline$h$ & Hessiano do elemento finito \\
\hline$i, j, k, l$ & Índices utilizados em notações indiciais \\
\hline$k$ & Módulo de compressibilidade volumétrica \\
\hline$l_{0}$ & Comprimento inicial (configuração indeformada) \\
\hline$l$ & Comprimento final (configuração deformada) \\
\hline$m, n, o, p$ & Índices utilizados em notações indiciais \\
\hline $\mathbf{n}$ & Vetor unitário à superfície na configuração atual deformada \\
\hline$p$ & Estado hidrostático de tensões \\
\hline$q, r$ & Nó qualquer do elemento de chapa \\
\hline$s, z$ & Nó qualquer do elemento de barra \\
\hline$s$ & $\begin{array}{l}\text { Área da secção transversal do elemento finito na configuração atual } \\
\text { deformada }\end{array}$ \\
\hline t & Forças de superfície \\
\hline$t$ & Instante de tempo \\
\hline $\mathbf{u}$ & Tensor de $1^{\mathrm{a}}$ ordem qualquer \\
\hline$u_{e}$ & Energia específica de deformação \\
\hline iso, & Energia específica de deformação isovolumétrica e volumétrica \\
\hline
\end{tabular}




\section{Letras Gregas Maiúsculas}

$\Theta$

Volume na configuração atual deformada

Parcela de alongamento do alongamento à esquerda de Cauchy-Green

Peso do ponto de Hammer

Posição na configuração atual deformada

Posição na configuração atual deformada

Ângulo formado entre dois vetores quaisquer na configuração inicial indeformada

\section{Letras Gregas Minúsculas}

$\alpha_{0}, \alpha_{1}, \alpha_{2} \quad$ Coeficiente da função resposta do material

$\alpha, \beta, \gamma \quad$ Direção qualquer no plano cartesiano

$\gamma \quad$ Distorção angular

$\delta \quad$ Deslocamento, Delta de Kronecker

$\tilde{\boldsymbol{\epsilon}}$

Deformação não linear de engenharia do elemento finito de barra simples

$\epsilon$

Deformação longitudinal

$\zeta, \eta, \pi \quad$ Direção qualquer no plano cartesiano

$\theta$

Ângulo formado entre dois vetores quaisquer na configuração atual deformada
$\lambda$
Alongamento
$\nu$
Coeficiente de Poisson
Coordenada adimensional
$\pi$
Energia potencial total
$\rho_{0}$
Densidade na configuração inicial indeformada
$\rho$
Densidade na configuração atual deformada
$\sigma$
Tensor de tensões de Cauchy
$\phi, \varphi$
Função de forma 


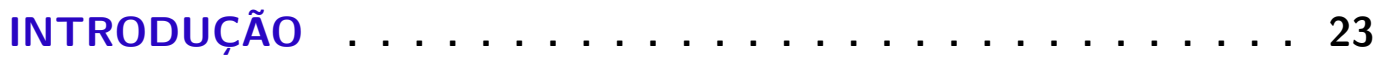

REVISÃO BIBLIOGRÁFICA . . . . . . . . . . . . . . 31

FUNDAMENTAÇÃO TEÓRICA . . . . . . . . . . . . . . 39

3.1 Mecânica do Contínuo e Elasticidade Não Linear . . . . . . . . . . . 39

3.1.1 Deformação . . . . . . . . . . . . . . . . . 40

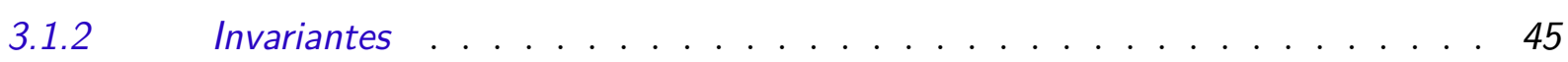

3.1.3 Fórmula de Nanson . . . . . . . . . . . . . . . 46

3.1.4 Fórmula do volume . . . . . . . . . . . . . . . . . . . . . . 46

3.1.5 Lei da conservação de massa . . . . . . . . . . . . . . . . 46

3.1.6 Equações de equilíbrio na forma integral . . . . . . . . . . . . . 47

3.1.7 Princípio da mínima energia potencial . . . . . . . . . . . . . . . 48

3.1.8 Tensores de tensão de Cauchy e de Piola-Kirchhoff . . . . . . . . . . . . . 52

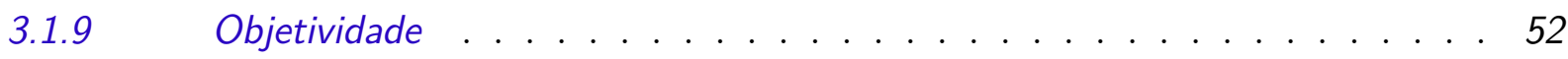

3.1.10 Leis constitutivas e hiperelasticidade . . . . . . . . . . . . . 54

3.2 Método dos Elementos finitos posicional . . . . . . . . . . . 64

3.2.1 Discretização do contínuo . . . . . . . . . . . . . . . 65

3.2.2 Análise não linear . . . . . . . . . . . . . . . 66

3.2.3 Elemento finito de chapa (2D) . . . . . . . . . . . . 69

3.2.4 Elemento finito de barra simples (1D) . . . . . . . . . . . . . . . 83

3.2.5 Imersão das fibras na matriz . . . . . . . . . . . . . . . 95

3.3 Leis constitutivas para Tecidos musculares . . . . . . . . . . . 104

3.3.1 Modelo de Hill . . . . . . . . . . . . . . . . . . . . 108

3.3.2 Comportamento muscular passivo . . . . . . . . . . . . . . . . . . 111

3.3.3 Comportamento muscular ativo . . . . . . . . . . . . . . . . . 112

3.3.4 Modelagem final tecido muscular . . . . . . . . . . . . . . . 113

$3.4 \quad$ Programação paralela . . . . . . . . . . . . . 113

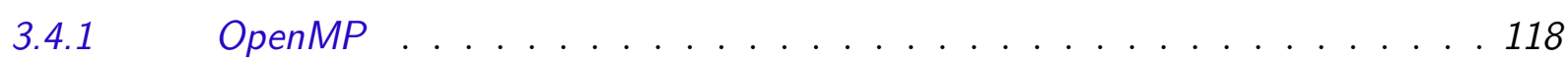


$4.1 \quad$ Chapa com Modelo constitutivo hiperelástico . . . . . . . . . . 122

4.1.1 Teste de convergência . . . . . . . . . . . . . . . 125

4.1 .2 Incompressibilidade . . . . . . . . . . . . . . . 128

4.2 Barra simples com Modelo constitutivo viscoelástico ativo . . . . . 129

4.3 Matriz reforçada com Fibras . . . . . . . . . . . . . . . . . . 134

4.4 Modelo de contração das Fibras . . . . . . . . . . . . . . . 137

4.4.1 A contração como variação de temperatura . . . . . . . . . . . . . . . 144

4.4.2 Tempos de processamento . . . . . . . . . . . . . . . . . . 147

$4.5 \quad$ Braço Biomecânico . . . . . . . . . . . . . . . . . . . . 149

4.5.1 Modelo neo-hookeno . . . . . . . . . . . . . . . . . 151

$4.5 .2 \quad$ Viscoelasticidade . . . . . . . . . . . . . . . . 153

$4.5 .3 \quad$ Tempos de processamento . . . . . . . . . . . . . . . . . . . . . . 154

4.5.4 Contração das fibras . . . . . . . . . . . . . . . . . . . 155

$5 \quad$ CONCLUSÕES . . . . . . . . . . . . . . 165

5.1 Sugestão para trabalhos futuros . . . . . . . . . . . 166

REFERÊNCIAS BIBLIOGRÁFICAS . . . . . . . . . . . . . . 167

APÊNDICES

APÊNDICE A $\quad$ NOTAÇÕES .................. 175

APÊNDICE B $\quad-\quad$ DEFORMAÇÕES DE ENGENHARIA . . . . . . 181

APÊNDICE C $\quad-\quad$ TENSORES CONSTITUTIVOS $\ldots \ldots \ldots$

APÊNDICE D $\quad$ - MODELOS CONSTITUTIVOS . . . . . . . 189

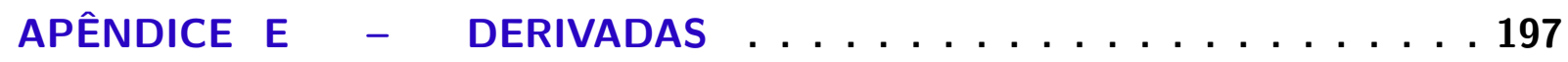

APÊNDICE F $\quad-\quad$ PROPRIEDADES TENSORIAIS ......... 201

APÊNDICE G - $\quad$ O ELEMENTO FINITO DE BARRA SIMPLES . . . 203

$\begin{array}{ll}\text { ANEXOS } & 207\end{array}$

ANEXO A - HISTÓRICO DOS MODELOS CONSTITUTIVOS . . . 209

ANEXO B - PONTOS E PESOS DE HAMMER . . . . . . . . 213 


\section{1}

INTRODUÇÃO

Tanto o desenvolvimento de dispositivos biomecânicos mais precisos, tais como válvulas e próteses, quanto o aprimoramento dos dispositivos atuais de proteção e segurança já existentes, como por exemplo cintos de segurança e air-bags, passam por modelagens biomecânicas cadas vez mais fiéis ao comportamento real do corpo humano (HUMPHREY, 2003).

Segundo Weiss, Maker e Govindjee (1996), e também como sugerido por diversos outros autores (HUMPHREY, 2003; MUGGENTHALER, 2006), um dos principais obstáculos no desenvolvimento dos modelos biomecânicos é a implementação de modelos constitutivos adequados, pois quase todos os tecidos biológicos são anisotrópicos, viscoelás$\operatorname{ticos}^{1}$, não homogêneos, quase incompressíveis e estão frequentemente sujeitos a altos níveis de deformação. A dificuldade de realização de ensaios in vivo em condições reais e a elevada não linearidade presente nas estruturas biológicas somadas ao fato de alguns dos tecidos biológicos possuírem fibras imersas e se encontrarem pré-tensionados, certamente dificulta ainda mais a modelagem biomecânica. Além do mais, a reprodutibilidade dos ensaios em tecidos biológicos é extremamente baixa, o que acaba gerando uma grande dispersão de dados (CHAGNON; REBOUAH; FAVIER, 2015). Se por um lado com experimentos em cadáveres só seja possível avaliar o comportamento passivo dos tecidos, por outro lado os testes em voluntários só são possíveis com pequenas cargas. Logo, a simulação numérica de estruturas biológicas constitui um grande desafio atual.

$\mathrm{Na}$ indústria automobilística, por exemplo, utilizam-se testes de colisão em escala real no desenvolvimento e otimização de sistemas de segurança. Algumas normas de segurança atuais definem procedimentos e parâmetros para os experimentos de colisão, tais como posição e velocidade de impacto, bem como a intensidade dos ferimentos resultantes. Nesses testes manequins são utilizados para simular o comportamento real dos ocupantes

\footnotetext{
${ }^{1}$ os efeitos viscoelásticos são caracterizados principalmente pela dependência do comportamento com a taxa de deformação (relaxamento ou fluência), além da histerese.
} 
durante a colisão e, a partir de parâmetros medidos nesses manequins, julgam-se então os danos e lesões que ocorreriam no complexo sistema do corpo humano. No entanto, devido às simplificações e à ausência, principalmente de tecido muscular ativo, os manequins são modelos idealizados do corpo humano. Juntas de ligações complexas são representadas por ligações mecânicas simplificadas, tecidos moles são substituídos por espumas e materiais sintéticos. (MUGGENTHALER, 2006)

Conforme demonstrado por Muggenthaler (2006), a atividade muscular modifica tanto as propriedades dos tecidos musculares como a cinemática geral de um modelo do corpo humano, podendo a ativação muscular (tanto voluntária quanto involuntária) exercer influência nas lesões resultantes de acidentes automobilísticos. Se essas lesões pudessem ser medidas de forma mais confiável e direta através de modelos numéricos com comportamento ativo, seria possível o desenvolvimento de sistemas mais seguros. Apesar disso, e conforme relatado por Muggenthaler (2006), existe atualmente uma carência de modelos numéricos humanos que consideram o comportamento muscular ativo.

Os tecidos biológicos podem ser divididos em dois grandes grupos: tecido duro e tecido mole. O tecido duro compreende os ossos e outras partes calcificadas, enquanto que o tecido mole engloba os músculos, tendões, ligamentos e órgãos. Tendões são estruturas biológicas que envolvem os músculos e os conectam aos ossos, já os ligamentos são as estruturas de conexão entre os diversos ossos (MUKHERJEE et al., 2007).

A caracterização e as propriedades dos tecidos duros já estão relativamente bem definidas e determinadas quando comparadas aos tecidos moles. É por isso que atualmente a modelagem do corpo humano está basicamente limitada à caracterização dos tecidos moles, os quais segundo diversos autores (WEISS; MAKER; GOVINDJEE, 1996; HUMPHREY, 2003; CHAGNON; REBOUAH; FAVIER, 2015) exibem características não lineares, heterogêneas, anisotrópicas e viscosas.

O tecido muscular pode ser imaginado tal como um material compósito formado por fibras musculares imersas em uma matriz (soft tissue). A matriz tem somente a função de estruturalmente organizar e conter as fibras. As fibras por sua vez são "animadas" e suas contrações induzem tensões tanto na matriz como nelas próprias. Logo, conforme inicialmente proposto por VanLeuwen (1992) e mais tarde também por Lu et al. (2010) e Böl et al. (2011), o comportamento mecânico de um tecido muscular pode ser decomposto em duas partes: uma ativa referente às fibras musculares e outra passiva correspondente tanto à matriz quanto às fibras.

O comportamento muscular passivo é o alongamento ou encurtamento muscular causado em resposta à aplicação de certa tensão, assim como a deformação de uma barra carregada axialmente em suas extremidades. Já o comportamento muscular ativo é a resposta em si em tensão ou deformação decorrente da tentativa de anular uma determinada distensão imposta, como por exemplo a contração de uma fibra (BAIOCCO; 
CODA; PACCOLA, 2013).

Segundo Tang, Zhang e Tsui (2009), a modelagem do comportamento mecânico de um tecido muscular pode seguir uma abordagem microscópica (Huxley (1957 apud TANG; ZHANG; TSUI, 2009)) ou macroscópica (Hill (1938 apud TANG; ZHANG; TSUI, 2009)). Geralmente o modelo macroscópico é utilizado para descrever o comportamento passivo que corresponde ao tecido mole (soft tissue) e às fibras musculares, enquanto que o modelo microscópico é utilizado para modelar o comportamento ativo que corresponde exclusivamente às fibras musculares (BAIOCCO; CODA; PACCOLA, 2013). As propriedades mecânicas das partes ativas e passivas constituem então as bases do desenvolvimento de modelos numéricos musculares.

De acordo com Chagnon, Rebouah e Favier (2015), o comportamento elástico geralmente é o que domina a resposta dos tecidos biológicos. Assim, o comportamento passivo não linear das fibras e do tecido mole geralmente é modelado através da Mecânica do Contínuo utilizando uma abordagem energética conhecida como hiperelasticidade. A hiperelasticidade consiste em escrever a energia específica de deformação em função (principalmente) dos invariantes do tensor de deformações, e constitui uma abordagem bastante geral e flexível com relação ao comportamento do material, pois permite considerar, além de grande deformações, também fenômenos de dano, efeitos viscoelástico, incompressibilidade e até anisotropia (HOLZAPFEL, 2000). Energias de deformação expressas em função dos invariantes $I_{1}, I_{2}$ e $I_{3}$ resultam em comportamentos isotrópicos, os quais somente se justificam para a matriz do tecido muscular.

O comportamento físico resultante da presença das fibras, que é de certa forma um tipo de anisotropia, pode ser levado em conta considerando a orientação preferencial das fibras através de um vetor orientado na direção das mesmas (WEICHERT et al., 2010). Nesse contexto, o tipo mais simples de anisotropia, a isotropia transversal, está presente em muitos tecidos biológicos (HUMPHREY, 2003) e pode ser considerada simplesmente introduzindo-se diretamente na equação da energia de deformação uma parcela de energia de deformação adicional que depende da direção preferencial do material na configuração de referência, conforme feito por alguns autores (WEISS; MAKER; GOVINDJEE, 1996; MARTINS et al., 1998; TANG; ZHANG; TSUI, 2009; CALVO et al., 2010; WEICHERT et al., 2010). A definição de novos invariantes dados em função das direções nas quais as fibras imersas estão orientadas permite definir parcelas adicionais de energia de deformação de uma forma compacta, admitindo inclusive considerar materiais com fibras orientadas em diversas direções (CHAGNON; REBOUAH; FAVIER, 2015). Assim, para um modelo muscular transversalmente isotrópico, a energia de deformação depende também de outros 2 invariantes adicionais $\left(I_{4}\right.$ e $\left.I_{5}\right)$, expressos em função de um vetor orientado na direção preferencial das fibras.

O comportamento ativo, por sua vez, é a própria tensão ou deformação das fibras 
escrita explicitamente através de uma função de ativação. Uma vez que as fibras musculares têm um comportamento tanto ativo quanto passivo, seu comportamento pode ser dado pela superposição em paralelo do seu comportamento ativo com o seu próprio comportamento passivo, conforme o modelo proposto por Hill.

Finalmente, segundo Calvo et al. (2010), tem-se que a superposição dos efeitos do comportamento muscular ativo (fibra muscular) com o comportamento muscular passivo (matriz e fibra muscular) descreve o comportamento do tecido muscular como um todo.

Em análises por elementos finitos, os músculos passivos geralmente são modelados através de elementos sólidos tridimensionais, enquanto os músculos ativos são representadas por modelos unidimensionais de barra simples (MUKHERJEE et al., 2007). Logo, é razoável propor a modelagem do tecido muscular através da imersão de fibras representadas por elementos unidimensionais de barra simples, que seguem o modelo muscular de Hill e transmitem forças quando ativados durante a simulação, em uma matriz discretizada através de elementos sólidos com relação não linear entre tensões e deformações, incluindo também eventuais efeitos viscosos.

Apesar dos tecidos musculares também exibirem propriedades viscoelásticas, poucos são os autores que consideram os efeitos viscosos em seus modelos (BOSBOOM et al., 2001; MUKHERJEE et al., 2007; MUGGENTHALER, 2006), e mesmo quando o fazem, geralmente adotam o modelo de Maxwell ao invés do modelo de Kelvin-Voigt. Apesar do modelo de Maxwell permitir expressar o fenômeno de relaxamento simplesmente através de uma rigidez escrita em função do tempo, o fenômeno de fluência descrito pelo modelo de Kelvin-Voigt é muito mais representativo do efeito muscular viscoso, pois através deste é possível simular um efeito de "fadiga" muscular, no sentido de que um músculo contraído por um determinado intervalo de tempo já não tem a mesma capacidade muscular que a do início da contração

O presente trabalho se fundamenta em três pilares da biomecânica, que segundo Humphrey (2003) são: Mecânica do Contínuo (elasticidade não linear), ferramentais computacionais e métodos matemáticos (método dos elementos finitos, por exemplo).

\subsection{Justificativa}

As principais justificativas para este trabalho são:

- Dentre os trabalhos de modelagem de tecidos biológicos (musculares) é comum adotar leis constitutivas hiperelásticas. Poucos são os trabalhos que utilizam a estratégia de abordar o problema tal como fibras imersas em uma matriz. A imersão de fibras na matriz possibilita incluir tanto um comportamento viscoelástico quanto um ativo do tecido muscular de uma forma simples e direta; 
- O método dos elementos finitos posicional, além de constituir uma nova abordagem em relação ao método baseado em deslocamentos, é também objeto de estudo do grupo de pesquisa em métodos numéricos SET/EESC/USP, no qual se insere o presente projeto;

- Demonstrar a aplicabilidade do método dos elementos finitos posicional em problemas da elasticidade não linear;

- O presente trabalho procura contribuir para a linha de pesquisa de modelagem de tecidos biológicos do Departamento de Engenharia de Estruturas (SET/EESC/USP);

\subsection{Objetivos}

Um dos objetivos desse trabalho é o desenvolvimento de um código computacional baseado no método dos elementos finitos posicional conforme proposto por Coda (2003), que utiliza modelos constitutivos hiperelásticos quaisquer ${ }^{2}$ para simular o comportamento plano de tecidos musculares quando sujeitos a grandes deslocamentos e grandes deformações.

Também é parte integrante dos objetivos deste trabalho o desenvolvimento de uma formulação baseada no método dos elementos finitos posicional e em uma estratégia inovadora de imersão de elementos finitos do tipo barra simples em elementos do tipo chapa. Essa formulação deve ser capaz de incluir tanto o comportamento viscoelástico quanto o ativo dos tecidos musculares, além de também permitir considerar relações não lineares entre tensões e deformações.

Utilizando a biblioteca OpenMP tem-se também como objetivo deste trabalho a paralelização de algumas partes do código desenvolvido.

\subsection{Metodologia}

Este trabalho se inicia com uma fundamentação teórica dos conceitos de: mecânica dos sólidos, mecânica das estruturas, método dos elementos finitos, Teoria da Elasticidade Linear e não linear, Mecânica do Contínuo, Álgebra Tensorial, métodos dos elementos finitos posicional e programação na linguagem FORTRAN. Um considerável tempo foi investido na familiarização com as bibliotecas OpenMP, OpenMPI, linguagem Phyton e o ambiente Linux, já que esses têm ocupado cada vez mais espaço na computação científica, especialmente em programação paralela (LEVEQUE, 2015).

O modelo muscular de Hill ou os modelos que consideram as fibras de forma indireta (por exemplo utilizando formulações hiperelásticas e através de parcelas adicionais de energia de deformação conforme as direções nas quais as fibras imersas estão orientadas)

\footnotetext{
${ }^{2}$ desde que a energia específica de deformação proposta seja composta de uma parcela de energia de deformação isovolumétrica e uma parcela de energia de deformação volumétrica, ambas escritas em função dos invariantes $\bar{I}_{1}, \bar{I}_{2}$ e $\bar{I}_{3}$
} 
podem ser ditos "contínuos", uma vez que as fibras e a matriz não estão separadas de uma forma explícita. Ao contrário destes, o modelo muscular proposto será de um tipo "discreto" por meio da adição de fibras musculares em uma matriz muscular (tecido mole) através da imersão de elementos finitos do tipo barra simples em elementos do tipo chapa. Isso será feito utilizando a formulação posicional do método dos elementos finitos e com base em uma estratégia inovadora desenvolvida no Departamento Engenharia de Estruturas da EESC - USP, que permite utilizar malhas independentes para a matriz e para as fibras. Essa estratégia possibilita, portanto, a imersão de fibras sem aumento do número de graus de liberdade do modelo ou necessidade de coincidência dos nós das fibras com os nós da matriz.

No modelo proposto, a contração muscular acontece através de deformações impostas diretamente nos elementos de barra simples imersos. Essas contrações impostas nos elementos de barra simples geram forças internas na matriz, fazendo com que o conjunto muscular (matriz + fibras) como um todo se contraia. Uma vez que a formulação proposta considera um modelo constitutivo viscoelástico para o elemento de barra simples, pode-se também admitir um certo grau de comportamento viscoso para o tecido muscular.

Para facilitar a consideração tanto do comportamento muscular ativo quanto viscoelástico foi necessário também formular um elemento de barra simples utilizando uma medida de deformação chamada de medida de deformação não linear de engenharia. Essa medida de deformação permitiu que a lei constitutiva e as medidas de tensão e deformação utilizadas para o elemento de barra simples fossem totalmente referenciados à configuração inicial indeformada, dando origem a um elemento finito ao mesmo tempo repleto de significado físico e adequado para análises envolvendo grandes deslocamentos e grandes deformações.

Os tópicos deste trabalho foram, portanto, os seguintes:

- Desenvolvimento de um código de elementos finitos posicional 2D (estruturas de chapa) não linear geométrico utilizando a elasticidade não linear (hiperelasticidade);

- Pesquisa sobre a modelagem de tecidos musculares contemplando tanto a abordagem de meio homogêneo como a de meio heterogêneo;

- Aprimoramento do código desenvolvido com a imersão dos elementos finitos de barra simples a fim de simular as fibras musculares;

- Inclusão do comportamento viscoelástico e ativação dos elemento de fibra, o que acabou resultando em uma reformulação do elemento finito de barra simples;

- Simulações numéricas de problemas para validação das implementações realizadas durante a pesquisa.

- Paralelização de algumas partes do programa e verificação dos ganhos de tempo. 
A fundamentação teórica a cerca da Teoria da Elasticidade Não Linear e da Álgebra Tensorial, imprescindíveis ao desenvolvimento do tema proposto, consumiram a maior parte do tempo deste trabalho. 



\section{REVISÃO BIBLIOGRÁFICA}

A modelagem numérica e o comportamento mecânico de tecidos biológicos são temas atuais e, por isso, diversos autores ainda buscam maneiras de conduzir tanto simulações numéricas quanto ensaios para o levantamento de parâmetros de estruturas biológicas que apresentem boa repetibilidade e confiabilidade. Esses autores continuam a propor várias formas de caracterizar as propriedades dos tecidos biológicos com o intuito de chegar a um consenso da melhor forma de quantificar as propriedades mecânicas das estruturas biológicas de uma forma mais geral e que possa ser aplicado em situações diversas.

Humphrey (2003) faz uma revisão do atual estado da arte da biomecânica, além de também descrever um pouco da história da evolução da biomecânica, destacando inclusive alguns nomes bastante conhecidos, tais como: Leonardo da Vinci (1452-1519), Galileo Galilei (1564-1642), René Descartes (1596-1650), Leonard Euler (1707-1783), Robert Hooke (1635-1703) e Thomas Young (1773-1829). Humphrey (2003) destaca que, devido a sua complexidade, a evolução da biomecânica moderna só foi possível devido aos avanços teóricos da Mecânica do Contínuo (elasticidade não linear) principalmente entre 1940-1970, graças a Ronald Samuel Rivlin, Leslie Ronald George Treloar, Albert Edward Green, Anthony James Merrill Spencer, Jerald LaVerne Ericksen, Clifford Truesdell, Walter Noll, John Edward Adkins entre outros, aos avanços tecnológicos computacionais e ao desenvolvimento de métodos matemáticos adequados (método dos elementos finitos, por exemplo).

No que se refere a modelagem de tecidos biológicos, Muggenthaler (2006), Muggenthaler et al. (2008) estudaram a influência da atividade muscular na cinemática e nas propriedades musculares por meio de experimentos em voluntários. As alterações nas propriedades devido a ativação muscular foram estimadas através de um corpo de impacto dotado de um acelerômetro interno que caía verticalmente em queda livre sobre o músculo frontal e traseiro da coxa bem como também sobre o bíceps de voluntários. Em seguida, 
utilizando as respectivas partes (perna e braço) do modelo humano em elementos finitos HUMOS, repetiram-se os mesmos experimentos em simulações numéricas. Nessas simulações numéricas, os modelos constitutivos foram aprimorados iterativamente até que as acelerações do corpo de impacto na simulação numérica coincidissem com aquelas medidas pelo acelerômetro nos experimentos reais. Concluiu-se que o modelo viscoelástico linear de Zerner baseado no modelo de Maxwell representa melhor o comportamento dos músculos da coxa e do bíceps (principalmente com o músculo ativado e na direção transversal às fibras) do que o modelo hiperelástico modificado de Hart - Smith anteriormente utilizado no HUMOS.

Muggenthaler (2006), Muggenthaler et al. (2008) também realizaram análises cinemáticas com pêndulos de impacto dotados de acelerômetros internos que atingiam os voluntários na lateral um pouco abaixo do ombro, no peito e nas costas. Utilizando o modelo humano completo em elementos finitos HUMOS, os mesmos experimentos foram então repetidos em simulações numéricas. As simulações numéricas cinemáticas mostraram que, mesmo adotando o modelo muscular viscoelástico de Zerner, o modelo humano completo superestima a rigidez do corpo humano como um todo. A fim de verificar a influência do nível de atividade muscular, todos os testes foram realizados sobre diferentes intensidades de contrações musculares dos voluntários. Os movimentos e o nível de atividade muscular, bem como o instante de ativação da musculatura de cada indivíduo, foram captados, respectivamente, por câmeras de alta velocidade e eletrodos superficiais sob a pele.

O HUMOS (Human Model for Safety) é um projeto financiado pela União Europeia do qual participam empresas ligadas à indústria automobilística, institutos de pesquisa e desenvolvedores de softwares. Seu principal objetivo é a criação de um banco de dados com informações referentes as propriedades geométricas, leis constitutivas e dados experimentais do corpo humano necessários à criação de modelos numéricos de ocupantes de veículos. (COMMUNITY RESEARCH AND DEVELOPMENT INFORMATION SERVICE, 2015)

Com o objetivo de capturar os efeitos do comportamento ativo dos tecidos musculares, Mukherjee et al. (2007) investiga a influência do comportamento muscular ativo de 40 músculos dos membros inferiores nas lesões resultantes nos joelhos e tornozelos decorrentes de atropelamentos. Os músculos foram modelados através de elementos de barras conforme o modelo muscular proposto por Hill, utilizando uma lei constitutiva viscoelástica linear para modelar o comportamento passivo e funções de ativação dependentes do comprimento, velocidade de contração e nível de ativação das fibras musculares para modelar o comportamento muscular ativo.

Sendo então a consideração do comportamento ativo das fibras um objetivo comum de muito autores, Martins et al. (1998) introduziram o modelo de comportamento ativo das fibras musculares conforme proposto por Zajac (1989) ao termo referente à energia específica de deformação dessas fibras no modelo constitutivo hiperelástico para comportamento 
passivo de tecidos musculares idealizado por Humphrey e Yin (1987). Assim foi possível correlacionar a dependência da resposta de um tecido muscular com a função de ativação.

Tang, Zhang e Tsui (2009) também desenvolveram um modelo 3D para simular o comportamento passivo e ativo de tecidos musculares. O modelo de Hill foi utilizado para descrever os comportamentos ativo e passivo da fibra. As relações constitutivas foram determinadas utilizando uma abordagem fundamentada na energia específica de deformação de tal forma que o músculo como um todo (fibras e matriz) foi modelado como um material hiperelástico. O comportamento ativo da fibra foi considerado através de incrementos de alongamento nos elementos do modelo de Hill.

A fim de considerar a distribuição e orientação das fibras, Weiss, Maker e Govindjee (1996) propõem uma formulação hiperelástica incompressível transversalmente isotrópica, onde as tensões no ponto dependem tanto do gradiente de deformação quanto da orientação das fibras do tecido. Os autores propuseram uma decomposição aditiva da energia de deformação em três parcelas: uma referente ao comportamento isotrópico da matriz, outra relativa as fibras e uma última que leva em conta o acoplamento entre a matriz e a fibra. A hipótese de incompressibilidade foi introduzida no modelo através de um multiplicador de Lagrange.

Visando a estabilidade do método dos elementos finitos, Weichert et al. (2010) propôs um método de reconstrução de malhas 3D a partir de cortes seriados em tecidos biológicos. A lei constitutiva hiperelástica de Mooney-Rivlin com energia de deformação decomposta em uma parcela isovolumétrica e outra volumétrica foi adotada na validação do método de geração de malha proposto. Da mesma forma que Weiss, Maker e Govindjee (1996) e a fim de também considerar a isotropia transversal, uma parcela adicional de energia de deformação do tipo exponencial na direção das fibras foi considerada.

Com relação a calibração de modelos constitutivos para tecidos biológicos, Bosboom et al. (2001) mediram a força necessária para comprimir a musculatura da tíbia de ratos entre duas placas paralelas sob controle de deslocamento. Utilizando os resultados desse experimento, calibraram um modelo não linear viscoelástico do comportamento muscular passivo por meio de uma simulação numérica do experimento. A não linearidade foi contemplada adotando-se o modelo hiperelástico incompressível de Ogden. A viscoelasticidade foi adicionada ao modelo constitutivo através de uma expansão em série de Prony.

Calvo et al. (2010) propõem um modelo constitutivo para o comportamento passivo tanto das fibras como da matriz de tecidos musculares. Tal modelo é baseado em resultados experimentais obtidos através de ensaios uniaxiais de músculos de ratazanas. O modelo hiperelástico é polinomial para o comportamento da matriz e exponencial para o comportamento da fibra.

Ao contrário dos dois últimos autores, Moerman et al. (2009) demonstram a 
possibilidade de calibração desses modelos constitutivos hiperelásticos por meio de técnicas não invasivas utilizando o método de correlação digital de imagens combinada com análises de elementos finitos iterativas, conhecidas como análises inversas. O trabalho de Moerman et al. (2009) consistiu em registrar imagens de testes de indentação em um gel de silicone, para em seguida, estimar as deformações a partir do processamento das imagens gravadas. Por fim, os parâmetros de uma lei constitutiva escolhida foram alterados de forma iterativa em simulações numéricas até que as deformações e a força de indentação medidas coincidissem com os valores obtidos nas simulações numéricas. Através da técnica inversa e utilizando uma lei constitutiva neo-hookena, os autores obtiveram praticamente as mesmas constantes de calibração obtidas em ensaios uniaxiais de compressão e, por isso, destacam o potencial de técnicas semelhantes no levantamento de propriedades de tecidos biológicos humanos.

Utilizando uma técnica parecida com a descrita por Moerman et al. (2009), Vannah e Childress (1996) calibraram um modelo constitutivo hiperelástico passivo baseado no modelo de Rivlin utilizando dados obtidos com a medição das forças necessárias para impor determinados deslocamentos prescritos de um endentador sob a panturrilha de voluntários. Foram feitas medições nos dois sentidos, isto é, aplicação de forças incrementais e posterior retirada da força final também de maneira incremental.

Vannah e Childress (1996) observaram que para pequenas cargas os fenômenos viscoelásticos (histerese, relaxamento e fluência) ocorreram, quase que exclusivamente, nos 5 segundos subsequentes a aplicação (ou incrementos) das forças. Assim, a fim de eliminar os efeitos da viscoelasticidade, aguardou-se 60 segundos entre o incremento de carga e a respectiva leitura dos dados. A geometria inferior da perna dos indivíduos foi obtida através de um processo de escaneamento. Os autores desenvolveram também um dispositivo para tentar garantir que os movimentos da parte inferior da perna fossem restringidos da mesma maneira que eles seriam restringidos na simulação numérica. Embora tenham sido realizados experimentos tanto na condição ativa como relaxada da musculatura, não foram propostos modelos diferentes e nem se calcularam diferentes constantes do modelo para cada condição.

A grande maioria das leis constitutivas propostas para tecidos biologicos apresentam parcelas hiperelásticas, conforme verificado em Chagnon, Rebouah e Favier (2015). Tais autores apresentam uma revisão de diversos modelos hiperelásticos comumente adotados na descrição de tecidos biológicos. Em Chagnon, Rebouah e Favier (2015) é possível encontrar as expressões para a energia específica de deformação de mais de 60 modelos hiperelásticos, divididos em três categorias: modelos isotrópicos (2 polinomiais e 8 exponenciais), modelos anisotrópicos e modelos estatísticos.

Johansson, Meier e Blickhan (2000) demonstraram que é possível retratar o comportamento incompressível dos tecidos musculares somente através de leis constitutivas hiperelásticas polinomiais ao invés de aplicar restrições aos graus de liberdade nodais a 
fim de garantir deformações isovolumétricas.

Na modelagem de tecidos biológicos destacam-se o modelo de Fung (1967) por ser um dos precursores na modelagem de tecidos biológicos, o modelo de Hart - Smith por ser um dos modelos utilizados no HUMOS (Human Model for Safety) e o modelo de Martins et al. (1998) por ser um dos poucos que tenta considerar a ativação das fibras musculares.

Segundo Holzapfel (2000), a hiperelasticidade é um dos ramos da Mecânica do Contínuo que estuda relações entre tensões e deformações. Um material hiperelástico é aquele cuja energia específica de deformação pode ser expressa através de uma função que relaciona um campo tensorial de tensões ou de deformações a um campo escalar.

Entre diversos trabalhos de investigação e propostas de novas leis constitutivas hiperelásticas está o trabalho de Hoss (2009) que estuda diversos modelos constitutivos para elastômeros incompressíveis disponíveis na literatura por meio da calibração das constantes constitutivas de cada modelo com dados obtidos em ensaios de tração uniaxial, cisalhamento puro e tração biaxial. O autor observou que muitos dos modelos estudados não geram predições teóricas satisfatórias para outros modos de deformação que não os empregados na calibração. A fim de propor um modelo hiperelástico, Hoss (2009) identificou tanto os termos que representam o enrijecimento dos elastômeros sob altas deformações quanto os termos responsáveis pela oscilação característica da curva tensão x deformação em baixas deformações.

Em Hoss (2009) também é possível encontrar um histórico bastante completo da evolução dos modelos hiperelásticos, desde a generalização proposta por Rivlin e Saunders (1951) do modelo de Mooney (1940), que mais tarde deu origem a família polinomial, passando pelos primeiros modelos logarítmicos e exponenciais idealizados respectivamente por Gent e Thomas (1958) e Smith et al. (1966), até os modelos que propõem uma expressão da energia de deformação baseada diretamente nos alongamentos principais $\lambda$ ao invés dos invariantes conforme introduzido por Ogden (1972). Hoss (2009) também menciona modelos da família limiting chain extensibility inicialmente proposta por Edwards e Vilgis (1987) e Takamizawa e Hayashi (1987), além de modelos baseados em termos de potências dos invariantes (inclusive com potências a determinar) inicialmente propostos por Knowles (1977). Dentre os modelos destaca-se o modelo de Yeoh (1990) pela sua simplicidade e bom desempenho na modelagem do comportamento de borrachas naturais.

Hoss e Marczak (2010) estudaram a energia de deformação de 40 modelos constitutivos hiperelásticos com o objetivo de identificar os termos responsáveis por introduzir o comportamento não linear entre tensões e deformações em pequenas e em grandes deformações. O método utilizado constituiu basicamente em calibrar as leis para diferentes modos e/ou intensidade de deformação com base em dados experimentais, seguido de uma posterior verificação da capacidade do modelo em predizer o comportamento para outros níveis e/ou modos de deformação. 
Segundo Hoss e Marczak (2010), muitos dos modelos hiperelásticos clássicos são falhos em reproduzir o comportamento não linear entre tensões e deformações em todos os regimes de deformações (intensidade e modo). Muitos desses modelos são, portanto, capazes de representar adequadamente o comportamento não linear somente entre certos níveis de deformação e/ou sob determinados modos de deformação. Sendo assim e com base em seu estudo, Hoss e Marczak (2010) propuseram uma lei constitutiva hiperelástica para representar o comportamento não linear de materiais biológicos e elastoméricos tanto em pequenas como em grandes deformações. Os autores concluíram que, ao contrário do indicado na literatura, os coeficientes dos modelos constitutivos hiperelásticos são melhor calibrados com dados experimentais obtidos em estados de deformação uniaxial ao invés de estados biaxiais ou de cisalhamento puro. Hoss e Marczak (2010) verificaram que as leis hiperelásticas contendo termos das potência dos invariantes estavam sempre entre as melhores em predizer o comportamento não linear. Eles observaram que as expressões contendo termos $e^{I_{1}}$ representam mais facilmente as não linearidades em pequenas deformações, enquanto expressões contendo termos $\ln \left(I_{2}\right)$ foram capazes de captar o enrijecimento em grandes deformações.

Ainda dentro do campo da hiperelasticidade, Pascon (2008) confrontou dados experimentais de materiais poliméricos com resultados de simulações do método dos elementos finitos posicional. O autor utilizou elementos finitos do tipo barra simples e casca e adotou leis constitutivas hiperelásticas polinomiais com a imposição de deformações a volume constante e concluiu que para materiais poliméricos naturais, o modelo de Yeoh reproduz adequadamente o comportamento experimental tanto em grandes como em pequenas deformações, provando, assim, que modelos hiperelásticos onde a energia específica de deformação varia somente com o primeiro invariante do tensor de alongamento à direita de Cauchy-Green podem resultar em leis hiperelásticas bastante representativas do comportamento real de determinados materiais. Pascon (2008) demonstrou que os modelos neo-hookeano e de Mooney-Rivlin reproduzem satisfatoriamente o comportamento de materiais poliméricos somente em pequenas deformações.

Adotando as leis constitutivas hiperelásticas de Rivilin-Sauders, Hartmmann Neff e neo-hookena com gradação funcional, isto é, variação gradual, contínua e suave dos parâmetros que caracterizam o material nas respectivas leis constitutivas, Pascon (2012) estendeu a formulação posicional do método dos elementos finitos para elementos sólidos tridimensionais hexaédricos e tetraédricos com grau de aproximação polinomial qualquer. O autor acrescentou também o fenômeno de plasticidade tanto com decomposição multiplicativa (grandes deformações plásticas) quanto aditiva (pequenas deformações plásticas) das parcelas elásticas e plásticas às leis constitutivas adotadas.

No que se refere a técnica de imersão das fibras na matriz, Vanalli (2004) investigou através do método dos elementos finitos baseado em deslocamentos e do método 
dos elementos de contorno o comportamento elástico, viscoelástico e viscoplástico de estruturas bidimensionais isotrópicas, anisotrópicas e ortotrópicas. Em seguida, Vanalli, Paccola e Coda (2008) propuseram um modelo para imersão de fibras em elementos finitos bidimensionais sem a necessidade de reordenação da malha e sem aumento do número de graus de liberdade. A formulação do modelo proposto consiste em escrever o campo de deslocamentos dos nós das fibras em função dos nós dos elementos da matriz. Os autores utilizaram elementos finitos triangulares planos de lados retos com 10 nós para a matriz e elementos lineares de barras de 2 nós para as fibras

Sampaio (2014), Sampaio, Paccola e Coda (2013) utilizaram a formulação do método dos elementos finitos baseado em posições para aperfeiçoar a metodologia de inclusão de fibras em matrizes inicialmente proposta por Vanalli (2004). A formulação posicional proposta adota funções de forma para escrever a posição de qualquer ponto da fibra em função dos nós da matriz. Essa nova formulação considera que as fibras possam ser formadas por elementos de barra retos ou curvos, e que a matriz seja constituída de elementos finitos planos triangulares de chapa ou casca, ambos com lados retos ou curvos. A metodologia reformulada contempla de forma natural e automática as não linearidades geométricas (grandes deslocamentos). Comprovou-se numericamente que, na metodologia posicional, a conformidade entre a fibra e a matriz é garantida desde que o grau de aproximação utilizado nas funções de forma que aproximam as posições das fibras seja no mínimo igual ao grau das funções de forma utilizadas para aproximar as posições do domínio da matriz. Assim, sendo os elementos conformes a aderência é perfeita e rígida.

Por meio dessa técnica proposta por Sampaio, Paccola e Coda (2013) para a imersão de fibras em uma matriz, Baiocco, Coda e Paccola (2013) propuseram, utilizando a lei constitutiva hiperelástica de Saint Venant-Kirchhoff, a modelagem do tecido muscular do bíceps. O comportamento ativo foi considerado impondo-se uma contração desejada diretamente nas fibras, a partir de onde foi possível estimar a força que seria gerada pelo músculo. O comportamento reativo da fibras, isto é, aquele se opõe em cada passo de carga a determinada ação externa procurando manter as deformações nulas foi apreciado de duas formas: uma considerando o módulo de elasticidade muito grande para as fibras, e outra, através de contrações propriamente ditas impostas em cada passo de carga nas fibras. Os autores concluíram que a matriz se deforma a fim de acomodar as distensões e contrações das fibras, e também sugerem melhorias no comportamento ativo e passivo das fibras.

O método dos elementos finitos posicional é bastante geral e flexível, podendo ser utilizado, por exemplo, em análises dinâmicas não lineares conforme Cavalcanti (2006). Tal autor comparou resultados de análises não lineares geométricas estáticas e dinâmicas com e sem impacto de sólidos bidimensionais obtidas com a formulação posicional Lagrangiana total exata do método dos elementos finitos (assim como apresentado no presente trabalho) 
com resultados obtidos por outros autores, bem como com soluções analíticas. Em seu trabalho, o impacto consiste na limitação das posições dos nós da estrutura. Cavalcanti (2006) utilizou o método de Newton-Raphson para a solução numérica dos sistemas não lineares resultantes. O algoritmo de integração temporal utilizado foi o trapezoidal implícito de Newmark para estruturas com a ausência de impacto. Um segundo algoritmo de integração temporal baseado no método de Newmark foi adotado para os casos de impacto sem atrito e sobre anteparo perfeitamente rígido. 


\section{3}

FUNDAMENTAÇÃO TEÓRICA

\subsection{Mecânica do Contínuo e Elasticidade Não Linear}

A fundamentação teórica sobre Mecânica do Contínuo e Elasticidade Não Linear foi retirada principalmente das aulas de SET5876 - Fundamentos da Mecânica dos Materiais e das Estruturas e SET 5884 - Introdução à Dinâmica Não-Linear de Estruturas Reticuladas ministradas pelo professor Humberto Breves Coda no departamento de Engenharia de Estruturas da EESC - USP, bem como das referências Holzapfel (2000), Novozhilov (1953) e Coda (2003). Em se tratando de Mecânica do Contínuo e elasticidade não linear, a referência Gurtin, Fried e Anand (2010) é também uma valiosa fonte de informação. A notação adotada neste trabalho é explicada no Apêndice A.

A Mecânica do Contínuo utiliza leis e conceitos físicos e termodinâmicos para equacionar o comportamento dos meios contínuos de forma geral através de uma linguagem matemática densa e de modo que as equações resultantes sirvam tanto para sólidos quanto para fluídos. Na Mecânica do Contínuo, a lei constitutiva é o único parâmetro que diferencia os sólidos dos fluidos. Geralmente, descrições Lagrangianas são utilizadas na mecânica dos sólidos, enquanto que descrições Eulerianas são utilizadas na mecânica dos fluidos. A descrição Lagrangiana utiliza referenciais fixos para caracterizar o movimento com relação à configuração inicial indeformada. Na descrição Lagrangiana do movimento, a análise é direcionada a uma partícula enquanto ela se move no espaço. Já a descrição Euleriana utiliza referenciais móveis para caracterizar o movimento com relação à configuração atual deformada. Na descrição Euleriana do movimento, a análise é direcionada a um ponto do espaço e observam-se as partículas que passam por esse ponto. (HOLZAPFEL, 2000)

Assim como geralmente acontece em mecânica dos sólidos, adota - se neste trabalho a forma Lagrangiana das equações da Mecânica do Contínuo ao invés da forma Euleriana.

A referência Novozhilov (1953) é particularmente interessante pela forma com que 
conduz a dedução das equações da elasticidade não linear. Ao contrário da maioria das abordagens tradicionais (modernas) que utilizam a Mecânica do Contínuo carregada de uma Álgebra Tensorial - inclusive com redefinições das medidas de tensões e deformações usuais -, Novozhilov (1953) aborda o problema utilizando a Teoria da Elasticidade em uma forma "pura" e praticamente sem utilizar qualquer notação tensorial.

Partindo exatamente das mesmas ideias fundamentais que norteiam a Teoria da Elasticidade Linear e seguindo inclusive a mesma sequência de raciocínio, Novozhilov (1953) mostra como seriam as equações da elasticidade se estas fossem deduzidas sem que as hipóteses de pequenas deformações (tanto normal quanto angular) e pequenas rotações fossem utilizadas. Assim, é possível compreender de forma bastante clara como os pilares da Teoria da Elasticidade (relações entre deslocamentos e deformações, equações de equilíbrio e lei constitutiva) ficam quase que intratáveis pela complexidade de suas equações, fazendose perceber a necessidade da utilização de uma nova teoria, a Mecânica do Contínuo, e um ferramental matemático poderoso, a Álgebra Tensorial, para o tratamento de problemas envolvendo grandes rotações e grandes deformações (este último com mais força ainda).

\subsubsection{Deformação}

Segundo Novozhilov (1953), o estudo das deformações consiste em, dadas as posições dos pontos de um corpo em suas configurações iniciais (antes da deformação) e finais (depois da deformação), determinar as alterações nas projeções da distância entre dois pontos arbitrários e infinitamente próximos do corpo causada pela transição da configuração inicial para a final. ${ }^{1}$. Essa é uma questão puramente geométrica, sendo que nem as causas da deformação (condições de contorno) e nem a lei de acordo com a qual o corpo resiste ou os efeitos resultantes (tensões) são importantes nesse estudo. A cinemática, por sua vez, é o estudo geral do movimento que contempla tanto as alterações de forma e volume (deformações) quanto os movimentos de corpo rígido.

Uma medida de deformação também pode ser matematicamente entendida como uma definição útil na formulação de problemas em elasticidade, enquanto que, fisicamente, as medidas de deformação representam as mudanças de forma do corpo. As principais medidas de deformação são: medida de deformação não linear de engenharia, medida de deformação linear de engenharia e medida de deformação de Green-Lagrange. As medidas de engenharia são de interesse prático, pois possuem significado físico (CODA, 2014a).

Neste trabalho optou-se por utilizar a deformação de Green-Lagrange para os elementos de chapa porque, além de ser uma medida de deformação tensorial (simétrica) livre de hipóteses de pequenos deslocamentos ou rotações, também não contém parcelas de movimento de corpo rígido (objetiva). Assim, a deformação de Green-Lagrange é adequada para análises não lineares. Além disso, a deformação de Green-Lagrange é definida a partir

\footnotetext{
${ }^{1}$ por se tratar das alterações nas projeções, a deformação angular também é contemplada
} 
da função mudança de configuração, a qual é função das posições nodais utilizadas para aproximar a solução na formulação posicional do método dos elementos finitos.

Para os elementos de barra simples adota-se uma medida de deformação chamada de deformação não linear de engenharia. Embora a utilização dessa medida de deformação resulte em uma formulação do método dos elementos finitos posicional com equações de tratamento matemático mais complicado, foi a utilização dessa medida de deformação para o elemento de barra simples que permitiu considerar tanto o comportamento ativo quanto o viscoelástico das fibras imersas nos elementos de chapa de uma forma simples e consistente. Essa medida de deformação de engenharia definida no Apêndice B também é adequada para análises não lineares envolvendo grandes deslocamentos e grandes deformações.

As deformações podem ser tanto reversíveis quanto irreversíveis, e ainda, dependentes ou não do tempo. As deformações reversíveis ou elásticas dependem apenas do estado final de deformações. Já as deformações irreversíveis ou plásticas dependem do histórico de deformações. Quando a deformação depende do tempo ela é denominada viscoelástica. Nesse trabalho todas as deformações são reversíveis.

Uma função mudança de configuração $f(\mathbf{X}, t)$ é um campo vetorial que mapeia todas as posições finais (condição atual deformada) $\mathbf{x}$ de todas as partículas de um corpo a partir das posições iniciais (condição inicial indeformada) $\mathbf{X}$ dessas partículas em um dado instante de tempo $t$, isto é, $\mathbf{x}=f(\mathbf{X}, t)$. A função mudança de configuração pode ou não assumir valores diversos no transcorrer do processo (CODA, 2003). Essa função mudança de configuração $f(\mathbf{X}, t)$, no entanto, não é conhecida e será aproximada através das posições nodais na formulação posicional do método dos elementos finitos.

Seja o conjunto formado pelos vetores diretores $\mathbf{e}_{1}, \mathbf{e}_{2}, \mathbf{e}_{3}$ uma base do espaço tridimensional. Seja ainda $\mathbf{X}$ o vetor contendo a posição inicial de uma determinada partícula no espaço tridimensional e $\mathbf{U}(\mathbf{X}, t)$ o campo de deslocamentos dessa partícula no instante $t$ dado em função de sua própria posição inicial $\mathbf{X}$, pode-se então escrever que a posição final x para qualquer partícula é:

$$
\mathbf{x}(\mathbf{X}, t)=\mathbf{X}+\mathbf{U}(\mathbf{X}, t)
$$

Na Equação 3.1, $\mathbf{U}(\mathbf{X}, t)$ é função das posições (fixas) na configuração inicial indeformada, caracterizando, dessa forma, uma descrição Lagrangiana do movimento. Em análises dependentes do tempo, a série de Taylor permite conhecer o posicionamento de uma partícula em um dado instante $t+\Delta t$ a partir do conhecimento de onde ela estava no instante $t$. Similarmente, nas análises não lineares, a série de Taylor permite conhecer a posição de uma partícula em relação a outra partícula infinitamente próxima a partir do conhecimento da posição relativa entre essas duas partículas antes da deformação. (HOLZAPFEL, 2000)

Considere $\mathbf{X}$ e $\mathbf{Y}$ os vetores posição de dois pontos infinitamente próximos na 
condição inicial indeformada. A posição desses mesmos dois pontos na condição atual deformada é dada através de funções mudança de configuração, isto é, $\mathbf{x}=f(\mathbf{X}, t)$ e $\mathbf{y}=f(\mathbf{Y}, t)$. Escrevendo então uma aproximação para essa última função mudança de configuração $(\mathbf{y}=f(\mathbf{Y}, t))$ no entorno na posição $\mathbf{X}$ (configuração de referência):

$$
\mathbf{y}=f(\mathbf{Y}, t)=f(\mathbf{X}+\Delta \mathbf{X}, t)=f(\mathbf{X}, t)+(\nabla \otimes f(\mathbf{X}, t)) \Delta \mathbf{X}+o^{2}
$$

No limite quando esses dois pontos se reduzem a um único ponto (limite quando $\Delta \mathbf{X} \rightarrow 0):$

$$
\begin{gathered}
\mathbf{y}=\mathbf{x}+\left(\frac{\partial\left(x_{i} \mathbf{e}_{i}\right)}{\partial X_{j}} \otimes \mathbf{e}_{j}\right) d X_{k} \mathbf{e}_{k}=\mathbf{x}+\left(\frac{\partial x_{i}}{\partial X_{j}} d X_{j}\right) \mathbf{e}_{i} \\
\mathbf{y}-\mathbf{x}=d \mathbf{x}=\left(\frac{\partial x_{i}}{\partial X_{j}} d X_{j}\right) \mathbf{e}_{i} \\
\therefore d x_{i}=\frac{\partial x_{i}}{\partial X_{j}} d X_{j}=F_{i j} d X_{j}
\end{gathered}
$$

Note que $\partial \mathbf{x}_{i} / \partial \mathbf{X}_{j}=F_{i j}$, por ser o gradiente de um campo vetorial, se caracteriza como um tensor de ordem 2 que relaciona a distância entre dois pontos infinitamente próximos na direção $i$ na configuração atual deformada $d x_{i}$, com a distância entre esses mesmos dois pontos na direção $j$ na condição inicial indeformada $d X_{j}$. O fato da distância $d x_{i}$ na direção $i$ e na configuração final deformada estar acoplada com a distância $d X_{j}$ na direção $j$ não necessariamente igual a $i$ e na configuração inicial indeformada advém do fato do sistema de coordenadas na configuração inicial indeformada se transformar em um sistema de coordenadas curvilíneo na configuração final deformada (NOVOZHILOV, 1953). Logo, para sistemas de coordenadas distintos, cada projeção $d X_{j}\left(d \mathbf{X}=\left(d X_{1}, d X_{2}, d X_{3}\right)\right)$ em um dos sistemas de coordenadas têm outras três projeções no outro sistema.

Esse tensor gradiente da função mudança de configuração $\mathbf{F}=\partial \mathbf{x} / \partial \mathbf{X}\left(\mathbf{e}_{i} \otimes \mathbf{e}_{j}\right)$ é uma medida do movimento no ponto ${ }^{2}$, que engloba tanto alterações/variações de comprimento, área e volume quanto parcelas de movimento de corpo rígido. Assim, F é uma medida primária de deformação que "informa" a mudança de forma do corpo no ponto X quando este sai da configuração inicial indeformada de referência para uma configuração final deformada. Além disso, $\mathbf{F}$ é uma medida Lagrangiana, pois, a posição atual x depende somente das posições iniciais $\mathbf{X}$ e a derivada $\partial \mathbf{x}_{i} / \partial \mathbf{X}_{j}$ é com relação a posição inicial $\mathbf{X}_{j}$ (CODA, 2003). Reescrevendo a Equação 3.3 em forma matricial:

$$
d \mathbf{x}=\left(\begin{array}{l}
d x_{1} \\
d x_{2} \\
d x_{3}
\end{array}\right)=\left(\begin{array}{lll}
\frac{\partial x_{1}}{\partial X_{1}} & \frac{\partial x_{1}}{\partial X_{2}} & \frac{\partial x_{1}}{\partial X_{3}} \\
\frac{\partial x_{2}}{\partial X_{1}} & \frac{\partial x_{2}}{\partial X_{2}} & \frac{\partial x_{2}}{\partial X_{3}} \\
\frac{\partial x_{3}}{\partial X_{1}} & \frac{\partial x_{3}}{\partial X_{2}} & \frac{\partial x_{3}}{\partial X_{3}}
\end{array}\right)\left(\begin{array}{l}
d X_{1} \\
d X_{2} \\
d X_{3}
\end{array}\right)
$$

\footnotetext{
${ }^{2}$ no ponto a igualdade da Equação 3.3 é exata, e não apenas uma aproximação
} 
Da mesma forma que algumas das equações encontradas por Novozhilov (1953), nota-se a partir da Equação 3.4 que as projeções de uma fibra infinitesimal de material após a deformação estão relacionadas de forma linear com as projeções desse mesmo elemento de fibra antes da deformação por meio de F. Utilizando a Equação 3.1:

$$
\begin{gathered}
\mathbf{F}=\operatorname{Grad}(\mathbf{x})=\nabla \otimes \mathbf{x}=\frac{\partial}{\partial X_{j}} \mathbf{e}_{j} \otimes\left(X_{k} \mathbf{e}_{k}+U_{k} \mathbf{e}_{k}\right)=\frac{\partial X_{k}}{\partial X_{j}}\left(\mathbf{e}_{k} \otimes \mathbf{e}_{j}\right)+\frac{\partial U_{k}}{\partial X_{j}}\left(\mathbf{e}_{k} \otimes \mathbf{e}_{j}\right) \\
\mathbf{F}=\left(\delta_{k j}+\frac{\partial U_{j}}{\partial X_{k}}\right)\left(\mathbf{e}_{j} \otimes \mathbf{e}_{k}\right)=\mathbf{I}+\operatorname{Grad}(\mathbf{U})
\end{gathered}
$$

Que também matricialmente é o mesmo que:

$$
\mathbf{F}=\left(\begin{array}{ccc}
1+U_{1,1} & U_{1,2} & U_{1,3} \\
U_{2,1} & 1+U_{2,2} & U_{2,3} \\
U_{3,1} & U_{3,2} & 1+U_{3,3}
\end{array}\right)
$$

Como do ponto de vista matemático as variações são vistas através das derivadas, o tensor gradiente da função mudança de configuração deve estar presente nas definições das deformações. Sendo assim, Green propôs em 1841 (OTTOSEN; RISTINMAA, 2005) a seguinte medida de deformação:

$$
\mathbf{E}=\frac{1}{2}\left(\mathbf{F}^{T} \mathbf{F}-\mathbf{I}\right)
$$

que é conhecida como medida de deformação de Green-Lagrange, uma vez que seu referencial é com relação à condição inicial indeformada (referencial Lagrangiano), conforme Equação 3.3. Observe na Equação 3.8 que movimentos de corpo rígido $\left(\mathbf{F}^{T} \mathbf{F}=\mathbf{I}\right)^{3}$ não introduzem deformações $(\mathbf{E}=0)$ e, portanto, a deformação de Green-Lagrange dada pela Equação 3.8 é uma medida da intensidade da variação da função mudança de configuração $\mathbf{x}$ do corpo já descontando o movimento de corpo rígido do mesmo. Logo, como a medida de deformação de Green-Lagrange contempla somente as alterações de forma e volume do corpo (CODA, 2003; PASCON, 2012), ela é uma medida objetiva de deformação. O tensor identidade I "desconta" a configuração inicial (fixa) indeformada de referência da medida de deformação. Lembrando que $\mathbf{F}$ é o gradiente da função mudança de configuração, tem se:

$$
\mathbf{F}=\operatorname{Grad}(\mathbf{U}+\mathbf{X})=\operatorname{Grad}(\mathbf{U})+\mathbf{I}
$$

Que substituindo na Equação 3.8 fica:

$$
\begin{gathered}
\mathbf{E}=\frac{1}{2}\left((\operatorname{Grad}(\mathbf{U})+\mathbf{I})^{T}(\operatorname{Grad}(\mathbf{U})+\mathbf{I})-\mathbf{I}\right) \\
\mathbf{E}=\frac{\operatorname{Grad}^{T}(\mathbf{U}) \operatorname{Grad}(\mathbf{U})}{2}+\frac{\operatorname{Grad}^{T}(\mathbf{U})+\operatorname{Grad}(\mathbf{U})}{2}
\end{gathered}
$$

\footnotetext{
${ }^{3}$ pelo Teorema da decomposição polar se $\mathbf{F}^{T} \mathbf{F}=\mathbf{I}$, então o movimento é puro de corpo rígido.
} 
Que em notação indicial é o mesmo que:

$$
E_{i j}=\frac{U_{k, i} U_{k, j}}{2}+\frac{U_{i, j}+U_{j, i}}{2}
$$

Assim como a deformação não linear de engenharia, a deformação de GreenLagrange para pequenos deslocamentos e pequenas rotações também se confunde com a deformação linear de engenharia, pois é possível desprezar o produto entre derivadas do deslocamento da Equação 3.11 e escrever:

$$
E_{i j} \simeq \frac{U_{i, j}+U_{j, i}}{2}
$$

Para o caso unidimensional e sem admitir qualquer hipótese de pequenos deslocamentos e pequenas rotações, tem - se para a medida de deformação de Green-Lagrange:

$$
\mathbf{E}=\frac{\operatorname{Grad}^{T}(\mathbf{U}) \operatorname{Grad}(\mathbf{U})}{2}+\frac{\operatorname{Grad}^{T}(\mathbf{U})+\operatorname{Grad}(\mathbf{U})}{2}=\frac{U_{1,1} U_{1,1}}{2}+\frac{U_{1,1}+U_{1,1}}{2}
$$

Como para o caso unidimensional:

$$
U_{1,1}=\frac{d u}{d x}=\frac{l-l_{0}}{l_{0}}
$$

A deformação de Green-Lagrange unidimensional então vale:

$$
\mathbf{E}=\frac{1}{2}\left(\frac{l^{2}-l_{0}^{2}}{l_{0}^{2}}\right)=\frac{1}{2}\left(\frac{l^{2}}{l_{0}^{2}}-1\right)
$$

Será visto mais adiante que, na Mecânica do Contínuo, é possível escrever a deformação de Green-Lagrange em função das posições, além de também definir, utilizando uma medida de tensão apropriada ( $2^{\circ}$ tensor de tensões de Piola-Kirchhoff), relações entre tensão e deformação . Uma vez que na Álgebra Tensorial I é equivalente a unidade e comparando agora as Equações 3.15 e 3.8, observa-se que $\mathbf{F}^{T} \mathbf{F}$ representa essencialmente uma medida de alongamento, ou seja, faz no espaço tridimensional o que o alongamento $\lambda^{2}=l^{2} / l_{0}^{2}$ faz no espaço unidimensional.

O produto $\mathbf{F}^{T} \mathbf{F}$ é conhecido por tensor de alongamento à direita de Cauchy-Green $\mathbf{C}$, isto porque o teorema da decomposição polar permite uma decomposição multiplicativa do tensor gradiente da função mudança de configuração $\mathbf{F}$ em dois outros tensores: um referente às rotações puras de corpo rígido $\mathbf{R}$, e outro relativo somente às parcelas de alongamento $\mathbf{U}$ (ou v), uma vez que $\mathbf{F}$ é uma medida primária de deformação que contém tanto parcelas de movimento de corpo rígido quanto alterações de forma e volume (deformação). A decomposição de $\mathbf{F}$ pode ser pela direita $\mathbf{F}=\mathbf{R} \mathbf{U}$ ou pela esquerda $\mathbf{F}=\mathbf{v R}$, de tal forma que existe um tensor de alongamento de Cauchy-Green a direita $\mathbf{C}=\mathbf{F}^{T} \mathbf{F}=\mathbf{U}^{2}$ e um tensor de alongamento de Cauchy-Green a esquerda $\mathbf{b}=\mathbf{F F}^{T}=\mathbf{v}^{2}$ (HOLZAPFEL, 2000; CODA, 2003). Logo, os tensores de alongamento a direita $\mathbf{C}$ e a esquerda b de Cauchy-Green não contêm parcelas de movimento de corpo rígido. 


\subsubsection{Invariantes}

Seja $\mathbf{C}$ um tensor que descreve o estado de tensões ou de deformações em um ponto qualquer de acordo com uma determinada orientação dos eixos. Da Álgebra Tensorial, têm-se sempre os mesmos valores de $I_{1}, I_{2}$ e $I_{3}$, qualquer que seja a orientação desses eixos:

$$
\begin{gathered}
I_{1}=C_{i i}=\operatorname{Tr}(\mathbf{C}) \\
I_{2}=\frac{1}{2}\left(C_{i i} C_{j j}-C_{i j} C_{j i}\right)=\frac{1}{2}\left(\operatorname{tr}(\mathbf{C})^{2}-\operatorname{tr}\left(\mathbf{C}^{2}\right)\right) \\
I_{3}=\epsilon_{i j k} C_{1 i} C_{2 j} C_{3 k}=\operatorname{det}(\mathbf{C})
\end{gathered}
$$

Os invariantes são bastante interessantes, uma vez que permitem escrever outras grandezas (por exemplo o escalar energia específica de deformação) em função de um estado de tensão ou de deformação qualquer, sem se preocupar com a orientação dos planos de corte no ponto.

Assim como as tensões e deformações principais, os invariantes também independem da orientação do sistema de coordenadas adotado. Isso permite definir critérios de falha e estabelecer propriedades mecânicas de forma consistente, pois seria totalmente incoerente assumir que as propriedades mecânicas ou colapso da estrutura dependesse(m) do sistema de referência escolhido.

A partir da decomposição multiplicativa do gradiente da função mudança de configuração $\mathbf{F}$, em uma parcela volumétrica $\mathbf{F}_{\text {vol }}$, referente às alterações de volume, e outra parcela isovolumétrica $\mathbf{F}_{\text {iso }}$, referente às mudanças de forma, determinam-se os invariantes a volume constante $\bar{I}_{1}, \bar{I}_{2}$ e $\bar{I}_{3}$ do tensor de alongamento à direita de CauchyGreen C:

$$
\begin{aligned}
& \mathbf{F}=\mathbf{F}_{v o l} \mathbf{F}_{i s o}=\left(J^{1 / 3} \mathbf{I}\right)\left(J^{-1 / 3} \mathbf{F}\right) \\
& \operatorname{det}\left(\mathbf{F}_{v o l}\right)=\operatorname{det}\left(J^{1 / 3} \mathbf{I}\right)=\left(J^{1 / 3}\right)^{3} \operatorname{det}(\mathbf{I})=J \\
& \operatorname{det}\left(\mathbf{F}_{i s o}\right)=\operatorname{det}\left(J^{-1 / 3} \mathbf{F}\right)=\left(J^{-1 / 3}\right)^{3} \operatorname{det}(\mathbf{F})=J^{-1} J=1 \\
& \mathbf{C}=\mathbf{C}_{i s o} \mathbf{C}_{v o l}=\left(\left(J^{-1 / 3} \mathbf{F}\right)^{T} J^{-1 / 3} \mathbf{F}\right)\left(\left(J^{1 / 3} \mathbf{I}\right)^{T} J^{1 / 3} \mathbf{I}\right) \rightarrow \mathbf{C}_{i s o}=\overline{\mathbf{C}}=J^{-2 / 3} \mathbf{C} \\
& J=\operatorname{det}(\mathbf{F}) \rightarrow J^{2}=\operatorname{det}(\mathbf{C}) \\
& \bar{I}_{1}=J^{-2 / 3} I_{1} \quad \bar{I}_{2}=J^{-4 / 3} I_{2} \quad \bar{I}_{3}=1
\end{aligned}
$$

Esses invariantes, $\bar{I}_{1}, \bar{I}_{2}$ e $\bar{I}_{3}$, a volume constante serão utilizados para decompor aditivamente a equação da energia específica de deformação na subseção 3.1.10. A decomposição aditiva da energia de deformação em uma parcela volumétrica e outra isovolumétrica é uma conveniência matemática mais do que uma constatação física, a qual permite expressar o tensor elástico de uma forma mais compacta (WEISS; MAKER; 
GOVINDJEE, 1996). Além disso, e segundo Chagnon, Rebouah e Favier (2015), essa decomposição é particularmente útil em implementações numéricas e permite considerar a incompressibilidade do material através de uma função penalizadora que depende de $I_{3}=J^{2}$.

O uso dos invariantes do tensor de alongamento à direita de Cauchy-Green na formulação de leis constitutivas hiperelásticas permite decompor a função energia específica de deformação em parcelas de energia de deformação isovolumétrica e volumétrica. O uso desses invariantes resulta em leis constitutivas isotrópicas. Parcelas de energia de deformação anisotrópicas conforme a orientação das fibras e o acoplamento dos comportamentos anisotrópico com o isotrópico podem ser consideradas por meio da definição de outros novos invariantes. (CHAGNON; REBOUAH; FAVIER, 2015)

\subsubsection{Fórmula de Nanson}

Seja $\mathbf{n}$ um vetor unitário normal à superfície infinitesimal $d s$ na configuração atual deformada, $\mathbf{F}$ o gradiente da função mudança de configuração $f, J$ o determinante de $\mathbf{F}$ e $\mathbf{N}$ um vetor unitário normal à superfície infinitesimal $d S$ na configuração inicial indeformada, a relação entre as áreas final $d s$ e inicial $d S$ vale (HOLZAPFEL, 2000, p. 75):

$$
\mathbf{n} d s=J \mathbf{F}^{-T} \mathbf{N} d S \rightarrow d \mathbf{s}=J \mathbf{F}^{-T} d \mathbf{S}
$$

A relação da Equação 3.20 é conhecida como fórmula de Nanson.

\subsubsection{Fórmula do volume}

Seja $\mathbf{F}$ o gradiente da função mudança de configuração $f, d V$ um infinitésimo de volume de material na condição indeformada e $d v$ esse mesmo infinitésimo de volume na situação deformada, tem-se que (HOLZAPFEL, 2000, p. 74):

$$
d v=J d V
$$

Portanto, $J=\operatorname{det}(\mathbf{F})>0$, uma vez que o material não pode degenerar $(d v=0)$ e muito menos sofrer inversão $(d v<0)(\mathrm{PASCON}, 2012)$. A condição é chamada de condição de preservação de orientação (MARSDEN; HUGHES, 1983).

\subsubsection{Lei da conservação de massa}

Seja $\rho(\mathbf{x}, t)$ uma função do tempo $t$ e das coordenadas cartesianas $\mathbf{x}$ das partículas dentro do domínio do corpo no espaço tridimensional, a qual define a densidade em cada ponto desse corpo na configuração atual deformada, e $\rho_{0}(\mathbf{X})$ a distribuição da densidade por todo esse mesmo corpo no instante inicial e na condição indeformada no ponto $\mathbf{X}$, 
pode-se então postular que se o corpo não estiver "perdendo massa", esta deve permanecer inalterada em qualquer instante, bem como nas situações deformada e indeformada:

$$
\int_{v} \rho(\mathbf{x}, t) d v=\int_{V} \rho_{0}(\mathbf{X}) d V
$$

Aplicando a fórmula do volume

$$
\int_{V} \rho(\mathbf{x}, t) J d V=\int_{V} \rho_{0}(\mathbf{X}) d V
$$

Ou então (HOLZAPFEL, 2000, p. 135):

$$
\rho_{0}(\mathbf{X})=J \rho(\mathbf{x}, t)
$$

\subsubsection{Equações de equilíbrio na forma integral}

A derivada da Equação 3.1 com relação ao tempo, mantendo a posição inicial indeformada de referência $\mathbf{X}$ fixa (descrição Lagrangiana):

$$
\dot{\mathbf{x}}(\mathbf{X}, t)=\frac{\partial \mathbf{x}(\mathbf{X}, t)}{\partial t}=\frac{\partial(\mathbf{X}+\mathbf{U}(\mathbf{X}, t))}{\partial t}=\frac{\partial \mathbf{U}(\mathbf{X}, t)}{\partial t}=\dot{\mathbf{U}}(\mathbf{X}, t)
$$

Ou seja, a velocidade da partícula é igual a sua variação de posição no tempo. Também:

$$
\ddot{\mathbf{x}}(\mathbf{X}, t)=\frac{\partial \dot{\mathbf{x}}(\mathbf{X}, t)}{\partial t}=\frac{\partial \dot{\mathbf{U}}(\mathbf{X}, t)}{\partial t}=\ddot{\mathbf{U}}(\mathbf{X}, t)
$$

Logo, a aceleração da partícula é igual a sua segunda variação de posição no tempo.

Seja agora b o campo vetorial das forças de domínio atuais distribuídas no volume do corpo, t o campo vetorial das tensões atuais sobre a superfície $d s$ atual e $\rho$ o campo escalar que determina a densidade atual em cada ponto, e ainda, aplicando a conclusão resultante da equação Equação 3.25, tem-se a equação de equilíbrio de momento linear na forma integral Euleriana:

$$
\int_{v} \mathbf{b} d v+\int_{s} \mathbf{t} d s=\frac{\partial}{\partial t} \int_{v} \rho \dot{\mathbf{x}} d v
$$

Apesar dos campos b, t e $\rho$ serem funções das coordenadas cartesianas do espaço tridimensional, estes podem (ou não) assumir valores variáveis com o tempo.

Aplicando a fórmula do volume (Equação 3.21) e a lei da conservação de massa (Equação 3.24) no termo da direita da equação Equação 3.27, e, admitindo que as letras maiúsculas identificam grandezas iniciais:

$$
\begin{aligned}
\frac{\partial}{\partial t} \int_{v} \rho \dot{\mathbf{x}} d v=\frac{\partial}{\partial t} \int_{V} \rho \dot{\mathbf{x}} J d V & =\frac{\partial}{\partial t} \int_{V} \rho_{0} \dot{\mathbf{x}} d V \\
\int_{V} \rho_{0} \ddot{\mathbf{x}} d V & =\int_{V} J \rho \ddot{\mathbf{x}} d V \\
\therefore \frac{\partial}{\partial t} \int_{v} \rho \dot{\mathbf{x}} d v & =\int_{v} \rho \ddot{\mathbf{x}} d v
\end{aligned}
$$


Utilizando a Equação 3.28 juntamente com o teorema e a fórmula de Cauchy, pode-se reescrever a Equação 3.27:

$$
\int_{v} \mathbf{b} d v+\int_{s} \boldsymbol{\sigma} \mathbf{n} d s=\int_{v} \rho \ddot{\mathbf{x}} d v
$$

Utilizado as fórmulas de Nanson (Equação 3.20) e do volume (Equação 3.21) na Equação 3.29 acima:

$$
\int_{V} J \mathbf{b} d V+\int_{S} J \boldsymbol{\sigma} \mathbf{F}^{-T} \mathbf{N} d S=\int_{V} J \rho \ddot{\mathbf{x}} d V
$$

Sendo o $1^{\circ}$ tensor de tensões de Piola- Kirchhoff (não simétrico) calculado através da seguinte relação (HOLZAPFEL, 2000, p. 113):

$$
\mathbf{P}=J \boldsymbol{\sigma} \mathbf{F}^{-T}
$$

Conclui-se utilizando a lei de conservação de massa (Equação 3.24) que:

$$
\int_{V} J \mathbf{b} d V+\int_{S} \mathbf{P N} d S=\int_{V} \rho_{0} \ddot{\mathbf{x}} d V
$$

E, aplicando o teorema da divergência de Gauss:

$$
\int_{V} J \mathbf{b} d V+\int_{V} \operatorname{Div}(\mathbf{P}) d V=\int_{V} \rho_{0} \ddot{\mathbf{x}} d V
$$

Finalmente, tem-se a equação de equilíbrio na formulação integral e na versão Lagrangiana (HOLZAPFEL, 2000, p. 146):

$$
\int_{V}\left(J \mathbf{b}+\operatorname{Div}(\mathbf{P})-\rho_{0} \ddot{\mathbf{x}}\right) d V=\mathbf{0}
$$

A equação de equilíbrio do momento angular irá revelar a simetria do tensor de tensões de Cauchy $\boldsymbol{\sigma}$, propriedade esta conhecida como teorema de Cauchy (HOLZAPFEL, 2000, p. 147).

\subsubsection{Princípio da mínima energia potencial}

A energia potencial total é o somatório de toda energia capaz de realizar trabalho e acumulada na estrutura em suas diversas formas (deformações, cargas externas, forças de domínio...).

O princípio da mínima energia potencial total estabelece que, dentre todos os campos cinematicamente admissíveis (campos que satisfazem as 3 condições ou restrições impostas de: contorno geométricas ou essenciais, relações deformação-deslocamento e relações tensão-deformação), o que estaciona o funcional da energia potencial total $(\delta \pi=0)$ 
é aquele que satisfaz as condições diferenciais de equilíbrio e as condições mecânicas ou naturais de contorno (SORIANO, 2003).

Enquanto que fisicamente o princípio da mínima energia potencial procura a configuração de mínima energia do sistema, matematicamente o que ele faz é (tentar) encontrar, dentre todas as soluções admissíveis (campos cinematicamente admissíveis), aquela que satisfaça as equações diferenciais de equilíbrio obedecendo às condições naturais ou mecânicas de contorno.

Como geralmente no cálculo variacional a busca da solução (aproximada) de uma equação diferencial, através da estacionariedade de um funcional, está limitada dentro de um conjunto de funções arbitrado para ser solução, tanto o tipo (polinomial, trigonométrica...) quanto o grau ( $1^{\circ}$ grau, $2^{\circ}$ grau...) da função candidata à solução escolhida, estas constituem restrições adicionais impostas ao processo de busca de solução.

É claro que buscar a solução de um problema diferencial cujo grau da resposta é maior que o grau da função arbitrada para solução, ou procurar uma solução dentro do conjunto de funções polinomiais para problemas cujas soluções exatas são trigonométricas, resulta em uma resposta aproximada para o problema. Soluções aproximadas encontradas através do princípio da mínima energia potencial total satisfazem a equação diferencial do problema em caráter aproximativo obedecendo às condições naturais de contorno também de forma aproximada.

As condições mecânicas (esforços) são intrínsecas ao processo de solução pelo princípio da mínima energia potencial total e são encontradas naturalmente, por isso naturais ${ }^{4}$. Já as condições geométricas (deslocamentos ou rotações) são restrições que devem ser impostas a priori nas soluções, e por isso essenciais.

A partir da Equação 3.34 tem-se que a variação da energia potencial vale:

$$
\begin{gathered}
\delta \pi=\int_{V}\left(J \mathbf{b}+\operatorname{Div}(\mathbf{P})-\rho_{0} \ddot{\mathbf{x}}\right) \cdot \delta \mathbf{x} d V \\
\delta \pi=\int_{V} J \mathbf{b} \cdot \delta \mathbf{x} d V+\int_{V} \operatorname{Div}(\mathbf{P}) \cdot \delta \mathbf{x} d V-\int_{V} \rho_{0} \ddot{\mathbf{x}} \cdot \delta \mathbf{x} d V
\end{gathered}
$$

que é a forma fraca ou variacional da equação de equilíbrio obtida através de uma perturbação $\delta \mathbf{x}$ que deve levar o sistema a procurar uma posição de equilíbrio. Na forma fraca, a equação diferencial de equilíbrio entre parênteses dentro da integral é, portanto, resolvida no sentido de uma média global e não mais ponto a ponto (forma forte).

Utilizando a propriedade tensorial (ver Apêndice F):

$$
\operatorname{Div}(\mathbf{P}) . \delta \mathbf{x}=\operatorname{Div}\left(\mathbf{P}^{T} \delta \mathbf{x}\right)-\mathbf{P}: \operatorname{Grad}(\delta \mathbf{x})
$$

\footnotetext{
${ }^{4}$ A princípio as condições mecânicas deveriam ser impostas no problema, mas devido a utilização do teorema da divergência de Gauss na manipulação da equação da mínima energia potencial total, essas condições "aparecem" sem que seja necessário introduzi-las de forma explícita e, por isso, são chamadas de naturais
} 
Tem-se:

$$
\begin{aligned}
\delta \pi= & \int_{V} J \mathbf{b} . \delta \mathbf{x} d V+\int_{V} \operatorname{Div}\left(\mathbf{P}^{T} \delta \mathbf{x}\right) d V-\int_{V} \mathbf{P}: \operatorname{Grad}(\delta \mathbf{x}) d V \\
& -\int_{V} \rho_{0} \ddot{\mathbf{x}} . \delta \mathbf{x} d V
\end{aligned}
$$

Que pelo teorema da divergência de Gauss resulta em:

$$
\begin{aligned}
\delta \pi= & \int_{V} J \mathbf{b} \cdot \delta \mathbf{x} d V+\int_{V} \mathbf{P}^{T} \delta \mathbf{x} \cdot \mathbf{N} d S-\int_{V} \mathbf{P}: \operatorname{Grad}(\delta \mathbf{x}) d V \\
& -\int_{V} \rho_{0} \ddot{\mathbf{x}} \cdot \delta \mathbf{x} d V
\end{aligned}
$$

Reconhecendo que na Equação 3.39 tem-se respectivamente: trabalho das forças de domínio na posição atual deformada, trabalho das forças de superfície na posição atual deformada, "termo desconhecido" e trabalho das forças inerciais na posição atual deformada. Ainda segundo Coda (2003):

\footnotetext{
Um sistema de forças em equilíbrio aplicado a um corpo rígido não realiza trabalho qualquer que seja a mudança de posição ou configuração do corpo. Assim, em um sistema conservativo onde as forças estão aplicadas em um corpo elástico, o trabalho realizado por essas forças deve ser armazenado no corpo. Essa "armazenagem" só pode estar associada a energia de deformação.
}

Sendo o $2^{\circ}$ tensor de tensões de Piola-Kirchhoff calculado através de (HOLZAPFEL, 2000, p. 127):

$$
\mathbf{P}=\mathbf{F S}
$$

tem-se que a parcela da energia de deformação vale:

$$
\begin{aligned}
\delta U=\int_{V} \mathbf{P}: \operatorname{Grad}(\delta \mathbf{x}) d V= & \int_{V} \mathbf{F S}:\left(\frac{\operatorname{Grad}(\delta \mathbf{x})+\operatorname{Grad}(\delta \mathbf{x})}{2}\right) d V \\
& =\int_{V}\left(\mathbf{F S}: \frac{\operatorname{Grad}(\delta \mathbf{x})}{2}+\mathbf{F S}: \frac{\operatorname{Grad}(\delta \mathbf{x})}{2}\right) d V
\end{aligned}
$$

A partir da seguinte propriedade tensorial para tensores de ordem 2 (ver Apêndice $\mathrm{F})$ :

$$
(\mathbf{A S}): \mathbf{C}=\left(\mathbf{A}^{T} \mathbf{C}\right): \mathbf{S}=\mathbf{S}:\left(\mathbf{A}^{T} \mathbf{C}\right)
$$

conclui-se que:

$$
\delta U=\int_{V} \mathbf{S}:\left(\frac{\mathbf{F}^{T} \operatorname{Grad}(\delta \mathbf{x})+\operatorname{Grad}^{T}(\delta \mathbf{x}) \mathbf{F}}{2}\right) d V
$$

Recordando que $\mathbf{F}$ é o gradiente da função mudança de configuração $f$ dado por $\mathbf{F}=\operatorname{Grad}(\mathbf{x})$, tem-se que:

$$
\delta U=\int_{V} \mathbf{S}:\left(\frac{\mathbf{F}^{T} \delta \mathbf{F}+\delta \mathbf{F}^{T} \mathbf{F}}{2}\right) d V
$$


Lembrando da definição da deformação de Green-Lagrange:

$$
\mathbf{E}=\frac{1}{2}\left(\mathbf{F}^{T} \mathbf{F}-\mathbf{I}\right)
$$

e linearizando agora a deformação de Green-Lagrange (ver Apêndice F):

$$
\delta \mathbf{E}=\frac{\partial \mathbf{E}}{\partial \mathbf{F}}: \delta \mathbf{F}=\frac{1}{2}\left(\mathbf{F}^{T} \delta \mathbf{F}+\delta \mathbf{F}^{T} \mathbf{F}\right)
$$

conclui-se finalmente que:

$$
\delta U=\int_{V} \mathbf{S}: \delta \mathbf{E} d V
$$

que quer dizer que a variação da energia por unidade de volume inicial vale:

$$
\delta u_{e}=\mathbf{S}: \delta \mathbf{E}
$$

A Equação 3.48 traduz matematicamente que mudanças de configuração que não sejam de corpo rígido causam interações entre os pontos materiais no interior do corpo através de forças internas de contato ou tensões S (PASCON, 2012). Sendo a energia por unidade de volume uma função de valores tensoriais a valores escalares escrita exclusivamente em função da deformação de Green-Lagrange (ou em função de seus invariantes $)^{5}$, tem-se que:

$$
\delta u_{e}=\frac{\partial u_{e}}{\partial \mathbf{E}}: \delta \mathbf{E}
$$

Note, portanto, das Equações 3.48 e 3.49 que:

$$
\mathbf{S}=\frac{\partial u_{e}}{\partial \mathbf{E}}
$$

Assim, o tensor de Piola-Kirchhoff de $2^{\text {a }}$ espécie é o conjugado energético da deformação de Green-Lagrange para materiais perfeitamente elásticos. Reescrevendo a Equação 3.39:

$$
\begin{gathered}
\delta \pi=\int_{V} J \mathbf{b} . \delta \mathbf{x} d V+\int_{S} \mathbf{P} \mathbf{N} . \delta \mathbf{x} d S-\int_{V} \mathbf{S}: \delta \mathbf{E} d V-\int_{V} \rho_{0} \ddot{\mathbf{x}} \cdot \delta \mathbf{x} d V \\
\therefore \delta \pi=\delta B+\delta P-\delta U-\delta K
\end{gathered}
$$

onde utilizou-se a definição do transposto de um tensor $\mathbf{A v} \cdot \mathbf{u}=\mathbf{A}^{T} \mathbf{u} . \mathbf{v}$. Na Equação 3.51, $\delta B, \delta P, \delta U$ e $\delta K$ representam respectivamente forças de domínio, forças de superfície, forças internas (deformação) e forças de inércia.

\footnotetext{
${ }^{5}$ as deformações/tensões principais também são invariantes
} 


\subsubsection{Tensores de tensão de Cauchy e de Piola-Kirchhoff}

As principais medidas de tensão utilizadas na Mecânica do Contínuo são: tensor de tensões Cauchy $(\boldsymbol{\sigma}), 1^{\circ}$ tensor de tensões de Piola-Kirchhoff $(\mathbf{P})$ e $2^{\circ}$ tensor de tensões de Piola-Kirchhoff $(\mathbf{S})$. O tensor de tensões de Cauchy é uma medida euleriana de tensão, isto é, referente à área da configuração deformada atual. Por outro lado e segundo Hoss (2009), os tensores de Piola-Kirchhoff propõem definições Lagrangianas para o cálculo das tensões. O $1^{\circ}$ tensor de tensões de Piola-Kirchhoff é uma medida Lagrangiana, pois é baseado na área da configuração indeformada inicial e fornece a força atual por unidade de área da configuração de referência (fixa) inicial indeformada. Apesar do $2^{\circ}$ tensor de tensões de Piola-Kirchhoff ser uma grandeza sem significado físico aparente, ele é de grande interesse tanto na formulação das equações constitutivas quanto em mecânica computacional por ser um tensor simétrico referenciado à posição inicial (fixa) indeformada e conhecida (medida Lagrangiana).

O $1^{\circ}$ tensor de tensões de Piola-Kirchhoff pode ser expresso tanto em função do tensor de tensões de Cauchy conforme a Equação 3.31, como em função do $2^{\circ}$ tensor de tensões de Piola-Kirchhoff conforme a Equação 3.40. O tensor de tensões de Cauchy expresso em função da $2^{\circ}$ tensor de tensões de Piola-Kirchhoff pode ser obtido combinandose as Equações 3.31 e 3.40. Seja então F o gradiente da função mudança de configuração, $\mathbf{S}$ o $2^{\circ}$ tensor de tensões de Piola-Kirchhoff e $J$ o determinante de $\mathbf{F}$, o tensor de tensões de Cauchy $(\boldsymbol{\sigma})$ é também:

$$
\boldsymbol{\sigma}=\frac{\mathbf{F S F}^{T}}{J}
$$

\subsubsection{Objetividade}

Na natureza os processos físicos acontecem independentemente do observador e, portanto, a representação matemática desses fenômenos deve refletir essa invariância ou objetividade, isto é, deve ser capaz de descrever um mesmo fenômeno da mesma maneira, independentemente da posição ou mesmo do movimento do ponto de observação. Logo, a objetividade é uma constatação que deve sempre ser respeitada.

Um corpo sujeito a uma força vai se deformar. Isso é um fato que vai acontecer não importa nem de onde e nem como se esteja olhando para esse corpo. No entanto, dependendo de como se mede esse fenômeno de deformação (medida de deformação utilizada), diferentes observadores podem "perceber" esse fenômeno de deformação de diferentes maneiras (medir diferentes valores) e, nesse caso, diz-se que a medida de deformação utilizada não é objetiva.

Se ao invés disso, uma medida objetiva de deformação fosse utilizada, o fenômeno físico da deformação iria ser "percebido" da mesma forma e medido com mesma intensidade por vários observadores distintos. Assim, uma medida objetiva é sempre interessante porque não se deseja medir diferentes valores a depender do observador. 
Medidas não objetivas também podem ser utilizadas desde que se saiba como "transformar" tais medidas entre os diferentes observadores. Velocidade e aceleração são alguns exemplos de medidas não objetivas. Alongamento à direita de Cauchy-Green $\mathbf{C}$ e o $2^{\circ}$ tensor de tensões de Piola-Kirchhoff $\mathbf{S}$ são exemplos de medidas objetivas.

A descrição de um único movimento visto por dois observadores distintos é equivalente a considerar a descrição de dois movimentos visto por um único observador e, portanto, a mudança de observador é equivalente a um movimento de corpo rígido. Sendo assim, o movimento $f^{+6}$ visto por um determinado observador A é equivalente a uma translação $\mathbf{c}(t)$ e uma rotação $\mathbf{Q}(t)$ do movimento $f$ visto por um outro observador $\mathrm{B}$, ou seja, $\mathbf{x}^{+}=\mathbf{c}(t)+\mathbf{Q}(t) \mathbf{x}$, onde a dependência da rotação $\mathbf{Q}(t)$ e da translação $\mathbf{c}(t)$ com o tempo indica um movimento relativo entre os dois observadores, Figura 1. Q(t) é um tensor ortogonal qualquer.

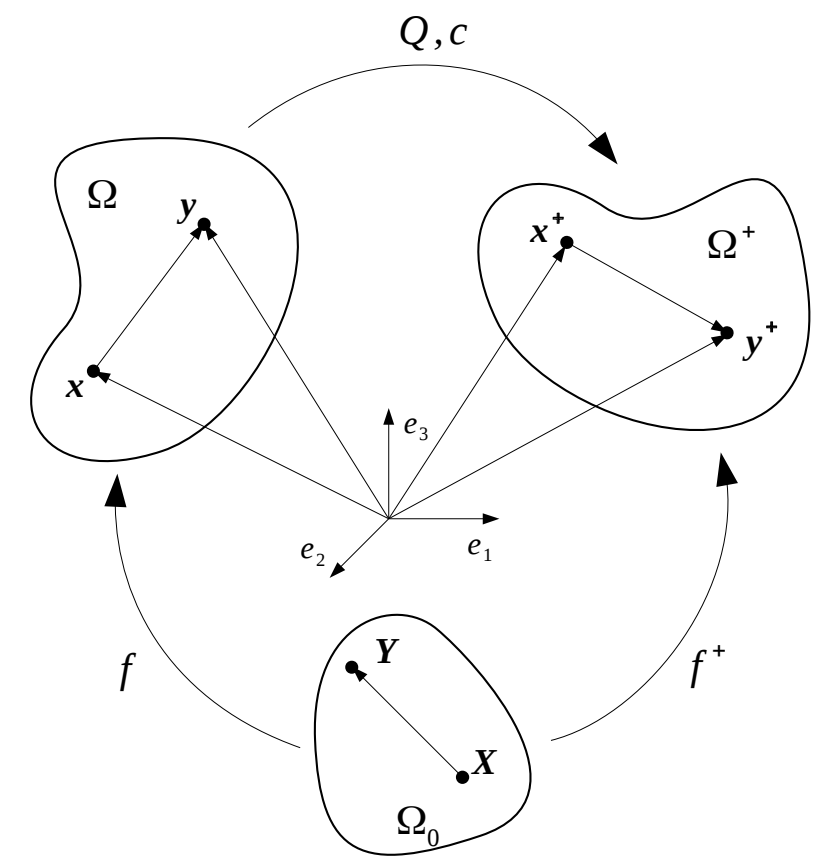

Figura 1 - Objetividade

fonte: adaptado de Holzapfel (2000)

Para diferentes observadores, grandezas objetivas se relacionam entre si somente através da parcela rotacional $\mathbf{Q}(t): a\left(\mathbf{x}^{+}, t^{+}\right)=a(\mathbf{x}, t)$ para escalares, $\mathbf{u}\left(\mathbf{x}^{+}, t^{+}\right)=$ $\mathbf{Q}(t) \mathbf{u}(\mathbf{x}, t)$ para vetores e $\mathbf{A}\left(\mathbf{x}^{+}, t^{+}\right)=\mathbf{Q}(t) \mathbf{A}(\mathbf{x}, t) \mathbf{Q}(t)^{T}$ para tensores de ordem 2.

A partir de $\mathbf{x}^{+}=\mathbf{c}(t)+\mathbf{Q}(t) \mathbf{x}$ é possível relacionar o gradiente da função mudança de configuração medido pelos dois observadores através de $\mathbf{F}^{+}=\mathbf{Q F}$. F. Observe que, pela sua própria definição, $\mathbf{F}=\partial \mathbf{x} / \partial \mathbf{X}$, tem tanto uma parcela $\mathbf{X}$ relativa à configuração

\footnotetext{
${ }^{6} \mathrm{O}$ sinal + é utilizado somente para diferenciar os observadores A e B
} 
inicial indeformada e fixa que independe do observador quanto uma parcela $\mathbf{x}$ relativa à configuração atual deformada dependente do observador.

Por sua vez, o tensor alongamento à direita de Cauchy-Green $\mathbf{C}$ e o $2^{\circ}$ tensor de tensões de Piola-Kirchhoff $\mathbf{S}$ são objetivos, uma vez que estão completamente referenciados à posição inicial (fixa) indeformada e sofrem transformação da seguinte maneira: $\mathbf{C}=\mathbf{C}^{+}$ e $\mathbf{S}=\mathbf{S}^{+}$. Essa objetividade do tensor de alongamento a direita de Cauchy pode ser facilmente demonstrada: $\mathbf{C}^{+}=\mathbf{F}^{T} \mathbf{Q}^{T} \mathbf{Q F}=\mathbf{F}^{T} \mathbf{I F}=\mathbf{F}^{T} \mathbf{F}=\mathbf{C}$

Uma medida de deformação objetiva é, portanto, aquela que não apresenta valores de deformação em movimentos de corpo rígido da configuração atual deformada, sendo, por isso, adequada para os casos de grandes deslocamentos (não linearidade geométrica), como é o caso do tensor de deformações de Green-Lagrange E.

\subsubsection{Leis constitutivas e hiperelasticidade}

Uma lei constitutiva estabelece relações entre as forças internas de contato (tensões) e as mudanças de forma do corpo (deformações) (PASCON, 2012). Em materiais perfeitamente elásticos, o estado de tensões independe do histórico de deformações, logo, um campo tensorial de tensões $\boldsymbol{\sigma}$ pode ser expresso em função de um campo de deformações $(\mathbf{F})$ através de uma função resposta tensorial $g$ de valores tensoriais a valores tensoriais $(\boldsymbol{\sigma}=g(\mathbf{F}))$. A objetividade da função resposta $g$ (invariância das propriedades do material com as mudanças de observador) é imposta através da seguinte igualdade $g\left(\mathbf{F}^{+}\right)=\mathbf{Q} g(\mathbf{F}) \mathbf{Q}^{T}=g(\mathbf{Q F})$, a partir de onde se conclui utilizando o teorema da decomposição polar $(\mathbf{F}=\mathbf{R U})$, que $\boldsymbol{\sigma}=\mathbf{R} g(\mathbf{U}) \mathbf{R}^{T}$. Isso quer dizer que a função resposta independe da parcela rotacional de $\mathbf{F}$.

Segundo (HOLZAPFEL, 2000), Rivilin e Ericksen estabeleceram em 1955 que a resposta de qualquer material elástico e isotrópico pode ser representada através de uma função resposta $g$ de 3 parâmetros $\left(\alpha_{0}, \alpha_{1}, \alpha_{2}\right)$ escrita apenas em função do alongamento à esquerda de Cauchy-Green b:

$$
\boldsymbol{\sigma}=\alpha_{0} \mathbf{I}+\alpha_{1} \mathbf{b}+\alpha_{2} \mathbf{b}^{2}
$$

Onde $\alpha_{0}, \alpha_{1}$ e $\alpha_{2}$ são escalares dados em função dos invariantes do tensor de alongamento à esquerda de Cauchy-Green b (ex: $\left.\alpha_{0}=\alpha_{0}\left(I_{1}, I_{2}, I_{3}\right)\right)$.

Utilizando equações de equilíbrio em tensões combinadas com algumas equações obtidas através do princípio da mínima energia potencial total (trabalhos virtuais) e, embora utilizando outras medidas de deformação e tensão, Novozhilov (1953) também conclui que o estado de tensões de um material isotrópico com forças não conservativas desprezíveis com relação às forças conservativas está completamente definido a partir de 
uma função que utiliza apenas 3 escalares escritos em função dos invariantes da deformação (assim como $\alpha_{0}, \alpha_{1}, \alpha_{2}$ ).

Da mesma forma que na Equação 3.53, Novozhilov (1953) também concluiu que essa função pode ser escrita em função de um tensor unitário (assim como I), um tensor com combinações lineares das deformações (assim como b) e um tensor com combinações quadráticas das deformações (assim como $\mathbf{b}^{2}$ )

A estratégia de caracterização do material através de uma função resposta é conhecida como elasticidade de Cauchy (OGDEN, 1997). Ao invés de utilizar uma função resposta, a hiperelasticidade ou elasticidade de Green admite a existência de uma energia de deformação $u_{e}$ por unidade de volume associada à energia interna do material, função apenas do nível de deformações $(\mathbf{F})$. É a partir dessa energia específica de deformação que se derivam as tensões.

Considerando agora que durante o processo de carregamento a estrutura se movimenta, as cargas externas aplicadas devem então produzir um trabalho decorrente de seus respectivos deslocamentos igual ao produto de cada força pelo correspondente deslocamento de seu ponto de aplicação. Esse trabalho produzido pelas forças externas é transferido à estrutura e se acumula na forma de energia específica de deformação ou trabalho das "forças internas".

Matematicamente e em sistemas conservativos, isto quer dizer que um incremento de trabalho das forças externas deve ser igual ao incremento de trabalho das forças internas. Esse trabalho das forças internas ou energia específica de deformação constitui um dos pontos chave nas formulações em elementos finitos tanto em análises não lineares como lineares, pois a energia específica de deformação é um termo presente na maioria das formulações em elementos finitos através de equações do tipo da Equação 3.102. A hiperelasticidade é uma área da elasticidade não linear que procura justamente identificar formas de calcular essa energia específica de deformação.

Assumindo que a energia de deformação armazenada seja totalmente recuperável (material perfeitamente elástico), a hiperelasticidade permite descrever um comportamento puramente elástico através de uma relação entre tensões e deformações por meio das chamadas leis constitutivas hiperelásticas. Os modelos hiperelásticos, além de permitirem considerar uma relação não linear entre tensão e deformação, podem também manifestar grandes deformações elásticas, uma vez que adotam medidas de tensão de deformação adequadas (S, P, F, C, E...). Aqui o prefixo "hiper-" reforça justamente a ideia de comportamento puramente elástico mesmo em regime de grandes deformações (>400 \%).

A partir dessa energia de deformação e utilizando a hipótese de material perfeitamente elástico, estabelece-se a partir da $2^{\text {a }}$ lei da termodinâmica uma relação entre uma medida apropriada de tensão e uma medida de deformação através da função energia de 
deformação $u_{e}$ associada à energia interna do material:

$$
\mathbf{P}=\frac{\partial u_{e}}{\partial \mathbf{F}} \quad \text { e } \quad \mathbf{S}=\frac{\partial u_{e}}{\partial \mathbf{E}}
$$

Na Equação 3.54, tem-se que o $1^{\circ}$ tensor de tensões de Piola-Kirchhoff $\mathbf{P}$ é o conjugado energético do gradiente da função mudança de configuração F. Por sua vez, o $2^{\circ}$ tensor de tensões de Piola-Kirchhoff $\mathbf{S}$ é o conjugado energético da deformação de Green-Lagrange E. Assim, estando a deformação de Green-Lagrange e o $2^{\circ}$ tensor de Piola-Kirchhoff combinados dentro de uma mesma grandeza denominada energia específica de deformação, é possível derivar uma função escalar energia específica de deformação qualquer em relação ao campo tensorial de deformações ou de tensões e obter uma relação explícita entre a tensão e a deformação. A essa relação é dado o nome de lei constitutiva (CODA, 2003). Essa função energia específica de deformação, no entanto, deve obedecer a alguns critérios, sendo eles:

- Normalização: ${ }^{7}$ A energia na condição de referência deve ser zero $(\mathbf{F}=\mathbf{I})$, isto é, não deve haver tensão residual.

$$
u_{e}(\mathbf{I})=0
$$

- Deve ser sempre positiva: Deformações introduzem sempre uma quantidade positiva de energia.

$$
u_{e}(\mathbf{F}) \geq 0
$$

Assim, o mínimo da função energia específica de deformação deve ser zero na condição de referência (Equação 3.55), não existindo também nenhum outro mínimo local.

- Policonvexidade: garante a existência de mínimos globais, hipótese essa utilizada na teoria das soluções. Segundo Chagnon, Rebouah e Favier (2015) a policonvexidade está garantida se:

$$
\frac{\partial u_{e}}{\partial I_{i}}>0 \quad \text { e }\left[\frac{\partial u_{e}}{\partial I_{i} \partial I_{j}}\right] \quad \text { positivo definido para } i, j=1,2
$$

- Condição de crescimento: Deve ser necessária uma quantidade infinita de energia tanto para expandir o material ao infinito $(\operatorname{det}(\mathbf{F}) \rightarrow+\infty)$ quanto para reduzi-lo a um ponto sem volume (degeneração $\operatorname{det}(\mathbf{F}) \rightarrow 0^{+}$). Esse critério é especialmente interessante em análises envolvendo grandes deformações.

$$
\left\{\begin{array}{lll}
u_{e}(\mathbf{F}) \rightarrow+\infty & \text { quando } & \operatorname{det}(\mathbf{F}) \rightarrow+\infty \\
u_{e}(\mathbf{F}) \rightarrow+\infty & \text { quando } & \operatorname{det}(\mathbf{F}) \rightarrow 0^{+}
\end{array}\right.
$$

\footnotetext{
${ }^{7}$ esse é um critério adicional adotado por conveniência
} 
- Objetividade: a energia de deformação deve ser independente de mudanças de observador, ou seja, vários observadores diferentes devem ser capazes de medir a mesma energia de deformação. Impondo a objetividade da energia específica de deformação $u_{e}$ da mesma forma que anteriormente para a função resposta $g$, temse que $u_{e}\left(\mathbf{F}^{+}\right)=u_{e}(\mathbf{Q F})$, a partir de onde se conclui, utilizando o teorema da decomposição polar $(\mathbf{F}=\mathbf{R U})$, que $u_{e}(\mathbf{F})=u_{e}(\mathbf{U})$. Isso quer dizer que a energia específica de deformação independe da parcela rotacional de F, e que, portanto, a energia de deformação pode ser também escrita tanto em função do tensor de alongamento à direita de Cauchy-Green $\mathbf{C}$ quanto em função da deformação de Green-Lagrange E. Por fim, conclui-se então que se a energia específica $u_{e}$ estiver escrita em função de $\mathbf{E}$ ou $\mathbf{C}$ (que são objetivos), a função energia de deformação $u_{e}$ é objetiva.

- Isotropia: Enquanto que objetividade da função energia específica de deformação é uma condição nescessária e obrigatória que deve ser obedecida pela função energia de deformação $u_{e}$, a isotropia é uma condição adicional que pode ser imposta à energia específica de deformação. Um material isotrópico é um material cuja resposta final independe de movimentos de corpo rígido da configuração inicial indeformada de referência $\Omega_{0}$. Assim, a resposta de um movimento $f$ da configuração inicial A indeformada $\Omega_{0}$ deve ser a mesma resposta de um movimento $f^{*} 8$ de uma outra nova configuração indeformada B de referência $\Omega^{*}$ que sofreu movimentos de translação c e rotação $\mathbf{Q}$ puros de corpo rígido com relação a configuração indeformada de referência original $\Omega_{0}$, ou seja, $\mathbf{X}^{*}=\mathbf{c}+\mathbf{Q X}$, onde $\mathbf{Q}$ é um tensor ortogonal qualquer.

\footnotetext{
${ }^{8} \mathrm{O}$ sinal $*$ é utilizado somente para diferenciar as configurações iniciais A e B
} 


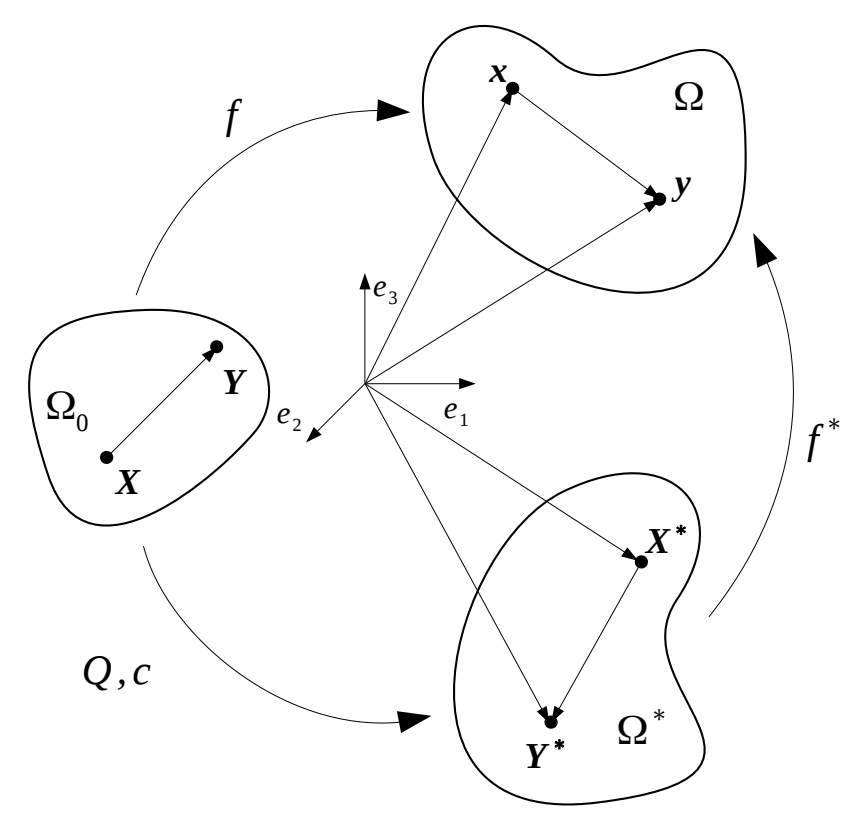

Figura 2 - Isotropia

fonte: adaptado de Holzapfel (2000)

Calculando o gradiente da função mudança de configuração $\mathbf{F}$ e utilizando a regra da cadeia:

$$
\mathbf{F}=\frac{\partial \mathbf{x}}{\partial \mathbf{X}}=\frac{\partial \mathbf{x}}{\partial \mathbf{X}^{*}} \frac{\partial \mathbf{X}^{*}}{\partial \mathbf{X}}=\mathbf{F}^{*} \mathbf{Q}
$$

Impondo a condição adicional de isotropia da energia específica de deformação $u_{e}\left(\mathbf{F}^{*}\right)=u_{e}\left(\mathbf{F} \mathbf{Q}^{T}\right)$, conclui-se que $u_{e}(\mathbf{C})=u_{e}\left(\mathbf{Q} \mathbf{C Q}^{T}\right)$. Isso significa que a função energia específica de deformação $u_{e}$ independe de rotações do tensor de alongamento à direita de Cauchy-Green $\mathbf{C}$, podendo então ser expressa em função dos invariantes desse tensor de alongamento $\left(I_{1}(\mathbf{C}), I_{2}(\mathbf{C}), I_{3}(\mathbf{C})\right)$. Essa importante constatação é conhecida como teorema dos invariantes. As equações da energia de deformação para materiais hiperelásticos podem ser expressas de 3 formas diferentes:

1. Forma Padrão: através de uma energia de deformação na forma acoplada escrita em função dos invariantes $I_{1}, I_{2}$ e $I_{3}$, que contém tanto parcelas de deformações volumétrica quanto isovolumétricas.

$$
u_{e}\left(I_{1}, I_{2}, I_{3}\right)
$$

2. Modelo compressível e quase incompressível: através de uma energia de deformação na forma desacoplada que consiste na soma de uma parcela de energia de deformação a volume constante $u_{i s o}$, escrita em função dos invariantes a volume constante $\bar{I}_{1}, \bar{I}_{2}$ referentes à parcela de deformações isovolumétricas do tensor de alongamento à direita de Cauchy-Green $\mathbf{C}$, com a energia de deformação volumétrica 
$u_{v o l}$ expressa em função da deformação volumétrica $J=\operatorname{det} \mathbf{F}$.

$$
u_{e}\left(I_{1}, I_{2}, I_{3}\right)=u_{i s o}\left(\bar{I}_{1}, \bar{I}_{2}\right)+u_{\text {vol }}(J)
$$

3. Incompressível: através da introdução na forma acoplada de uma restrição interna $p$ ao material através de um multiplicador de Lagrange a fim de considerar a incompressibilidade do material.

$$
u_{e}\left(I_{1}, I_{2}\right)-p(J-1)
$$

As leis constitutivas hiperelásticas mais simples e mais conhecidas (neo-hookeano, Yeoh, Mooney-Rivlin, Rivilin-Saunders...) adotam expressões polinomiais para $u_{\text {iso }}\left(\bar{I}_{1}, \bar{I}_{2}\right)$ conforme o modelo proposto por Mooney (1940) e em seguida generalizado por Rivlin e Saunders (1951):

$$
u_{i s o}\left(\bar{I}_{1}, \bar{I}_{2}\right)=c_{i j}\left(\bar{I}_{1}-3\right)^{i}\left(\bar{I}_{2}-3\right)^{j}
$$

onde nesse caso $i$ e $j$ assumem valores de 0 até $\infty$ (e não apenas 1, 2 ou 3 conforme usualmente utilizado em notação indicial) e $c_{i j}$ são constantes do material ${ }^{9}$. A energia de deformação em uma lei constitutiva hiperelástica não precisa necessariamente ser expressa na forma de um polinômio. A expressão pode ser exponencial por exemplo, e, além disso, essas expressões também não precisam obrigatoriamente serem funções dos invariantes. Assim, diferentemente de Rivilin, Ogden (1972a) propôs então escrever a energia de deformação em função dos alongamentos principais $\lambda_{1}, \lambda_{2}, \lambda_{3}$ (OGDEN, 1997, p. 493):

$$
u_{i s o}\left(\bar{\lambda}_{1}, \bar{\lambda}_{2}, \bar{\lambda}_{3}\right)=\sum_{n=1}^{\infty} \frac{\nu_{n}}{\alpha_{n}}\left(\bar{\lambda}_{1}^{\alpha_{n}}+\bar{\lambda}_{2}^{\alpha_{n}}+\bar{\lambda}_{3}^{\alpha_{n}}-3\right)
$$

onde agora $\nu_{n} / \alpha_{n}$ é que são as constantes do material a serem calibradas. A lei constitutiva de Saint Venant-Kirchhoff é outro exemplo de lei constitutiva que não utiliza os invariantes para escrever a função energia específica de deformação. Nesse caso, e assim como será visto mais adiante, a própria deformação de Green-Lagrange é que é utilizada. Os invariantes e os alongamentos principais são especialmente interessantes porque independem da orientação das coordenadas no ponto de análise.

As equações para $u_{v o l}$ envolvem expressões polinomiais, exponenciais e logarítmicas escritas em função do jacobiano $J$, uma vez que este é uma medida da deformação volumétrica conforme visto na subseção 3.1.4.

A princípio, as leis constitutivas hiperelásticas podem assumir formas diversas a partir de variadas expressões matemáticas com inúmeros parâmetros. No entanto, como frequentemente os códigos de elementos finitos são utilizados para simular estados de

\footnotetext{
${ }^{9} c_{i j}$ são constantes do material, não necessariamente iguais a termos $\left(\mathbb{C}_{i j k l}\right)$ do tensor constitutivo $\mathbb{C}$. Tensor constitutivo só existe um, enquanto que as constantes do material podem ser infinitas
} 
carregamento bem diferentes daqueles adotados na calibração das constante do material (uniaxial, biaxial, cisalhamento puro...), limitar a quantidade de invariantes e números de constantes de material é geralmente uma boa escolha, reduzindo a ocorrência de comportamentos anômalos. Nesse sentido, o invariante $I_{2}$ é frequentemente negligenciado devido à sua dificuldade de obtenção (CHAGNON; REBOUAH; FAVIER, 2015). É tarefa de quem propõe a lei garantir que a mesma lei represente de fato algum material real. A viabilidade/facilidade de calibração dos seus coeficientes $\left(c_{i j}, \nu_{n} / \alpha_{n} \ldots\right)$ é outro aspecto também a ser estudado antes de simplesmente se propor alguma lei constitutiva de forma aleatória que, na maioria das vezes, terá um significado puramente abstrato.

O fato das leis constitutivas hiperelásticas adotarem expressões polinomiais, exponenciais ou logarítmicas para escrever o escalar energia específica de deformação em função de grandezas relacionadas a essa deformação, tais como alongamentos, invariantes do tensor de deformações ou então as próprias deformações em si, também pode ser compreendido fisicamente, uma vez que a energia de deformação obviamente deve depender do nível ou estado de deformações. Outro aspecto importante é que, dependendo das grandezas escolhidas e da forma adotada para expressar a energia específica de deformação, as operações de derivadas utilizadas para encontrar o tensor constitutivo $\mathbb{C}$ ou o $2^{\circ}$ tensor de tensões de Piola-Kirchhoff $\mathbf{S}$ podem ser mais ou menos complicadas.

Muitos modelos são falhos em reproduzir o comportamento não linear observado em todos os modos e intensidades de deformações (HOSS; MARCZAK, 2010), especialmente aqueles diferentes dos utilizados na calibração do modelo, como observado no trabalho de Hoss (2009). Por isso, a generalização de expressões para a energia específica de deformação é algo complexo e representa ainda um ideal comum buscado por inúmeros autores. Hoss (2009) sugere ainda a divisão dos modelos hiperelásticos em seis grandes famílias (em ordem cronológica de surgimento):

- Polinomiais: normalmente se ajustam bem a dados experimentais de um determinado ensaio, no entanto, os modelos que contemplam o segundo invariante de deformação geralmente predizem um comportamento excessivamente rígido para os demais ensaios que não os da calibração;

- $u_{e}=g(\lambda)$ : não apresentam bons resultados especialmente em pequenas deformações;

- Base Exponencial: apresentam um comportamento limitado a faixas específicas de deformação e fornecem predições ruins para os ensaios diferentes do da calibração;

- Base Logarítmica: apresentam comportamento limitado a faixas específicas de deformação e fornecem predições ruins para os ensaios diferentes dos da calibração; 
- Limiting chain extensibility ${ }^{10}$ : não capturaram com fidelidade o efeito de enrijecimento do material;

- Modelos Mistos: a melhor solução é combinar as famílias de modelos;

Uma lei constitutiva neo-hookeana pode ser da forma $u_{e}=c_{10}\left(\bar{I}_{1}-3\right)+u_{v o l}$ ou $u_{e}=c_{10}\left(I_{1}-3\right)$. Assim, dizer apenas que se esta adotando uma lei constitutiva hiperelástica neo-hookeana é um termo bastante vago. Apesar de se ter uma ideia da forma do polinômio, não se sabe a forma da parcela volumétrica $u_{v o l}$, e que pode inclusive não estar presente. O mesmo acontece com todas as leis constitutivas hiperelásticas. Embora o nome da lei dê uma vaga ideia da forma da expressão, não diz nada sobre as hipóteses fundamentais de compressibilidade ou incompressibilidade adotadas. Em resumo, ao se referir a um modelo hiperelástico qualquer que seja, é sempre importante apresentar a expressão completa. No Anexo A encontram-se listadas várias leis constitutivas hiperelásticas.

As soluções dos problemas da elasticidade não linear frequentemente são obtidas resolvendo-se uma sequência de problemas lineares através de técnicas incrementais e iterativas. Essa estratégia de resolução requer, portanto, uma equação constitutiva na forma linearizada. Sendo assim, considere que o segundo tensor de Piola $\mathbf{S}$ em um determinado ponto e num instante de tempo qualquer seja uma função de uma variável de valores tensoriais a valores tensoriais. Assumindo agora que essa variável seja o tensor de deformações de Green-Lagrange (o que não é nenhum absurdo, já que fisicamente o nível de tensões deve depender do nível de deformações), ou seja, $\mathbf{S}(\mathbf{E})$. Uma relação linear variacional entre tensões e deformações pode então ser obtida através de uma linearização da $2^{\text {a }}$ tensão de Piola-Kirchhoff $\mathbf{S}$ (HOLZAPFEL, 2000):

$$
\delta \mathbf{S}=\frac{\partial \mathbf{S}}{\partial \mathbf{E}}: \delta \mathbf{E}=\mathbb{C}: \delta \mathbf{E}
$$

A Equação 3.65 relaciona variações de tensões $\delta \mathbf{S}$ em função de variações de deformações $\delta \mathbf{E}$ através do tensor constitutivo de $4^{\mathrm{a}}$ ordem $\mathbb{C}$ :

$$
\mathbb{C}=\frac{\partial \mathbf{S}}{\partial \mathbf{E}} \rightarrow \mathbb{C}_{i j k l}=\frac{\partial S_{i j}}{\partial E_{k l}}
$$

Note que a simetria de $S_{i j}=S_{j i}$ e $E_{k l}=E_{l k}$ implica a simetria de $\mathbb{C}_{i j k l}=\mathbb{C}_{j i k l}=$ $\mathbb{C}_{i j l k}$. Logo, o tensor constitutivo elástico de $4^{\mathrm{a}}$ ordem $\mathbb{C}$ de qualquer material elástico é um tensor com 36 constantes ("pseudo-matriz 6x6"). De acordo com Holzapfel (2000) essa é uma propriedade que independe da existência da energia específica de deformação $u_{e}$, e

\footnotetext{
${ }^{10}$ limiting chain extensibility são modelos que apresentam singularidades na expressao da energia específica de deformação para determinados níveis de deformação, ex: $u_{e}=\ln (0)$
} 
que vale para qualquer material elástico. No entanto, assumindo a existência da energia específica de deformação $u_{e}$, a partir da Equação 3.54 tem-se que:

$$
\mathbb{C}=\frac{\partial \mathbf{S}}{\partial \mathbf{E}}=\frac{\partial^{2} u_{e}}{\partial \mathbf{E} \partial \mathbf{E}} \rightarrow \mathbb{C}_{i j k l}=\frac{\partial^{2} u_{e}}{\partial E_{i j} \partial E_{k l}} \rightarrow \mathbb{C}_{k l i j}=\frac{\partial^{2} u_{e}}{\partial E_{k l} \partial E_{i j}}
$$

de onde se conclui uma outra simetria adicional válida para materiais hiperelásticos $\mathbb{C}_{i j k l}=\mathbb{C}_{k l i j}$. Logo, o tensor constitutivo elástico de $4^{\mathrm{a}}$ ordem $\mathbb{C}$ dos materiais hiperelásticos tem 21 constantes ("pseudo-matriz matriz 6x6 simétrica"). A simetria menor do tensor $\mathbb{C}_{i j k l}=\mathbb{C}_{j i k l}=\mathbb{C}_{i j l k}$ está, portanto, relacionada com a propriedade elástica do material, enquanto que a simetria maior $\mathbb{C}_{i j k l}=\mathbb{C}_{k l i j}$ está relacionada com a existência da energia específica de deformação.

A tensão para um determinado nível de deformações seria obtida da seguinte forma:

$$
\mathbf{S}=\sum_{k=1}^{n} \delta \mathbf{S}^{k}=\mathbb{C}^{k}: \delta \mathbf{E}^{k}
$$

onde $n$ é o número de passos incrementais utilizado para aproximar a solução, $\delta \mathbf{E}^{k}$ é o incremento de deformação no passo $k$ e $\mathbb{C}^{k}$ é o tensor constitutivo durante o incremento $\mathrm{k}$. Nos modelos constitutivos lineares, tem-se que $\mathbb{C}^{k}$ é constante, logo, a Equação 3.68 pode ser resolvida em um único passo, ou seja, $\mathbf{S}=\mathbb{C}: \mathbf{E}$.

As leis constitutivas hiperelásticas são essencialmente tridimensionais, isto é, relacionam as variações de deformações e as variações de tensões sempre de forma tridimensional através de um tensor de quarta ordem $\mathbb{C}$ conforme demonstrado pela Equação 3.65. Dessa forma, um estado plano de deformações pode ser facilmente obtido simplesmente assumindo que determinadas deformações sejam nulas. $\mathrm{O}$ mesmo, no entanto, não vale para obter um estado plano de tensões, ou seja, não se pode assumir simplesmente que determinados incrementos de tensões na equação $\delta S=\mathbb{C}: \delta E$ sejam nulos. Isto acontece porque os planos e as direções livres de incrementos de tensões não estão necessariamente livres de incrementos de deformações. Ao invés disso, deve-se determinar quais são as deformações que geram um estado plano de tensões através da inversão do tensor $\mathbb{C}$ em cada passo incremental de deformações, uma vez que $\mathbb{C}$ varia com o nível de deformações.

As derivadas necessárias para a implementação de leis constitutivas hiperelásticas quando escritas sob a forma $u_{e}=u_{i s o}\left(\bar{I}_{1}, \bar{I}_{2}\right)+u_{v o l}(J)$ em um código de elementos finitos posicional (utilizando a descrição Lagrangiana total) foram desenvolvidas em notação indicial e são apresentadas no Apêndice E, sendo assim diretamente programáveis (essa é uma outra grande vantagem da notação indicial.)

A lei constitutiva de Saint Venant-Kirchhoff é um modelo hiperelástico não linear compressível bastante simples que relaciona linearmente a tensão de Piola-Kirchhoff com a deformação de Green-Lagrange (duas grandezas sem significado físico direto). A lei 
constitutiva de Saint Venant-Kirchhoff é um modelo adequado para análises envolvendo grandes deslocamentos e deformações moderadas (HOLZAPFEL, 2000). Observe a seguir que a lei de Saint Venant-Kirchhoff é análoga à lei de Hooke, com a diferença que nesta última se relacionam duas grandezas com significado físico: a tensão de engenharia com a deformação de engenharia.

Considere que exista um tensor constitutivo de quarta ordem $\mathbb{C}$ constante. Sendo $\mathbb{C}$ constante, não é mais nescessário resolver a Equação 3.65 de forma incremental. É como se a Equação 3.65 pudesse ser resolvida em um único passo incremental:

$$
\mathbf{S}=\mathbb{C}: \mathbf{E}
$$

que é o mesmo que dizer que:

$$
\frac{\partial u_{e}}{\partial \mathbf{E}}=\mathbb{C}: \mathbf{E}
$$

e por isso:

$$
u_{e}=\frac{1}{2} \mathbf{E}: \mathbb{C}: \mathbf{E} \rightarrow u_{e}=\frac{1}{2} E_{i j}: \mathbb{C}_{i j k l}: E_{k l}
$$

Observe que o tensor $\mathbb{C}$ tem 21 constantes distintas ("pseudo-matriz 6 x6 simétrica") e não 81 como eram de se esperar, uma vez que o tensor de deformação de Green-Lagrange é simétrico $\left(E_{i j}=E_{j i}\right)$ e $\mathbf{E}: \mathbb{C}: \mathbf{E}=E_{i j}\left(\mathbf{e}_{i} \otimes \mathbf{e}_{j}\right): \mathbb{C}_{m n o p}\left(\mathbf{e}_{m} \otimes \mathbf{e}_{n} \otimes \mathbf{e}_{o} \otimes \mathbf{e}_{p}\right): E_{k l}\left(\mathbf{e}_{k} \otimes \mathbf{e}_{l}\right)=$ $E_{k l}\left(\mathbf{e}_{k} \otimes \mathbf{e}_{l}\right): \mathbb{C}_{\text {mnop }}\left(\mathbf{e}_{m} \otimes \mathbf{e}_{n} \otimes \mathbf{e}_{o} \otimes \mathbf{e}_{p}\right): E_{i j}\left(\mathbf{e}_{i} \otimes \mathbf{e}_{j}\right) \rightarrow E_{i j} \mathbb{C}_{i j k l} E_{k l}=E_{k l} \mathbb{C}_{k l i j} E_{i j}$. Conforme já demonstrado na subseção 3.1.10, uma das simetrias de $\mathbb{C}$ é decorrente da simetria de $\mathbf{E}$, enquanto que a outra simetria de $\mathbb{C}$ depende da existência da energia específica de deformação $u_{e}$. No Apêndice C é detalhada a representação "pseudo-matricial" dos tensores constitutivos $\mathbb{C}$ de $4^{\text {a }}$ ordem.

A lei constitutiva de Saint Venant-Kirchhoff utiliza uma medida de deformação objetiva, tornando-a adequada para problemas com grandes deslocamentos (não linearidade geométrica). No entanto, a sua energia específica de deformação não tende a infinito na degeneração, sendo por isso inadequada para casos de grandes deformações (especialmente em estados predominantemente compressíveis).

A dedução completa da lei constitutiva de Saint Venant-Kirchhoff a partir de uma formulação geral hiperelástica é apresentada no Apêndice D.

O tensor constitutivo $\mathbb{C}$ para um estado plano de deformações da lei constitutiva de Saint Venant-Kirchhoff pode ser obtido de forma explícita simplesmente assumindo que determinadas deformações sejam nulas e eliminando os respectivos termos do tensor constitutivo $\mathbb{C}$. O mesmo, no entanto, não vale para obter um estado plano de tensões, ou seja, não se pode assumir simplesmente que determinadas tensões sejam nulas e eliminando os respectivos termos do tensor constitutivo $\mathbb{C}$. Isto acontece porque os planos e as direções livres de tensões não estão necessariamente livres deformações, como já mencionado. 
Apesar disso, como $\mathbb{C}$ é constante, ainda é possível determinar um tensor constitutivo $\mathbb{C}$ de forma a reproduzir o estado plano de tensões da seguinte maneira: Primeiramente se inverte o tensor constitutivo $\mathbb{C}$. Em seguida eliminam-se as tensões e os respectivos termos no inverso tensor constitutivo $\mathbb{C}$ referentes ao estado plano de tensões. Por fim "desinverte-se" o inverso do tensor constitutivo $\mathbb{C}$ que teve os termos eliminados.

\subsection{Método dos Elementos finitos posicional}

As principais referências consultadas sobre o método dos elementos finitos foram as seguintes: Savassi (1996), Assan (2003), Soriano (2003), Proença (2010), Vaz (2010), Alves Filho (2012), Paiva (2012), Alves Filho (2013) e Proença (2013). Com relação à formulação posicional do método, a referência Coda (2003) e as aulas de SET 5884 Introdução à Dinâmica Não - linear de Estruturas Reticuladas ministradas pelo Prof. Dr. Humberto Breves Coda constituíram as principais fontes de informação. Neste contexto é importante também destacar o trabalho de Bonet et al. (2000), por ser um dos precursores na abordagem posicional do método dos elementos finitos.

O método dos elementos finitos propõe a subdivisão da estrutura em elementos de geometria bem definida (triângulos, quadriláteros...), de tal maneira que as equações da elasticidade possam ser resolvidas em trechos da estrutura por meio de 3 princípios gerais da Mecânica do Contínuo: equações de equilíbrio, equações cinemáticas (relações entre deslocamento/posição e deformação) e relações constitutivas (relações entre tensões e deformações), as quais com o acréscimo das condições de contorno em forças e/ou deslocamentos compõem os modelos matemáticos (PROENÇA, 2013).

Esses elementos estão conectados uns aos outros através de nós e devem ser capazes de descrever o comportamento estrutural (viga, placa, chapa, casca, sólido) entre esses nós. Adicionalmente sobre esses nós atuam cargas que provocam efeitos equivalentes aos das cargas distribuídas de superfície e de volume. Através do somatório das equações de todos os trechos estendem-se as equações de equilíbrio para toda a estrutura. A notação matricial permite organizar eficientemente as operações e os cálculos, embora as formulações não tenham surgido em notação matricial. (SAVASSI, 1996; VAZ, 2010; ASSAN, 2003; SORIANO, 2003; ALVES FILHO, 2013)

O método dos elementos finitos baseado em posições constitui uma formulação alternativa ao método dos elementos finitos baseado em deslocamentos ao propor a utilização da função mudança de configuração para escrever a energia específica de deformação e o potencial das cargas externas em função das posições nodais. Essa função mudança de configuração também é utilizada para definir grandezas não lineares de tensão e deformação. Sendo assim, as posições nodais constituem valores atuais de cada nó e, portanto, esse método considera naturalmente a não linearidade geométrica (CODA, 2003; CODA, 
2014a).

A elasticidade não linear permite introduzir relações constitutivas não lineares utilizando-se uma formulação integral conhecida como hiperelasticidade. No entanto, como as soluções dos problemas da elasticidade não linear frequentemente são obtidas resolvendose uma sequência de problemas lineares através de técnicas incrementais e iterativas, essa estratégia de resolução requer também uma equação constitutiva na forma linearizada. Essa equação constitutiva linearizada é obtida em formato variacional.

\subsubsection{Discretização do contínuo}

A solução das equações da Mecânica do Contínuo em sua forma integral e contínua tal como apresentada na seção 3.1 dificilmente poderá ser obtida em sua forma analítica. Assim, o método dos elementos finitos propõe a subdivisão geométrica de um meio contínuo de formato qualquer em vários elementos com formatos variáveis e dimensões quaisquer, como por exemplo em elementos de formato triangular no caso de problemas bidimensionais.

Por sua vez, no interior de cada elemento finito, impõe-se que a solução para determinada grandeza seja dada na forma de uma função conhecida, como por exemplo um polinômio completo de grau 3. Esta função, que é conhecida como função aproximadora, deve ser suficientemente continua de modo a garantir a continuidade da grandeza aproximada entre os elementos, assim como ocorre no problema físico.

Em seguida, de acordo com o número de constantes necessárias para definir a função aproximadora, escolhem-se dentro do elemento pontos onde se deseja conhecer os valores dessa função aproximadora. Esses pontos são chamados de nós. Reescrevem-se então as constantes que definem a função aproximadora em função dos valores da própria função aproximadora nesses nós. Dessa forma, as constantes que definem a função aproximadora passam agora a ter também um significado físico, ou seja, as funções são escritas em parâmetros nodais e não mais em parâmetros generalizados.

Observe que, estimar o valor da grandeza incógnita do problema nos nós, passa agora a ser o mesmo que determinar as constantes que definem a função aproximadora. No nó, cada grandeza que é utilizada como parâmetro de aproximação e que, portanto, é também incógnita do problema, recebe o nome de parâmetro nodal, como por exemplo posição em x e posição em y.

Somando as soluções de cada elemento que compõe o contínuo e compatibilizando as soluções de um elemento com as soluções de seus elementos vizinhos, obtém-se um sistema de equações que descreve o problema de forma discretizada.

O problema final consiste então em determinar as constantes que definem as funções aproximadoras. Essas constantes já são, no entanto, os próprios valores das funções aproximadoras nos nós e, portanto, já são estimativas para a grandeza que se deseja avaliar. 
No método posicional essa grandeza é a posição atual (coordenadas cartesianas x, y, z) de todas as partículas que compõem o corpo, ou seja, é uma aproximação da função mudança de configuração da subseção 3.1.1.

\subsubsection{Análise não linear}

Em mecânica estrutural, um problema é dito não linear quando a rigidez estrutural depende dos próprios deslocamentos da estrutura. Logo, a não linearidade se manifesta em decorrência da variação da rigidez da estrutura a medida que o carregamento atua ou que a estrutura se deforma ou desloca. Em problemas não lineares, a rigidez dos elementos e, consequentemente da estrutura inteira, depende principalmente das propriedades físicas, das características geométricas e das condições de contorno. De maneira geral, o comportamento global estrutural pode ser identificado por uma curva força aplicada contra o deslocamento de um ponto, na qual a inexistência de proporcionalidade entre as forças e os deslocamentos caracteriza a não linearidade. As principais não linearidades estruturais são três: não linearidade física, não linearidade geométrica e não linearidade de contato.

A não linearidade física decorre do comportamento não linear do material induzido por processos físicos de dano, plastificação ou fenômenos viscosos. As não linearidades geométricas ocorrem devido a mudanças geométricas que resultam na necessidade da formulação das equações de equilíbrio na posição deslocada, podendo inclusive estarem acompanhadas de fenômenos de instabilidade tais como snap-back e snap-through. A não linearidade de contato ocorre devido a variações nas condições de contorno em força e/ou deslocamento resultantes de alterações nas ações das forças em função do processo de deformação ou modificações nos vínculos (Gap) (PROENÇA, 2013).

Geralmente, as não linearidades estão acompanhadas de alterações dimensionais significativas dos componentes ou grandes deslocamentos de corpo rígido e, portanto, as grandezas tensão e deformação são frequentemente redefinidas.

Assim, como a rigidez da estrutura varia, esta deve ser determinada em pequenos trechos ou incrementos de carga ou deslocamento. E ainda, como não se sabe de antemão o valor dessa rigidez em um próximo trecho, a priori não seria possível calcular os deslocamentos em um trecho seguinte. A solução de um problema não linear adota então uma estratégia incremental e iterativa. Essas tentativas no entanto não são deliberadamente ao acaso. Ao invés disso, utilizam-se métodos numéricos organizados que permitem conduzir a estratégia de tentativa e erro de maneira estruturada e racional por meio de sucessivas melhoras/refinamentos de uma aproximação inicial.

Note que, apesar de conceitualmente correto, geralmente não é possível previamente dividir o comportamento não linear em trechos lineares, uma vez que isso seria o mesmo que já conhecer a solução do problema antes mesmo de resolvê-lo. Assim, em análise não linear, 
o equilíbrio da estrutura é imprevisível e evolui passo a passo até atingir uma configuração final de equilíbrio, passando por sucessivas posições intermediárias de equilíbrio.

Em análise linear, o princípio de equivalência da energia de deformação e do trabalho das cargas externas é o procedimento padrão que permite determinar a rigidez dos elementos e consequentemente da estrutura inteira de sorte que o problema estrutural já está resolvido no âmbito dos deslocamentos unitários. Em contrapartida, na análise não linear, o princípio da conservação de energia deve ser verificado dentro de cada incremento ou passo, pois a rigidez da estrutura é variável. Ainda como na análise não linear não é possível determinar uma "matriz de rigidez" para a estrutura, a estacionariedade do funcional da mínima energia potencial total estabelece a igualdade entre o chamado vetor de forças internas ( $\delta U$ e $\delta K$ na Equação 3.51), que deve conter todas as não linearidades presentes no problema, e o vetor de forças externas ( $\delta B$ e $\delta P$ na Equação 3.51).(ALVES FILHO, 2012)

Estando a estrutura deformada, seus elementos estarão submetidos a forças internas, as quais serão transferidas aos nós e deverão estar em equilíbrio com as forças externas atuantes nesses mesmos nós. A condição de equilíbrio das forças internas com as forças externas constitui, portanto, uma abordagem alternativa quando não é possível de antemão determinar explicitamente a rigidez da estrutura. O vetor de forças internas dá origem a matriz hessiana, a qual, assim como a matriz de rigidez, contabiliza variações de deslocamento em função de variações nas cargas externas atuantes. Tal como o vetor de forças internas, a matriz hessiana também é corrigida iterativamente dentro de cada passo incremental de modo a fornecer incrementos de deslocamentos reais em função de incrementos nas cargas externas atuantes. Assim, o equilíbrio em análise não linear sempre é escrito em sua forma variacional, ou seja, estabelecendo relações entre as variações do trabalho externo e interno conforme pode-se notar na Equação 3.51.

A análise não linear constitui, portanto, da atribuição de uma configuração deformada à estrutura bem como aos seus elementos através da imposição de condições geométricas (deslocamentos) compatíveis com as cargas externas atuantes, seguida da verificação do equilíbrio estrutural (forças internas = forças externas) dentro de uma certa tolerância.

Finalmente, observa-se que os procedimentos numéricos em análises não lineares são incrementais e/ou iterativos, uma vez que o equilíbrio estrutural é resolvido passo a passo em trechos de maneira que a busca da solução aconteça por meio de sucessivas tentativas estruturadas, organizadas e racionais dentro de um incremento.

Segundo Novozhilov (1953), o processo de deformação pode ser dividido em três etapas a partir de três elementos lineares de material definidos a partir de dois pontos (e que podem ser imaginados como fibras de material) dispostos em quaisquer direções: 
1. Translação da fibras.

2. Rotação da fibras.

3. Alongamento da fibras.

Logo, sendo as deformações vistas a partir de variações nas posições relativas entre os pontos do material, e, uma vez que deslocamentos puro de corpo rígido sempre devem ser restringidos pelas condições de contorno, o movimento de translação é irrelevante para a descrição do fenômeno da deformação. Assim, e conforme demonstrado em Novozhilov (1953), são 4 as possíveis abordagens para os problemas da elasticidade:

1. Grandes deformações e grandes rotações: teoria geral da elasticidade não linear sem qualquer hipótese restringindo a magnitude das deformações e das rotações.

2. Pequenas deformações e grandes rotações: deformações longitudinais e angulares negligenciáveis quando comparadas com a unidade.

3. Pequenas deformações e médias rotações: deformações tanto longitudinais quanto angulares e ângulos de rotação negligenciáveis quando comparados com a unidade, porém rotações significativas quando comparadas com a magnitude das deformações.

4. Pequenas deformações e pequenas rotações: deformações tanto longitudinais quanto angulares e ângulos de rotação negligenciáveis quando comparados com a unidade, bem como rotações insignificantes quando comparadas com a magnitude das deformações. Esse é o caso da Teoria da Elasticidade Linear, conhecido como a teoria das pequenas deformações e dos pequenos deslocamentos.

Pequenos deslocamentos e pequenas rotações automaticamente implicam em pequenas deformações, no entanto, o contrário não é verdade. Ou seja, pequenas deformações necessariamente não implicam em pequenas rotações e/ou deslocamentos, como por exemplo no caso da flexão de uma tira de metal. Embora em corpos maciços (espessos) pequenas deformações geralmente impliquem em pequenas rotações, isso nunca é verdade para corpos flexíveis, podendo, nesse último, os ângulos de rotação excederem a magnitude das deformações. Novamente, o caso da flexão de uma tira de metal é um exemplo típico, onde apesar de se observarem grandes deflexões (rotações), não se observam grandes deformações. Prova disso é que, removido o carregamento, essa tira volta à condição inicial sem deformações residuais, atestando assim a hipótese da ausência de grandes deformações.

Não havendo acoplamento entre os esforços de flexão e normal, a relação entre deformação e deslocamento da Teoria da Elasticidade Linear pode ser utilizada na formulação dos problemas de flexão (NOVOZHILOV, 1953). Já em problemas de flexão com 
acoplamento entre os esforços de flexão e normal, uma medida de deformação do tipo dada pela Equação B.18 deve ser utilizada desde que não haja grandes deformações.

\subsubsection{Elemento finito de chapa (2D)}

No método dos elementos finitos posicional são utilizadas três configurações para formulação de um elemento finito: a configuração final deformada, a configuração inicial indeformada e o elemento adimensional de referência. A Figura 3 ilustra o mapeamento entre o domínio adimensional de referência $\left(\Omega_{0}\right)$, a configuração inicial indeformada $\left(\Omega_{1}\right)$ e a configuração final deformada $(\Omega)$ utilizando as funções mudança de configuração $\left(f, f_{0}\right.$ e $\left.f_{1}\right)$ e seus respectivos gradientes $\left(F, F_{0}\right.$ e $\left.F_{1}\right)$.

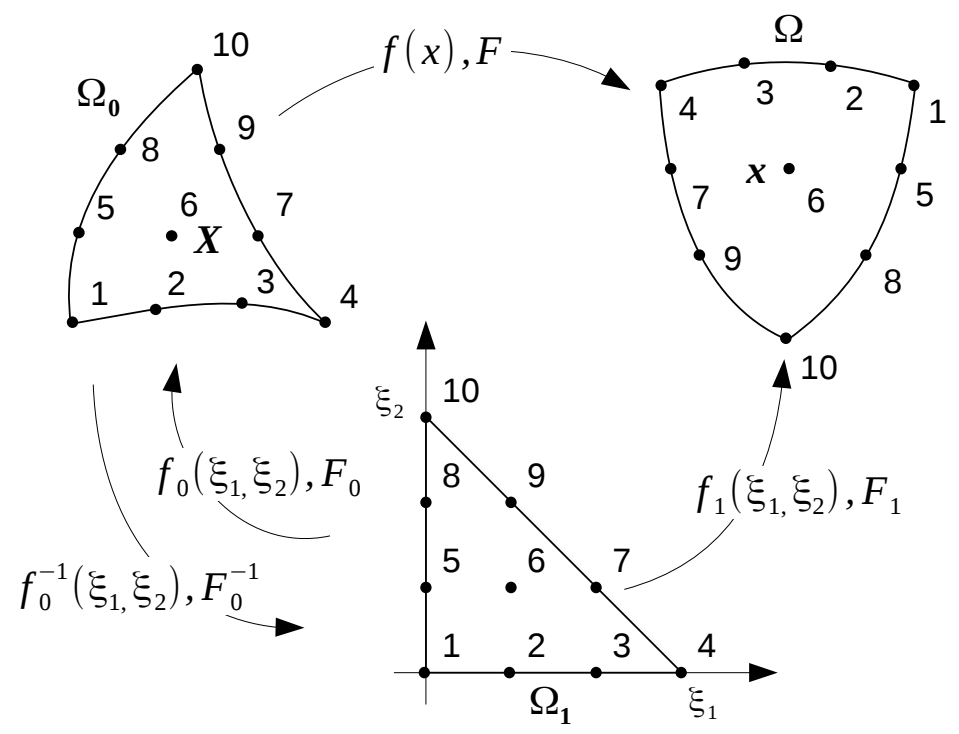

Figura 3 - Formulação de um elemento finito posicional 2D

Adotando uma aproximação cúbica para a função mudança de configuração $f_{1}\left(\xi_{1}, \xi_{2}\right)$ que mapeia todas as partículas do contínuo no domínio de um elemento triangular em relação às coordenadas adimensionais $\xi_{1}, \xi_{2}$ e em um dado instante, têm-se para as direções 1 e 2 no plano a seguinte equação apresentada de forma matricial:

$$
\left\{\begin{array}{l}
x_{1}\left(\xi_{1}, \xi_{2}\right) \\
x_{2}\left(\xi_{1}, \xi_{2}\right)
\end{array}\right\}=\left(\begin{array}{cc}
{\left[\varphi_{1}\right]} & 0 \\
0 & {\left[\varphi_{2}\right]}
\end{array}\right)\left\{\begin{array}{l}
\left\{a_{1}^{n}\right\} \\
\left\{a_{2}^{n}\right\}
\end{array}\right\}
$$

onde $\left[\varphi_{1}\right]$ e $\left[\varphi_{2}\right]$ são polinômios completos de grau 3, enquanto que os termos $\left\{a_{1}^{n}\right\}$ e $\left\{a_{2}^{n}\right\}$ são vetores que contém as constantes da função utilizada na aproximação das posições. 
Expandindo agora a Equação 3.72 na direção 1:

$$
x_{1}\left(\xi_{1}, \xi_{2}\right)=\left[\begin{array}{llllllllll}
1 & \xi_{1} & \xi_{2} & \xi_{1}^{2} & \xi_{1} \xi_{2} & \xi_{2}^{2} & \xi_{1}^{3} & \xi_{1}^{2} \xi_{2} & \xi_{1} \xi_{2}^{2} & \xi_{2}^{3}
\end{array}\right]\left\{\begin{array}{l}
a_{1}^{0} \\
a_{1}^{1} \\
a_{1}^{2} \\
a_{1}^{3} \\
a_{1}^{4} \\
a_{1}^{5} \\
a_{1}^{6} \\
a_{1}^{7} \\
a_{1}^{8} \\
a_{1}^{9}
\end{array}\right\}
$$

Reconhecendo que a função $x_{1}\left(\xi_{1}, \xi_{2}\right)$ na direção 1 deve assumir os valores nodais de posição dos nós:

$$
\left\{\begin{array}{l}
x_{1}^{1} \\
x_{1}^{2} \\
x_{1}^{3} \\
x_{1}^{4} \\
x_{1}^{5} \\
x_{1}^{6} \\
x_{1}^{7} \\
x_{1}^{8} \\
x_{1}^{9} \\
x_{1}^{10}
\end{array}\right\}=\left(\begin{array}{cccccccccc}
1 & 0 & 0 & 0 & 0 & 0 & 0 & 0 & 0 & 0 \\
1 & 1 / 3 & 0 & 1 / 9 & 0 & 0 & 1 / 27 & 0 & 0 & 0 \\
1 & 2 / 3 & 0 & 4 / 9 & 0 & 0 & 8 / 27 & 0 & 0 & 0 \\
1 & 1 & 0 & 1 & 0 & 0 & 1 & 0 & 0 & 0 \\
1 & 0 & 1 / 3 & 0 & 0 & 1 / 9 & 0 & 0 & 0 & 1 / 27 \\
1 & 1 / 3 & 1 / 3 & 1 / 9 & 1 / 9 & 1 / 9 & 1 / 27 & 1 / 27 & 1 / 27 & 1 / 27 \\
1 & 2 / 3 & 1 / 3 & 4 / 9 & 2 / 9 & 1 / 9 & 8 / 27 & 4 / 27 & 2 / 27 & 1 / 27 \\
1 & 0 & 2 / 3 & 0 & 0 & 4 / 9 & 0 & 0 & 0 & 8 / 27 \\
1 & 1 / 3 & 2 / 3 & 1 / 9 & 2 / 9 & 4 / 9 & 1 / 27 & 2 / 27 & 4 / 27 & 8 / 27 \\
1 & 0 & 1 & 0 & 0 & 1 & 0 & 0 & 0 & 1
\end{array}\right)\left\{\begin{array}{l}
a_{1}^{0} \\
a_{1}^{1} \\
a_{1}^{2} \\
a_{1}^{3} \\
a_{1}^{4} \\
a_{1}^{5} \\
a_{1}^{6} \\
a_{1}^{7} \\
a_{1}^{8} \\
a_{1}^{9}
\end{array}\right\}
$$

que resumidamente é o mesmo que:

$$
\left\{x_{1}^{q}\right\}=\left[\varphi_{1}^{n}\right]\left\{a_{1}^{n}\right\} \rightarrow\left\{a_{1}^{n}\right\}=\left[\varphi_{1}^{n}\right]^{-1}\left\{x_{1}^{q}\right\}
$$

onde $q$ refere-se aos nós do elemento adotado e $n$ depende do grau de aproximação utilizado (que por sua vez depende do número de nós do elemento escolhido). Assim, têm-se as constantes que definem a função aproximadora escritas em função dos valores da própria função aproximadora nos nós do elemento (valores nodais). Fazendo o mesmo procedimento agora na direção 2 e substituindo $\left\{a_{1}^{n}\right\}$ e $\left\{a_{2}^{n}\right\}$ na Equação 3.72 resulta em:

$$
\begin{gathered}
\left\{\begin{array}{l}
x_{1}\left(\xi_{1}, \xi_{2}\right) \\
x_{2}\left(\xi_{1}, \xi_{2}\right)
\end{array}\right\}=\left(\begin{array}{cc}
{\left[\varphi_{1}\right]} & 0 \\
0 & {\left[\varphi_{2}\right]}
\end{array}\right)\left\{\begin{array}{l}
{\left[\varphi_{1}^{n}\right]^{-1}\left\{x_{1}^{n}\right\}} \\
{\left[\varphi_{2}^{n}\right]^{-1}\left\{x_{2}^{n}\right\}}
\end{array}\right\}=\left\{\begin{array}{l}
{\left[\varphi_{1}\right]\left[\varphi_{1}^{n}\right]^{-1}\left\{x_{1}^{n}\right\}} \\
{\left[\varphi_{2}\right]\left[\varphi_{2}^{n}\right]^{-1}\left\{x_{2}^{n}\right\}}
\end{array}\right\} \\
\therefore\left\{\begin{array}{l}
x_{1}\left(\xi_{1}, \xi_{2}\right) \\
x_{2}\left(\xi_{1}, \xi_{2}\right)
\end{array}\right\}=\left\{\begin{array}{l}
{[\phi]\left\{x_{1}^{n}\right\}} \\
{[\phi]\left\{x_{2}^{n}\right\}}
\end{array}\right\}
\end{gathered}
$$


onde $[\phi]$ são as chamadas funções de forma. Explicitando essas funções de forma:

$$
\begin{aligned}
& {[\phi]=\left[\begin{array}{llllllllll}
\phi_{1} & \phi_{2} & \phi_{3} & \phi_{4} & \phi_{5} & \phi_{6} & \phi_{7} & \phi_{8} & \phi_{9} & \phi_{10}
\end{array}\right]} \\
& \phi_{1}\left(\xi_{1}, \xi_{2}, \xi_{3}\right)=\frac{1}{2} \xi_{1}\left(3 \xi_{1}-1\right)\left(3 \xi_{1}-2\right) \\
& \phi_{2}\left(\xi_{1}, \xi_{2}, \xi_{3}\right)=\frac{9}{2} \xi_{1} \xi_{2}\left(3 \xi_{1}-1\right) \\
& \phi_{3}\left(\xi_{1}, \xi_{2}, \xi_{3}\right)=\frac{9}{2} \xi_{1} \xi_{2}\left(3 \xi_{2}-1\right) \\
& \phi_{4}\left(\xi_{1}, \xi_{2}, \xi_{3}\right)=\frac{1}{2} \xi_{2}\left(3 \xi_{2}-1\right)\left(3 \xi_{2}-2\right) \\
& \phi_{5}\left(\xi_{1}, \xi_{2}, \xi_{3}\right)=\frac{9}{2} \xi_{3} \xi_{1}\left(3 \xi_{1}-1\right) \\
& \phi_{6}\left(\xi_{1}, \xi_{2}, \xi_{3}\right)=27 \xi_{1} \xi_{2} \xi_{3} \\
& \phi_{7}\left(\xi_{1}, \xi_{2}, \xi_{3}\right)=\frac{9}{2} \xi_{2} \xi_{3}\left(3 \xi_{2}-1\right) \\
& \phi_{8}\left(\xi_{1}, \xi_{2}, \xi_{3}\right)=\frac{9}{2} \xi_{3} \xi_{1}\left(3 \xi_{3}-1\right) \\
& \phi_{9}\left(\xi_{1}, \xi_{2}, \xi_{3}\right)=\frac{9}{2} \xi_{2} \xi_{3}\left(3 \xi_{3}-1\right) \\
& \phi_{10}\left(\xi_{1}, \xi_{2}, \xi_{3}\right)=\frac{1}{2} \xi_{3}\left(3 \xi_{3}-1\right)\left(3 \xi_{3}-2\right)
\end{aligned}
$$

Sejam $X_{1}$ e $X_{2}$ a posição inicial de uma das partículas do corpo na situação indeformada e dadas em função das coordenadas adimensionais $\xi_{1}$ e $\xi_{2}$ no domínio do elemento triangular de referência, respectivamente nas direções 1 e 2. As variações infinitesimais $d X_{1}$ e $d X_{2}$ dessas posições iniciais no entorno de um ponto, respectivamente nas direções 1 e 2, podem então ser calculadas através das seguintes relações:

$$
\begin{aligned}
& d X_{1}=\frac{\partial X_{1}}{\partial \xi_{1}} d \xi_{1}+\frac{\partial X_{1}}{\partial \xi_{2}} d \xi_{2} \\
& d X_{2}=\frac{\partial X_{2}}{\partial \xi_{1}} d \xi_{1}+\frac{\partial X_{2}}{\partial \xi_{2}} d \xi_{2}
\end{aligned}
$$

que matricialmente é o mesmo que:

$$
\left\{\begin{array}{l}
d X_{1} \\
d X_{2}
\end{array}\right\}=\left(\begin{array}{ll}
\frac{\partial X_{1}}{\partial \xi_{1}} & \frac{\partial X_{1}}{\partial \xi_{2}} \\
\frac{\partial X_{2}}{\partial \xi_{1}} & \frac{\partial X_{2}}{\partial \xi_{2}}
\end{array}\right)\left\{\begin{array}{l}
d \xi_{1} \\
d \xi_{2}
\end{array}\right\} \rightarrow\left\{\begin{array}{l}
d X_{1} \\
d X_{2}
\end{array}\right\}=\left[F_{0}\right]\left\{\begin{array}{l}
d \xi_{1} \\
d \xi_{2}
\end{array}\right\}
$$

Também é válida a relação "inversa" à Equação 3.79:

$$
\begin{aligned}
& d \xi_{1}=\frac{\partial \xi_{1}}{\partial X_{1}} d X_{1}+\frac{\partial \xi_{2}}{\partial X_{1}} d X_{1} \\
& d \xi_{2}=\frac{\partial \xi_{1}}{\partial X_{2}} d X_{2}+\frac{\partial \xi_{2}}{\partial X_{2}} d X_{2}
\end{aligned}
$$


que matricialmente também é o mesmo que:

$$
\left\{\begin{array}{l}
d \xi_{1} \\
d \xi_{2}
\end{array}\right\}=\left(\begin{array}{ll}
\frac{\partial \xi_{1}}{\partial X_{1}} & \frac{\partial \xi_{1}}{\partial X_{2}} \\
\frac{\partial \xi_{2}}{\partial X_{1}} & \frac{\partial \xi_{2}}{\partial X_{2}}
\end{array}\right)\left\{\begin{array}{l}
d X_{1} \\
d X_{2}
\end{array}\right\} \rightarrow\left\{\begin{array}{l}
d \xi_{1} \\
d \xi_{2}
\end{array}\right\}=\left[F_{0}\right]^{-1}\left\{\begin{array}{l}
d X_{1} \\
d X_{2}
\end{array}\right\}
$$

Finalmente, utilizando uma função aproximadora para estimar as posições iniciais iguais àquelas que foram usadas para aproximar as posições atuais na Equação 3.76:

$$
\mathbf{F}_{0}=\left(\begin{array}{ll}
\frac{\partial X_{1}}{\partial \xi_{1}} & \frac{\partial X_{1}}{\partial \xi_{2}} \\
\frac{\partial X_{2}}{\partial \xi_{1}} & \frac{\partial X_{2}}{\partial \xi_{2}}
\end{array}\right)=\left(\begin{array}{ll}
\frac{\partial[\phi]}{\partial \xi_{1}}\left\{X_{1}^{n}\right\} & \frac{\partial[\phi]}{\partial \xi_{2}}\left\{X_{1}^{n}\right\} \\
\frac{\partial[\phi]}{\partial \xi_{1}}\left\{X_{2}^{n}\right\} & \frac{\partial[\phi]}{\partial \xi_{2}}\left\{X_{2}^{n}\right\}
\end{array}\right)
$$

Já o gradiente $\mathbf{F}$ da função mudança de configuração na posição atual deformada nas direções 1 e 2 é um tensor de ordem 2, que organizado matricialmente e tendo em mente a regra da cadeia vale:

$$
\begin{aligned}
\mathbf{F}=\nabla \otimes \mathbf{x}=\frac{\partial\left(x_{i} \mathbf{e}_{i}\right)}{\partial X_{j}} \otimes \mathbf{e}_{j} & =\left(\begin{array}{lll}
\frac{\partial x_{1}}{\partial \xi_{1}} \frac{\partial \xi_{1}}{\partial X_{1}}+\frac{\partial x_{1}}{\partial \xi_{2}} \frac{\partial \xi_{2}}{\partial X_{1}} & \frac{\partial x_{1}}{\partial \xi_{1}} \frac{\partial \xi_{1}}{\partial X_{2}}+\frac{\partial x_{1}}{\partial \xi_{2}} \frac{\partial \xi_{2}}{\partial X_{2}} \\
\frac{\partial x_{2}}{\partial \xi_{1}} \frac{\partial \xi_{1}}{\partial X_{1}}+\frac{\partial x_{2}}{\partial \xi_{2}} \frac{\partial \xi_{2}}{\partial X_{1}} & \frac{\partial x_{2}}{\partial \xi_{1}} \frac{\partial \xi_{1}}{\partial X_{2}}+\frac{\partial x_{2}}{\partial \xi_{2}} \frac{\partial \xi_{2}}{\partial X_{2}}
\end{array}\right) \\
& =\left(\begin{array}{ll}
\frac{\partial x_{1}}{\partial \xi_{1}} & \frac{\partial x_{1}}{\partial \xi_{2}} \\
\frac{\partial x_{2}}{\partial \xi_{1}} & \frac{\partial x_{2}}{\partial \xi_{2}}
\end{array}\right)\left(\begin{array}{ll}
\frac{\partial \xi_{1}}{\partial X_{1}} & \frac{\partial \xi_{1}}{\partial X_{2}} \\
\frac{\partial \xi_{2}}{\partial X_{1}} & \frac{\partial \xi_{2}}{\partial X_{2}}
\end{array}\right)
\end{aligned}
$$

Reescrevendo a Equação 3.84 de uma forma mais compacta tendo em vista a Equação 3.82:

$$
\mathbf{F}=\left(\begin{array}{ll}
\frac{\partial x_{1}}{\partial \xi_{1}} & \frac{\partial x_{1}}{\partial \xi_{2}} \\
\frac{\partial x_{2}}{\partial \xi_{1}} & \frac{\partial x_{2}}{\partial \xi_{2}}
\end{array}\right) \mathbf{F}_{0}^{-1}
$$

Substituindo na Equação 3.85 a função aproximadora adotada na Equação 3.76 para a função mudança de configuração $\mathbf{F}_{1}$ na posição atual deformada com relação ao domínio adimensional, semelhantemente ao que foi feito para $\mathbf{F}_{0}$, obtém-se que:

$$
\mathbf{F}_{1}=\left(\begin{array}{ll}
\frac{\partial x_{1}}{\partial \xi_{1}} & \frac{\partial x_{1}}{\partial \xi_{2}} \\
\frac{\partial x_{2}}{\partial \xi_{1}} & \frac{\partial x_{2}}{\partial \xi_{2}}
\end{array}\right)=\left(\begin{array}{ll}
\frac{\partial[\phi]}{\partial \xi_{1}}\left\{x_{1}^{n}\right\} & \frac{\partial[\phi]}{\partial \xi_{2}}\left\{x_{1}^{n}\right\} \\
\frac{\partial[\phi]}{\partial \xi_{1}}\left\{x_{2}^{n}\right\} & \frac{\partial[\phi]}{\partial \xi_{2}}\left\{x_{2}^{n}\right\}
\end{array}\right)
$$

Logo, a partir das Equações 3.85 e 3.86, a deformação de Green-Lagrange fica então sendo dada por:

$$
\mathbf{E}=\frac{1}{2}\left(\mathbf{F}^{T} \mathbf{F}-\mathbf{I}\right)=\frac{1}{2}\left(\mathbf{F}_{0}^{-T} \mathbf{F}_{1}^{T} \mathbf{F}_{1} \mathbf{F}_{0}^{-1}-\mathbf{I}\right)
$$


Observe que adotar funções de aproximação de mesmo grau tanto para a posição inicial quanto para a posição final é análogo a formular um elemento isoparamétrico. Assim, o elemento aqui formulado pode inclusive apresentar lados curvos na configuração inicial indeformada, os quais conforme já mostrado são aproximados por funções cúbicas. Adotar elementos paramétricos na formulação posicional não acarreta diminuição do grau de aproximação dos parâmetros nodais como acontece na formulação baseada em deslocamentos (SORIANO, 2003).

Além da geometria, é necessário também definir o vetor de forças externas. Desprezando forças de volume e de inércia, a Equação 3.51 fica sendo:

$$
\delta \pi=\int_{V} \mathbf{P N} \cdot \delta \mathbf{x} d S-\int_{V} \mathbf{S}: \delta \mathbf{E} d V=0
$$

Reconhecendo que $\mathbf{T}=\mathbf{P N}=P_{i j}\left(\mathbf{e}_{i} \otimes \mathbf{e}_{j}\right) \mathbf{e}_{\alpha}=T_{\alpha}$ é uma força de superfície externa referente à configuração inicial indeformada, a Equação 3.88 na notação indicial é dada por:

$$
\delta \pi=\int_{V} T_{\alpha} \delta x_{\alpha} d S-\int_{V} S_{i j} \delta E_{i j} d V=0 \rightarrow \delta \pi=\delta P-\delta U=0
$$

Note que $T_{\alpha}$ são forças de superfície, ou seja, é um carregamento externo conhecido. $\delta x_{\alpha}$ também é conhecido em função de seus valores nodais $\left(\left\{\delta x_{\alpha}^{q}\right\}\right)$ e da função de aproximação $([\phi])$ adotada, isto é, $\delta x_{\alpha}=[\phi]\left\{\delta x_{\alpha}^{q}\right\}$, onde o índice $q$ é referente ao nó e o índice $\alpha$ é referente a direção. Assumindo uma lei constitutiva hiperelástica qualquer, ou seja, explicitando uma energia específica de deformação $u_{e}$ em função do tensor de deformações de Green-Lagrange $\mathbf{E}$ ou de parâmetros à ele relacionados tais como seus invariantes, é possível determinar o $2^{\circ}$ tensor de tensões de Piola-Kirchhoff $S_{i j}$ através da Equação 3.50 .

A Figura 4 ilustra um elemento triangular de chapa com carregamento linearmente distribuído ao longo de um dos seus lados. O termo $T_{\alpha}^{q}$ é o valor da carga distribuída no nó q, que varia de 1 a 4 , na direção $\alpha$, que também varia de 1 a 2 para o caso bidimensional. $\mathrm{Na}$ Figura 4, as posições são aproximadas por funções cúbicas, enquanto que os carregamentos são adotados como tendo comportamento linear 


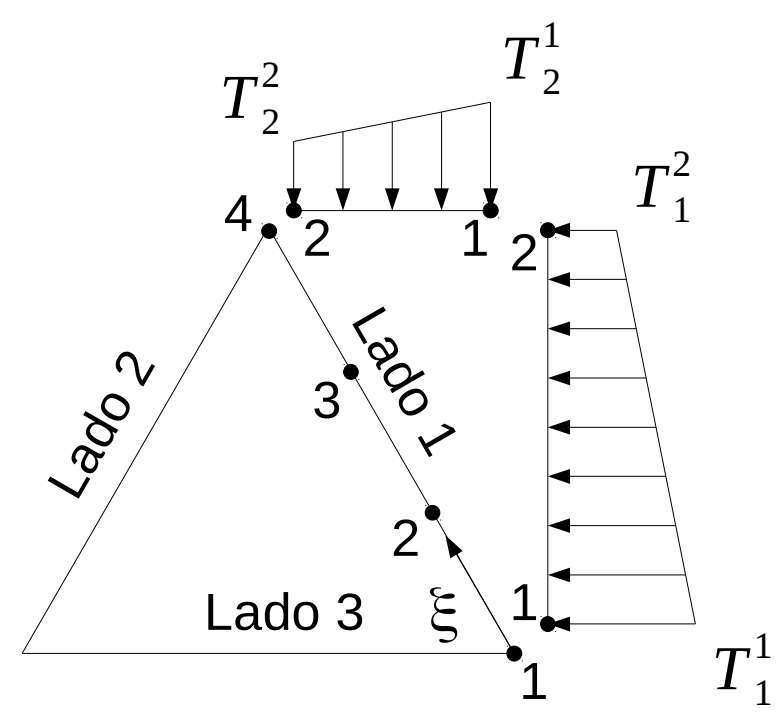

Figura 4 - Carregamento distribuído nos lados do elemento finito de chapa

Como o elemento triangular adotado de 10 nós tem 4 nós em cada um de seus lados, é razoável também adotar um polinômio cúbico para aproximar as posições nodais dos nós no lado do elemento no cálculo da força externa equivalente:

$$
\left\{\begin{array}{l}
x_{1}\left(\xi_{1}, \xi_{2}\right) \\
x_{2}\left(\xi_{1}, \xi_{2}\right)
\end{array}\right\}=\left(\begin{array}{cccccccc}
1 & \xi & \xi^{2} & \xi^{3} & 0 & 0 & 0 & 0 \\
0 & 0 & 0 & 0 & 1 & \xi & \xi^{2} & \xi^{3}
\end{array}\right)\left\{\begin{array}{l}
a_{1}^{0} \\
a_{1}^{1} \\
a_{1}^{2} \\
a_{1}^{3} \\
a_{2}^{0} \\
a_{2}^{1} \\
a_{2}^{2} \\
a_{2}^{3}
\end{array}\right\}=\left(\begin{array}{cc}
{\left[\varphi_{1}\right]} & 0 \\
0 & {\left[\varphi_{2}\right.}
\end{array}\right)\left\{\begin{array}{l}
\left\{a_{1}^{n}\right\} \\
\left\{a_{2}^{n}\right\}
\end{array}\right\}
$$

Reconhecendo que as funções mudança de configuração $x_{1}\left(\xi_{1}, \xi_{2}\right)$ e $x_{2}\left(\xi_{1}, \xi_{2}\right)$ devem assumir os valores nodais de posição nos nós:

$$
\left\{\begin{array}{l}
x_{1}^{1} \\
x_{1}^{2} \\
x_{1}^{3} \\
x_{1}^{4} \\
x_{2}^{1} \\
x_{2}^{2} \\
x_{2}^{3} \\
x_{2}^{4}
\end{array}\right\}=\left(\begin{array}{cccccccc}
1 & 0 & 0 & 0 & 0 & 0 & 0 & 0 \\
1 & 1 / 3 & 1 / 9 & 1 / 27 & 0 & 0 & 0 & 0 \\
1 & 2 / 3 & 4 / 9 & 8 / 27 & 0 & 0 & 0 & 0 \\
1 & 1 & 1 & 1 & 0 & 0 & 0 & 0 \\
0 & 0 & 0 & 0 & 1 & 0 & 0 & 0 \\
0 & 0 & 0 & 0 & 1 & 1 / 3 & 1 / 9 & 1 / 27 \\
0 & 0 & 0 & 0 & 1 & 2 / 3 & 4 / 9 & 8 / 27 \\
0 & 0 & 0 & 0 & 1 & 1 & 1 & 1
\end{array}\right)\left\{\begin{array}{l}
a_{1}^{0} \\
a_{1}^{1} \\
a_{1}^{2} \\
a_{1}^{3} \\
a_{2}^{0} \\
a_{2}^{1} \\
a_{2}^{2} \\
a_{2}^{3}
\end{array}\right\}
$$


Portanto, sendo $q$ o nó na lateral do elemento (1,2,3 ou 4) e $\alpha$ a direção (1 ou 2) tem-se:

$$
\begin{gathered}
\left\{\begin{array}{l}
x_{1}\left(\xi_{1}, \xi_{2}\right) \\
x_{2}\left(\xi_{1}, \xi_{2}\right)
\end{array}\right\}=\left(\begin{array}{cc}
{\left[\varphi_{1}\right]} & 0 \\
0 & {\left[\varphi_{2}\right]}
\end{array}\right)\left(\begin{array}{cc}
{\left[\varphi_{1}^{n}\right]^{-1}} & 0 \\
0 & {\left[\varphi_{2}^{n}\right]^{-1}}
\end{array}\right)\left\{\begin{array}{l}
\left\{x_{1}^{q}\right\} \\
\left\{x_{2}^{q}\right\}
\end{array}\right\} \\
x_{\alpha}\left(\xi_{1}, \xi_{2}\right)=[\phi]\left\{x_{\alpha}^{q}\right\}
\end{gathered}
$$

onde as funções de forma $[\phi]=\left[\begin{array}{llll}\phi_{1} & \phi_{2} & \phi_{3} & \phi_{4}\end{array}\right]$ valem:

$$
[\phi]=\left[\varphi_{1}\right]\left[\varphi_{1}^{n}\right]^{-1} \text { ou }[\phi]=\left[\varphi_{2}\right]\left[\varphi_{2}^{n}\right]^{-1}
$$

Explicitando tais funções de forma para $\xi \in[0,1]$ :

$$
\begin{aligned}
& \phi_{1}(\xi)=1-\frac{11 \xi}{2}+9 \xi^{2}-\frac{9 \xi^{3}}{2} \\
& \phi_{2}(\xi)=9 \xi-\frac{45 \xi^{2}}{2}+\frac{27 \xi^{3}}{2} \\
& \phi_{3}(\xi)=-\frac{9 \xi}{2}+18 \xi^{2}-\frac{27 \xi^{3}}{2} \\
& \phi_{4}(\xi)=\xi-\frac{9 \xi^{2}}{2}+\frac{9 \xi^{3}}{2}
\end{aligned}
$$

Adotando uma aproximação linear para o carregamento distribuído $T_{1}$ e $T_{2}$ respectivamente nas direções 1 e 2 :

$$
\left\{\begin{array}{l}
T_{1}(\xi) \\
T_{2}(\xi)
\end{array}\right\}=\left(\begin{array}{cccc}
1 & \xi & 0 & 0 \\
0 & 0 & 1 & \xi
\end{array}\right)\left\{\begin{array}{l}
a_{1}^{0} \\
a_{1}^{1} \\
a_{2}^{0} \\
a_{2}^{1}
\end{array}\right\}
$$

Reconhecendo que as funções $T_{1}(\xi)$ e $T_{2}(\xi)$ também devem assumir os valores nodais nos nós:

$$
\left\{T_{\alpha}^{q}\right\}=\left\{\begin{array}{l}
T_{1}^{2} \\
T_{1}^{2} \\
T_{2}^{1} \\
T_{2}^{2}
\end{array}\right\}=\left(\begin{array}{llll}
1 & 0 & 0 & 0 \\
1 & 1 & 0 & 0 \\
0 & 0 & 1 & 0 \\
0 & 0 & 1 & 1
\end{array}\right)\left\{\begin{array}{l}
a_{1}^{0} \\
a_{1}^{1} \\
a_{2}^{0} \\
a_{2}^{1}
\end{array}\right\}
$$

onde o índice inferior $\alpha$ indica a direção e o índice superior $q$ indica o nó na lateral do elemento. A inversão da matriz da Equação 3.96 que relaciona as cargas nos nós com os parâmetros generalizados fornece:

$$
\left\{\begin{array}{l}
a_{1}^{0} \\
a_{1}^{1} \\
a_{2}^{0} \\
a_{2}^{1}
\end{array}\right\}=\left(\begin{array}{cc}
\left(\begin{array}{ll}
1 & 0 \\
1 & 1
\end{array}\right)^{-1} & 0 \\
0 & \left(\begin{array}{ll}
1 & 0 \\
1 & 1
\end{array}\right)^{-1}
\end{array}\right)\left\{\begin{array}{l}
T_{1}^{1} \\
T_{1}^{2} \\
T_{2}^{1} \\
T_{2}^{2}
\end{array}\right\}
$$


Portanto das Equações 3.95 e 3.97 obtém-se que:

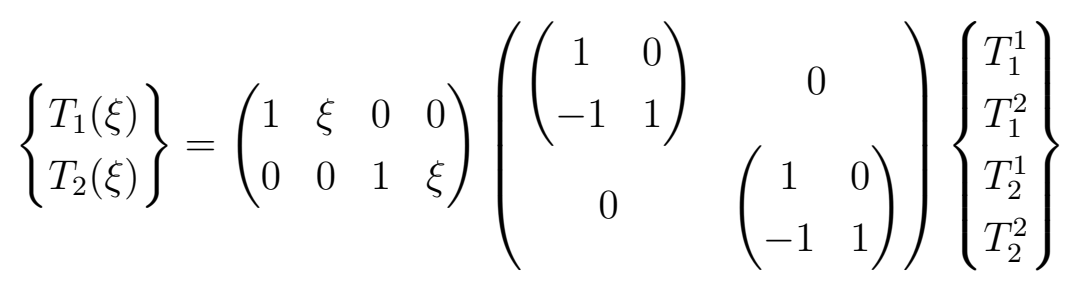

$$
\begin{aligned}
& \left\{\begin{array}{l}
T_{1}(\xi) \\
T_{2}(\xi)
\end{array}\right\}=\left(\begin{array}{cccc}
1-\xi & \xi & 0 & 0 \\
0 & 0 & 1-\xi & \xi
\end{array}\right)\left\{\begin{array}{l}
T_{1}^{1} \\
T_{1}^{2} \\
T_{2}^{1} \\
T_{2}^{2}
\end{array}\right\} \rightarrow T_{\alpha}(\xi)=\left[\phi_{p}\right]\left\{T_{\alpha}^{q}\right\}
\end{aligned}
$$

Assim, a parcela referente à variação do potencial das cargas externas na Equação 3.89 em sua forma matricial e em coordenadas adimensionais é dada por:

$$
\begin{gathered}
\delta P=\int_{S} T_{\alpha} \delta x_{\alpha} d S=\int_{S}\left(\left[\phi_{p}\right]\left\{T_{\alpha}^{q}\right\}\right)^{T}[\phi]\left\{\delta x_{\alpha}^{q}\right\} d S \\
=L e\left\{\delta x_{\alpha}^{q}\right\} \int[\phi]^{T}\left[\phi_{p}\right]\left\{T_{\alpha}^{q}\right\} d \xi \\
\delta P=L e \int_{\xi}\left(\begin{array}{l}
\delta x_{1}^{1} \\
\delta x_{1}^{2} \\
\delta x_{1}^{3} \\
\delta x_{1}^{4} \\
\delta x_{2}^{1} \\
\delta x_{2}^{2} \\
\delta x_{2}^{3} \\
\delta x_{2}^{4}
\end{array}\right\}\left(\begin{array}{cc}
\phi_{1}(\xi) & 0 \\
0 & \phi_{1}(\xi) \\
\phi_{2}(\xi) & 0 \\
0 & \phi_{2}(\xi) \\
\phi_{3}(\xi) & 0 \\
0 & \phi_{3}(\xi) \\
\phi_{4}(\xi) & 0 \\
0 & \phi_{4}(\xi)
\end{array}\right)\left(\begin{array}{cccc}
1-\xi & 0 & \xi & 0 \\
0 & 1-\xi & 0 & \xi
\end{array}\right)\left\{\begin{array}{l}
T_{1}^{1} \\
T_{2}^{1} \\
T_{1}^{2} \\
T_{2}^{2}
\end{array}\right\} d \xi
\end{gathered}
$$

onde e é a espessura do elemento e L é o comprimento do lado do mesmo ao longo do qual têm-se a carga aplicada. As funções de forma $\phi_{1}(\xi), \phi_{2}(\xi), \phi_{3}(\xi), \phi_{4}(\xi)$ são dadas 
respectivamente pela Equação 3.94. Resolvendo portanto a Equação 3.99:

$$
\delta P=L e\left\{\begin{array}{l}
\delta x_{1}^{1} \\
\delta x_{1}^{2} \\
\delta x_{1}^{3} \\
\delta x_{1}^{4} \\
\delta x_{2}^{1} \\
\delta x_{2}^{2} \\
\delta x_{2}^{3} \\
\delta x_{2}^{4}
\end{array}\right\}\left\{\begin{array}{c}
\frac{13}{120} T_{1}^{1}+\frac{1}{60} T_{1}^{2} \\
\frac{13}{120} T_{2}^{1}+\frac{1}{60} T_{2}^{2}+\frac{3}{40} T_{1}^{2} \\
\frac{3}{10} T_{2}^{1}+\frac{3}{40} T_{2}^{2} \\
\frac{3}{40} T_{1}^{1}+\frac{3}{10} T_{1}^{2} \\
\frac{1}{60} T_{1}^{1}+\frac{3}{10} T_{2}^{2} \\
\frac{1}{60} T_{2}^{1}+\frac{13}{120} T_{1}^{2}
\end{array}\right\}=\left\{\delta x_{\alpha}^{q}\right\}^{T}\left\{T_{\alpha}^{q}\right\}
$$

Fazendo em cada elemento o espalhamento dos três vetores de cargas nodais equivalentes $\left\{T_{\alpha}^{q}\right\}=\left\{T_{1}^{1} T_{2}^{1} T_{1}^{2} \ldots\right\}^{T}$ cada um referente a um dos três lados deste elemento, os três vetores $\left\{T_{\alpha}^{q}\right\}$ se transformam em um único vetor de cargas nodais externas equivalente desse elemento. Espalhando esses vetores de cargas nodais equivalente de cada elemento para a estrutura, têm-se o vetor de cargas nodais equivalentes global da estrutura $\left\{T_{\alpha}^{q}\right\}_{G}$, onde $q$ é referente ao nó e $\alpha$ a direção. As cargas aplicadas diretamente nos nós são simplesmente somadas em suas respectivas posições. Então:

$$
\delta P=\left\{\delta x_{\alpha}^{q}\right\}^{T}\left\{T_{\alpha}^{q}\right\}_{G}
$$

Note que agora na Equação 3.101, q varia de 1 ao número de nós totais da estrutura.

Na presente formulação o referencial adotado para as cargas é o global. As forças são conservativas, ou seja, a direção, sentido e módulo da força não se alteram mesmo com a deformação e o deslocamento do seu ponto de aplicação.

Por fim, resta então definir o termo $\delta U$ da Equação 3.89. Adotando então uma lei constitutiva hiperelástica qualquer, ou seja, especificando uma energia de deformação $u_{e}$ em função do tensor de deformações de Green $\mathbf{E}$ ou de parâmetros à ele relacionados tais como seus invariantes, tem-se que a energia de deformação total acumulada é dada pela seguinte integral:

$$
U=e \int_{S} u_{e} d S
$$

Onde $S$ refere-se à área inicial e $e$ é a espessura da chapa considerada constante. Fazendo a mudança de coordenadas para o domínio adimensional e reescrevendo a Equa- 
ção 3.102 na forma de uma integral dupla:

$$
U=e \int_{0}^{1-\xi_{1}} \int_{0}^{1} u_{e} \operatorname{det}(S) d \xi_{1} d \xi_{2}
$$

onde $\operatorname{det}(S)$ é o Jacobiano ou o determinante da transformação $\operatorname{det}(S) \rightarrow d \xi_{1} d \xi_{2}$.

Para leis constitutivas hiperelásticas, a energia de deformação é função da deformação de Green-Lagrange E (ou de então de seus invariantes ou deformações/alongamentos principais) e, conforme mostrado na Equação 3.87, a deformação de Green-Lagrange depende dos gradientes $\mathbf{F}_{0}$ e $\mathbf{F}_{1}$, os quais por sua vez, de acordo com as Equações 3.83 e 3.86, estão escritos em função das posições iniciais $X_{\alpha}^{q}$ e finais $x_{\alpha}^{q}$ no nó $q$ e na direção $\alpha$. Logo, utilizando a regra da cadeia tem-se as variações de deformações em funções de variações em posições:

$$
\delta \mathbf{E}=\frac{\partial \mathbf{E}}{\partial x_{\alpha}^{q}} \delta x_{\alpha}^{q}=\frac{\partial \mathbf{E}}{\partial x_{1}^{1}} \delta x_{1}^{1}+\frac{\partial \mathbf{E}}{\partial x_{2}^{1}} \delta x_{2}^{1}+\frac{\partial \mathbf{E}}{\partial x_{1}^{2}} \delta x_{1}^{2},,
$$

E portanto, a parcela referente a variação da energia de deformação na Equação 3.88 em sua forma tensorial e considerando a Equação 3.50 é dada por:

$$
\delta U=e \int_{S} \mathbf{S}: \delta \mathbf{E} d S=e \int_{0}^{1-\xi_{1}} \int_{0}^{1} \frac{\partial u_{e}}{\partial \mathbf{E}}: \frac{\partial \mathbf{E}}{\partial x_{\alpha}^{q}} \delta x_{\alpha}^{q} \operatorname{det}(S) d \xi_{1} d \xi_{2}
$$

A integral da Equação 3.105 no domínio adimensional do elemento triangular é calculada numericamente através de um somatório do produto do valor do integrando avaliado no ponto de hammer ih $\left(\left.\right|_{i h}\right)$ pelo peso de Hammer $w_{i h}$ no mesmo ponto:

$$
\begin{aligned}
\delta U & =e \int_{0}^{1-\xi_{1}} \int_{0}^{1} \frac{\partial u_{e}}{\partial \mathbf{E}}: \frac{\partial \mathbf{E}}{\partial x_{\alpha}^{q}} \delta x_{\alpha}^{q} \operatorname{det}(S) d \xi_{1} d \xi_{2} \\
& =\left.\left(e \sum_{i h=1}^{n h} \mathbf{S}: \frac{\partial \mathbf{E}}{\partial x_{\alpha}^{q}} \operatorname{det}(S) w_{i h}\right)\right|_{i h} \delta x_{\alpha}^{q}
\end{aligned}
$$

Para cada direção $\alpha$ e para cada nó $q$, o resultado dos termos entre parênteses na Equação 3.106 é um escalar que está associado às deformações, as quais por sua vez estão relacionadas aos esforços internos desenvolvidos no elemento. Por isso, esses escalares são organizados na forma de um vetor denominado vetor de forças internas do elemento $\left\{f_{\alpha}^{q}\right.$ \}$=\left\{\begin{array}{lllll}F_{1}^{1} & F_{2}^{1} & F_{1}^{2} & \ldots\end{array}\right\}^{T}$, onde $q$ é referente ao nó, $\alpha$ a direção e nh é o número de pontos de Hammer adotado para o cálculo (Anexo B). Observe que o termo $\partial \mathbf{E} / \partial x_{\alpha}^{q}$ independe da lei constitutiva adotada, sendo calculado da seguinte forma:

$$
\begin{aligned}
\frac{\partial \mathbf{E}}{\partial x_{\alpha}^{q}} & =\frac{1}{2} \frac{\partial}{\partial x_{\alpha}^{q}}\left(\mathbf{F}_{0}^{-T} \mathbf{F}_{1}^{T} \mathbf{F}_{1} \mathbf{F}_{0}^{-1}-\mathbf{I}\right) \\
\frac{\partial \mathbf{E}}{\partial x_{\alpha}^{q}} & =\frac{1}{2}\left(\mathbf{F}_{0}^{-T} \frac{\partial \mathbf{F}_{1}^{T}}{\partial x_{\alpha}^{q}} \mathbf{F}_{1} \mathbf{F}_{0}^{-1}+\mathbf{F}_{0}^{-T} \mathbf{F}_{1}^{T} \frac{\partial \mathbf{F}_{1}}{\partial x_{\alpha}^{q}} \mathbf{F}_{0}^{-1}\right)
\end{aligned}
$$


Note que $\partial \mathbf{F}_{1} / \partial x_{\alpha}^{q}$ é um tensor de ordem 2 para cada direção $\alpha$ e para cada nó $q$. Assim, este pode ser organizado matricialmente para cada direção $\alpha$ e para cada nó $q$. Uma vez que $q$ varia de 1 ao número de nós do elemento, têm-se para a direção 1, por exemplo, 10 matrizes no seguinte formato:

$$
\begin{gathered}
\frac{\partial F_{i j}}{\partial x_{1}^{\beta}}=\left(\begin{array}{cc}
\frac{\partial[\phi]}{\partial \xi_{1}} \frac{\partial\left\{x_{1}^{n}\right\}}{\partial x_{1}^{\beta}} & \frac{\partial[\phi]}{\partial \xi_{2}} \frac{\partial\left\{x_{1}^{n}\right\}}{\partial x_{1}^{\beta}} \\
\frac{\partial[\phi]}{\partial \xi_{1}} \frac{\partial\left\{x_{2}^{n}\right\}}{\partial x_{1}^{\beta}} & \frac{\partial[\phi]}{\partial \xi_{1}} \frac{\partial\left\{x_{2}^{n}\right\}}{\partial x_{1}^{\beta}}
\end{array}\right)=\left(\begin{array}{cc}
\frac{\partial[\phi]}{\partial \xi_{1}} \frac{\partial\left\{x_{1}^{n}\right\}}{\partial x_{1}^{\beta}} & \frac{\partial[\phi]}{\partial \xi_{2}} \frac{\partial\left\{x_{1}^{n}\right\}}{\partial x_{1}^{\beta}} \\
\frac{\partial[\phi]}{\partial \xi_{1}}\{0\} & \frac{\partial[\phi]}{\partial \xi_{1}}\{0\}
\end{array}\right) \\
\partial\left\{x_{1}^{n}\right\} / \partial x_{1}^{\beta}=0 \text { quando } n \neq \beta \\
\partial\left\{x_{1}^{n}\right\} / \partial x_{1}^{\beta}=1 \text { quando } n=\beta
\end{gathered}
$$

Não é correto concluir que $\partial \mathbf{F}_{1} / \partial x_{\alpha}^{q}=\partial F_{i j}\left(\mathbf{e}_{i} \otimes \mathbf{e}_{j}\right) / \partial x_{\alpha}^{q}$ é um tensor de ordem 4 devido ao fato de possuir quatro índices. Utilizar índices com intuito de organizar o cálculo, não faz de algo um tensor. No entanto, como a notação utilizada é a indicial, tem-se a garantia de que cada $\partial F_{i j} / \partial x_{\alpha}^{q}$ é um escalar. Essa garantia de trabalhar sempre com escalares é uma grande vantagem da notação indicial.

O vetor de forças internas do elemento $\left\{F_{\alpha}^{q}\right\}$ é espalhado para a estrutura, obtendose então o vetor de forças internas global da estrutura $\left\{F_{\alpha}^{q}\right\}_{G}$ e, portanto, da Equação 3.105:

$$
\delta U=\left\{\delta x_{\alpha}^{q}\right\}^{T}\left\{F_{\alpha}^{q}\right\}_{G}
$$

Das Equações 3.89, 3.100 e 3.105 nota-se que a equação de equilíbrio está completamente determinada uma vez conhecidas as cargas externas e a energia específica de deformação e suas derivadas. Da Equação 3.101 e Equação 3.109:

$$
\begin{gathered}
\left\{\begin{array}{c}
\delta x_{1}^{1} \\
\delta x_{2}^{1} \\
\delta x_{1}^{2} \\
\delta x_{2}^{2} \\
\vdots
\end{array}\right\}^{T}\left\{\begin{array}{c}
F_{1}^{1} \\
F_{2}^{1} \\
F_{1}^{2} \\
F_{2}^{2} \\
\vdots
\end{array}\right\}-\left\{\begin{array}{c}
\delta x_{1}^{1} \\
\delta x_{2}^{1} \\
\delta x_{1}^{2} \\
\delta x_{2}^{2} \\
\vdots
\end{array}\right\}^{T}\left\{\begin{array}{c}
T_{1}^{1} \\
T_{2}^{1} \\
T_{1}^{2} \\
T_{2}^{2} \\
\vdots
\end{array}\right\}=0 \\
\left\{\delta x_{\alpha}^{q}\right\}^{T}\left\{F_{\alpha}^{q}\right\}_{G}-\left\{\delta x_{\alpha}^{q}\right\}^{T}\left\{T_{\alpha}^{q}\right\}_{G}=0 \\
\therefore\left\{F_{\alpha}^{q}\right\}_{G}=\left\{T_{\alpha}^{q}\right\}_{G}
\end{gathered}
$$

onde o índice superior $q$ é referente ao nó e o índice inferior $\alpha$ é referente a direção, com $\alpha$ variando de 1 a 2 e $q$ variando de 1 ao número de nós totais da estrutura. Observe ainda que, dada uma posição atual e, conhecida a posição inicial, com exceção do $2^{\circ}$ tensor de tensões de Piola-Kirchhoff $\mathbf{S}$, todos os termos necessários para determinar os vetores globais de forças internas e externas são conhecidos. S, por sua vez depende da lei constitutiva hiperelástica adotada e é determinado através da relação da Equação 3.50. 
Em cada iteração, a relação não linear entre tensões e deformações presente no vetor de forças internas é então introduzida no problema através de S. Se, e somente se, a energia de deformação estiver escrita em função de uma parcela de energia de deformação isovolumétrica $u_{i s o}\left(\bar{I}_{1}, \bar{I}_{2}\right)$ dada em função dos invariantes de deformação a volume constante $\bar{I}_{1}, \bar{I}_{2}$, acrescida de uma outra parcela de energia referente a alterações volumétricas $u_{v o l}(J)$ escrita em função do jacobiano $J, \mathbf{S}$ está completamente determinado dentro de cada iteração como apresentado no Apêndice E. A seguir será visto que a energia específica de deformação introduz relações não lineares entre tensões e deformações no problema através de um outro termo, o tensor constitutivo $\mathbb{C}$.

É evidente na Equação 3.110 que a solução do problema consiste em encontrar a posição na qual o vetor de cargas externas se iguala ao vetor de forças internas e, como o vetor de cargas internas é função da deformação de Green-Lagrange (ou de então de seus invariantes ou deformações/alongamentos principais), e esta, por sua vez, é função das próprias posições que se buscam, têm-se portanto um problema não linear. A solução é encontrada através do método de Newton-Raphson descrito a seguir.

Considere um vetor posição $\left\{x_{\beta}^{r}\right\}_{t}=\left\{\begin{array}{llll}x_{1}^{1} & x_{2}^{1} & x_{1}^{2} & \ldots\end{array}\right\}^{T}$ tentativa qualquer, onde o índice $r$ é referente aos nós da estrutura e o índice $\beta$ é referente as direções. Nessa configuração calculam-se, no elemento, os vetores de forças internas $\left\{F_{\alpha}^{q}\right\}$ e externas $\left\{T_{\alpha}^{q}\right\}$ conforme as Equações 3.106 e 3.100, respectivamente. A posição $\left\{x_{\beta}^{r}\right\}_{t}$ tentativa adotada provavelmente não será a solução, havendo portanto um resíduo $\left\{g_{\alpha}^{\beta}\right\}_{t}$ :

$$
\left\{g_{\alpha}^{q}\right\}_{t}=\left\{F_{\alpha}^{q}\right\}-\left\{T_{\alpha}^{q}\right\}
$$

Um incremento $\left\{\Delta x_{\beta}^{r}\right\}$, ainda a determinar, na posição tentativa na direção $\beta$ e no nó $r$ fornecerá uma segunda aproximação para a posição:

$$
\left\{x_{\beta}^{r}\right\}_{t+1}=\left\{x_{\beta}^{r}\right\}_{t}+\left\{\Delta x_{\beta}^{r}\right\}
$$

Fazendo uma expansão linear em série de Taylor de $1^{\mathrm{a}}$ ordem do resíduo gerado nessa próxima aproximação:

$$
\left\{g_{\alpha}^{q}\right\}_{t+1}=\left\{g_{\alpha}^{q}\right\}_{t}+\frac{\partial\left\{g_{\alpha}^{q}\right\}_{t}}{\partial x_{\beta}^{r}} \Delta x_{\beta}^{r}
$$

O que se deseja é que o resíduo fosse nulo, portanto:

$$
\begin{gathered}
\left\{g_{\alpha}^{q}\right\}_{t+1}=\left\{g_{\alpha}^{q}\right\}_{t}+\frac{\partial\left\{g_{\alpha}^{q}\right\}_{t}}{\partial x_{\beta}^{r}} \Delta x_{\beta}^{r}=0 \\
\therefore \frac{\partial\left\{g_{\alpha}^{q}\right\}_{t}}{\partial x_{\beta}^{r}} \Delta x_{\beta}^{r}=-\left\{g_{\alpha}^{q}\right\}_{t}
\end{gathered}
$$


Para forças externas conservativas, o primeiro termo da esquerda na Equação 3.114 é o hessiano $h_{\alpha \beta}^{q r}$ :

$$
\begin{aligned}
h_{\alpha \beta}^{q r}=\frac{\partial\left\{g_{\alpha}^{q}\right\}_{t}}{\partial y_{\beta}^{r}} & =\frac{\partial\left(\left\{F_{\alpha}^{q}\right\}-\left\{T_{\alpha}^{q}\right\}\right)}{\partial x_{\beta}^{r}}=\frac{\partial\left\{F_{\alpha}^{\beta}\right\}}{\partial x_{\beta}^{r}} \\
& =\frac{\partial}{\partial x_{\beta}^{r}}\left[\left.e \sum_{i h=1}^{n h}\left(\mathbf{S}: \frac{\partial \mathbf{E}}{\partial x_{\alpha}^{q}} \operatorname{det}(S)\right)\right|_{i h} w_{i h}\right] \\
& =\left.e \sum_{i h=1}^{n h}\left[\left(\frac{\partial \mathbf{S}}{\partial x_{\beta}^{r}}: \frac{\partial \mathbf{E}}{\partial x_{\alpha}^{q}}+\mathbf{S}: \frac{\partial \mathbf{E}}{\partial x_{\beta}^{r} \partial x_{\alpha}^{q}}\right) \operatorname{det}(S)\right]\right|_{i h} w_{i h}
\end{aligned}
$$

A Equação 3.115 em notação indicial resulta em:

$$
\begin{aligned}
& =\left.e \sum_{i h=1}^{n h}\left[\left(\frac{\partial \mathbf{S}}{\partial \mathbf{E}}: \frac{\partial \mathbf{E}}{\partial x_{\beta}^{r}}: \frac{\partial \mathbf{E}}{\partial x_{\alpha}^{q}}+\mathbf{S}: \frac{\partial \mathbf{E}}{\partial x_{\beta}^{r} \partial x_{\alpha}^{q}}\right) \operatorname{det}(S)\right]\right|_{i h} w_{i h} \\
& =\left.e \sum_{i h=1}^{n h}\left[\left(\frac{\partial S_{i j}}{\partial E_{k l}} \frac{\partial E_{k l}}{\partial x_{\beta}^{r}} \frac{\partial E_{i j}}{\partial x_{\alpha}^{q}}+S_{o p} \frac{\partial E_{o p}}{\partial x_{\beta}^{r} \partial x_{\alpha}^{q}}\right) \operatorname{det}(S)\right]\right|_{i h} w_{i h} \\
& =\left.e \sum_{i h=1}^{n h}\left[\left(\mathbb{C}_{i j k l} \frac{\partial E_{k l}}{\partial x_{\beta}^{r}} \frac{\partial E_{i j}}{\partial x_{\alpha}^{q}}+S_{o p} \frac{\partial E_{o p}}{\partial x_{\beta}^{r} \partial x_{\alpha}^{q}}\right) \operatorname{det}(S)\right]\right|_{i h} w_{i h}
\end{aligned}
$$

O termo $\partial \mathbf{E} / \partial x_{\alpha}^{q}$ é dado pela Equação 3.107 e independe da lei constitutiva adotada. O termo $\partial \mathbf{E} / \partial x_{\beta}^{r} \partial x_{\alpha}^{q}$ também independe da lei constitutiva adotada e é calculado da seguinte forma:

$$
\begin{aligned}
\frac{\partial \mathbf{E}}{\partial x_{\beta}^{r} \partial x_{\alpha}^{q}} & =\frac{\partial}{\partial x_{\beta}^{r}}\left[\frac{1}{2}\left(\mathbf{F}_{0}^{-T} \frac{\partial \mathbf{F}_{1}^{T}}{\partial x_{\alpha}^{q}} \mathbf{F}_{1} \mathbf{F}_{0}^{-1}+\mathbf{F}_{0}^{-T} \mathbf{F}_{1}^{T} \frac{\partial \mathbf{F}_{1}}{\partial x_{\alpha}^{q}} \mathbf{F}_{0}^{-1}\right)\right] \\
\frac{\partial \mathbf{E}}{\partial x_{\beta}^{r} \partial x_{\alpha}^{q}} & =\frac{1}{2}\left(\mathbf{F}_{0}^{-T} \frac{\partial \mathbf{F}_{1}^{T}}{\partial x_{\alpha}^{q}} \frac{\partial \mathbf{F}_{1}}{\partial x_{\beta}^{r}} \mathbf{F}_{0}^{-1}+\mathbf{F}_{0}^{-T} \frac{\partial \mathbf{F}_{1}}{\partial x_{\beta}^{r}} \frac{\partial \mathbf{F}_{1}}{\partial x_{\alpha}^{q}} \mathbf{F}_{0}^{-1}\right)
\end{aligned}
$$

A partir da Equação 3.115, conclui-se então que o hessiano do elemento vale:

$$
\begin{aligned}
h_{\alpha \beta}^{q r} & =\left.e \sum_{i h=1}^{n h}\left[\frac{\partial \mathbf{S}}{\partial x_{\beta}^{r}}: \frac{1}{2}\left(\mathbf{F}_{0}^{-T} \frac{\partial \mathbf{F}_{1}^{T}}{\partial x_{\alpha}^{q}} \mathbf{F}_{1} \mathbf{F}_{0}^{-1}+\mathbf{F}_{0}^{-T} \mathbf{F}_{1}^{T} \frac{\partial \mathbf{F}_{1}}{\partial x_{\alpha}^{q}} \mathbf{F}_{0}^{-1}\right)\right]\right|_{i h} w_{i h} \operatorname{det}(S) \\
& +\left.e \sum_{i h=1}^{n h}\left[\frac{1}{2} \mathbf{S}:\left(\mathbf{F}_{0}^{-T} \frac{\partial \mathbf{F}_{1}^{T}}{\partial x_{\alpha}^{q}} \frac{\partial \mathbf{F}_{1}}{\partial x_{\beta}^{r}} \mathbf{F}_{0}^{-1}+\mathbf{F}_{0}^{-T} \frac{\partial \mathbf{F}_{1}^{T}}{\partial x_{\beta}^{r}} \frac{\partial \mathbf{F}_{1}}{\partial x_{\alpha}^{q}} \mathbf{F}_{0}^{-1}\right)\right]\right|_{i h} w_{i h} \operatorname{det}(S)
\end{aligned}
$$

Os termos $\mathbf{S}$ e $\partial \mathbf{S} / \partial x_{\beta}^{r}$ dependem da lei constitutiva adotada (e portanto, são os que introduzem a não linearidade entre tensões e deformações no problema). O hessiano do elemento triangular de 10 nós é organizado na forma de uma matriz hessiana $\left[h_{\alpha \beta}^{q r}\right]$ 
20x20 da seguinte maneira:

$$
h_{\alpha \beta}^{q r}=\left(\begin{array}{cccc}
h_{1111} & h_{1121} & h_{1112} & \ldots \\
h_{2111} & h_{2121} & h_{2112} & \ldots \\
h_{1211} & h_{1221} & h_{1212} & \ldots \\
h_{2211} & h_{2221} & h_{2212} & \ldots \\
\vdots & \vdots & \vdots & h_{[2(q-1)+\alpha][2(r-1)+\beta]}
\end{array}\right)
$$

Da mesma forma que para os vetores de forças internas e externas, faz-se agora o espalhamento da matriz hessiana local $\left[h_{\alpha \beta}^{q r}\right]$ para a matriz hessiana global $\left[H_{\alpha \beta}^{q r}\right]$ da estrutura. Resolve-se então a Equação 3.114 determinando assim o incremento em posição $\left\{\Delta x_{\beta}^{r}\right\}$ que irá corrigir a posição tentativa na Equação 3.112:

$$
\left[H_{\alpha \beta}^{q r}\right]\left\{\Delta x_{\beta}^{r}\right\}=-\left\{g_{\alpha}^{q}\right\}_{t}
$$

Se a nova posição corrigida for tal que os valores das forças internas estejam suficientemente próximo das forças externas, tem-se a solução do problema (posição dos nós). Senão, a nova posição recém encontrada passa a ser então uma nova posição tentativa de equilíbrio e o procedimento aqui descrito é repetido até que os valores das forças internas e externas estejam satisfatoriamente próximos ou até que as correções $\left\{\Delta x_{\beta}^{r}\right\}$ sejam suficientemente pequenas.

As forças externas podem ainda ser aplicadas de forma incremental objetivando-se obter uma trajetória de equilíbrio. Novamente, apenas o fato de se atribuir 4 índices ao hessiano não faz dele um tensor de ordem 4. No entanto, como a notação utilizada é a indicial, tem-se a garantia de que cada $h_{\alpha \beta}^{q r}$ é um escalar. Essa garantia de trabalhar sempre com escalares é uma grande vantagem da notação indicial.

Note pela Equação 3.116 e, conforme já comentado, que a chave para a inclusão da relação não linear entre tensão e deformação no problema é, portanto, conhecer o $2^{\circ}$ tensor de tensões de Piola-Kirchhoff $(\mathbf{S})$ e o tensor constitutivo $(\mathbb{C})$ nos respectivos incrementos e iterações, já que os termos restantes $\partial \mathbf{E} / \partial x_{\alpha}^{q}$ e $\partial \mathbf{E} / \partial x_{\beta}^{r} \partial x_{\alpha}^{q}$ são conhecidos. Se esses dois tensores forem conhecidos dentro de cada iteração e em cada passo, automaticamente a hessiana estará completamente definida também dentro de cada iteração e em cada passo. Isso permitirá resolver o problema de forma incremental e iterativa determinando os incrementos nas posições devido aos incrementos nas cargas atuantes ou vice-versa. Note que, se a energia de deformação fosse conhecida de maneira explícita através de uma expressão, poder-se-ia aplicar sucessivas operações de derivadas a fim de determinar o $2^{\circ}$ tensor de tensões de Piola-Kirchhoff $(\mathbf{S})$ e o tensor constitutivo $(\mathbb{C})$, conhecer a hessiana e resolver o problema.

É por isso que a hiperelasticidade e quase todas as formulações em cálculo estrutural se preocupam tanto em investigar a energia de deformação. Da mesma forma que 
anteriormente para $\mathbf{S}$ na subseção 3.2.3, se, e somente se, a energia de deformação estiver escrita em função de uma parcela de energia de deformação isovolumétrica $u_{i s o}\left(\bar{I}_{1}, \bar{I}_{2}\right)$ dada em função dos invariantes de deformação a volume constante $\bar{I}_{1}, \bar{I}_{2}$, acrescida de uma outra parcela de energia referente a alterações volumétricas $u_{v o l}(J)$ escrita em função do jacobiano $J, \mathbb{C}$ está completamente determinado dentro de cada iteração como apresentado no Apêndice E.

Pode-se imaginar que os problemas lineares são sempre resolvidos em um único passo incremental aplicando-se um passo de carga ou deslocamento respectivamente igual a carga final ou ao deslocamento da configuração final, isto porque nesses casos a hessiana é a própria matriz de rigidez da estrutura e é constante.

\subsubsection{Elemento finito de barra simples (1D)}

Para o caso específico do elemento de barra, que se deforma somente na direção axial, o gradiente $\mathbf{F}$ da função mudança de configuração $f$ pode ser escrito em função do alongamento longitudinal (principal) $\lambda$ da barra. Fisicamente, atribuir $F_{22}=1 \mathrm{e}$ $F_{33}=1$ equivale a desconsiderar as deformações nas outras duas direções que não a do eixo principal. Poder-se-ia também estimar uma estricção da área da secção transversal da barra, por exemplo, através de uma hipótese de incompressibilidade (ver seção G.1).

$$
\mathbf{F}=\left(\begin{array}{ccc}
\lambda & 0 & 0 \\
0 & 1 & 0 \\
0 & 0 & 1
\end{array}\right)
$$

Apesar da $2^{\text {a }}$ tensão de Piola-Kirchhoff $\mathbf{S}$, da $1^{\text {a }}$ tensão de Piola-Kirchhoff $\mathbf{P}$ e das medidas de deformação de Green-Lagrange $\mathbf{E}$ e não linear de Engenharia $\boldsymbol{\epsilon}$ serem, para o elemento finito de barra simples, escalares e não mais tensores, a fim de manter um padrão ao longo de todo o trabalho e não confundir com outras grandezas, essas continuarão sendo escritas em negrito conforme a convenção adotada para tensores. A seguir será descrita a formulação posicional do elemento finito de barra simples, bem como o procedimento de imersão das fibras na matriz conforme proposto por (VANALLI, 2004) e apresentado por Sampaio, Paccola e Coda (2013) e Sampaio (2014).

Na formulação posicional do elemento de barra simples, as medidas de deformação utilizadas podem ser definidas a partir do alongamento longitudinal (principal) $\lambda$ da barra. Isso permite utilizar um escalar como medida de deformação para fibra ao invés de um tensor, o que simplifica a abordagem do problema.

Da elasticidade não linear, tem-se que o vetor de alongamento $\boldsymbol{\lambda}=\left[\lambda_{1}, \lambda_{2}, \lambda_{3}\right]$ na direção do vetor unitário $\mathbf{a}_{0}$ fixo na condição inicial indeformada pode ser determinado a partir da função mudança de configuração $f$ e do seu gradiente $\mathbf{F}$ (ver Holzapfel (2000, p.76-78)). Estes, por sua vez, serão estimados utilizando-se funções de aproximação $\mathbf{x}$ 
escritas em função das posições dos nós e das funções de forma $\phi$.

$$
\lambda_{1}^{2}=\frac{|d \mathbf{x}|^{2}}{|d \mathbf{X}|^{2}}=\mathbf{F} \mathbf{a}_{0} \cdot \mathbf{F} \mathbf{a}_{0}=\lambda^{2}
$$

Como era de se esperar, conclui-se que $\boldsymbol{\lambda}=\left[\lambda_{1}, \lambda_{2}, \lambda_{3}\right]=[\lambda, 1,1]$ para o elemento de barra simples com deformações transversais desprezíveis e sendo $\mathbf{a}_{0}=[1,0,0]$ é a direção do eixo do elemento de barra simples. Apesar de na maioria das vezes, ao abordar os alongamentos esteja-se referindo aos alongamentos principais, estes nem sempre devem ser necessariamente os principais. Isso acontece porque frequentemente a abordagem e a formulação adotada para os problemas recaem em casos particulares, onde os alongamentos observados coincidentemente já são os principais (assim como para o elemento de barra simples e para alguns casos de elemento de chapa, conforme Equação 4.4). O alongamento é a relação entre os comprimentos deformado e indeformado de uma fibra infinitesimal de material em determinada direção. O vetor de alongamento contém os alongamentos sofridos pelo material nas três direções conforme a orientação dos vetores unitários $\mathbf{a}_{0}$ escolhidos.

Na Equação 3.122, F é o gradiente da função mudança de configuração $f$. Ao invés de utilizar a definição "original" dessa função mudança de configuração $f$ para mapear as posições atuais em função das coordenadas iniciais $\mathbf{X}$ dos pontos da fibra, a posição atual $x_{\gamma}$ de um ponto do elemento de barra na direção $\gamma$ é mapeada a partir de um elemento finito de referência com coordenada adimensional $\xi$ por meio de funções de forma $\tilde{\phi}$ e dos valores das posições $x_{\gamma}^{s}$ dos nós desse elemento de barra na direção $\gamma$ e no nó $s$ $\left(x_{\gamma}=\tilde{\phi}_{s}(\xi) x_{\gamma}^{s}\right)$. O mesmo raciocínio é utilizado para mapear as posições iniciais dos pontos do elemento de barra na configuração indeformada inicial. A Figura 5 ilustra essa idéia:

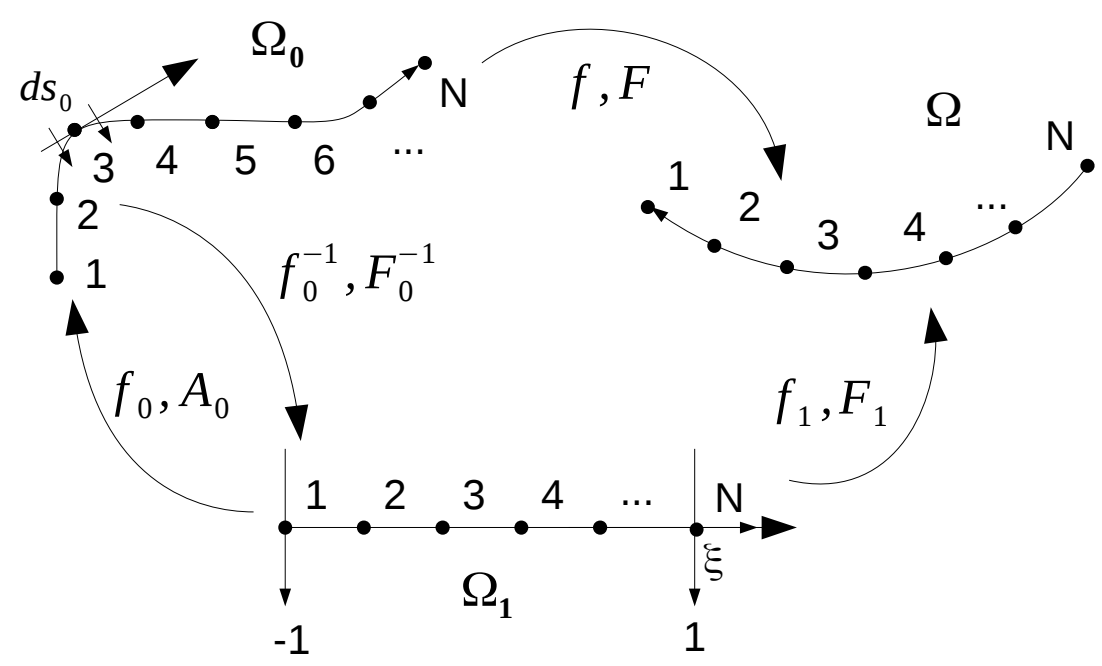

Figura 5 - Formulação de um elemento finito de barra simples posicional Fonte: adaptado de Sampaio, Paccola e Coda (2013) 
onde $\Omega_{0}, \Omega_{1}, \Omega$ se referem, respectivamente, a configurações inicial, configuração do elemento de referência adimensional e configuração atual. $f, f_{0}$ e $f_{1}$ são as funções mudança de configuração e $\tilde{\mathbf{F}}, \tilde{\mathbf{F}}_{0}$ e $\tilde{\mathbf{F}}_{1}$ são os gradientes dessas funções mudança de configuração.

Sendo a fibra um elemento finito uniaxial de barra simples, determina-se, respectivamente, que a variação das posições finais e iniciais das fibras em função das variações das posições no elemento finito de referência com coordenadas adimensionais vale:

$$
d \mathbf{x}=\frac{\partial \mathbf{x}}{\partial \xi} d \xi \quad \text { e } \quad d \mathbf{X}=\frac{\partial \mathbf{X}}{\partial \xi} d \xi
$$

Logo, como o alongamento para o elemento de barra com relação a coordenada adimensional $\xi$ do elemento finito de referência fica sendo:

$$
\lambda_{1}^{2}=\lambda^{2}=\left[\frac{\left(\frac{\partial x_{1}}{\partial \xi} d \xi\right)^{2}+\left(\frac{\partial x_{2}}{\partial \xi} d \xi\right)^{2}}{\left(\frac{\partial X_{1}}{\partial \xi} d \xi\right)^{2}+\left(\frac{\partial X_{2}}{\partial \xi} d \xi\right)^{2}}\right]=\left[\frac{\left(\frac{\partial x_{1}}{\partial \xi}\right)^{2}+\left(\frac{\partial x_{2}}{\partial \xi}\right)^{2}}{\left(\frac{\partial X_{1}}{\partial \xi}\right)^{2}+\left(\frac{\partial X_{2}}{\partial \xi}\right)^{2}}\right]
$$

A deformação de Green-Lagrange é então dada por:

$$
\tilde{\mathbf{E}}=\frac{1}{2}\left(\lambda^{2}-1\right)=\frac{1}{2}\left[\frac{\left(\frac{\partial x_{1}}{\partial \xi}\right)^{2}+\left(\frac{\partial x_{2}}{\partial \xi}\right)^{2}}{\left(\frac{\partial X_{1}}{\partial \xi}\right)^{2}+\left(\frac{\partial X_{2}}{\partial \xi}\right)^{2}}-1\right]=\frac{1}{2}\left[\frac{\left(\frac{\partial x_{\gamma}}{\partial \xi}\right)^{2}}{\left(\frac{\partial X_{\zeta}}{\partial \xi}\right)^{2}}-1\right]
$$

A posição atual $x_{\gamma}$ de cada ponto do elemento de barra na direção $\gamma$ é mapeada a partir de um elemento finito de referência com coordenada adimensional $\xi$ através de funções de forma $\tilde{\phi}$ utilizando as próprias posições nodais do nó $s$ desse elemento de barra, ou seja, $x_{\gamma}=\tilde{\phi}_{s}(\xi) x_{\gamma}^{s}$. O mesmo acontece para as posições iniciais. Então:

$$
\tilde{\mathbf{E}}=\frac{1}{2}\left[\frac{\left(\frac{\partial \tilde{\phi}_{s}(\xi)}{\partial \xi} x_{\gamma}^{s}\right)^{2}}{\left(\frac{\partial \tilde{\phi}_{z}(\xi)}{\partial \xi} X_{\zeta}^{z}\right)^{2}}-1\right]
$$

com $\gamma$ e $\zeta$ variando de 1 ao número total de direções (2 para o caso plano) e $s$ e $z$ variando de 1 ao número total de nós do elemento de barra. O somatório sobre os nós do elemento já está implícito pela repetição do índices $s$ e $z$. A fim de compactar as equações, adota-se aqui por convenção um somatório implícito sobre as direções $\gamma$ e $\zeta$ no espaço bidimensional, apesar de não haver repetição desses índices do lado direito da equação. Note que, a medida de deformação de Green $\tilde{\mathbf{E}}$ para o elemento de barra é um escalar e não mais um tensor. A medida de deformação de Green-Lagrange para o caso unidimensional é, portanto, o mesmo que:

$$
\tilde{\mathbf{E}}=\frac{1}{2}\left(\lambda^{2}-1\right)=\frac{1}{2}\left(\frac{l^{2}-l_{0}^{2}}{l_{0}^{2}}\right)
$$


onde $l$ e $l_{0}$ são respectivamente os comprimentos final e inicial do elemento finito de barra. Uma outra forma de obter a deformação de Green-Lagrange para o elemento de barra, e ao mesmo tempo visualiza-lá fisicamente, é assumindo que a deformação de Green-Lagrange uniaxial é dada pela Equação 3.127. Sendo assim pela Figura 6, tem-se no limite quanto $d X_{1} \simeq 0$ e $d X_{2} \simeq 0$ que o vetor tangente à fibra $\vec{T}_{0}$ na configuração inicial vale:

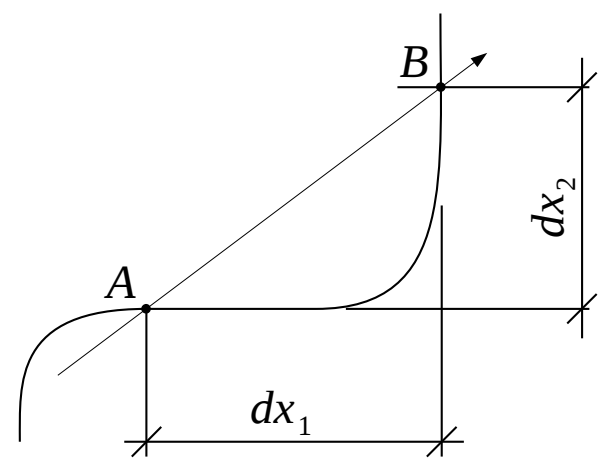

Figura 6 - Vetor tangente ao elemento finito de barra simples

$$
\begin{gathered}
\vec{T}_{0}=d X_{1} \mathbf{e}_{i}+d X_{2} \mathbf{e}_{j} \\
X_{1}=\tilde{\phi}_{s}(\xi) X_{1}^{s} \\
X_{2}=\tilde{\phi}_{z}(\xi) X_{2}^{z}
\end{gathered}
$$

onde $X_{1}$ e $X_{2}$ são respectivamente as posições iniciais de todos os pontos do elemento finito de barra nas direções 1 e 2, mapeadas a partir de um elemento finito de referência com coordenada adimensional $\xi$ através das funções de forma $\tilde{\phi}$. Nesse caso, $X_{1}^{s}$ e $X_{2}^{z}$ são as posições iniciais dos nós do elemento finito de barra respectivamente nas direções 1 e 2 , com $s$ e $z$ variando de 1 ao número total de nós utilizados nesse elemento finito de barra.

A variação das posições iniciais das fibras em função das variações das posições no elemento finito de referência com coordenadas adimensionais é:

$$
\begin{aligned}
& d X_{1}=\frac{\partial X_{1}}{\partial \xi} d \xi=\left(\frac{\partial \tilde{\phi}_{s}(\xi)}{\partial \xi} X_{1}^{s}\right) d \xi \\
& d X_{2}=\frac{\partial X_{2}}{\partial \xi} d \xi=\left(\frac{\partial \tilde{\phi}_{z}(\xi)}{\partial \xi} X_{2}^{z}\right) d \xi
\end{aligned}
$$

E, portanto, substituindo a Equação 3.129 na Equação 3.128:

$$
\vec{T}_{0}=\left(\frac{\partial \tilde{\phi}_{s}(\xi)}{\partial \xi} X_{1}^{s}\right) \mathbf{e}_{i}+\left(\frac{\partial \tilde{\phi}_{z}(\xi)}{\partial \xi} X_{2}^{z}\right) \mathbf{e}_{j}
$$

Similarmente para as posições atuais:

$$
\vec{T}=\left(\frac{\partial \tilde{\phi}_{s}(\xi)}{\partial \xi} x_{1}^{s}\right) \mathbf{e}_{i}+\left(\frac{\partial \tilde{\phi}_{z}(\xi)}{\partial \xi} x_{2}^{z}\right) \mathbf{e}_{j}
$$


Logo, a deformação de Green-Lagrange vale:

$$
\tilde{\mathbf{E}}=\frac{1}{2}\left(\frac{l^{2}-l_{0}^{2}}{l_{0}^{2}}\right)=\frac{1}{2}\left(\frac{|\vec{T}|^{2}-\left|\vec{T}_{0}\right|^{2}}{\left|\vec{T}_{0}\right|^{2}}\right)
$$

De onde se verifica o mesmo resultado da Equação 3.126. A energia de deformação total acumulada na fibra é:

$$
U=\int_{V} u_{e} d V
$$

A derivada dessa energia específica de deformação com relação aos parâmetros nodais de posição $x_{\gamma}^{s}$ na direção $\gamma$ e no nó $s$ do elemento de barra é a força interna:

$$
\begin{gathered}
\tilde{F}_{\gamma}^{s}=\frac{\partial U}{\partial x_{\gamma}^{s}}=\int_{V} \frac{\partial u_{e}}{\partial x_{\gamma}^{s}} d V=\int_{V} \frac{\partial u_{e}}{\partial \tilde{\mathbf{E}}} \frac{\partial \tilde{\mathbf{E}}}{\partial x_{\gamma}^{s}} d V=\int_{L} \tilde{\mathbf{S}}_{L} \frac{\partial \tilde{\mathbf{E}}}{\partial x_{\gamma}^{s}} S d y \\
\tilde{F}_{\gamma}^{s}=\int_{-1}^{1} \tilde{\mathbf{S}} \frac{\partial \tilde{\mathbf{E}}}{\partial x_{\gamma}^{s}} J(\xi) S d \xi
\end{gathered}
$$

onde $J$ é o jacobiano que troca o domínio de integração para o domínio adimensional, sendo calculado da seguinte forma:

$$
J=|\vec{T}|=\sqrt{\left(\frac{\partial \tilde{\phi}_{s}(\xi)}{\partial \xi} X_{1}^{s}\right)^{2}+\left(\frac{\partial \tilde{\phi}_{z}(\xi)}{\partial \xi} X_{2}^{z}\right)^{2}}=\sqrt{\left(\frac{\partial \tilde{\phi}_{s}(\xi)}{\partial \xi} X_{\gamma}^{s}\right)^{2}}
$$

Nas Equações 3.134 e 3.135, $\gamma$ varia de 1 ao número total de direções (2 para o caso plano) e $s$ varia de 1 ao número total de nós do elemento de barra. Na Equação 3.135, o somatório sobre os nós dos elementos já está implícito pela repetição do índice $s$. Porém, a fim de compactar as equações, adota-se aqui por convenção um somatório implícito sobre a direção $\gamma$ no espaço bidimensional na Equação 3.135, apesar de não haver repetição desse índice do lado direito da equação. Na Equação 3.134, $\partial \tilde{\mathbf{E}} / \partial x_{\gamma}^{s}$ independe da lei constitutiva adotada e pode ser calculado da seguinte forma:

$$
\begin{aligned}
\frac{\partial \tilde{\mathbf{E}}}{\partial x_{\gamma}^{s}}=\frac{\partial}{\partial x_{\gamma}^{s}}\left\{\frac{1}{2}\left[\frac{\left(\frac{\partial \tilde{\phi}_{m}(\xi)}{\partial \xi} x_{\eta}^{m}\right)^{2}}{\left(\frac{\partial \tilde{\phi}_{z}(\xi)}{\partial \xi} X_{\zeta}^{z}\right)^{2}}-1\right]\right\}=\frac{\left(\frac{\partial \tilde{\phi}_{n}(\xi)}{\partial \xi} x_{\eta}^{n}\right) \frac{\partial \tilde{\phi}_{m}(\xi)}{\partial \xi} \frac{\partial x_{\eta}^{m}}{\partial x_{\gamma}^{s}}}{\left(\frac{\partial \tilde{\phi}_{z}(\xi)}{\partial \xi} X_{\zeta}^{z}\right)^{2}} \\
=\frac{\left(\frac{\partial \tilde{\phi}_{n}(\xi)}{\partial \xi} x_{\eta}^{n}\right) \frac{\partial \tilde{\phi}_{m}(\xi)}{\partial \xi} \delta_{s m} \delta_{\gamma \eta}}{\left(\frac{\partial \tilde{\phi}_{z}(\xi)}{\partial \xi} X_{\zeta}^{z}\right)^{2}}=\frac{\left(\frac{\partial \tilde{\phi}_{n}(\xi)}{\partial \xi} x_{\gamma}^{n}\right) \frac{\partial \tilde{\phi}_{s}(\xi)}{\partial \xi}}{\left(\frac{\partial \tilde{\phi}_{z}(\xi)}{\partial \xi} X_{\zeta}^{z}\right)^{2}}
\end{aligned}
$$

com $\gamma$ e $\zeta$ variando de 1 ao número total de direções (2 para o caso plano) e $s, n$ e $z$ variando de 1 ao número total de nós do elemento de barra. A fim de compactar as equações, adota-se aqui por convenção um somatório implícito sobre a direção $\zeta$ no espaço 
bidimensional, apesar de não haver repetição desse índice do lado direito da equação. Finalmente, substituindo a Equação 3.136 na Equação 3.134 tem-se que a força interna $\tilde{F}_{\gamma}^{s}$ no nó $s$ no elemento de barra na direção $\gamma$ vale:

$$
\tilde{F}_{\gamma}^{s}=\int_{-1}^{1} \tilde{\mathbf{S}} \frac{\left(\frac{\partial \tilde{\phi}_{m}(\xi)}{\partial \xi} x_{\gamma}^{m}\right) \frac{\partial \tilde{\phi}_{s}(\xi)}{\partial \xi}}{\left(\frac{\partial \tilde{\phi}_{z}(\xi)}{\partial \xi} X_{\zeta}^{z}\right)^{2}} J(\xi) S d \xi
$$

Na Equação 3.137, $m, s$ e $z$ variam de 1 ao número total de nós do elemento de barra e $\gamma$ e $\zeta$ variam de 1 ao número total de direções (2 para o caso plano). A fim de compactar as equações, adota-se aqui por convenção um somatório implícito sobre a direção $\zeta$ no espaço bidimensional, apesar de não haver repetição desse índice do lado direito da equação. A variável $\xi$ é a coordenada adimensional com relação ao elemento de referência, $S$ é a área inicial da seção transversal do elemento de barra e $J$ é o jacobiano calculado conforme a Equação 3.135, em virtude da mudança do domínio de integração para o domínio adimensional de referência.

Da mesma forma que para o elemento de chapa da subseção 3.2.3, a derivada do vetor de forças internas dado pela Equação 3.137 é a matriz hessiana e pode ser calculada 
da seguinte maneira:

$$
\begin{aligned}
& \tilde{h}_{\gamma \zeta}^{s z}=\frac{\partial \tilde{F}_{\gamma}^{s}}{\partial x_{\zeta}^{z}}=\int_{-1}^{1}\left[\frac{\frac{\partial \tilde{\mathbf{S}}}{\partial x_{\zeta}^{z}}\left(\frac{\partial \tilde{\phi}_{n}(\xi)}{\partial \xi} x_{\gamma}^{n}\right) \frac{\partial \tilde{\phi}_{s}(\xi)}{\partial \xi}}{\left(\frac{\partial \tilde{\phi}_{m}(\xi)}{\partial \xi} X_{\eta}^{m}\right)^{2}}\right. \\
& \left.+\frac{\tilde{\mathbf{S}}\left(\frac{\partial \tilde{\phi}_{n}(\xi)}{\partial \xi} \frac{\partial \tilde{\phi}_{s}(\xi)}{\partial \xi}\right) \frac{\partial x_{\gamma}^{n}}{\partial x_{\zeta}^{z}}}{\left(\frac{\partial \tilde{\phi}_{m}(\xi)}{\partial \xi} X_{\eta}^{m}\right)^{2}}\right] J(\xi) S d \xi \\
& =\int_{-1}^{1}\left[\frac{\frac{\partial \tilde{\mathbf{S}}}{\partial x_{\zeta}^{z}}\left(\frac{\partial \tilde{\phi}_{n}(\xi)}{\partial \xi} x_{\gamma}^{n}\right) \frac{\partial \tilde{\phi}_{s}(\xi)}{\partial \xi}}{\left(\frac{\partial \tilde{\phi}_{m}(\xi)}{\partial \xi} X_{\eta}^{m}\right)^{2}}\right. \\
& \left.+\frac{\tilde{\mathbf{S}}\left(\frac{\partial \tilde{\phi}_{n}(\xi)}{\partial \xi} \frac{\partial \tilde{\phi}_{s}(\xi)}{\partial \xi}\right) \delta_{\gamma \zeta} \delta_{z n}}{\left(\frac{\partial \tilde{\phi}_{m}(\xi)}{\partial \xi} X_{\eta}^{m}\right)^{2}}\right] J(\xi) S d \xi \\
& =\int_{-1}^{1}\left[\frac{\frac{\partial \tilde{\mathbf{S}}}{\partial x_{\zeta}^{z}}\left(\frac{\partial \tilde{\phi}_{n}(\xi)}{\partial \xi} x_{\gamma}^{n}\right) \frac{\partial \tilde{\phi}_{s}(\xi)}{\partial \xi}}{\left(\frac{\partial \tilde{\phi}_{m}(\xi)}{\partial \xi} X_{\eta}^{m}\right)^{2}}\right. \\
& \left.+\frac{\tilde{\mathbf{S}}\left(\frac{\partial \tilde{\phi}_{z}(\xi)}{\partial \xi} \frac{\partial \tilde{\phi}_{s}(\xi)}{\partial \xi}\right) \delta_{\gamma \zeta}}{\left(\frac{\partial \tilde{\phi}_{m}(\xi)}{\partial \xi} X_{\eta}^{m}\right)^{2}}\right] J(\xi) S d \xi
\end{aligned}
$$

Na Equação 3.138, s, z e $m$ e $n$ variam de 1 ao número total de nós do elemento de barra e $\gamma, \zeta$ e $\eta$ variam de 1 ao número total de direções (2 para o caso plano). A fim de compactar as equações, adota-se aqui por convenção um somatório implícito sobre a direção $\eta$ no espaço bidimensional, apesar de não haver repetição desse índice do lado direito da equação. A variável $\xi$ é a coordenada adimensional com relação ao elemento de referência, $S$ é a área inicial da seção transversal do elemento de barra e $J$ é o jacobiano calculado conforme a Equação 3.135, em virtude da mudança do domínio de integração para o domínio adimensional de referência.

As Equações 3.138 e 3.134 anteriores são resolvidas numericamente pelo somatório do integrando avaliado em pontos de Gauss. Os termos $\partial \tilde{\mathbf{S}} / \partial x_{\zeta}^{z}$ e $\tilde{\mathbf{S}}$ são parâmetros que dependem da lei constitutiva adotada. A lei constitutiva de Saint Venant-Kirchhoff para o 
caso unidimensional é dada por:

$$
u_{e}=\frac{1}{2} \mathbb{C} \tilde{\mathbf{E}}^{2}
$$

onde para o caso unidimensional, $\mathbb{C}$ passa a ser simplesmente o módulo de elasticidade do material (módulo Young $\mathbb{E}$ ). Assim, utilizando a lei constitutiva de Saint Venant-Kirchhoff, a derivada da $2^{\text {a }}$ tensão de Piola-Kirchhoff $\mathbf{S}$ com relação aos parâmetros nodais de posição $x_{\zeta}^{z}$ no nó do elemento de barra simples $z$ na direção $\zeta, \partial \tilde{\mathbf{S}} / \partial x_{\zeta}^{z}$, é resolvida utilizando a regra da cadeia, que tendo em vista a Equação 3.136 resulta em:

$$
\frac{\partial \tilde{\mathbf{S}}}{\partial x_{\zeta}^{z}}=\frac{\partial \tilde{\mathbf{S}}}{\partial \tilde{\mathbf{E}}} \frac{\partial \tilde{\mathbf{E}}}{\partial x_{\zeta}^{z}}=\mathbb{E} \frac{\left(\frac{\partial \tilde{\phi}_{n}(\xi)}{\partial \xi} x_{\zeta}^{n}\right) \frac{\partial \tilde{\phi}_{z}(\xi)}{\partial \xi}}{\left(\frac{\partial \tilde{\phi}_{m}(\xi)}{\partial \xi} X_{\eta}^{m}\right)^{2}}
$$

com $\zeta$ e $\eta$ variando de 1 ao número total de direções (2 para o caso plano) e $z, m$ e $n$ variando de 1 ao número total de nós do elemento de barra. A fim de compactar as equações, adota-se aqui um somatório implícito sobre a direção $\eta$ no espaço bidimensional, apesar de não haver repetição desse índice do lado direito da equação

Neste trabalho, a medida de deformação utilizada para o elemento finito de barra simples foi a medida de deformação não linear de engenharia $\boldsymbol{\epsilon}$. Isso permitiu não só adotar um modelo viscoelástico para o elemento de fibra de forma consistente com os resultados físicos esperados, como também admitiu considerar a ativação das fibras através de uma medida deformação com um significado físico mais imediato e intuitivo.

Utilizar a medida de deformação não linear de engenharia resultou em uma formulação contendo o $1^{\circ}$ tensor de tensão de Piola-Kirchhoff $\mathbf{P}$ que, para o caso de secção transversal constante da barra, coincide com a tensão de Cauchy $\boldsymbol{\sigma}$, simplificando assim o entendimento do problema físico em termos de tensões. Para elementos finitos de barra simples, as tensões e deformações são na verdade escalares ao invés de tensores e, utilizar medidas de tensão e deformação com significado físico, apesar de vantajosas justamente por terem um significado físico, traz uma dificuldade adicional em termos de formulação do problema, conforme pode-se notar no cálculo das derivadas adiante.

A deformação não linear de engenharia (ver Apêndice B) para o elemento de fibra é dada por:

$$
\tilde{\boldsymbol{\epsilon}}=\left(\sqrt{\lambda^{2}}-1\right)=(\lambda-1)=\left(\frac{l-l_{0}}{l_{0}}\right)
$$

De maneira semelhante ao que foi feito para encontrar a Equação 3.126, tem-se que a deformação não linear de engenharia $\tilde{\boldsymbol{\epsilon}}$ escrita em função das funções de forma $\phi$, das 
posições nodais $\mathbf{x}$ na condição atual deformada e $\mathbf{X}$ na condição inicial indeformada é:

$$
\tilde{\boldsymbol{\epsilon}}=\left[\frac{\sqrt{\left(\frac{\partial \tilde{\phi}_{s}(\xi)}{\partial \xi} x_{1}^{s}\right)^{2}+\left(\frac{\partial \tilde{\phi}_{s}(\xi)}{\partial \xi} x_{2}^{s}\right)^{2}}}{\sqrt{\left(\frac{\partial \tilde{\phi}_{z}(\xi)}{\partial \xi} X_{1}^{z}\right)^{2}+\left(\frac{\partial \tilde{\phi}_{z}(\xi)}{\partial \xi} X_{2}^{z}\right)^{2}}}-1\right]=\left[\frac{\sqrt{\left(\frac{\partial \tilde{\phi}_{s}(\xi)}{\partial \xi} x_{\gamma}^{s}\right)^{2}}}{\sqrt{\left(\frac{\partial \tilde{\phi}_{z}(\xi)}{\partial \xi} X_{\zeta}^{z}\right)^{2}}}-1\right]
$$

Com $\gamma$ e $\zeta$ variando de 1 ao número total de direções (2 para o caso plano) e $s$ e $z$ variando de 1 ao número total de nós do elemento de barra. O somatório sobre os nós do elemento já está implícito pela repetição do índices $s$ e $z$. A fim de compactar as equações, adota-se aqui por convenção um somatório implícito sobre as direções $\gamma$ e $\zeta$ no espaço bidimensional, apesar de não haver repetição desses índices do lado direito da equação. Portanto, como o quadrado da soma não é a soma dos quadrados, tem-se que:

$$
\sqrt{\left(\frac{\partial \tilde{\phi}_{s}(\xi)}{\partial \xi} x_{\gamma}^{s}\right)^{2}} \neq \frac{\partial \tilde{\phi}_{s}(\xi)}{\partial \xi} x_{\gamma}^{s}
$$

A derivada da energia específica de deformação com relação aos parâmetros nodais de posição $x_{\gamma}^{s}$ na direção $\gamma$ e no nó $s$ do elemento de barra continua, ainda, sendo a força interna. Porém, a partir da Equação 3.54, tem-se que a derivada da energia interna com relação a deformação não linear de engenharia é a agora $1^{\mathrm{a}}$ tensão de Piola-Kirchhoff $\mathbf{P}^{11}$, que é uma medida de tensão de engenharia (força atual distribuída sob a área inicial).

$$
\begin{gathered}
\tilde{F}_{\gamma}^{s}=\frac{\partial U}{\partial x_{\gamma}^{s}}=\int_{V} \frac{\partial u_{e}}{\partial x_{\gamma}^{s}} d V=\int_{V} \frac{\partial u_{e}}{\partial \tilde{\boldsymbol{\epsilon}}} \frac{\partial \tilde{\boldsymbol{\epsilon}}}{\partial x_{\gamma}^{s}} d V=\int_{L} \tilde{\mathbf{P}} \frac{\partial \tilde{\boldsymbol{\epsilon}}}{\partial x_{\gamma}^{s}} S d y \\
\tilde{F}_{\gamma}^{s}=\int_{-1}^{1} \tilde{\mathbf{P}} \frac{\partial \tilde{\boldsymbol{\epsilon}}}{\partial x_{\gamma}^{s}} J(\xi) S d \xi
\end{gathered}
$$

Nesse caso, como a redução da área da secção transversal está sendo desconsiderada, a $1^{\text {a }}$ tensão de Piola-Kirchhoff $\mathbf{P}$ e a tensão de Cauchy $\boldsymbol{\sigma}$ se confundem, conforme verificado através da Equação 3.31. Na Equação 3.144, $J$ é o jacobiano calculado conforme a Equação 3.135 em virtude da mudança do domínio de integração para o domínio adimensional de referência e $S$ é a área inicial da seção transversal do elemento de barra

A derivada da deformação não linear de engenharia com relação às posições nodais $\mathbf{x}$ da configuração atual deformada, $\partial \tilde{\boldsymbol{\epsilon}} / \partial x_{\gamma}^{s}$, independe da lei constitutiva adotada e pode

$$
{ }_{11} \frac{\partial u_{e}}{\partial \boldsymbol{\epsilon}}=\frac{\partial u_{e}}{\partial \mathbf{F}} \frac{\partial \mathbf{F}}{\partial \boldsymbol{\epsilon}}=\mathbf{P} \frac{\partial \lambda}{\partial \boldsymbol{\epsilon}}=\mathbf{P} \frac{\partial[(\lambda-1)}{\partial(\lambda-1)}=\mathbf{P}
$$


ser calculada da seguinte forma:

$$
\begin{gathered}
\frac{\partial \tilde{\boldsymbol{\epsilon}}}{\partial x_{\gamma}^{s}}=\frac{\partial}{\partial x_{\gamma}^{s}}\left[\frac{\sqrt{\left(\frac{\partial \tilde{\phi}_{m}(\xi)}{\partial \xi} x_{\eta}^{m}\right)^{2}}}{\left.\sqrt{\left(\frac{\partial \tilde{\phi}_{z}(\xi)}{\partial \xi} X_{\zeta}^{z}\right)^{2}}-1\right]}\right. \\
=\frac{\frac{1}{2}\left[\left(\frac{\partial \tilde{\phi}_{n}(\xi)}{\partial \xi} x_{\pi}^{n}\right)^{2}\right]^{-1 / 2} 2\left(\frac{\partial \tilde{\phi}_{p}(\xi)}{\partial \xi} x_{\eta}^{p}\right) \frac{\partial \tilde{\phi}_{m}(\xi)}{\partial \xi} \frac{\partial x_{\eta}^{m}}{\partial x_{\gamma}^{s}}}{\sqrt{\left(\frac{\partial \tilde{\phi}_{z}(\xi)}{\partial \xi} X_{\zeta}^{z}\right)^{2}}} \\
\frac{\partial \tilde{\boldsymbol{\epsilon}}}{\partial x_{\gamma}^{s}}=\frac{\left[\left(\frac{\partial \tilde{\phi}_{n}(\xi)}{\partial \xi} x_{\pi}^{n}\right)^{2}\right]^{-1 / 2}\left(\frac{\partial \tilde{\phi}_{p}(\xi)}{\partial \xi} x_{\gamma}^{p}\right) \frac{\partial \tilde{\phi}_{s}(\xi)}{\partial \xi}}{\sqrt{\left(\frac{\partial \tilde{\phi}_{z}(\xi)}{\partial \xi} X_{\zeta}^{z}\right)^{2}}}
\end{gathered}
$$

com $\pi, \gamma$ e $\zeta$ variando de 1 ao número total de direções (2 para o caso plano) e $n, p, s$ e $z$ variando de 1 ao número total de elementos de nós do elemento de barra. A fim de compactar as equações, adota-se aqui por convenção um somatório implícito sobre as direções $\pi$ e $\zeta$ no espaço bidimensional, apesar de não haver repetição desses índices do lado direito da equação. Finalmente, substituindo a Equação 3.145 na Equação 3.144, tem-se que a força interna $\tilde{F}_{\gamma}^{s}$ no nó $s$ no elemento de barra na direção $\gamma$ vale:

$$
\tilde{F}_{\gamma}^{s}=\int_{-1}^{1} \tilde{\mathbf{P}} \frac{\left[\left(\frac{\partial \tilde{\phi}_{n}(\xi)}{\partial \xi} x_{\pi}^{n}\right)^{2}\right]^{-1 / 2}\left(\frac{\partial \tilde{\phi}_{p}(\xi)}{\partial \xi} x_{\gamma}^{p}\right) \frac{\partial \tilde{\phi}_{s}(\xi)}{\partial \xi}}{\sqrt{\left(\frac{\partial \tilde{\phi}_{z}(\xi)}{\partial \xi} X_{\zeta}^{z}\right)^{2}}} J(\xi) S d \xi
$$

onde $S$ é a área inicial da seção transversal do elemento de barra e $J$ é o jacobiano calculado conforme a Equação 3.135 em virtude da mudança do domínio de integração para o domínio adimensional de referência. Na Equação 3.146, $n, p, s$ e $z$ variam de 1 ao número total de nós do elemento de barra e $\pi, \gamma$ e $\zeta$ variam de 1 ao número total de direções (2 para o caso plano). A fim de compactar as equações, adota-se aqui por convenção um somatório implícito sobre as direções $\pi$ e $\zeta$ no espaço 2D, apesar de não haver repetição desses índices do lado direito da equação. A variável $\xi$ é a coordenada adimensional com relação ao elemento de referência. A derivada da força interna com relação aos parâmetros nodais de posição é o hessiano:

$$
\begin{gathered}
\tilde{h}_{\gamma \zeta}^{s z}=\frac{\partial \tilde{F}_{\gamma}^{s}}{\partial x_{\zeta}^{z}}=\frac{\partial}{\partial x_{\zeta}^{z}} \int_{-1}^{1} \tilde{\mathbf{P}} \frac{\partial \tilde{\boldsymbol{\epsilon}}}{\partial x_{\gamma}^{s}} J(\xi) S d \xi=\int_{-1}^{1}\left(\frac{\partial \tilde{\mathbf{P}}}{\partial x_{\zeta}^{z}} \frac{\partial \tilde{\boldsymbol{\epsilon}}}{\partial x_{\gamma}^{s}}+\tilde{\mathbf{P}} \frac{\partial^{2} \tilde{\boldsymbol{\epsilon}}}{\partial x_{\zeta}^{z} \partial x_{\gamma}^{s}}\right) J(\xi) S d \xi \\
\tilde{h}_{\gamma \zeta}^{s z}=\int_{-1}^{1}\left(\frac{\partial \tilde{\mathbf{P}}}{\partial \tilde{\boldsymbol{\epsilon}}} \frac{\partial \tilde{\boldsymbol{\epsilon}}}{\partial x_{\zeta}^{z}} \frac{\partial \tilde{\boldsymbol{\epsilon}}}{\partial x_{\gamma}^{s}}+\tilde{\mathbf{P}} \frac{\partial^{2} \tilde{\boldsymbol{\epsilon}}}{\partial x_{\zeta}^{z} \partial x_{\gamma}^{s}}\right) J(\xi) S d \xi
\end{gathered}
$$


Na Equação 3.147, tanto $\partial \tilde{\boldsymbol{\epsilon}} / \partial x_{\gamma}^{s}$ quanto $\partial \tilde{\boldsymbol{\epsilon}} / \partial x_{\zeta}^{z}$ são calculados conforme a Equação 3.145. Para calcular $\partial \tilde{\boldsymbol{\epsilon}} / \partial x_{\zeta}^{z}$ basta substituir $s$ por $z$ e $\gamma$ por $\zeta$ na Equação 3.145. Já o segundo termo, $\partial^{2} \tilde{\boldsymbol{\epsilon}} / \partial x_{\zeta}^{z} \partial x_{\gamma}^{s}$, é calculado da seguinte forma:

$$
\begin{gathered}
\frac{\partial^{2} \tilde{\boldsymbol{\epsilon}}}{\partial x_{\zeta}^{z} \partial x_{\gamma}^{s}}=\frac{\partial}{\partial x_{\zeta}^{z}}\left\{\frac{\left[\left(\frac{\partial \tilde{\phi}_{n}(\xi)}{\partial \xi} x_{\pi}^{n}\right)^{2}\right]^{-1 / 2}\left(\frac{\partial \tilde{\phi}_{p}(\xi)}{\partial \xi} x_{\gamma}^{p}\right) \frac{\partial \tilde{\phi}_{s}(\xi)}{\partial \xi}}{\sqrt{\left(\frac{\partial \tilde{\phi}_{l}(\xi)}{\partial \xi} X_{\alpha}^{l}\right)^{2}}}\right\} \\
=\frac{-\frac{1}{2}\left[\left(\frac{\partial \tilde{\phi}_{m}(\xi)}{\partial \xi} x_{\eta}^{m}\right)^{2}\right]^{-3 / 2} 2\left(\frac{\partial \tilde{\phi}_{o}(\xi)}{\partial \xi} x_{\pi}^{o}\right) \frac{\partial \tilde{\phi}_{n}(\xi)}{\partial \xi} \frac{\partial x_{\pi}^{n}}{\partial x_{\zeta}^{z}}\left(\frac{\partial \tilde{\phi}_{p}(\xi)}{\partial \xi} x_{\gamma}^{p}\right) \frac{\partial \tilde{\phi}_{s}(\xi)}{\partial \xi}}{\left.+\frac{\partial \tilde{\phi}_{l}(\xi)}{\partial \xi} X_{\alpha}^{l}\right)^{2}} \\
\left.\left.+\frac{\partial \tilde{\phi}_{m}(\xi)}{\partial \xi} x_{\eta}^{m}\right)^{2}\right]^{-1 / 2}\left(\frac{\partial \tilde{\phi}_{p}(\xi)}{\partial \xi} \frac{\partial x_{\gamma}^{p}}{\partial x_{\zeta}^{z}}\right)^{\frac{\partial \tilde{\phi}_{s}(\xi)}{\partial \xi}} \\
+\sqrt{\left(\frac{\partial \tilde{\phi}_{l}(\xi)}{\partial \xi} X_{\alpha}^{l}\right)^{2}} \\
\left.\left.+\frac{\partial \tilde{\phi}_{m}(\xi)}{\partial \xi} x_{\eta}^{m}\right)^{2}\right]^{-3 / 2}\left(\frac{\partial \tilde{\phi}_{o}(\xi)}{\partial \xi} x_{\zeta}^{o}\right)\left(\frac{\partial \tilde{\phi}_{p}(\xi)}{\partial \xi} x_{\gamma}^{p}\right) \frac{\partial \tilde{\phi}_{s}(\xi)}{\partial \xi} \frac{\partial \tilde{\phi}_{z}(\xi)}{\partial \xi}
\end{gathered}
$$

Na Equação 3.148, $l, m, o, p, s$ e $z$ variam de 1 ao número total de nós do elemento de barra e $\alpha, \gamma, \zeta$ e $\eta$ variam de 1 ao número total de direções (2 para o caso plano). A fim de compactar as equações, adota-se aqui por convenção um somatório implícito sobre as direções $\alpha$ e $\eta$ no espaço bidimensional, apesar de não haver repetição desses índices do lado direito da equação. A variável $\xi$ é a coordenada adimensional com relação ao elemento de referência, $S$ é a área incial da seção transversal do elemento de barra e $J$ é o jacobiano calculado conforme a Equação 3.135 em virtude da mudança do domínio de integração para o domínio adimensional de referência. As potências não podem ser simplificadas pelo motivo já explicado na Equação 3.143.

As Equações 3.146 e 3.147 são resolvidas numericamente pelo somatório do integrando avaliado nos pontos de Gauss. Os termos $\partial \tilde{\mathbf{P}} / \partial \tilde{\boldsymbol{\epsilon}}$ e $\tilde{\mathbf{P}}$ são parâmetros que dependem 
da lei constitutiva adotada, os quais serão calculados no a seguir.

O comportamento viscoelástico é um fenômeno de dissipação de energia interna não reversível que resulta na existência de estados não equilibrados que evoluem ao longo do tempo. Os fenômenos de relaxamento e fluência são dois efeitos viscoelásticos típicos, onde o retorno à uma (nova) posição de equilíbrio após uma pertubação depende do tempo. O relaxamento descreve a diminuição da tensão sob um regime de deformação constante, enquanto a fluência descreve o aumento da deformação sob a aplicação de uma tensão constante. Os modelos de Maxwell e Kelvin-Voigt são dois modelos mecânicos típicos utilizados na descrição dos fenômenos de relaxamento e fluência, respectivamente. (HOLZAPFEL, 2000)

A fim de levar em conta o comportamento viscoso dos tecidos musculares (fenômeno de relaxamento ou fadiga), este trabalho propõe um modelo constitutivo viscoelástico para o elemento de barra simples baseado no modelo de Kelvin-Voigt. Esse modelo, ilustrado na Figura 7, consiste de um elemento elástico em paralelo com um elemento de amortecedor. Devido ao efeito do amortecedor no modelo, as deformações não surgem imediatamente após a aplicação de um carregamento. Isto acontece porque no instante de aplicação da carga, toda a força é inicialmente suportada pelo amortecedor, o qual diferentemente do elemento elástico, não responde com deformações imediatas ante a aplicação de uma tensão. No entanto, com o passar do tempo, esse amortecedor tende a "relaxar", transferindo gradualmente a carga para o elemento elástico.

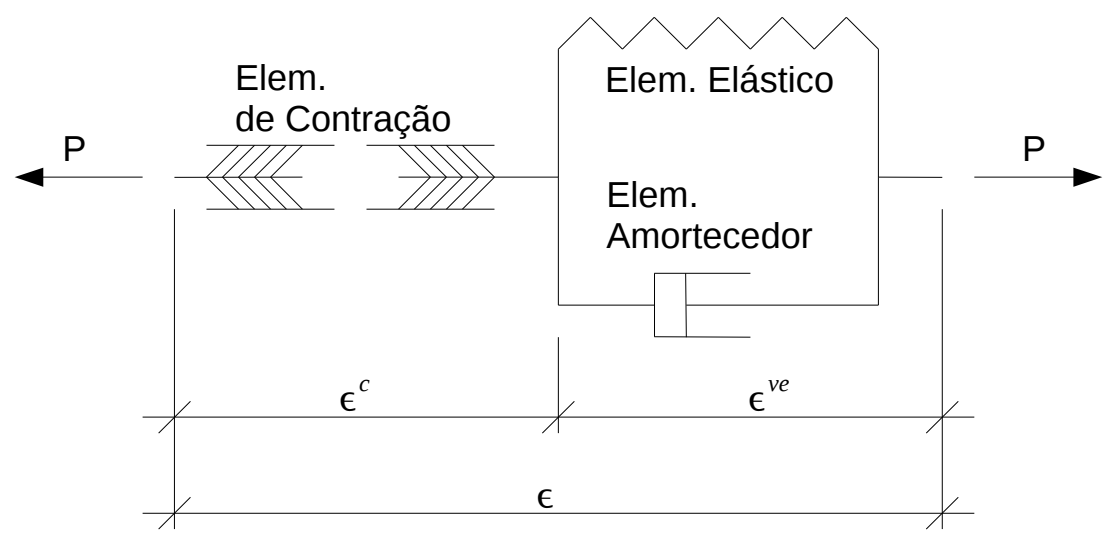

Figura 7 - Modelo viscoelástico ativo do elemento finito de barra simples

Conforme a Figura 7, adicionalmente considera-se um elemento ativo de contração em série com o modelo viscoelástico de Kevin - Voigt. O posicionamento do elemento de contração foi escolhido estrategicamente de modo a permitir a contração imediata do elemento de fibra. Assim, o comportamento esperado é que uma deformação prescrita no elemento de contração gere imediatamente uma contração no elemento de barra simples (deformação instantânea), sem que o elemento de contração interfira no modelo viscoelástico 
ou vice-versa.

No modelo proposto, a tensão $\mathbf{P}$ no elemento de fibra é igual a tensão $\mathbf{P}^{c}$ no elemento de contração, que é igual a tensão viscoelástica $\mathbf{P}^{v e}$, que por sua vez é a soma da tensão elástica $\mathbf{P}^{e}$ com a tensão viscosa $\mathbf{P}^{v}$, isto é, $\mathbf{P}=\mathbf{P}^{c}=\mathbf{P}^{v e}=\mathbf{P}^{v}+\mathbf{P}^{e}$. Logo, adotando um modelo elástico linear para o comportamento do elemento elástico tal que $\mathbf{P}^{v e}=\mathbb{E} \tilde{\boldsymbol{\epsilon}}^{v e}$, onde $\mathbb{E}$ é o módulo de elasticidade (Young) e, sendo ainda $c$ a constante viscosa do modelo, $\tilde{\boldsymbol{\epsilon}}_{t+1}^{v e}$ e $\tilde{\boldsymbol{\epsilon}}_{t}^{v e}$, respectivamente, as deformações no instante atual e num instante anterior, têm-se pelo método das diferenças finitas para um intervalo de tempo $\Delta t$ que:

$$
\mathbf{P}_{t+1}=c \frac{\partial \tilde{\boldsymbol{\epsilon}}_{t+1}^{v e}}{\partial t}+\mathbb{E} \tilde{\boldsymbol{\epsilon}}_{t+1}^{v e}=c\left(\frac{\tilde{\boldsymbol{\epsilon}}_{t+1}^{v e}-\tilde{\boldsymbol{\epsilon}}_{t}^{v e}}{\Delta t}\right)+\mathbb{E} \tilde{\boldsymbol{\epsilon}}_{t+1}^{v e}
$$

Como a deformação total $\tilde{\boldsymbol{\epsilon}}_{t+1}$ do modelo, tanto no instante $t+1$ como no instante anterior $t$, é igual a deformação $\tilde{\boldsymbol{\epsilon}}^{c}$ prescrita no elemento de contração mais a deformação viscoelástica $\tilde{\boldsymbol{\epsilon}}^{v e}$, ou seja, $\tilde{\boldsymbol{\epsilon}}=\tilde{\boldsymbol{\epsilon}}^{c}+\tilde{\boldsymbol{\epsilon}}^{v e}$ :

$$
\mathbf{P}_{t+1}=c\left(\frac{\tilde{\boldsymbol{\epsilon}}_{t+1}-\tilde{\boldsymbol{\epsilon}}_{t+1}^{c}-\tilde{\boldsymbol{\epsilon}}_{t}+\tilde{\boldsymbol{\epsilon}}_{t}^{c}}{\Delta t}\right)+\mathbb{E}\left(\tilde{\boldsymbol{\epsilon}}_{t+1}-\tilde{\boldsymbol{\epsilon}}_{t+1}^{c}\right)
$$

A derivada da $1^{\text {a }}$ tensão de Piola-Kirchhoff $\mathbf{P}$ com relação a deformação não linear de engenharia:

$$
\frac{\partial \mathbf{P}}{\partial \tilde{\boldsymbol{\epsilon}}}=\mathbb{C}=\mathbb{E}+\frac{c}{\Delta t}
$$

Nas Equações 3.149 e 3.150, a deformação $\tilde{\boldsymbol{\epsilon}}^{c}$ prescrita no elemento de contração, tanto no instante atual $t+1$ como no instante anterior $t$, é conhecida. A deformação total $\tilde{\boldsymbol{\epsilon}}$ do elemento de fibra, por sua vez, é aproximada iterativamente pelo método conforme Equação 3.142

\subsubsection{Imersão das fibras na matriz}

Na estratégia de imersão de fibras proposta por (VANALLI, 2004) e apresentada por Sampaio (2014), as posições nodais dos nós dos elementos de barra são escritos em função das posições dos nós dos elementos de chapa no qual se encontram inseridos esses nós de elemento de barra por meio das mesmas funções de forma $\phi$ utlizadas para aproximar as posições nodais do elemento de chapa. Isso permite eliminar os graus de liberdade referentes às posições nodais dos elementos de barra.

Assim, sendo $x_{\gamma}^{s}$ a posição atual na direção $\gamma$ de um nó $s$ qualquer de algum elemento de barra, tem-se que a derivada na direção $\alpha$ das posições dos nós desse elemento de barra com relação ao nó $q$ dos respectivos elementos de chapa dentro dos quais se 
encontram inseridos os nós $s$ do elemento de barra, vale:

$$
\begin{aligned}
x_{\gamma}^{s}=\phi_{r}\left(\xi_{1}^{s}, \xi_{2}^{s}\right) x_{\gamma}^{r} \rightarrow & \frac{\partial x_{\gamma}^{s}}{\partial x_{\alpha}^{q}}=\frac{\partial}{\partial x_{\alpha}^{q}}\left(\phi_{r}\left(\xi_{1}^{s}, \xi_{2}^{s}\right) x_{\gamma}^{r}\right)=\phi_{r}\left(\xi_{1}^{s}, \xi_{2}^{s}\right) \delta_{\alpha \gamma} \delta_{q r} \\
& \frac{\partial x_{\gamma}^{s}}{\partial x_{\alpha}^{q}}=\phi_{q}\left(\xi_{1}^{s}, \xi_{2}^{s}\right) \delta_{\gamma \alpha}, \text { onde } \delta_{\gamma \alpha} \text { é o delta de Kronecker }
\end{aligned}
$$

O resultado da Equação 3.152, que é a derivada dos nós dos elementos de barra com relação aos nós dos elementos de chapa, será frequentemente utilizado nos desenvolvimentos que se seguem. A energia específica de deformação total acumulada é a soma da energia de deformação acumulada na matriz $u_{m}$ com a energia de deformação acumulada na fibra $u_{f}$. Logo, a força interna em um nó $q$ de elemento de chapa que contém um nó $s$ de um elemento de barra é:

$$
\begin{aligned}
\frac{\partial\left(u_{m}+u_{f}\right)}{\partial x_{\alpha}^{q}} & =\frac{\partial u_{m}}{\partial x_{\alpha}^{q}}+\frac{\partial u_{f}}{\partial x_{\gamma}^{s}} \frac{\partial x_{\gamma}^{s}}{\partial x_{\alpha}^{q}}=\frac{\partial u_{m}}{\partial x_{\alpha}^{q}}+\frac{\partial u_{f}}{\partial x_{\gamma}^{s}} \frac{\partial x_{\gamma}^{s}}{\partial x_{\alpha}^{q}}=\frac{\partial u_{m}}{\partial x_{\alpha}^{q}}+\frac{\partial u_{f}}{\partial x_{\gamma}^{s}} \phi_{q}\left(\xi_{1}^{s}, \xi_{2}^{s}\right) \delta_{\gamma \alpha} \\
& =F_{\alpha}^{q}+\frac{\partial u_{f}}{\partial x_{\gamma}^{s}} \phi_{q}\left(\xi_{1}^{s}, \xi_{2}^{s}\right) \delta_{\gamma \alpha} \\
F_{\alpha}^{q} & =F_{\alpha}^{q}+\tilde{F}_{\alpha}^{s} \phi_{q}\left(\xi_{1}^{s}, \xi_{2}^{s}\right)
\end{aligned}
$$

onde $\phi_{q}$ é a função de forma utilizada para aproximar a posição do nó $q$ do elemento de chapa dentro do qual se encontra inserido o nó de elemento de barra $s$. A variável $\tilde{F}_{\alpha}^{s}$ é a força interna no nó de barra $s$ na direção $\alpha$ e $\xi_{1}, \xi_{2}$ são as coordenadas adimensionais desse nó $s$ de elemento de barra com relação ao elemento de chapa, dentro do qual está inserido esse nó de elemento de barra, respectivamente, nas direções 1 e 2.

A fim de exemplificar a contribuição do vetor de forças internas do elemento de barra no vetor de forças internas globais, considere o seguinte vetor de forças internas de um elemento de barra de 2 nós, onde $\alpha$ é a direção no plano cartesiano e $s$ é um nó local desse elemento de barra:

$$
\tilde{F}_{\alpha}^{s}=\left\{\begin{array}{c}
\tilde{F}_{1}^{1} \\
\tilde{F}_{2}^{1} \\
\tilde{F}_{1}^{2} \\
\tilde{F}_{2}^{2}
\end{array}\right\}
$$

O termo $\tilde{F}_{\alpha}^{s} \phi_{q}\left(\xi_{1}^{s}, \xi_{2}^{s}\right)$ é o vetor de forças internas do elemento de barra "transferido" para os nós dos elementos de chapa. A força interna atuante em um nó de um elemento de barra é "transferida" para os nós do elemento de chapa conforme a posição do respectivo nó do elemento de barra em relação a cada nó do elemento de chapa, dentro do qual esse nó do elemento de barra está inserido, através da função de forma $\phi_{q}\left(\xi_{1}^{s}, \xi_{2}^{s}\right)$. A Figura 8 ilustra essa importante idéia que elimina os graus de liberdade dos nós de chapa: 


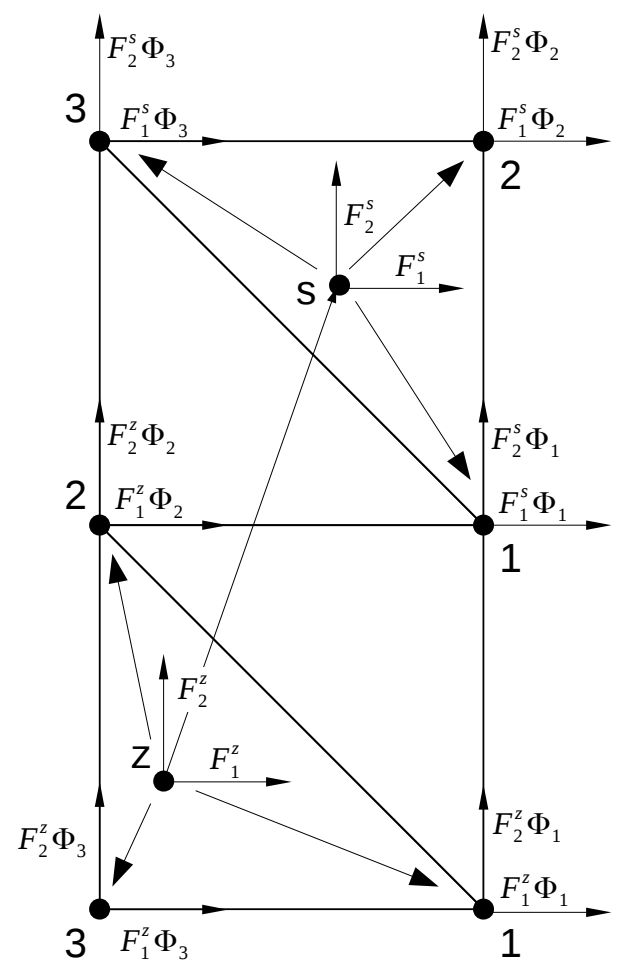

Figura 8 - Espalhamento das forças internas do elemento finito de barra

Na Figura 8, por exemplo, a força interna nos nós $s$ e $z$ do elemento de barra é transferida para os nós 1, 2 e 3 dos respectivos elementos de chapa no qual esses nós de elemento de barra estão inseridos. Isso é feito através de funções de forma e de acordo com a posição dos nós de elemento de barra com a relação aos nós de elemento de chapa.

Para elementos de chapa de 3 nós e elementos de barra de 2 nós, tem-se o vetor de forças internas do elemento de barra "transferido" para os elementos de chapa da estrutura:

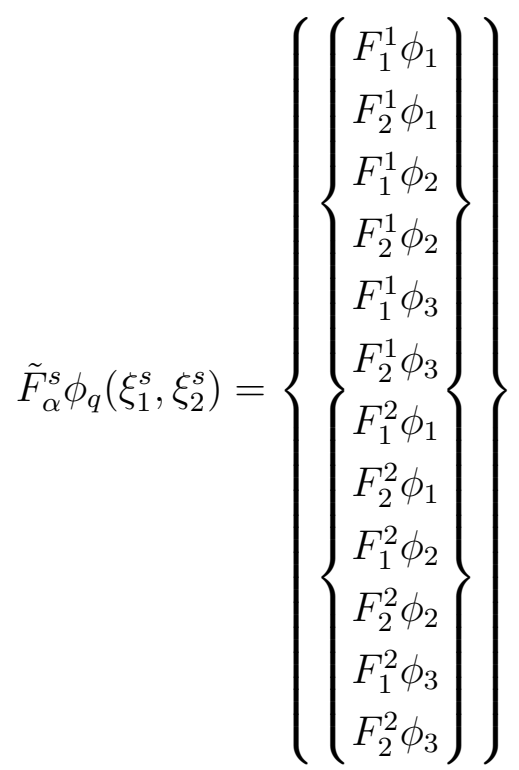

O termo $\tilde{F}_{\alpha}^{s} \phi_{q}\left(\xi_{1}^{s}, \xi_{2}^{s}\right)$ ocupa a linha $2(q-1)+\alpha+6(s-1)$ no vetor de forças 
internas da Equação 3.155. O vetor da Equação 3.155 pode ser reorganizado em outros dois subvetores $\left\{F_{\alpha}^{1}\right\}$ e $\left\{F_{\alpha}^{2}\right\}$, cada uma referente a um nó do elemento de barra.

$$
\left.\tilde{F}_{\alpha}^{s} \phi_{q}\left(\xi_{1}^{s}, \xi_{2}^{s}\right)=\left\{\begin{array}{c}
\left\{F_{\alpha}^{1}\right. \\
F_{\alpha}^{2}
\end{array}\right\}\right\}
$$

Esses subvetores representam as forças internas induzidas nos nós do elemento de chapa pelas forças internas atuantes nos nós de elemento de barra. Ou seja, fisicamente os termos desses subvetores são as forças internas na direção $\alpha$ no nó local $q$ de um elemento de chapa geradas pelas forças internas atuantes na direção $\alpha$ em um nó local $s$ de um elemento de barra. As variáveis $\xi_{1}^{s}$ e $\xi_{2}^{s}$ são as coordenadas adimensionais desse nó $s$ de elemento de barra com relação ao elemento de chapa, dentro do qual esta inserido o nó $s$ de elemento de barra, respectivamente nas direções 1 e 2 .

Cada subvetor $\left\{F_{\alpha}^{1}\right\}$ ou $\left\{F_{\alpha}^{2}\right\}$, referente a cada nó do elemento de barra, deve contribuir com forças internas nos respectivos nós do elemento de chapa no qual esse nó de elemento de barra esta localizado. Essa contribuição também pode ser feita de forma direta no vetor de forças internas global da estrutura. Para tanto, basta identificar o grau de liberdade global referente a cada nó de elemento de chapa e contribuir diretamente no vetor de forças internas global, ao invés de contribuir no vetor de forças internas de cada respectivo elemento de chapa no qual se encontra inserido o nó do elemento de barra, para só então contribuir na matriz global.

A hessiana global é obtida derivando-se duas vezes a energia específica total acumulada em relação aos parâmetros nodais do elemento de chapa. Logo, a influência dos deslocamentos do nó $z$ de um elemento de barra na direção $\beta$ nos deslocamentos do nó $s$ desse mesmo elemento de barra na direção $\alpha$ é transferida para os nós $q$ e $r$ dos respectivos elementos de chapa nos quais estão localizados esses nós de barra, conforme respectivamente a posição dos nós $s$ e $z$ de elemento de barra em relação aos nós $q$ e $r$ de elementos de chapa nos quais estão inseridos esses nós $s$ e $z$ de elemento de barra. Para elementos de chapa que contêm algum nó de elemento de barra tem-se que:

$$
\begin{aligned}
\frac{\partial^{2}\left(u_{m}+u_{f}\right)}{\partial x_{\alpha}^{q} \partial x_{\beta}^{r}} & =\frac{\partial}{\partial x_{\alpha}^{q}}\left(\frac{\partial u_{m}}{\partial x_{\beta}^{r}}\right)+\frac{\partial}{\partial x_{\alpha}^{q}}\left(\frac{\partial u_{f}}{\partial x_{\zeta}^{z}} \frac{\partial x_{\zeta}^{z}}{\partial x_{\beta}^{r}}\right)=\frac{\partial^{2} u_{m}}{\partial x_{\alpha}^{q} \partial x_{\beta}^{r}}+\frac{\partial^{2} u_{f}}{\partial x_{\gamma}^{s} \partial x_{\zeta}^{z}} \frac{\partial x_{\zeta}^{z}}{\partial x_{\beta}^{r}} \frac{\partial x_{\gamma}^{s}}{\partial x_{\alpha}^{q}} \\
& =h_{\alpha \beta}^{q r}+\tilde{h}_{\gamma \zeta}^{s z} \phi_{q}\left(\xi_{1}^{s}, \xi_{2}^{s}\right) \phi_{r}\left(\xi_{1}^{z}, \xi_{2}^{z}\right) * \delta_{\alpha \gamma} \delta_{\beta \zeta} \\
h_{\alpha \beta}^{q r} & =h_{\alpha \beta}^{q r}+\tilde{h}_{\alpha \beta}^{s z} \phi_{q}\left(\xi_{1}^{s}, \xi_{2}^{s}\right) \phi_{r}\left(\xi_{1}^{z}, \xi_{2}^{z}\right)
\end{aligned}
$$

Na Equação $3.157 \phi_{q}$ e $\phi_{r}$ são as funções de forma dos nós $q$ e $r$ do elemento de chapa, onde se encontram inseridos respectivamente os nós de elemento de barra $s$ e $z$. A variável $\xi_{1}^{s}, \xi_{2}^{s}, \xi_{1}^{z}, \xi_{2}^{z}$ são, respectivamente, as coordenadas adimensionais dos nós de elemento de barra inseridos em elementos de chapa nas direções 1 e 2 . 
A fim de exemplificar a contribuição da matriz hessiana do elemento de barra na matriz hessiana do elemento de chapa, considere a matriz hessiana de um elemento de barra de 2 nós, onde $\alpha$ e $\beta$ são direções no plano cartesiano e $s$ e $z$ são os nós locais desse elemento de barra:

$$
\tilde{h}_{\alpha \beta}^{s z}=\left[\begin{array}{cccc}
\tilde{h}_{11}^{11} & \tilde{h}_{12}^{11} & \tilde{h}_{11}^{12} & \tilde{h}_{12}^{12} \\
\tilde{h}_{21}^{11} & \tilde{h}_{22}^{11} & \tilde{h}_{21}^{12} & \tilde{h}_{22}^{12} \\
\tilde{h}_{11}^{21} & \tilde{h}_{12}^{21} & \tilde{h}_{11}^{22} & \tilde{h}_{12}^{22} \\
\tilde{h}_{21}^{21} & \tilde{h}_{22}^{21} & \tilde{h}_{21}^{22} & \tilde{h}_{22}^{22}
\end{array}\right]
$$

No caso do vetor de forças internas, um determinado nó de elemento de barra contribui somente com termos nos nós de elemento de chapa no qual se encontra inserido esse nó de elemento de barra. No caso da matriz hessiana, deve-se considerar tanto a contribuição de termos referentes a um determinado nó de elemento de barra nos nós do elemento de chapa no qual se insere esse nó de elemento de barra, como também contribuições nos nós de elemento de chapa onde estão inseridos os outros nós desse mesmo elementos de barra.

Isso acontece porque as direções e os nós dos elementos estão acoplados, ou seja, fisicamente o termo $\tilde{h}_{\alpha \beta}^{s z}$ em uma matriz hessiana qualquer indica a variação de posição ${ }^{12}$ na direção $\alpha$ e no nó local $s$, decorrente de uma variação de posição na direção $\beta$ e no nó local $z$. Isso quer dizer que, ao finalizar a montagem da matriz hessiana global, um deslocamento horizontal em um determinado nó da estrutura pode vir a gerar um deslocamento vertical em um outro nó da estrutura. Essa idéia de relacionar as variações de posição ou deslocamento de forma completamente acoplada é o significado físico mais importante de uma matriz hessiana.

Assim, $\tilde{h}_{\alpha \beta}^{s z} \phi_{q}\left(\xi_{1}^{s}, \xi_{2}^{s}\right) \phi_{r}\left(\xi_{1}^{z}, \xi_{2}^{z}\right)$ são os termos que acoplam as variações de posição em um nó de um elemento de chapa que contém algum nó do elemento de barra, com as variações de posição de um determinado nó qualquer desse mesmo elemento de barra. A variação de posição de um nó de um elemento de barra causa variações de posição nos nós do elemento chapa no qual esse nó do elemento de barra está inserido, conforme a posição desse nó do elemento de barra em relação a cada nó do elemento de chapa, no qual está inserido o nó de elemento de barra, através das funções de forma $\phi_{q}\left(\xi_{1}^{s}, \xi_{2}^{s}\right)$ e $\phi_{r}\left(\xi_{1}^{z}, \xi_{2}^{z}\right)$. A Figura 9 ilustra essa importante idéia que elimina os graus de liberdades dos nós de barra:

\footnotetext{
${ }^{12} \mathrm{Na}$ formulação em deslocamentos tem-se variação de deslocamento. Na formulação posicional, a variação de posição é o próprio deslocamento.
} 


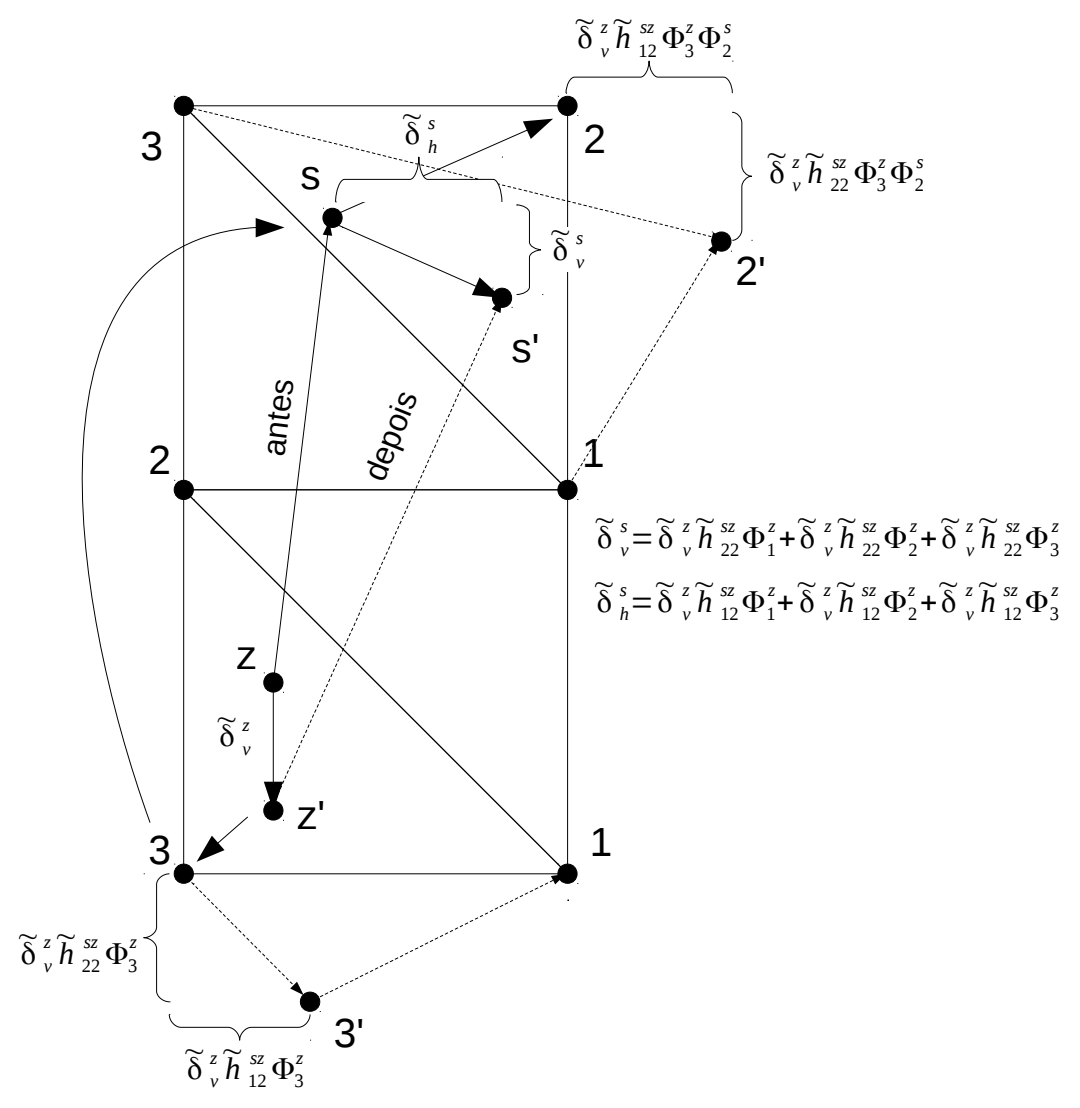

Figura 9 - Espalhamento do hessiano do elemento finito de barra simples

Por exemplo, na Figura 9 tem-se que uma variação de posição vertical $\delta_{v}^{z}$ no nó local do elemento de barra $z$ causa tanto uma variação vertical quanto horizontal do nó local 3 do elemento de chapa. Essa variação de posição no nó local 3 do elemento de chapa irá causar variações de posição em um outro nó local $s$ desse mesmo elemento de barra, as quais por sua vez irão causar variações, por exemplo, no nó local 2 de um outro elemento de chapa. Logo, diferentemente do vetor de forças internas, termos da hessiana do nó de elemento de barra $z$ é transferido para os nós 1, 2 e 3 dos elementos de chapa nos quais se encontram inseridos tanto o nó de elemento de barra $s$ quanto $z$, conforme indicado pela 9.

Para elementos de chapa de 3 nós e elementos de barra de 2 nós, tem-se a matriz 
hessiana do elemento de barra "transferida" para os elementos de chapa:

$$
\begin{aligned}
& \tilde{h}_{\alpha \beta}^{s z} \phi_{q}\left(\xi_{1}^{s}, \xi_{2}^{s}\right) \phi_{r}\left(\xi_{1}^{z}, \xi_{2}^{z}\right)= \\
& \left(\begin{array}{cccccc}
\tilde{h}_{11}^{11} \phi_{1}^{2} & \tilde{h}_{12}^{11} \phi_{1}^{2} & \tilde{h}_{11}^{11} \phi_{1} \phi_{2} & \tilde{h}_{12}^{11} \phi_{1} \phi_{2} & \tilde{h}_{11}^{11} \phi_{1} \phi_{3} & \tilde{h}_{12}^{11} \phi_{1} \phi_{3} \\
\tilde{h}_{21}^{11} \phi_{1}^{2} & \tilde{h}_{22}^{11} \phi_{1}^{2} & \tilde{h}_{21}^{11} \phi_{1} \phi_{2} & \tilde{h}_{22}^{11} \phi_{1} \phi_{2} & \tilde{h}_{21}^{11} \phi_{1} \phi_{3} & \tilde{h}_{22}^{11} \phi_{1} \phi_{3} \\
\tilde{h}_{11}^{11} \phi_{1} \phi_{2} & \tilde{h}_{12}^{11} \phi_{1} \phi_{2} & \tilde{h}_{11}^{11} \phi_{2}^{2} & \tilde{h}_{12}^{11} \phi_{2}^{2} & \tilde{h}_{11}^{11} \phi_{2} \phi_{3} & \tilde{h}_{12}^{11} \phi_{2} \phi_{3} \\
\tilde{h}_{21}^{11} \phi_{1} \phi_{2} & \tilde{h}_{22}^{11} \phi_{1} \phi_{2} & \tilde{h}_{21}^{11} \phi_{2}^{2} & \tilde{h}_{22}^{11} \phi_{2}^{2} & \tilde{h}_{21}^{11} \phi_{2} \phi_{3} & \tilde{h}_{22}^{11} \phi_{2} \phi_{3} \\
\tilde{h}_{11}^{11} \phi_{1} \phi_{3} & \tilde{h}_{12}^{11} \phi_{1} \phi_{3} & \tilde{h}_{11}^{11} \phi_{2} \phi_{3} & \tilde{h}_{12}^{11} \phi_{2} \phi_{3} & \tilde{h}_{11}^{11} \phi_{3}^{2} & \tilde{h}_{12}^{11} \phi_{3}^{2} \\
\tilde{h}_{21}^{11} \phi_{1} \phi_{3} & \tilde{h}_{22}^{11} \phi_{1} \phi_{3} & \tilde{h}_{21}^{11} \phi_{2} \phi_{3} & \tilde{h}_{22}^{11} \phi_{2} \phi_{3} & \tilde{h}_{21}^{11} \phi_{3}^{2} & \tilde{h}_{22}^{11} \phi_{3}^{2} \\
\tilde{h}_{11}^{21} \phi_{1}^{2} & \tilde{h}_{12}^{21} \phi_{1}^{2} & \tilde{h}_{11}^{21} \phi_{1} \phi_{2} & \tilde{h}_{12}^{21} \phi_{1} \phi_{2} & \tilde{h}_{11}^{21} \phi_{1} \phi_{3} & \tilde{h}_{12}^{21} \phi_{1} \phi_{3} \\
\tilde{h}_{21}^{21} \phi_{1}^{2} & \tilde{h}_{22}^{21} \phi_{1}^{2} & \tilde{h}_{21}^{21} \phi_{1} \phi_{2} & \tilde{h}_{22}^{21} \phi_{1} \phi_{2} & \tilde{h}_{21}^{21} \phi_{1} \phi_{3} & \tilde{h}_{22}^{21} \phi_{1} \phi_{3} \\
\tilde{h}_{11}^{21} \phi_{1} \phi_{2} & \tilde{h}_{12}^{21} \phi_{1} \phi_{2} & \tilde{h}_{11}^{21} \phi_{2}^{2} & \tilde{h}_{12}^{21} \phi_{2}^{2} & \tilde{h}_{11}^{21} \phi_{2} \phi_{3} & \tilde{h}_{12}^{21} \phi_{2} \phi_{3} \\
\tilde{h}_{21}^{21} \phi_{1} \phi_{2} & \tilde{h}_{22}^{21} \phi_{1} \phi_{2} & \tilde{h}_{21}^{21} \phi_{2}^{2} & \tilde{h}_{22}^{21} \phi_{2}^{2} & \tilde{h}_{21}^{21} \phi_{2} \phi_{3} & \tilde{h}_{22}^{21} \phi_{2} \phi_{3} \\
\tilde{h}_{11}^{21} \phi_{1} \phi_{3} & \tilde{h}_{12}^{21} \phi_{1} \phi_{3} & \tilde{h}_{11}^{21} \phi_{2} \phi_{3} & \tilde{h}_{12}^{21} \phi_{2} \phi_{3} & \tilde{h}_{11}^{21} \phi_{3}^{2} & \tilde{h}_{12}^{21} \phi_{3}^{2} \\
\tilde{h}_{21}^{21} \phi_{1} \phi_{3} & \tilde{h}_{22}^{21} \phi_{1} \phi_{3} & \tilde{h}_{21}^{21} \phi_{2} \phi_{3} & \tilde{h}_{22}^{21} \phi_{2} \phi_{3} & \tilde{h}_{21}^{21} \phi_{3}^{2} & \tilde{h}_{22}^{21} \phi_{3}^{2}
\end{array}\right) \\
& \left.\left(\begin{array}{cccccc}
\tilde{h}_{11}^{12} \phi_{1}^{2} & \tilde{h}_{12}^{12} \phi_{1}^{2} & \tilde{h}_{11}^{12} \phi_{1} \phi_{2} & \tilde{h}_{12}^{12} \phi_{1} \phi_{2} & \tilde{h}_{11}^{12} \phi_{1} \phi_{3} & \tilde{h}_{12}^{12} \phi_{1} \phi_{3} \\
\tilde{h}_{21}^{12} \phi_{1}^{2} & \tilde{h}_{22}^{12} \phi_{1}^{2} & \tilde{h}_{21}^{12} \phi_{1} \phi_{2} & \tilde{h}_{22}^{12} \phi_{1} \phi_{2} & \tilde{h}_{21}^{12} \phi_{1} \phi_{3} & \tilde{h}_{22}^{12} \phi_{1} \phi_{3} \\
\tilde{h}_{11}^{12} \phi_{1} \phi_{2} & \tilde{h}_{12}^{12} \phi_{1} \phi_{2} & \tilde{h}_{11}^{12} \phi_{2}^{2} & \tilde{h}_{12}^{12} \phi_{2}^{2} & \tilde{h}_{11}^{12} \phi_{2} \phi_{3} & \tilde{h}_{12}^{12} \phi_{2} \phi_{3} \\
\tilde{h}_{21}^{12} \phi_{1} \phi_{2} & \tilde{h}_{22}^{12} \phi_{1} \phi_{2} & \tilde{h}_{21}^{12} \phi_{2}^{2} & \tilde{h}_{22}^{12} \phi_{2}^{2} & \tilde{h}_{21}^{12} \phi_{2} \phi_{3} & \tilde{h}_{22}^{12} \phi_{2} \phi_{3} \\
\tilde{h}_{11}^{12} \phi_{1} \phi_{3} & \tilde{h}_{12}^{12} \phi_{1} \phi_{3} & \tilde{h}_{11}^{12} \phi_{2} \phi_{3} & \tilde{h}_{12}^{12} \phi_{2} \phi_{3} & \tilde{h}_{11}^{12} \phi_{3}^{2} & \tilde{h}_{12}^{12} \phi_{3}^{2} \\
\tilde{h}_{21}^{12} \phi_{1} \phi_{3} & \tilde{h}_{22}^{12} \phi_{1} \phi_{3} & \tilde{h}_{21}^{12} \phi_{2} \phi_{3} & \tilde{h}_{22}^{12} \phi_{2} \phi_{3} & \tilde{h}_{21}^{12} \phi_{3}^{2} & \tilde{h}_{22}^{12} \phi_{3}^{2} \\
\tilde{h}_{11}^{22} \phi_{1}^{2} & \tilde{h}_{12}^{22} \phi_{1}^{2} & \tilde{h}_{11}^{22} \phi_{1} \phi_{2} & \tilde{h}_{12}^{22} \phi_{1} \phi_{2} & \tilde{h}_{11}^{22} \phi_{1} \phi_{3} & \tilde{h}_{12}^{22} \phi_{1} \phi_{3} \\
\tilde{h}_{21}^{22} \phi_{1}^{2} & \tilde{h}_{22}^{22} \phi_{1}^{2} & \tilde{h}_{21}^{22} \phi_{1} \phi_{2} & \tilde{h}_{22}^{22} \phi_{1} \phi_{2} & \tilde{h}_{21}^{22} \phi_{1} \phi_{3} & \tilde{h}_{22}^{22} \phi_{1} \phi_{3} \\
\tilde{h}_{11}^{22} \phi_{1} \phi_{2} & \tilde{h}_{12}^{22} \phi_{1} \phi_{2} & \tilde{h}_{11}^{22} \phi_{2}^{2} & \tilde{h}_{12}^{22} \phi_{2}^{2} & \tilde{h}_{11}^{22} \phi_{2} \phi_{3} & \tilde{h}_{12}^{22} \phi_{2} \phi_{3} \\
\tilde{h}_{21}^{22} \phi_{1} \phi_{2} & \tilde{h}_{22}^{22} \phi_{1} \phi_{2} & \tilde{h}_{21}^{22} \phi_{2}^{2} & \tilde{h}_{22}^{22} \phi_{2}^{2} & \tilde{h}_{21}^{22} \phi_{2} \phi_{3} & \tilde{h}_{22}^{22} \phi_{2} \phi_{3} \\
\tilde{h}_{11}^{22} \phi_{1} \phi_{3} & \tilde{h}_{12}^{22} \phi_{1} \phi_{3} & \tilde{h}_{11}^{22} \phi_{2} \phi_{3} & \tilde{h}_{12}^{22} \phi_{2} \phi_{3} & \tilde{h}_{11}^{22} \phi_{3}^{2} & \tilde{h}_{12}^{22} \phi_{3}^{2} \\
\tilde{h}_{21}^{22} \phi_{1} \phi_{3} & \tilde{h}_{22}^{22} \phi_{1} \phi_{3} & \tilde{h}_{21}^{22} \phi_{2} \phi_{3} & \tilde{h}_{22}^{22} \phi_{2} \phi_{3} & \tilde{h}_{21}^{22} \phi_{3}^{2} & \tilde{h}_{22}^{22} \phi_{3}^{2}
\end{array}\right)\right)
\end{aligned}
$$

O termo $\tilde{h}_{\alpha \beta}^{s z} \phi_{q}\left(\xi_{1}^{s}, \xi_{2}^{s}\right) \phi_{r}\left(\xi_{1}^{z}, \xi_{2}^{z}\right)$ ocupa a linha $2(q-1)+\alpha+6(s-1)$ e a coluna $2(r-1)+\beta+6(z-1)$ na matriz hessiana acima. A matriz anterior pode ser reorganizada em quatro submatrizes $\left[H_{\alpha \beta}^{11}\right],\left[H_{\alpha \beta}^{12}\right],\left[H_{\alpha \beta}^{21}\right]$ e $\left[H_{\alpha \beta}^{22}\right]$ :

$$
\left[\begin{array}{l}
{\left[H_{\alpha \beta}^{11}\right]\left[H_{\alpha \beta}^{12}\right]} \\
{\left[H_{\alpha \beta}^{21}\right]\left[H_{\alpha \beta}^{22}\right]}
\end{array}\right]
$$

A submatriz $\left[H_{\alpha \beta}^{12}\right]$, por exemplo, acopla a variação de posição do nó 1 do elemento de barra com a variação de posição do nó 2 desse mesmo elemento de barra. Portanto, os termos da submatriz $\left[H_{\alpha \beta}^{12}\right]$ relacionam as variações nas posições dos nós do elemento de 
chapa, no qual está localizado o nó 1 de um elemento de barra, com a variação de posição do nó 2 desse mesmo elemento de barra, qualquer que seja o elemento chapa no qual o nó 2 esteja localizado. Assim, fisicamente, os termos das submatrizes representam as variações de posição do nó local $q$ de um elemento de chapa na direção $\alpha$ devido as variações de posição do nó local $r$ de um elemento de chapa (mesmo ou outro) na direção $\beta$ induzidas por variações na posição do nó local $s$ de um elemento de barra na direção $\alpha$ geradas por variações de posição no nó local $z$ desse mesmo elemento de barra na direção $\beta$, quaisquer que sejam os elementos de chapa nos quais estão inseridos os nós de barra $s$ e $z$.

As variáveis $\xi_{1}^{s}$ e $\xi_{2}^{s}$ são as coordenadas adimensionais do nó $s$ de um elemento de barra, respectivamente, nas direções 1 e 2 com relação ao elemento de chapa no qual o nó $s$ esta localizado. As variáveis $\xi_{1}^{z}$ e $\xi_{2}^{z}$ são as coordenadas adimensionais do nó $z$ de um elemento de barra, respectivamente, nas direções 1 e 2 com relação ao elemento de chapa no qual o nó z esta localizado. Da mesma forma que anteriormente para o vetor de forças internas, pode-se também fazer a contribuição diretamente na matriz hessiana global ao invés de contribuir na hessiana local de cada elemento, para só então contribuir na matriz hessiana global.

Durante o desenvolvimento das equações anteriores assumiu-se que, tanto o elemento dentro do qual se encontra um determinado nó de elemento de barra $s$, quanto as coordenadas adimensionais $\xi_{1}^{s}$ e $\xi_{2}^{s}$ nas direções 1 e 2 desse nó de elemento de barra com relação ao elemento de chapa que contém esse nó de elemento de barra $s$ eram conhecidos. Isso, no entanto, não é o que de fato acontece. No início do algoritmo, o que se conhece são apenas as posições iniciais na direção $\gamma$ do nó $s$ do elemento de barra $X_{\gamma}^{s}$ e do nó $q$ do elemento de chapa $X_{\gamma}^{q}$. As coordenadas adimensionais $\xi_{1}$ e $\xi_{2}$ dos nós dos elementos de barra com relação ao elemento de chapa dentro do qual se encontra esse nó de elemento de barra devem, portanto, ser determinadas. Isso acontece através de um processo iterativo descrito a seguir.

Como já se sabe, as posições dos nós de elemento de barra são escritas em função das posições dos nós de elementos de chapa, dentro dos quais se encontram inseridos esses nós de elementos de barra e utilizando as mesmas funções de forma $\phi$ adotadas para aproximar as posições dos pontos dentro do elemento de chapa. Assim, assumindo que o nó de elemento de barra $s$ esteja localizado em um determinado elemento chapa qualquer e, adotando inicialmente valores adequados de $\xi_{1}^{s}, \xi_{2}^{s}$ (por exemplo 0,3 e 0,3) para uma aproximação inicial das coordenadas adimensionais, muito provavelmente em uma tentativa $t$ haverá um erro $g_{\gamma(t)}^{s}$ na direção $\gamma$ entre o valor real $X_{\gamma}^{s}$ da posição inicial do nó $s$ de elemento de barra e a aproximação escolhida para a posição adimensional $\xi_{1}^{s}$, $\xi_{2}^{s}$ desse nó $s$ de elemento de barra inserido no elemento de chapa, isto é:

$$
g_{\gamma(t)}^{s}=X_{\gamma}^{s}-\phi_{q}\left(\xi_{1}^{s}, \xi_{2}^{s}\right) X_{\gamma}^{q}
$$


O que se deseja é minimizar esse erro. Portanto, fazendo a expansão da expressão anterior em série de Taylor de $1^{\mathrm{a}}$ ordem:

$$
g_{\gamma(t+1)}^{s}=g_{\gamma(t)}^{s}-\left.\frac{\partial \phi_{q}\left(\xi_{1}, \xi_{2}\right)}{\partial \xi_{j}} X_{\gamma}^{q}\right|_{\xi_{1(t)}^{s}, \xi_{2(t)}^{s}} \Delta \xi_{j}=g_{\gamma(t)}^{s}-H_{\gamma j} \Delta \xi_{j}
$$

O ideal é que esse seja fosse zero ou suficientemente pequeno:

$$
\begin{gathered}
g_{\gamma(t)}^{s}-H_{\gamma j} \Delta \xi_{j}=0 \rightarrow g_{\gamma(t)}^{s}=H_{\gamma j} \Delta \xi_{j} \\
H_{\gamma j}=\left.\left[\begin{array}{ll}
\frac{\partial \phi_{1}\left(\xi_{1}, \xi_{2}\right)}{\partial \xi_{1}} X_{1}^{1}+\frac{\partial \phi_{2}\left(\xi_{1}, \xi_{2}\right)}{\partial \xi_{1}} X_{1}^{2}+\ldots & \frac{\partial \phi_{1}\left(\xi_{1}, \xi_{2}\right)}{\partial \xi_{2}} X_{1}^{1}+\frac{\partial \phi_{2}\left(\xi_{1}, \xi_{2}\right)}{\partial \xi_{2}} X_{1}^{2}+\ldots \\
\frac{\partial \phi_{1}\left(\xi_{1}, \xi_{2}\right)}{\partial \xi_{1}} X_{2}^{1}+\frac{\partial \phi_{2}\left(\xi_{1}, \xi_{2}\right)}{\partial \xi_{1}} X_{2}^{2}+\ldots & \frac{\partial \phi_{1}\left(\xi_{1}, \xi_{2}\right)}{\partial \xi_{2}} X_{2}^{1}+\frac{\partial \phi_{2}\left(\xi_{1}, \xi_{2}\right)}{\partial \xi_{2}} X_{2}^{2}+\ldots
\end{array}\right]\right|_{\xi_{1(t)}^{s}, \xi_{(t)}^{s}}
\end{gathered}
$$

Resolvendo a Equação 3.163 chega-se as correções que devem ser aplicadas as coordenadas adimensionais:

$$
\xi_{1(t+1)}^{s}=\xi_{1(t)}^{s}+\Delta \xi_{1} \quad \xi_{2(t+1)}^{s}=\xi_{2(t)}^{s}+\Delta \xi_{2}
$$

O processo anterior é novamente repetido até se atingir uma convergência. Se as coordenadas adimensionais $\xi_{1}^{s}, \xi_{2}^{s}$ ou $\xi_{3}^{s}=1-\xi_{1}^{s}-\xi_{2}^{s}$ convergirem para um valor negativo, isto quer dizer que o nó de elemento de barra para o qual estamos determinando suas coordenadas adimensionais está localizado fora do elemento de chapa escolhido. Deve-se então escolher outro elemento de chapa e repetir o procedimento até que as coordenadas adimensionais $\xi_{1}^{s}, \xi_{2}^{s}$ e $\xi_{3}^{s}$ resultem todas em valores positivos.

A fim de otimizar a localização dos nós dos elementos de barra e suas coordenadas adimensionais, somente os nós de elementos de barra que estivem dentro de um círculo circunscrito em cada elemento de chapa são candidatos a estarem dentro desse elemento de chapa. Isso evita realizar o procedimento de determinação das coordenadas adimensionais para nós de elementos de barra que claramente não podem estar contidos em determinados elementos de chapa. 


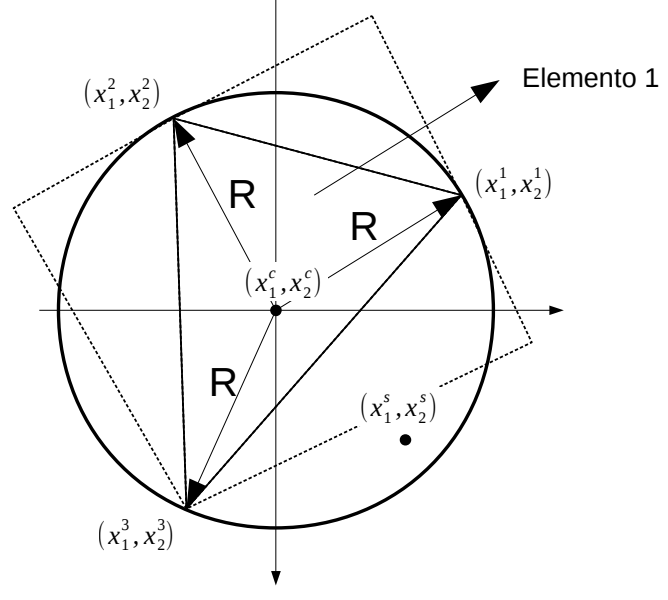

$\left(x_{1}^{2}, x_{2}^{2}\right)$

Figura 10 - Localização dos nós dos elementos finitos de barra simples

Por exemplo, na Figura 10 é impossível que o nó de elemento de barra z esteja contido no elemento de chapa 1. Embora o procedimento iterativo de determinação das coordenadas adimensionais $\xi_{1}^{s}$ e $\xi_{2}^{s}$ seja executado para o nó $s$ e resulte em valores negativos para $\xi_{1}^{s}, \xi_{2}^{s}$ ou $\xi_{3}^{s}=1-\xi_{1}^{s}-\xi_{2}^{s}$, a técnica reduz substancialmente o número de tentativas frustadas. A posição do centro da circunferência $\left(X_{1}^{c}, X_{2}^{c}\right)$ pode ser encontrada resolvendo-se o seguinte sistema não linear utilizando o método de Newton-Raphson:

$$
\begin{aligned}
& \left\{\begin{array}{l}
\left(X_{1}^{1}-X_{1}^{c}\right)^{2}+\left(X_{2}^{1}-X_{2}^{c}\right)^{2}=\left(X_{1}^{2}-X_{1}^{c}\right)^{2}+\left(X_{2}^{2}-X_{2}^{c}\right)^{2} \\
\left(X_{1}^{1}-X_{1}^{c}\right)^{2}+\left(X_{2}^{1}-X_{2}^{c}\right)^{2}=\left(X_{1}^{3}-X_{1}^{c}\right)^{2}+\left(X_{2}^{3}-X_{2}^{c}\right)^{2}
\end{array}\right. \\
R^{2}= & \left(X_{1}^{1}-X_{1}^{c}\right)^{2}+\left(X_{2}^{1}-X_{2}^{c}\right)^{2} \\
= & \left(X_{1}^{2}-X_{1}^{c}\right)^{2}+\left(X_{2}^{2}-X_{2}^{c}\right)^{2} \\
= & \left(X_{1}^{3}-X_{1}^{c}\right)^{2}+\left(X_{2}^{3}-X_{2}^{c}\right)^{2}
\end{aligned}
$$

Assim, devido a possibilidade dos nós de elemento de barra estarem próximos ou mesmo nos vértices dos elementos de chapa, se $\left(X_{1}^{s}-X_{1}^{c}\right)^{2}+\left(X_{2}^{s}-X_{2}^{c}\right)^{2} \leq a R^{2}$ então o nó $s$ de elemento de barra é um candidato a estar inserido no elemento de chapa 1 , onde $a \geq 1$ é uma constante de tolerância. Ainda, como todo o procedimento é numérico, existe também a possibilidade de obter valores ligeiramente negativos para $\xi_{1}^{s}, \xi_{2}^{s}$ ou $\xi_{3}^{s}=1-\xi_{1}^{s}-\xi_{2}^{s}$, pois algum nó de elemento de barra pode estar muito próximo de um lado do elemento triangular de chapa ou mesmo sobre ele. Portanto, os valores $\xi_{1}^{s}$, $\xi_{2}^{s}$ ou $\xi_{3}^{s}=1-\xi_{1}^{s}-\xi_{2}^{s}$ devem ser positivos dentro de uma certa tolerância ao invés de serem estritamente positivo.

\subsection{Leis constitutivas para Tecidos musculares}

Devido à complexidade microestrutural dos tecidos biológicos frequentemente as relações constitutivas utilizadas nesses casos são baseadas em descrições fenomenológicas 
utilizando a Teoria da Elasticidade (HUMPHREY, 2003). A caracterização e as propriedades dos tecidos duros (ossos e partes calcificadas) já estão relativamente bem definidas e determinadas se comparadas com as dos tecidos moles (músculos, tendões, órgãos e ligamentos). É por isso que, atualmente, a modelagem do corpo humano está mais focada na caracterização dos tecidos moles. Segundo Mukherjee et al. (2007) esses tecidos moles exibem características não lineares, heterogênicas, anisotrópicas. Além disso e devido à presença de bastante água em sua composição, os tecidos biológicos exibem tanto um comportamento de sólido quanto de fluído.

Assim, características viscoelásticas também são frequentemente observadas nesses materiais. Essas teorias viscoelásticas são desenvolvidas em duas linhas: modelos diferenciais (Maxwell e Voigt) ou integrais (Boltzman) (HUMPHREY, 2003). Os modelos hiperelásticos descrevem razoavelmente o comportamento muscular em nível macroscópio e podem, inclusive, ser combinados com modelos viscoelásticos a fim de representar melhor o comportamento em função de taxas (WEICHERT et al., 2010).

Os modelos hiperelásticos são os mais adequados para representarem o comportamento de tecidos musculares na sua condição relaxada (comportamento passivo), pois contemplam as relações não lineares entre tensões e deformações presentes nos tecidos musculares. Segundo Muggenthaler (2006) e conforme já proposto por Hill em 1938 (ver subseção 3.3.1), os modelos viscoelásticos são os mais adequados para a modelagem dos tecidos musculares quando ativos (comportamento ativo), isto porque os modelos viscoelásticos permitem expressar os fenômenos característicos de tecidos musculares de histerese, relaxamento, fluência e dependência da taxa de deformação.

Segundo Chagnon, Rebouah e Favier (2015), os tecidos biológicos são formados por células e uma matriz extracelular. A matriz extracelular é formada por fibras imersas em uma substância base. Logo, é natural pensar em dois caminhos distintos para a modelagem do tecido muscular. Uma primeira abordagem, que é a adotada neste trabalho, consiste em separar as fibras da matriz e considerar modelos hiperelásticos, viscoelástico ou hiperviscoelástico em separado e diferentes para a fibra e para a matriz, introduzindo a ativação muscular diretamente através de contrações impostas nas fibras (modelo discreto). Uma abordagem mais grosseira seria a de considerar um modelo hiperelástico, viscoelástico ou hiperviscoelástico para o tecido muscular como um todo com os parâmetros da respectiva lei constitutiva adota ajustados especificamente para cada nível de ativação muscular. Nessa segunda abordagem considerar-se-ia a ativação muscular de uma forma indireta (modelo homogêneo equivalente).

Embora as propriedades do tecido muscular possam também variar ponto a ponto (VANNAH; CHILDRESS, 1996), a maioria das modelagens do comportamento passivo dos tecidos musculares é feita através de modelos hiperelásticos homogêneos. Apesar dos parâmetros das leis constitutivas serem calibrados para vários níveis de ativação 
muscular, raramente os modelos consideram a imersão de fibras ou a ativação das mesmas. Geralmente a ativação muscular é considerada através de um aumento da rigidez das fibras e poucos modelos consideram a ativação muscular (MUGGENTHALER et al., 2008). Os efeitos viscoelásticos também são frequentemente negligenciados.

Em se tratando das leis constitutivas hiperelásticas aplicadas aos tecidos biológicos, muitos modelos utilizados para descrever o comportamento de tecidos biológicos advêm de modelos utilizados para a borracha, sendo a alteração da inclinação da curva tensão e deformação em médias deformações a principal característica dessas equações constitutivas. É por isso que muitas leis constitutivas incluem formas exponenciais (CHAGNON; REBOUAH; FAVIER, 2015). De fato, Fung (1973 apud HUMPHREY, 2003) e Fung (1967 apud HUMPHREY, 2003) demonstraram que as curvas obtidas com ensaios de tecidos biológicos indicam uma relação exponencial entre tensões e deformações. Entre 1967 e 1983 Fung refinou essa teoria exponencial e postulou a existência de uma energia de deformação exponencial escrita em função da deformação de Green-Lagrange, sugerindo uma relação exponencial entre essa medida de deformação e a $2^{\text {a }}$ tensão de Piola-Kirchhoff. Segundo Humphrey (2003), a utilidade das leis constitutivas baseadas em relações exponenciais têm sido demonstrada por anos através de dados experimentais.

De acordo com Chagnon, Rebouah e Favier (2015), a hiperelasticidade deve ser o ponto de partida em programas de modelagem e deve ser descrita da melhor forma possível antes de introduzir demais efeitos e, embora as equações constitutivas hiperelásticas frequentemente sejam expressas somente em função do $1^{\circ}$ invariante, o $2^{\circ}$ invariante também pode ser empregado para capturar diferentes condições de carregamento. Assim, apesar de existirem limitações quanto ao uso somente de $I_{1}$, a utilização de $I_{1}$ e $I_{2}$ depende dos dados experimentais disponíveis para calibração. Em regime de pequenas deformações todas as equações constitutivas se reduzem ao modelo neo-hookeano. (CHAGNON; REBOUAH; FAVIER, 2015)

Funções hiperelásticas puramente isotrópicas são, no entanto, em muitos casos demasiadamente simplificadas, uma vez que os tecidos biológicos possuem uma estrutura formada por fibras, as quais devem ser levadas em conta de acordo as com direções privilegiadas que correspondem à orientação física dessas fibras (CHAGNON; REBOUAH; FAVIER, 2015). Assim, o comportamento muscular pode ser mais ou menos isotrópico, dependendo da quantidade e orientação das fibras musculares. Essa anisotropia pode ser levada em conta de diferentes formas conforme verifica-se em Chagnon, Rebouah e Favier (2015).

Modelos anisotrópicos hiperelásticos baseados na deformação de Green-Lagrange podem ser propostos. Nesses modelos, a densidade de energia específica de deformação é decomposta em contribuições de cada componente do tensor de deformações de GreenLagrange com diferentes pesos, permitindo inclusive a formulação de leis constitutivas em 
coordenadas cilíndricas. A principal desvantagem desse tipo de modelo é possuir muitas constantes de material a serem calibradas.

Uma segunda abordagem para o caso de anisotropia é somar parcelas adicionais de energia no modelo isotrópico. Essas parcelas de energia adicionais referentes ao comportamento anisotrópico são escritas em função de novos invariantes recém definidos de acordo com as direções que possuem comportamento diferente do modelo isotrópico. O enrijecimento, que é umas das propriedades chaves das leis constitutivas para tecidos biológicos pode ser facilmente obtido a partir de funções exponenciais desses novos invariantes.

Alguns modelos também consideram parcelas de energia que levam em conta a interação entre as fibras e a matriz e entre fibras com diferentes direções. Existem ainda modelos hiperelásticos estatísticos, onde vetores orientados nas direções das fibras são distribuídos de acordo com uma função distribuição. Assim, uma função distribuição constante significa que a "densidade" das fibras é igual em todas as direções e, portanto, o modelo é isotrópico.

Ao invés de considerar as fibras musculares através da modificação das funções de densidade de energia hiperelásticas, neste trabalho as fibras serão imersas de forma "direta e discreta", sem aumento do número de graus de liberdade ou necessidade de coincidência dos nós das fibras com os nós da matriz por meio da técnica proposta por (VANALLI, 2004) e apresentada Sampaio (2014). Essa técnica evita a criação de novas leis constituivas hiperelásticas, uma vez que permite variar a orientação, distribuição e quantidade de fibras sem alteração das leis constitutivas já existentes e utilizadas. O método de imersão proposto possibilita considerar a contração das fibras de forma direta e imediata, além de permitir também considerar comportamentos (elástico, não linear, viscoelástico, plástico, dano...) completamente distintos para a fibra e a matriz.

Assim como em outras áreas da engenharia e segundo Moerman et al. (2009), os ensaios experimentais utilizados na caracterização de tecidos biológicos podem utilizar tanto técnicas invasivas ou destrutivas (conforme Bosboom et al. (2001) e Calvo et al. (2010)) quanto técnicas não invasivas ou não destrutivas (conforme Muggenthaler et al. (2008) e Vannah e Childress (1996)).

Usualmente, os ensaio não destrutivos utilizam endentadores que medem, por exemplo, grandezas tais como deslocamento, aceleração ou força. Os testes usuais de tração, compressão e flexão são alguns dos ensaios destrutivos também utilizados na caracterização de materiais biológicos. Os ensaios destrutivos têm a vantagem de serem mais "bem controlados", enquanto que os ensaios não destrutivos, além de permitirem a obtenção de parâmetros in vivo (post-mortem os tecidos e suas propriedades sofrem alterações), também são capazes, de certa forma, de contemplar as interações entre elementos adjacentes (como por exemplo no caso dos músculos: tendões, o tecido conjuntivo que envolve os músculos, bem como grupos musculares adjacentes). 
Devido à complexidade das equações constitutivas utilizadas, em geral, a determinação das propriedades do material é feita de maneira indireta, numérica e iterativa. Isto é feito repetindo-se o ensaio real em várias simulações numéricas com diferentes parâmetros para as leis constitutivas até que determinadas grandezas na simulação numérica convirjam para os valores dessas grandezas observadas no experimento real. É comum, também, a realização do mesmo experimento real utilizando-se um material com propriedades bem definidas e conhecidas para, em seguida, validar o modelo numérico adotado através da verificação da capacidade do modelo numérico em prever as propriedades do material conhecido.

Conforme destacado por Fung (1973 apud HUMPHREY, 2003) e também por outros autores (TANG; ZHANG; TSUI, 2009), o grande desafio da biomecânica é desenvolver modelos reológicos gerais capazes de representar o comportamento multiaxial dos tecidos biológicos, já que os modelos baseados em de Hill (1938) e Huxley (1957) são modelos unidimensionais. Segundo Humphrey (2003), as relações constitutivas atuais ainda são deficientes em descrever o comportamento mecânico muscular multiaxial.

\subsubsection{Modelo de Hill}

Os modelos baseados nas observações de Huxley (1957) são fisiológicos e levam, portanto, em conta processos que ocorrem em nível molecular durante o ciclo de pontes cruzadas da contração muscular. Já os modelos fenomenológicos baseiam-se em relações acerca da energia durante a contração nas observações feitas por Hill (1938) em experimentos com músculos de sapos. Ao estabelecer uma relação de equilíbrio de forma a manter o princípio da conservação de energia, Hill (1938) obteve uma relação entre a velocidade de contração v e a tensão muscular P (MUGGENTHALER, 2006):

$$
(a+P)(v+b)=b\left(P_{0}+a\right)
$$

onde a e b são constantes e $P_{0}$ é a tensão sob força isométrica máxima. Observe que, na Equação 3.167, não existe uma dependência entre a força muscular e o comprimento da fibra muscular. Baseado em experimentos com fibras isoladas, Gordon, Huxley e Julian (1966) estabeleceram uma relação entre o comprimento da fibra muscular e tensão resultante. Isto ocorre porque a tensão muscular ativa depende do número de pontes cruzadas que se formam durante a contração muscular, as quais por sua vez, dependem do comprimento atual da fibra. Um maior número de pontes cruzadas e, por consequência uma máxima tensão isométrica $P_{0}$, é alcançada com o músculo no seu comprimento ótimo. Com a contração muscular, tem-se uma redução no número máximo possível de pontes cruzadas, havendo então uma redução na máxima força isométrica possível $P_{0}$. (MUGGENTHALER, 2006) 
A Figura 11 ilustra a dependência entre o comprimento e a tensão muscular, bem como a dependência entre a velocidade de contração e a força muscular. Se o músculo também sofrer um alongamento, deve-se então também considerar uma parcela passiva adicional de tensão. (MUGGENTHALER, 2006)
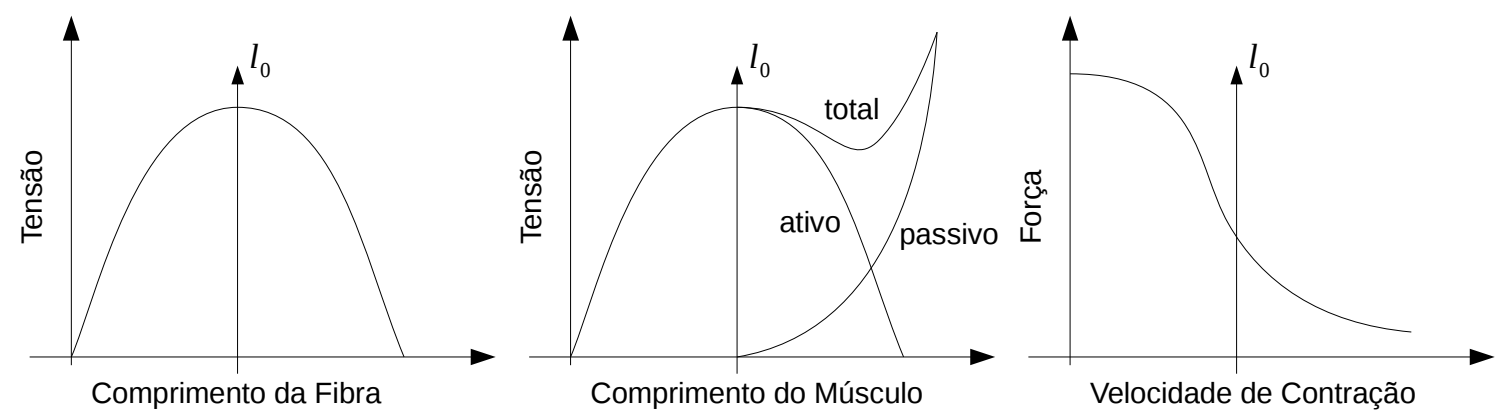

Figura 11 - Propriedades musculares

Fonte: adaptado de Muggenthaler (2006)

Um modelo muscular clássico baseado em Hill (1938) conta com três componentes e está ilustrada na Figura 12. O esquema consiste de um elemento de contração EC, um elemento elástico em paralelo EP e um elemento elástico em série ES. O elemento de contração EC representa a componente ativa e geradora de força muscular da fibra muscular com suas estruturas moleculares de contração e dependência da velocidade de contração e comprimento da fibra. O comportamento passivo do tecido de ligação que envolve a fibra é representado através do elemento elástico em paralelo. A transmissão de força dos músculos, órgãos e ossos acontece através do elemento em série ES e pode ser atribuída aos tendões. (MUGGENTHALER, 2006)

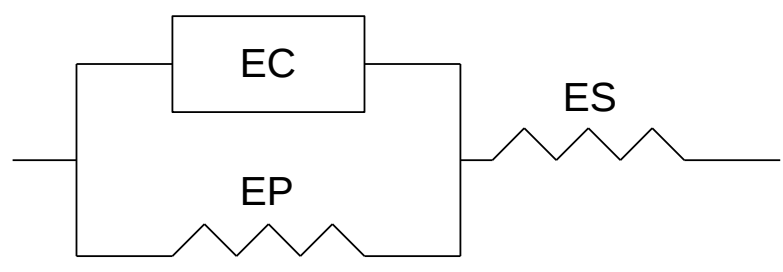

Figura 12 - Modelo de Hill

Fonte: adaptado de Muggenthaler (2006)

Para o modelo da Figura 12, a força transmitida através do tendão é igual a soma da força gerada pelo elemento de contração EC com a força passiva provocada pelo elemento elástico em paralelo EP (MUGGENTHALER, 2006):

$$
F_{E S}=F_{E C}+F_{E P}
$$


Para os elementos elásticos em paralelo EP e em série ES valem relações visco hiperelásticas. Também é possível representar a contração (elemento EC) através de uma função dependente da atividade muscular q, comprimento do músculo l e da velocidade de contração v. Uma expressão matemática da força muscular frequentemente utilizada é uma relação multiplicativa conforme Equação 3.169, onde cada dependência entra como um fator no cálculo da força muscular (MUGGENTHALER, 2006):

$$
F_{E C}=q f_{l} f_{v} F_{\max }
$$

Em medições experimentais observa-se a máxima força isométrica possível $F_{\max }$ sob condições de comprimento ótimo do músculo $l_{\text {opt }}$, velocidade de contração de $v=0$ e máxima atividade muscular $q=1$. Portanto, para $l=l_{\text {opt }}$ e $v=0$ têm-se respectivamente $f_{l}=1$ e $f_{v}=1$.

Conforme ilustrado na Figura 13, Fung (1993 apud MUGGENTHALER, 2006) introduziu um mecanismo adicional de armazenamento de energia no modelo de Hill através de um elemento elástico em série (ES2) com o elemento de contração (EC). Segundo Martins et al. (1998), esse é o elemento que permite o músculo passar rapidamente do estado inativo para o estado ativo.

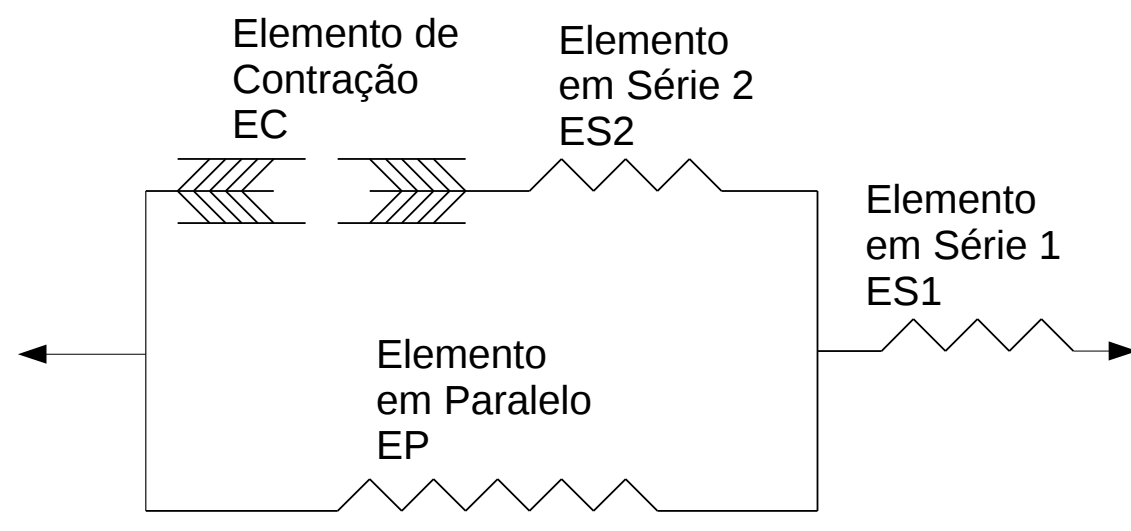

Figura 13 - Modelo de Hill (1938) modificado

onde na anterior têm-se que:

- Elemento de Contração (EC) representa o comportamento muscular ativo. É livremente extensível quando inativo, porém capaz de se contrair quando ativado (MARTINS et al., 1998).

- Elemento em Série (ES1) representa o tecido de acoplamento entre os músculos e os ossos e pode ser atribuido aos tendões.

- Elemento em Série (ES2) representa a chamada elasticidade intrínseca relacionada com as propriedades mecânicas das moléculas de miosina, actina e com o mecanismo das 
pontes cruzadas (MUGGENTHALER, 2006). Esse é o elemento que permite a contração da fibra.

- Elemento em Paralelo (EP) representa o comportamento muscular passivo, mesmo quando o elemento de contração está desativado. (MARTINS et al., 1998)

O modelo unidimensional de Hill (1938) é um modelo contínuo (unidimensional) que não separa as fibras (elemento de contração EC com comportamento ativo) da matriz (elemento em paralelo EP com comportamento passivo). No entanto, a abordagem proposta neste trabalho, e que será detalhada adiante, é discreta e consiste em separar o comportamento ativo do comportamento passivo, isto é, separar as fibras da matriz.

\subsubsection{Comportamento muscular passivo}

A modelagem do comportamento muscular passivo (elementos EP, ES1 e ES2 no modelo de Hill (1938)) consiste em encontrar a relação não linear existente entre tensão e deformação através de modelos constitutivos hiperelásticos e/ou viscoelásticos. No entanto, diferente do que ocorre na lei de Hooke, a hiperelasticidade não relaciona a tensão e a deformação de uma maneira explicita. Ao invés disso, utiliza a Mecânica do Contínuo para redefinir os conceitos de tensão e deformação usuais e concluir a existência de uma grandeza fundamental chamada energia específica de deformação, a qual engloba em uma única grandeza tanto a tensão como a deformação.

Assim e, conforme já mencionado anteriormente, a hiperelasticidade consiste em escrever o escalar energia específica de deformação em função do campo de tensões ou deformações e a partir daí, então, derivar relações entre esses dois campos. Essa energia específica é geralmente escrita em função dos invariantes de deformação, facilitando assim o seu cálculo uma vez que os invariantes independem da orientação dos planos de corte no ponto.

Sendo a energia específica de deformação no ponto escrita em função das deformações é possível demonstrar que sua primeira derivada com relação ao tensor de deformações de Green é o $2^{\circ}$ tensor de tensões de Piola-Kirchhoff e, finalmente, através da Álgebra Tensorial é possível relacionar as tensões de Piola-Kirchhoff e as deformações de Green com as tensões e deformações usuais de engenharia.

Segundo Johansson, Meier e Blickhan (2000), a descrição Lagrangiana do comportamento passivo dos tecidos biológicos frequentemente adota uma expressão exponencial para a parcela de energia de deformação a volume constante ( $u_{\text {iso }}$ na Equação 3.61 ).

Além do fato dos tecidos musculares serem essencialmente incompressíveis (provavelmente devido a presença de bastante água em sua composição (HUMPHREY, 2003)), pouco se conhece acerca de seu comportamento tridimensional e suas leis constitutivas (MARTINS et al., 1998). 


\subsubsection{Comportamento muscular ativo}

O comportamento muscular ativo (Elemento EC no modelo de Hill (1938)) pode ser atribuído às fibras, as quais podem ser representadas por um modelo unidimensional proposto na Figura 14:

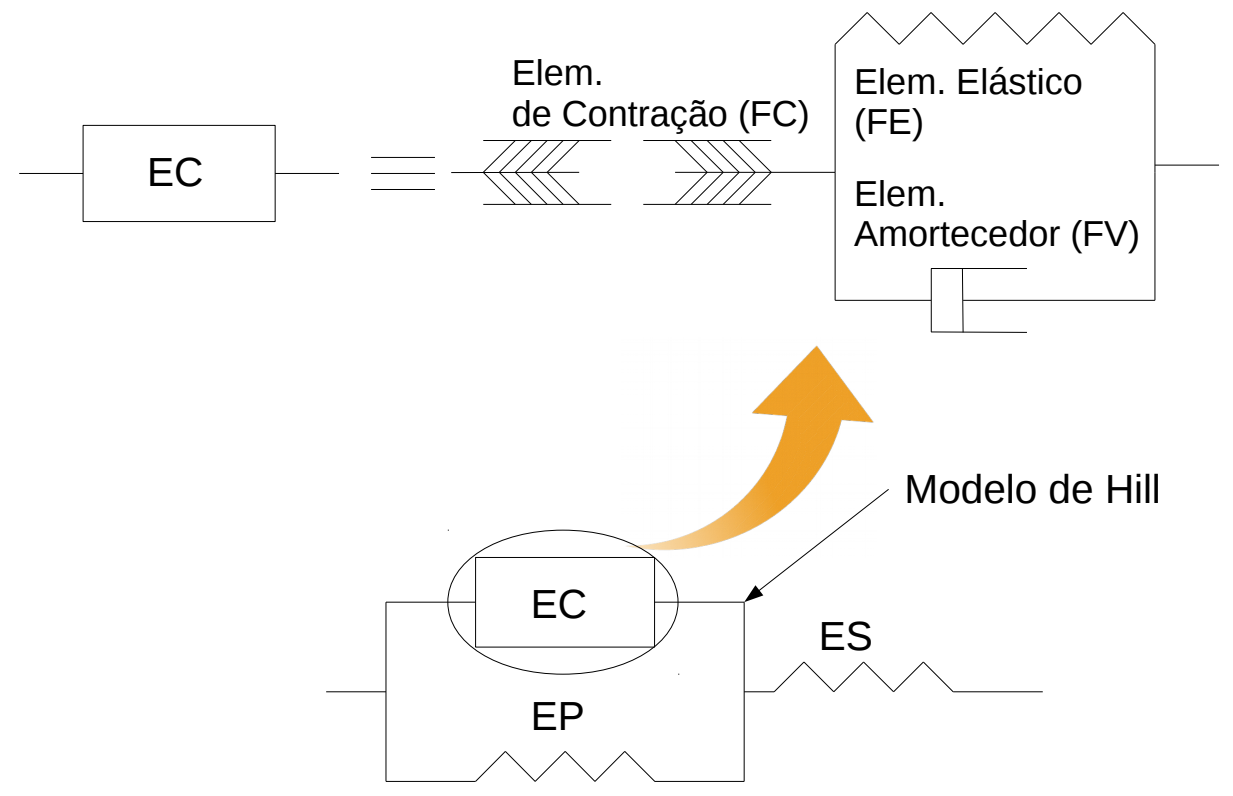

Figura 14 - Modelo para a fibra muscular

No modelo da Figura 14 tem-se:

- Elemento de Contração (FC) representa o comportamento ativo da fibra. É livremente extensível quando inativo, porém capaz de se contrair quando ativado.

- Elemento Elástico (FE) permite a contração da fibra muscular. Esse é um elemento de comportamento passivo e que deverá ser modelado através de modelos constitutivos hiperelásticos.

- Elemento de Amortecedor (FV) é um amortecedor que foi adicionado ao modelo com o intuito de introduzir um comportamento viscoso na modelagem do tecido muscular.

O comportamento ativo do elemento de contração EC pode ser escrito de forma explícita através de uma função de ativação e por meio de uma composição de funções (ver Equação 3.169).

Segundo Mukherjee et al. (2007), a força muscular depende principalmente do nível de atividade muscular, comprimento da fibra, velocidade de ativação da fibra (ver Equação 3.169), bem como do arranjo e da distribuição das fibras (fusiforme, unipenado, bipenado e multipenado). Esses fatores, no entanto, não serão levados em conta no presente trabalho. 


\subsubsection{Modelagem final tecido muscular}

A modelagem final do tecido muscular adota o seguinte modelo baseado no modelo de Hill (1938), conforme ilustrado na Figura 15:

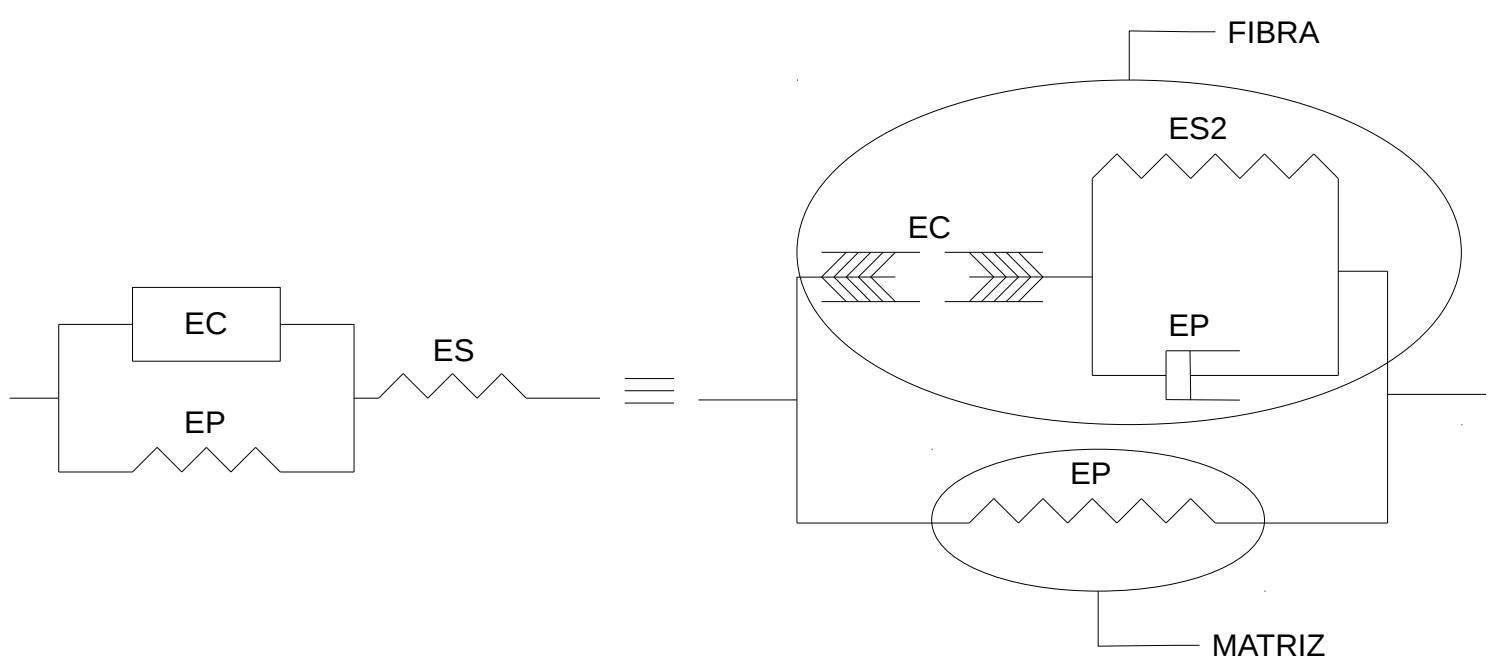

Figura 15 - Modelo para o tecido muscular

Note que, no modelo proposto, o acoplamento entre a fibra e a matriz é do tipo rígido. Além disso, o acoplamento entre os grupos musculares e os ossos também será rígido, uma vez que o elemento em série ES atribuído aos tendões foi omitido.

\subsection{Programação paralela}

As principais referências consultas sobre programação paralela e que serviram de base para a paralelização de algumas rotinas do programa desenvolvido foram as video aulas ministradas por Leveque (2015) e Mattson (2015), o site oficial da linguagem OpenMP mantido pela The Architecture Review Board - ARB (2015), além do livro Using OpenMP: portable shared memory programming escrito por Chapman, Jost e Pas (2008).

A velocidade de um processador é medida em $\mathrm{GHz}\left(10^{9}\right.$ ciclos por segundo). Cada operação aritmética, acesso a ou movimento de dados armazenados nas diferentes memórias (registro, cache, RAM...) são executadas pelo processador e consomem um determinado número de ciclos disponíveis.

A velocidade com que o processador consegue acessar os dados armazenados nas memórias em ordem decrescente (e portanto em ordem crescente de ciclos consumidos) é: registro (1 ciclo), cache ( $\sim 10$ ciclos $), \operatorname{RAM}(\sim 250$ ciclos $)$ e disco rígido $(\sim 1000$ ciclos $)$.

$\mathrm{A}(\mathrm{s})$ estrutura(s) de organização da memória bem como as estratégias de gerenciamento da(s) mesma(s) é parte da chamada arquitetura da máquina e varia conforme a 
escolha de cada fabricante em cada máquina.

Assim, dependendo da arquitetura escolhida pelo fabricante, um computador pode ter diferentes tipos de memória, sendo ainda algumas compartilhadas entre os processadores e outras não (múltiplas caches por exemplo). É comum dizer que quanto mais rápida determinada memória, mais "próxima" ela está do processador. As memórias mais próximas aos processadores tendem a não ser compartilhadas e, por serem mais caras, também tendem a ser menores. A memória de registro é a única em contato direto com o processador

É importante mencionar que, devido a uma estratégia de gerenciamento de memória utilizada em praticamente todos os computadores, os processadores não trazem dados individualmente em cache, mas sim em pacotes e, por isso, a utilização dos dados trazidos pelo processador deve ser otimizada.

Isto é, uma vez que um determinado dado esteja em cache, deve-se fazer o maior número possível de operações com ele antes que o processador remova esses dados para dar lugar a novos dados. Assim, evita-se o consumo ciclos para trazer em cache novamente um mesmo dado que já esteve em algum momento anterior em cache.

Na prática isso significa que, por exemplo, duas operações dentro de um mesmo looping serão sempre mais rápidas que dois loopings com uma operação em separado cada um (desde que os dados referentes a essas operações já estejam em cache conforme mencionado anteriormente) e que, em Fortran, os loopings envolvendo matrizes devem sempre que possível serem feitos percorrendo-se primeiramente as colunas dessas matrizes, pois em Fortran matrizes são na verdade armazenadas como uma sequência de dados percorrendo-se as colunas. Logo, vários elementos de uma mesma coluna de uma matriz são trazidos à memória cache de uma vez. No caso mais extremo, e dependendo do tamanho da memória cache, percorrer uma matriz por colunas pode significar um ganho de velocidade de mais de 10 vezes.

Por isso, o comportamento dos diferente tipos de memória (cache, registro e RAM) são cruciais na performance de programas computacionais e, portanto, conhecer a estrutura de organização e a forma de gerenciamento dos dados na memória é indispensável em computação de alta performance.

A programação em paralelo consiste em dividir um programa em threads. Um thread é uma tarefa ou sequência de instruções de um programa que pode ser manipulado individualmente do restante das instruções do programa principal. Por exemplo, o seguinte looping:

1 do $i=1,30$

3 end do

pode ser dividido em 3 threads: 


$\begin{array}{lll}1 \text { do } i=1,10 & 1 \text { do } i=11,20 & 1 \text { do } i=21,30 \\ 2 \quad x(i)=i & 2 \quad x(i)=i & 2 \quad x(i)=i \\ 3 \text { end do } & 3 \text { end do } & 3 \text { end do }\end{array}$

Na paralelização com memória compartilhada (bliblioteca OpenMP), os vários threads armazenam e acessam dados e instruções em uma mesma porção de memória. Dessa forma, um thread tem acesso livre e direto aos dados e as instruções dos demais threads, podendo inclusive modificá-los sem que o outro thread saiba.

Na paralelização com memória distribuída (OpenMPI), cada thread tem a sua própria porção de memória. Nesse caso, o thread passa a se chamar processo. Caso um processo necessite conhecer os dados ou instruções de outro processo, é necessário que eles troquem informações entre si.

Logo, a paralelização com memória compartilhada permite somente aumentar a velocidade de processamento, enquanto que a paralelização com memória distribuída permite tanto um aumento de velocidade como um aumento do tamanho do problema armazenado. Finalmente, conclui-se que a paralelização com memória compartilhada (OpenMP) é mais adequada para máquinas multicores, como por exemplo um laptop pessoal, enquanto que a técnica de memória distribuída é mais adequada para clusters.

Muito provavelmente os threads/processos nunca poderão ser executados todos de uma vez, pois fatalmente um thread/processo terá que esperar por informações atualizadas que estão sendo geradas em algum outro thread/processo antes de poder executar suas próprias instruções. Além disso, como os threads são de forma aleatória várias vezes colocados em espera (criados) e reativados (destruídos) pelos processadores de modo que o computador possa rodar varios programas com vários threads cada um, não é possível ter controle nem do momento exato nem da ordem de execução das tarefas pelos threads. Inclusive não se tem nem a garantia de que um thread depois de reativado será executado no mesmo processador que estava sendo executado antes de ser desativado ou colocado em espera. Programas cujos resultados dependem de qual thread chegue a determinado ponto primeiro ou da ordem de execução das tarefas pelos threads são ditos programas com race condition. Esses programas produzem resultados aleatórios e, portanto, não são confiáveis.

Outro aspecto muito importante é que, mesmo em memória compartilhada, um determinado thread não tem conhecimento imediato de atualizações nos dados realizadas por algum outro thread (é claro que se um thread prosseguir com algum valor desatualizado o resultado não será o esperado). Isso acontece porque, dependendo da arquitetura utilizada, podem existir algumas memórias que de fato não são realmente compartilhadas (o mecanismo de cache coherence explicado adiante garante que elas operem como se fossem compartilhadas entre os processadores). Assim, uma sincronização tanto de dados entre os threads bem como da ordem e do momento de execução das tarefas pelos threads 
deve sempre estar presente.

Nas bibliotecas OpenMP e OpenMPI existem comandos específicos que permitem acertar o sincronismo de dados e threads a fim de eliminar race conditions. O termo race condition é no sentido de que os threads "correm" para finalizar suas tarefas, mesmo que isso signifique, por exemplo, "atrapalhar" outro thread modificando variáveis que este outro thread esteja utilizando.

Em memória compartilhada (OpenMP), as race conditions introduzem uma dificuldade adicional que é a de garantir que dois threads não estejam tentando modificar o mesmo endereço de memória ao mesmo tempo, ou então que um thread não modifique dados que estão sendo utilizado por outro thread. Infelizmento dois threads modificando um mesmo endereço de memória produzem um resultado aleatório ao invés de um erro.

Tipicamente somente algumas partes dos algoritmos podem ser paralelizadas, pois frequentemente existe uma ordem pré-definida ou momento correto de execução de algumas tarefas ou blocos de tarefas. Por exemplo, loopings nos quais os cálculos em uma determinada iteração dependam de valores calculados em iterações anteriores desse mesmo looping não podem ser paralelizados simplesmente executando várias iterações desse looping simultaneamente como no exemplo anteriormente utilizado para explicar o que é um thread. Esse é o caso, por exemplo, dos problemas dinâmicos resolvidos pelos métodos de integração direta onde não é possível calcular todos os passos de tempo simultaneamente, pois, nesse caso, um passo de tempo seguinte depende de um passo anterior. Dessa forma os programas, exceto os muitos simples, não podem ser paralelizados indefinidamente.

Para ilustrar, considere um algoritmo onde X \% do processamento deve ser necessariamente executado de forma sequencial. Neste caso, o ganho máximo teórico de velocidade, que é de 100 / X, é obtido utilizando infinitos processadores de modo a reduzir o tempo da parcela (100 - X) \% paralelizável a zero. Essa importante constatação de que não é possível ganhar indefinidamente tempo de processamento, pois sempre existem algumas partes do algoritmo que devem ser executadas de forma sequencial, é conhecido como lei de Amdahl's. Uma simples operação de leitura de dados a partir de um único arquivo já é uma operação não paralelizável e que só pode ser executada exclusivamente por um único thread.

Existem basicamente duas abordagens de paralelização: a paralelização fina e a paralelização grossa. A paralelização fina consiste em paralelizar localmente algumas partes como alguns loopings, ou então determinadas tarefas. Nessa abordagem, o programa é em geral executado pelo thread mestre, o qual aloca outros threads em regiões que devem ser executadas em paralelo e que foram especificadas pelo programador. Ao final dessas regiões, o thread mestre destroi os outros e continua a executar o programa. Como criar (ativar) e destruir (desativar) threads consome tempo, uma vez que um thread foi alocado, 
ele deve ser utilizado ao máximo antes de ser destruido ou mesmo colocado em espera ou desativado.

Por outro lado, o extremo da paralelização grossa é criar vários threads logo no início do programa e fazê-los todos percorrerem todas as partes do programa com as devidas sincronias nos pontos críticos. A biblioteca OpenMPI é mais adequada para as paralelizações mais grosseiras. Por outro lado, a biblioteca OpenMP é mais adequada para paralelizações mais refinadas, não estando no entanto limitada somente a esse tipo de abordagem conforme demonstrado em Chapman, Jost e Pas (2008).

As possíveis estratégias de paralelização são duas: single programm multiple data (SPMD) ou paralelização de dados e task parallelism ou paralelização de tarefas (CHAPMAN; JOST; PAS, 2008). Na paralelização de dados, os vários threads/processos executam essencialmente a mesma tarefa em diferentes conjuntos de dados. Essa estratégia é especialmente interessante no processamento de um grande volume de informação, de tal forma que um conjunto maior de dados é divido entre os threads/processos de acordo com o número de identificação atribuído a cada thread/processo no momento de sua criação. A paralelização de dados pode ser utilizada, por exemplo, para o cálculo das matrizes de rigidez locais dos elementos de uma malha em elementos finitos.

A paralelização de tarefas, que é de difícil implementação, consiste em dividir uma tarefa maior em múltiplas tarefas menores, independentes e sincronizadas. Um programa que lê um arquivo de dados, processa esses dados e depois escreve o resultado em um outro arquivo poderia ser paralelizado em tarefas da seguinte forma: um thread lê dados em blocos ao mesmo tempo em que outros threads processam blocos de dados já lidos enquanto um outro thread escreve os blocos já processados. Na paralelização de tarefas deve-se procurar balancear as tarefas entre os threads, de modo que um determinado thread não tenha muito mais trabalho que os demais, caso contrário alguns threads irão perder muito tempo esperando informações ou mesmo outros threads em determinados pontos de sincronia. No exemplo anterior tem-se os threads que processam as informações em espera, caso terminem suas tarefas muito antes que o outro thread tenha finalizado a leitura de um novo bloco. Nesse cenário, o programa estaria funcionando praticamente como se fosse sequencial.

A paralelização em memória compartilhada esta sujeita a ocorrência de um fenômeno denominado false sharing, o qual pode reduzir drasticamente a performance de programas que utilizam a biblioteca OpenMP. Esse fenômeno acontece devido a duas estratégias de gerenciamento de memória utilizadas: a de trazer dados em cache por pacote e a um mecanismo denominado cache coherence. O mecanismo de cache coherence é responsável por garantir a consistência dos dados em memórias não compartilhadas chamadas de memórias locais dos processadores (memórias cache não compartilhadas em uma máquina com múltiplos núcleos por exemplo). 
O ponto chave é que o mecanismo de cache coherence também trabalha em blocos de dados, podendo acontecer da seguinte maneira: ao tentar utilizar um dado (3) contido em um bloco de dados $(1-10)$ em sua cache local, um determinado processador pode ser informado pelo mecanismo de cache coherence que esse bloco de dados $(1-10)$ não esta mais consistente com uma outra cópia desse bloco em uma outra cache local, pois algum dado (7) foi alterado pelo seu respectivo processador. Dessa forma, embora não exista inconsistência de dados propriamente dita, todo o bloco $(1-10)$ é atualizado.

Esse efeito pode ser especialmente severo em matrizes quando diferentes threads modificam dados em diferentes posições, mas que estão dentro do mesmo bloco armazenado nas caches locais (MATTSON, 2015). Por outro lado e desde que não ocorra o false sharing, um programa em paralelo utiliza as caches locais que normalmente não seriam utilizadas na versão sequencial. Ao tirar vantagem da velocidade com que os dados são acessados nas caches locais, a versão paralela pode experimentar um ganho de velocidade maior que o previsto conhecido como superlinear speedup, dependendo do volume de dados processados e do tamanho dessas caches locais (CHAPMAN; JOST; PAS, 2008).

\subsubsection{OpenMP}

A biblioteca OpenMP surgiu por meio de um esforço conjunto de diferentes fabricantes de hardware com o intuito de estabelecer uma notação comum para a paralelização em máquinas de memória compartilhada e múltiplos processadores. Atualmente o OpenMP é mantido pela The Architecture Review Board - ARB (2015), uma organização sem fins lucrativos onde participam os principais fornecedores de hardware interessados em desenvolver produtos para o OpenMP.

O OpenMP consiste de um conjunto de diretivas (as quais podem ser modificadas por meio de cláusulas), rotinas e variáveis de ambiente utilizadas para especificar paralelismo de alto nivel em Fortran e C/C++ (THE ARCHITECTURE REVIEW BOARD - ARB, 2015). As instruções OpenMP são interpretadas pelos compiladores e traduzidas em uma linguagem de paralelização de mais baixo nível. O OpenMP define pontos de sincronia implícitos (de dados e threads), além de também manejar a criação/destruição de threads e gerenciar a memória dos threads de forma consistente e automática.

Conforme lembrado por Chapman, Jost e Pas (2008), uma das principais vantagens da biblioteca OpenMP é a possibilidade de escrever tanto a versão paralela quanto a versão sequencial do programa em um mesmo código, preservando dessa forma a versão sequencial do código. Assim e em geral, a paralelização de um programa utilizando o OpenMP se concentra em identificar o paralelismo e não em reprogramar o código de maneira a implementar o paralelismo. Além disso, uma outra grande vantagem é que, devido ao seu impacto "localizado", o OpenMP pode ser aplicado incrementalmente na paralelização de programas a partir de códigos sequenciais. 
Em clusters, as bibliotecas MPI/OpenMP podem ser mescladas eficientemente em um mesmo código e dar origem a programas híbridos através da utilização do MPI em paralelizações grosseiras entre os nós e o OpenMP em paralelizações adicionais mais refinadas dentro desses nós (espaços com memória compartilhada), explorando assim dois níveis de paralelização ao mesmo tempo. Nesse caso e a fim de reduzir o tempo de acesso a memória, os threads (OpenMP) sempre devem ser executados dentro do mesmo nó do processo (MPI) que os criou. (CHAPMAN; JOST; PAS, 2008)

No programa desenvolvido neste trabalho foram paralelizadas 5 tarefas: o cálculo do vetor de forças internas local dos elementos de chapa da matriz, o cálculo da hessiana local dos elementos de chapa da matriz, o procedimento para encontrar o elemento de chapa no qual se encontra inserido cada nó de elemento de fibra, o cálculo da matriz hessiana local dos elementos de fibra e a solução dos sistemas lineares resultantes através do solver hsl_ma86 disponível em STFC Rutherford Appleton Laboratory (2015a).

Depois de sua implementação dentro do programa desenvolvido, o solver hsl_ma86 reduziu o tempo de processamento de alguns problemas em mais de 100 vezes quando comparado com outros solvers mais antigos e/ou menos elaborados que estavam sendo anteriormente utilizados. Assim, pode-se dizer que a implementação de um solver eficiente e adequado ao tipo de problema bem como a diretriz que permite ao compilador otimizar o código (-O3 em gfortran) foram importantes para este trabalho, uma vez que permitiram reduzir o tempo de execução do programa ainda durante a fase de desenvolvimento do programa.

Depois que as hessianas locais de todos os elementos estavam todas calculadas, não se observou nenhum ganho expressivo em paralelizar o simples procedimento de montagem da matriz hessiana global a partir das hessianas locais utilizando a linguagem OpenMP (pelo menos para o tamanho de alguns problemas analisados). Frequentemente também se observam grandes ganhos relativos (em \%) e baixos ganhos absolutos (em segundos).

Um exemplo disso foi o cálculo das matrizes hessianas locais dos elementos de fibra na seção 4.4. Nesse caso e conforme a Tabela 1, a soma dos tempos de cálculo em todas as 8 iterações da versão sequencial foi de 1,5540 s contra 0,8850 s da versão paralela com 4 threads. Apesar da versão paralela corresponder a uma redução de mais de $40 \%$ do tempo, no fim não faria nenhuma diferença em executar essa tarefa em 0,1 ou mesmo $2 \mathrm{~s}$ (soma do tempo em todas as iterações). Isso, no entanto, pode vir a ser significativo em problemas com um grande número de passos de tempo ou de carga, mesmo em problemas com malhas pouco refinadas, como é o caso do problema da Tabela 1, onde foram utilizados 200 elementos de chapa e 2550 elementos de barra simples. 



\section{EXEMPLOS NUMÉRICOS}

Nesse capítulo são apresentados 5 exemplos, sendo 4 com objetivo de verificar as formulações propostas e um para demonstrar a aplicabilidade dessas formulações na modelagem de tecidos musculares.

O primeiro exemplo trata-se da validação da implementação de modelos constitutivos hiperelásticos no elemento de chapa. O segundo exemplo é uma validação da formulação do elemento finito de barra simples que utiliza a chamada medida de deformação não linear de engenharia e considera comportamento viscoelástico e capacidade de ativação (contrações) desses elementos de barra simples. O terceiro exemplo é uma verificação da estratégia de imersão dos elementos finitos de barra simples nos elementos de chapa conforme proposto por Vanalli (2004) e apresentado por Sampaio, Paccola e Coda (2013) e Sampaio (2014). O quarto exemplo ilustra o funcionamento do modelo de contração das fibras quando imersas na matriz formada por elementos finitos de chapa. O quinto exemplo, além de fazer uma comparação com o exemplo proposto por Baiocco, Coda e Paccola (2013), ilustra algumas das vantagens da formulação adotada na presente pesquisa para representação de tecidos musculares quando comparada aos resultados obtidos no trabalho dos referidos autores.

Nos exemplos a seguir todas as grandezas foram consideradas adimensionais (sem unidade). Assim, a unidade dos resultados é de acordo com a unidade dos parâmetros de entrada. Por exemplo, se o módulo de elasticidade for $\mathrm{N} / \mathrm{mm}^{2}$, as áreas deverão estar em $m m^{2}$, os comprimentos em $m m$, bem como as forças em $N$ e, portanto, o deslocamento final obtido será em $m m$, as forças em $N$ e as tensões em $M P a$. Se todas as unidades de entrada estiverem no $S I$, todas as respostas obtidas também estarão no SI. 


\subsection{Chapa com Modelo constitutivo hiperelástico}

Este exemplo consiste na validação da implementação de um modelo constitutivo hiperelástico no código de elementos finitos posicional plano descrito na subseção 3.2.3. O modelo constitutivo escolhido foi o de Yeoh na forma $u_{e}\left(\bar{I}_{1}, J\right)=c_{10}\left(\bar{I}_{1}-3\right)+c_{20}\left(\bar{I}_{1}-\right.$ $3)^{2}+c_{30}\left(\bar{I}_{1}-3\right)^{3}+k\left(J^{2}+J^{-2}-2\right)$.

Neste exemplo, as condições de contorno impostas reduziram um estado plano de deformações a um estado unidimensional de deformações, o que permitiu obter uma solução analítica e compará-la com a resposta obtida com o programa desenvolvido. Além disso, verifica-se neste exemplo também a possibilidade de introduzir uma relativa incompressibilidade em modelos hiperelásticos compressíveis.

O exemplo escolhido, que deve ser representativo de um estado uniaxial de deformações, esta ilustrado na Figura 16 e consiste de um quadrado de lados unitários discretizado com 2 elementos triangulares com aproximação cúbica para as posições.

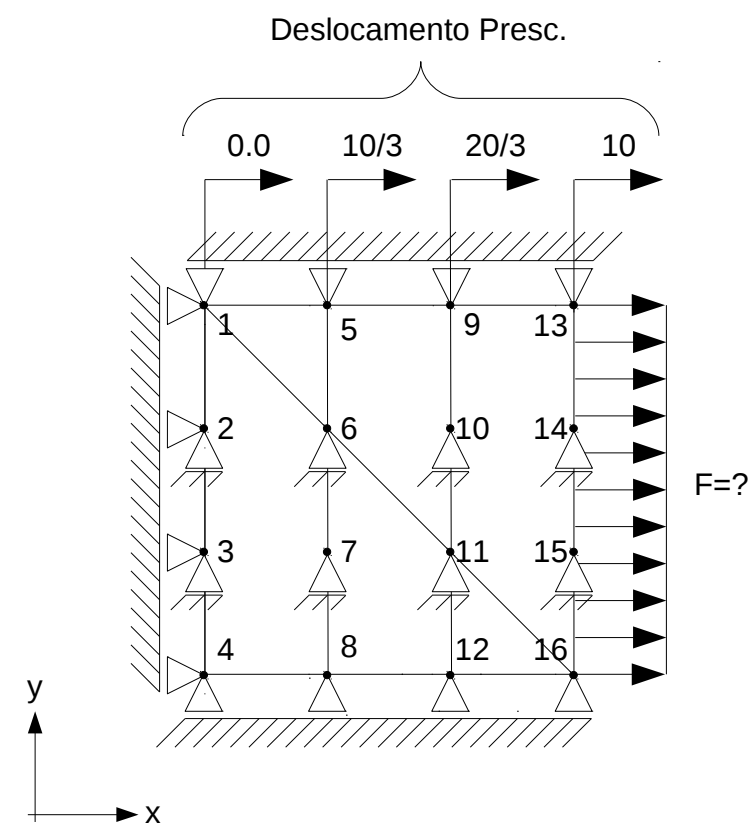

Figura 16 - Exemplo numérico 1

Na Figura 16, as duas faces horizontais estão impedidas de se movimentarem na direção y, enquanto que a face vertical esquerda está impedida de se movimentar na direção x. Por outro lado, na face vertical direita age uma carga distribuída a ser determinada por um processo de deslocamento controlado de modo que o deslocamento total final de 10,0 unidades de comprimento aplicado na face da direita deforme o elemento em $1.000 \%$ na direção $x$. Adicionalmente, agem nos nós internos deslocamentos proporcionais à distância entre cada nó interno e a face vertical direita. Esses nós internos estão, ainda, impedidos 
de se movimentarem na direção vertical.

Observe que, assim como no caso unidimensional, o único deslocamento possível é ao longo do eixo horizontal. A estratégia de controle de deslocamento foi escolhida por apresentar melhor estabilidade numérica do que a estratégia de controle de força na curva de força $\mathrm{x}$ deslocamento esperada.

Vale lembrar que, se o estado plano fosse o de tensões e, se a lei constitutiva adotada fosse a lei de Hooke, poderia-se esperar que $\sigma_{22}=\nu \sigma_{11}$, mas, como o estado plano adotado é o de deformações e a lei constitutiva não é a de Hooke, não se pode esperar que isso seja verdade nesse exemplo. Considerar um estado plano de tensões ao invés de um estado plano de deformações traria algumas dificuldades adicionais. (subseção 3.1.10)

As propriedades utilizadas para o material foram escolhidas de forma arbitrária somente com o intuito de validação do modelo. São elas:

$$
\mathbb{E}=2,1 \times 10^{6} \quad \nu=0,3 \quad G=\frac{E}{2(1+\nu)} \quad k=\frac{\mathbb{E}}{3(1-2 \nu)}
$$

Sendo $E$ o módulo de Young, $\nu$ o coeficiente de Poisson, $G$ o módulo de elasticidade ao cisalhamento e $k$ o módulo de compressão volumétrica. Os parâmetros $c_{10}, c_{20} e c_{30}$ do modelo de Yeoh podem ser escritos em função do módulo de elasticidade ao cisalhamento $G$. Assim, o modelo foi verificado com três valores distintos para as constantes $c_{10}, c_{20}$ e $c_{30}$, denominados de YEOH1, YEOH2 e YEOH3.

YEOH1:

$$
c_{10}=\frac{G}{2} \quad c_{20}=-\frac{G}{2,5} \quad c_{30}=\frac{G}{100}
$$

YEOH2:

$$
c_{10}=\frac{G}{2} \quad c_{20}=-\frac{G}{2} \quad c_{30}=\frac{G}{100}
$$

YЕОНЗ:

$$
c_{10}=\frac{G}{2} \quad c_{20}=-\left(\frac{0,05}{0,55}\right) \frac{G}{2} \quad c_{30}=\left(\frac{0,015}{0,55}\right) \frac{G}{2}
$$

Em YEOH1 e YEOH2, as constantes foram escolhidas de forma arbitrária, sem qualquer relação com valores observados na prática. Essa escolha foi feita de modo a garantir a estabilidade do método, uma vez que a estabilidade da solução depende das constantes escolhidas. Embora em YEOH3 as constantes do modelo também tenham sido ecolhidas de forma aleatória, a relação entre elas foi mantida conforme em Centeno (2009).

É importante lembrar que, grandezas tais como o tensor de alongamento à direita de Cauchy-Green $(\mathbf{C})$, os invariantes $\left(I_{1}, I_{2}, I_{3}\right)$ e o Jacobiano J envolvidas nos cálculos, 
são grandezas essencialmente tridimensionais (matrizes sempre "cheias"). Logo, uma lei constitutiva hiperelástica sempre é tridimensional. Assim, não se pode simplesmente negligenciar algumas componentes dessas grandezas a fim de considerar, por exemplo, estados uniaxiais ou planos de tensão e deformação. Nesse trabalho, considera-se um estado plano de deformações ao reduzir o tensor de alongamento de Cauchy-Green à seguinte forma:

$$
\mathbf{C}=\left(\begin{array}{ccc}
C_{11} & C_{12} & 0 \\
C_{21} & C_{22} & 0 \\
0 & 0 & 1
\end{array}\right)
$$

A Equação 4.3 é o alongamento que se encontra implementado no código desenvolvido nesse trabalho. No entanto, devido as condições de contorno deste exemplo, o estado plano de deformações imposto através da Equação 4.3 deve se "transformar" no seguinte estado uniaxial de deformações:

$$
\mathbf{C}=\left(\begin{array}{lll}
\lambda^{2} & 0 & 0 \\
0 & 1 & 0 \\
0 & 0 & 1
\end{array}\right)
$$

Assim, considera-se, por exemplo, que uma barra se deforma unicamente por meio de alterações de comprimento, negligenciando, portanto, os efeitos de Poisson. Logo, tem-se também para o caso unidimensional de deformações:

$$
\mathbf{C}^{-1}=\left(\begin{array}{ccc}
1 / \lambda^{2} & 0 & 0 \\
0 & 1 & 0 \\
0 & 0 & 1
\end{array}\right)
$$

A partir das Equações 4.4 e 4.5 pode-se encontrar analiticamente as respostas através das equações apresentadas no Apêndice E. Sendo assim, a $1^{\text {a }}$ tensão de PiolaKirchhoff ( $\mathbf{P}=\mathbf{F S}$ ) para o caso unidimensional assume a seguinte forma:

$$
\mathbf{P}=\left(\begin{array}{lll}
\lambda & 0 & 0 \\
0 & 1 & 0 \\
0 & 0 & 1
\end{array}\right)\left(\begin{array}{lll}
S_{11} & S_{12} & S_{13} \\
S_{12} & S_{22} & S_{23} \\
S_{13} & S_{23} & S_{33}
\end{array}\right)
$$

ou seja:

$$
P_{11}=S_{11} \lambda \rightarrow \frac{F}{S}=S_{11} \lambda
$$

pois a $1^{\text {a }}$ tensão de Piola-Kirchhoff $\mathbf{P}$ é uma medida de tensão referente à área inicial $S$ na configuração inicial indeformada. É a partir daí que se calcula a força $F$ aplicada no modelo unidimensional de forma analítica, e que deve ser a mesma calculada pelo programa desenvolvido. 
As respostas analíticas e numéricas obtidas (força em função do deslocamento horizontal da face vertical direita da Figura 16) para o modelo de Yeoh escolhido com 100 passos de deslocamento estão representadas no gráfico abaixo:

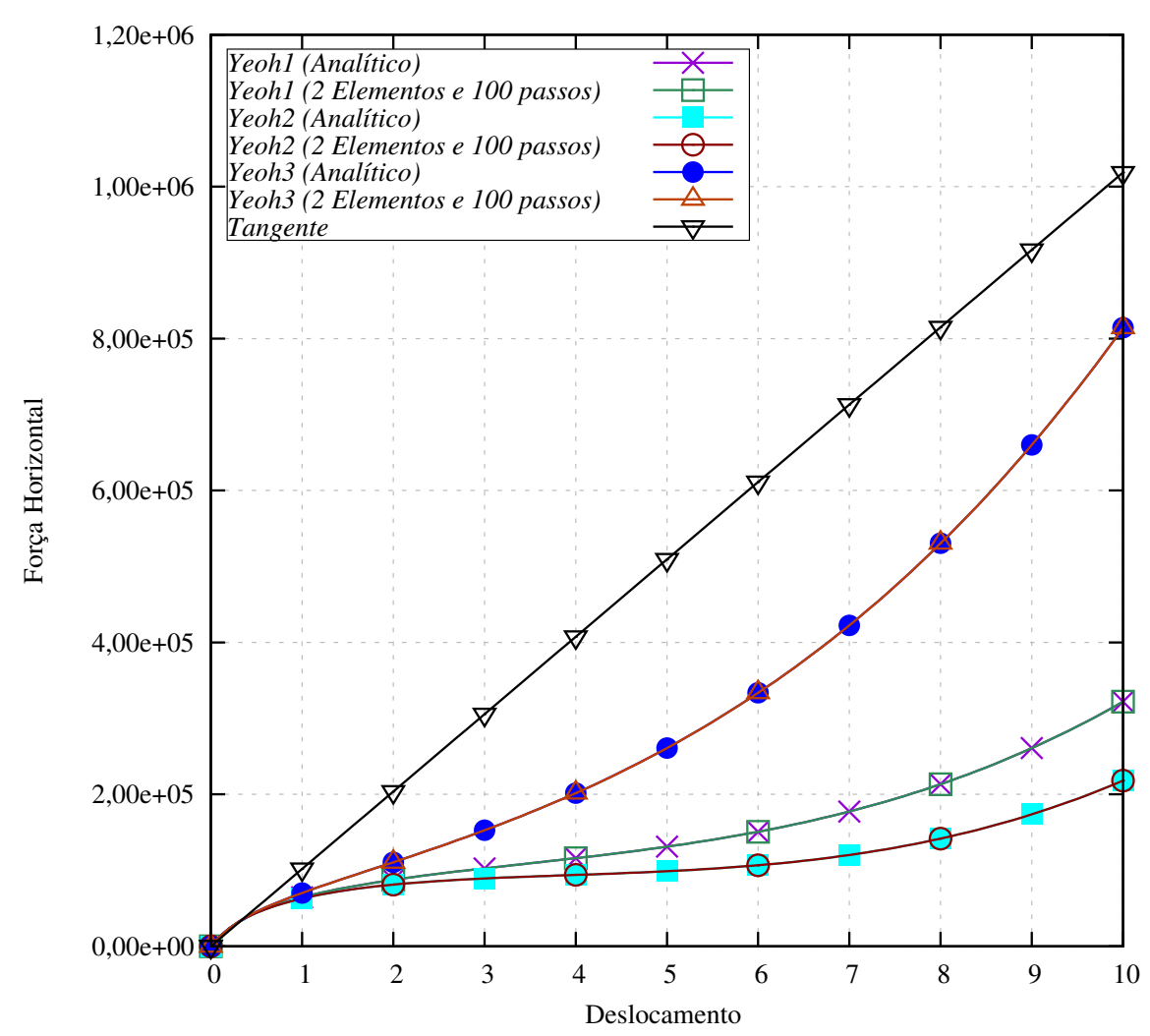

Figura 17 - Modelo hiperelástico compressível de Yeoh sob deformação uniaxial

Na Figura 17 nota-se que um passo de deslocamento de 0,1 adotado foi suficiente para atingir uma boa convergência com o resultado analítico. Segundo Centeno (2009), o comportamento em baixas e altas deformações são influenciadas majoritariamente pelos coeficientes $c_{10}$ e $c_{30}$, respectivamente. A reta "TANGENTE" é a rigidez inicial dos modelos que depende, portanto, basicamente de $c_{10}$. Observa-se também que o coeficiente $c_{20}$ é o que mais influencia no comportamento das curvas em médias deformações. A expressão e o desenvolvimento da solução analítica do modelo de Yeoh, com as condições de contorno (restrições em deslocamento) impostas nesse exemplo, são desenvolvidas e apresentadas no Apêndice D.

\subsubsection{Teste de convergência}

Verifica-se que em malhas mais refinadas (200 elementos), os modelos YEOH1 e YEOH2 têm dificuldade de convergência, o que se deve, provavelmente, ao comportamento "quase" não policonvexo da lei constitutiva para os parâmetros $c_{10}, c_{20}$ e $c_{30}$ adotados nos referidos casos. Isso pode ser verificado na Figura 17 pela relação entre carga e deslocamento praticamente horizontal, tanto para o modelo YEOH1 quanto para o modelo YEOH2. 
Nesse caso, um determinado nível carregamento apresenta diversos valores possíveis de deslocamento. A malha discretizada com 2 elementos não apresentou esse problema porque, ao contrário da malha de 200 elementos, tanto os deslocamentos dos nós internos quanto os das faces foram controlados.

Toda lei constitutiva hiperelástica deve ser policonvexa, isto é, um valor de tensão deve corresponder a um único valor de deformação, pois pela sua própria definição, uma lei constituiva hiperelástia define um estado de tensões única e exclusivamente em função do estado de deformações ou vice versa. Para que a lei seja policonvexa, basta que o tensor constitutivo $\mathbb{C}$ seja positivo definido.

A Figura 18 abaixo ilustra os resultados em deslocamento (na direção $x$ ) e tensões (também na direção $x$ ) obtidos através da discretização do exemplo da Figura 16 em malhas com 2 e 200 elementos. Nesse caso, o deslocamento prescrito na face vertical da direita foi reduzido para 1,0, de modo a deformar o elemento quadrilateral de lado unitário em $100 \%$.

As constantes escolhidas para o material são aquelas de YEOH3. Ao contrário da malha discretizada em 2 elementos, os nós internos da malha com 200 elementos não estão impedidos de se deslocarem na direção y. Os nós internos da malha com 200 elementos também não estão submetidos a deslocamento horizontal proporcional assim como no caso da malha com 2 elementos. As restrições do problema do elemento continuam as mesmas (faces horizontais com deslocamentos impedidos na direção $y$ e face vertical esquerda restringida para o deslocamento na direção $x$ ). 


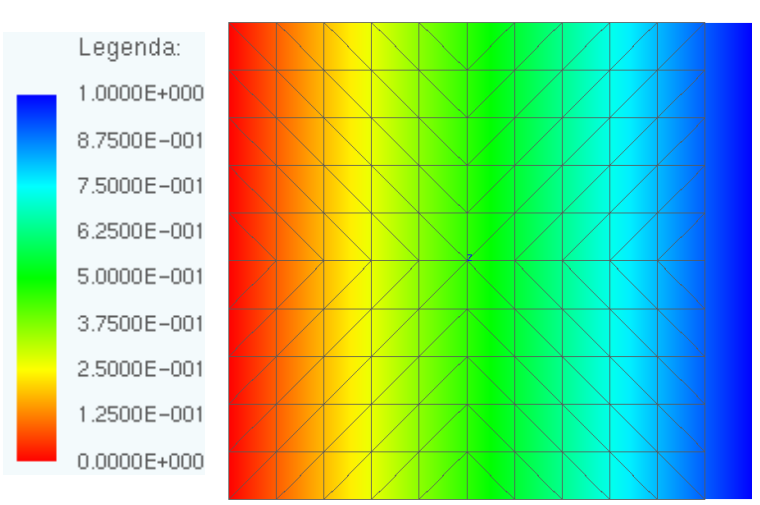

(a) Deslocamento na direção $\mathrm{x}$

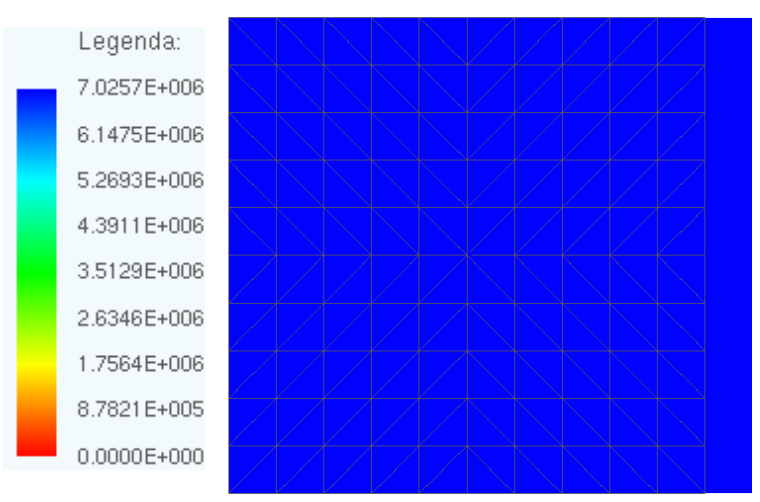

(c) Tensão de Cauchy na direção x

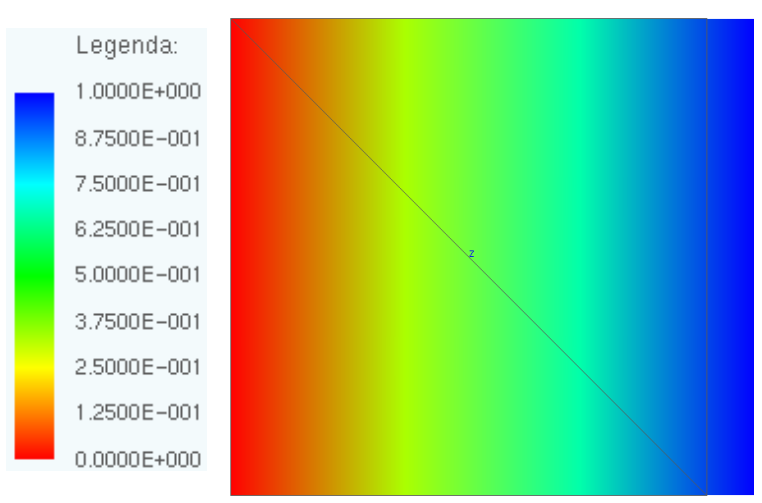

(b) Deslocamento na direção x

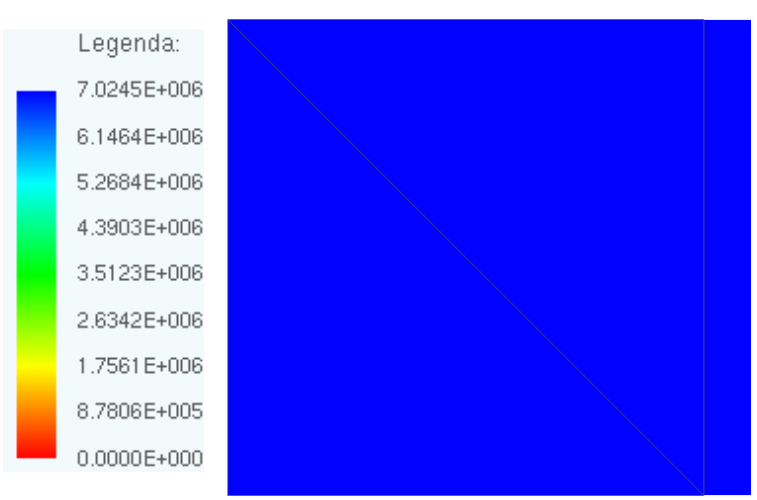

(d) Tensão de Cauchy na direção x

Figura 18 - Teste de convergência em tensões e deslocamentos

Os resultados da Figura 18 foram obtidos dividindo-se o deslocamento prescrito de 1,0 em 1000 passos, uma vez que com 100 passos o programa não se demonstrou estável para malha de 200 elementos devido a dificuldade de convergência conforme já comentada. Mesmo com o deslocamento prescrito dividido em 1000 passos, o programa não apresentou uma convergência satisfatória quando se tentou utilizar a malha de 200 elementos com as constantes para o material conforme YEOH1 e YEOH2. Note que a malha com 2 elementos já apresenta quase que os mesmos resultados da malha com 200 elementos. Para esse exemplo específico isso acontece porque as propriedades mecânicas do material (lei constitutiva) independem da quantidade de elementos utilizada na discretização.

A boa convegência do exemplo que utiliza malha com 2 elementos e deforma o elemento em $1000 \%$, mesmo para coeficientes que resultam em uma lei constitutiva "quase" não policonvexa (YEOH1 e YEOH2) se deve, muito provavelmente, ao reduzido número de elementos e ao controle rigoroso de deslocamentos de todos os nós da malha com 2 elementos da Figura 16. Centeno (2009) também aponta dificuldade de convergência conforme a escolha dos parâmetros $c_{10}, c_{20}$, e $c_{30}$ do modelo de Yeoh e Humphrey (2003) enfatiza o cuidado na calibração dos parâmetros das leis constitutivas de forma a manter a convexidade. 


\subsubsection{Incompressibilidade}

Geralmente, a hipótese de incompressibilidade do material é considerada impondose uma restrição interna no material ao escrever um dos alongamentos em função dos outros dois utilizando a condição suficiente de incompressibilidade $\lambda_{1} \lambda_{2} \lambda_{3}=1$. Ao invés disso, a estratégia adotada para esse trabalho será a de considerar $\nu=0,499999$, de forma que $k>>E$. Isso faz com que a parcela de energia referente à alteração volumétrica seja muito maior que a parcela de energia referente à mudanças de forma nas equações da energia de deformação do modelo constitutivo e, ao buscar a configuração de mínima energia através do método dos elementos finitos, a condição $J \simeq 1$ deve ser automaticamente encontrada, conforme é possível verificar na parcela $u_{v o l}$ adotada para o modelo.

Considerar a condição de incompressibilidade do material deve "travar" o exemplo escolhido, pois o estado plano de deformações adotado e as restrições externas escolhidas já eliminaram as deformações em duas direções, isto é, $\lambda_{3}=1$ e $\lambda_{2}=1$. Esse "travamento" foi verificado no programa desenvolvido aplicando-se, ao invés de um deslocamento, uma carga distribuída na face vertical direita da Figura 16 de 8,14314E + 07, utilizando as constantes do modelo YEOH3 e adotando $\nu=0,499999$. Essa carga distribuída aplicada foi a carga necessária para causar o deslocamento de 10,0 nesse mesmo modelo YEOH3 e, como o deslocamento obtido foi muito menor (que os 10,0), pode-se dizer então que a incompressibilidade adicionou uma restrição interna ao material "travando" a malha. Ademais espera-se, portanto, verificar tensões iguais nas duas direções do plano e deslocamento nulo da face direita. Nesta verificação da incompressibilidade, os nós $6,7,10,11,14$ e 15 do modelo da Figura 16 foram soltos. 


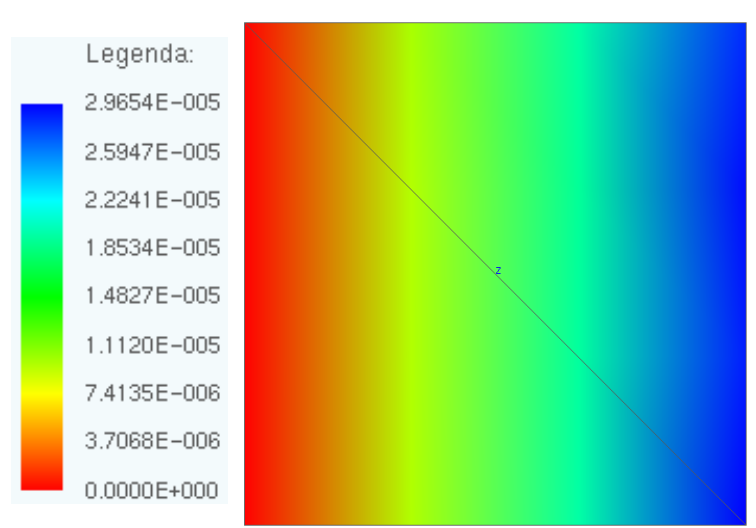

(a) Deslocamento na direção $x$

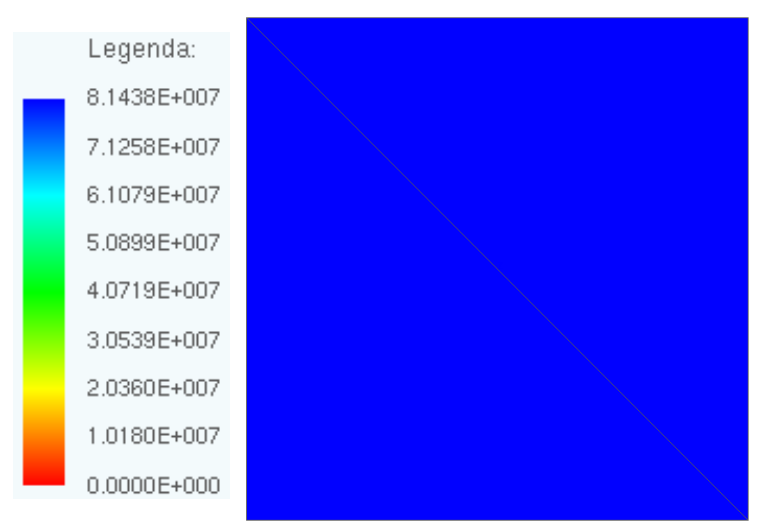

(c) Tensão de Cauchy na direção x

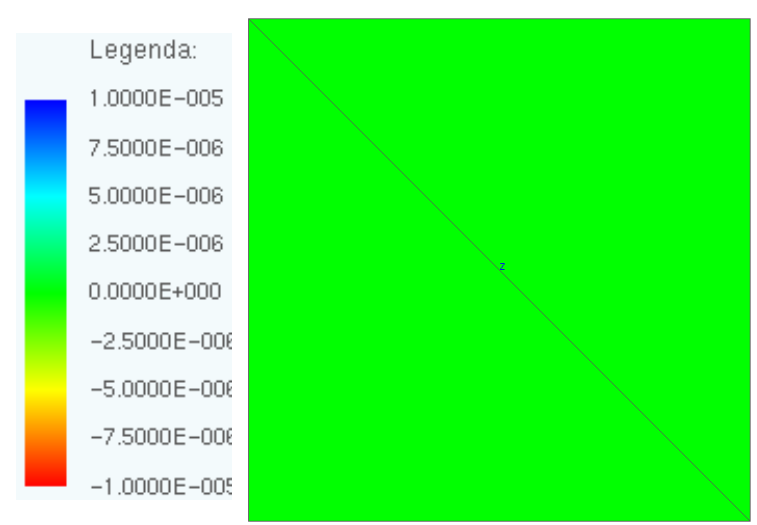

(b) Deslocamento na direção y

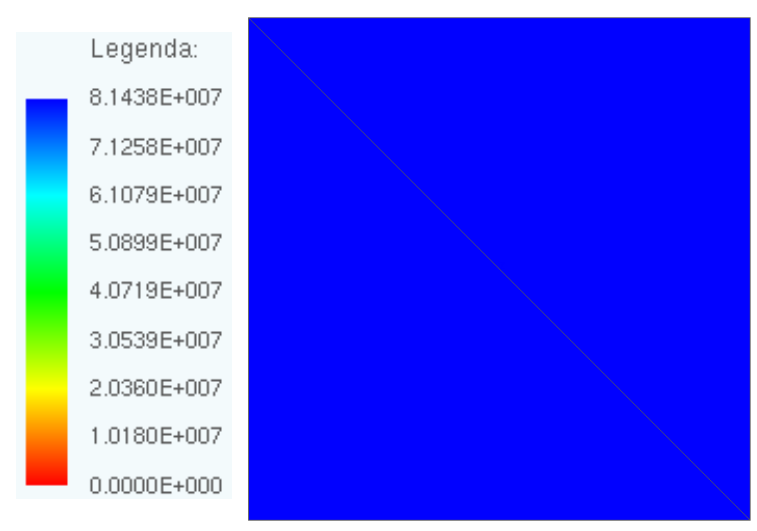

(d) Tensão de Cauchy na direção y

Figura 19 - Tensões e deslocamentos do modelo incompressível

Na Figura 19 observa-se uma boa concordância com os resultados esperados. As tensões iguais nas direções x e y indicam um estado hidrostático de tensões necessário para manter a conservação do volume.

\subsection{Barra simples com Modelo constitutivo viscoelástico ativo}

A validação da implementação do modelo constitutivo viscoelástico ativo em elementos de barra simples utilizando a deformação não linear de engenharia e a $1^{\text {a }}$ tensão de Piola-Kirchhoff, respectivamente como medidas de deformação e tensão, foi feita a partir de uma estrutura composta por 3 elementos de barra simples: 


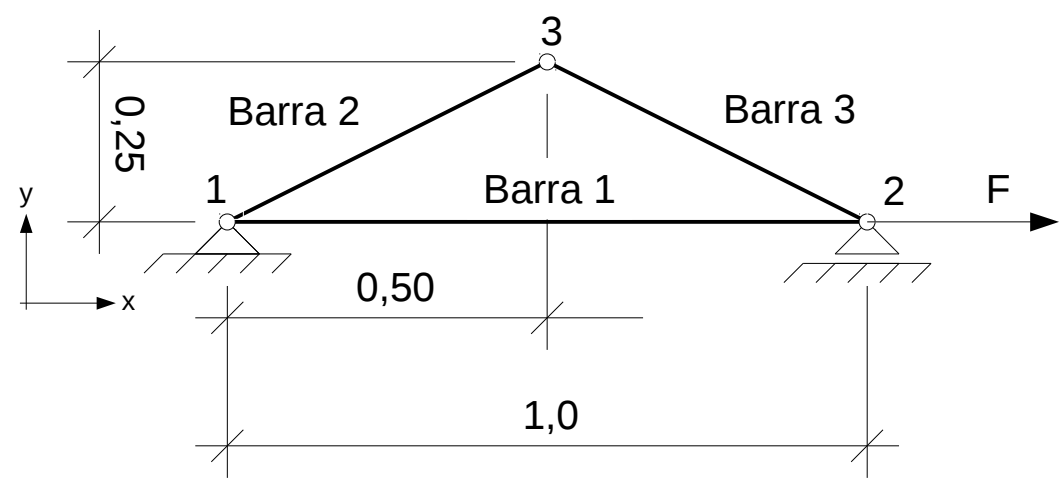

Figura 20 - Exemplo numérico 2

As propriedades admitidas para todos os elementos de barra são as seguintes: módulo de elasticidade $\mathbb{E}=2,1 \times 10^{6}$, constante viscosa $\mathrm{c}=2,1 \times 10^{3}$ e área da secção transversal $\mathrm{S}=1,0 \times 10^{-3}$. No modelo proposto, a estricção da secção transversal da barra é desprezada (uma redução da área da seção transversal poderia ser estimada através de uma hipótese de incompressibilidade). Assim, na formulação sugerida, a tensão de Cauchy e a $1^{\text {a }}$ tensão de Piola-Kirchhoff coincidem. A $1^{\text {a }}$ tensão de Piola-Kirchhoff é uma medida de tensão bastante interessante, pois é baseada na área inicial, que é conhecida. Esse exemplo foi resolvido em 23.000 passos e adotando um intervalo de tempo constante $\Delta t=1,0 \times 10^{-6}$. A atualização viscosa é feitas através da Equação 3.149 e da Equação 3.150 utilizando o método das diferenças finitas.

Na Figura 20, o nó 1 está impedido de se movimentar tanto na direção $x$ quanto na direção $y$, enquanto que o nó 2 esta restrito apenas na direção $y$. No nó 2 age ainda uma força horizontal a ser determinada de modo que o deslocamento vertical do nó 3 seja igual a 0,25 (para baixo), conforme a Figura 21:

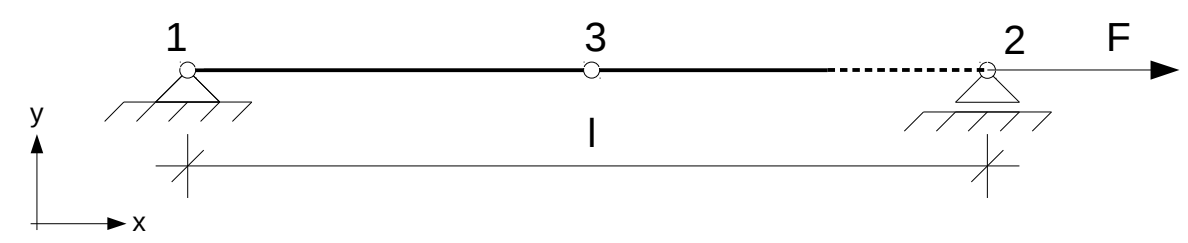

Figura 21 - Estrutura de treliça na configuração deformada

O objetivo deste exemplo é apresentar o gráfico das tensões elásticas e viscosas para o elemento de barra 1, bem como os deslocamentos horizontais e verticais do nó 3 e também o deslocamento horizontal do nó 2. Este exemplo é particularmente interessante para verificar que, na formulação proposta, as barras 2 e 3 estão livres de tensões durante todo o processo de carregamento, uma vez que estas sofrem apenas movimento puro de 
corpo rígido. O comprimento final esperado para a barra 1 é de:

$$
l=2,0 \sqrt{0,5^{2}+0,25^{2}}=1,1180
$$

Como a viscosidade é um fenômeno transiente, que tende a desaparecer com o tempo, a força necessária para causar o alongamento proposto de 1,1180 na barra 1 (após o desaparecimento do fenômeno viscoelástico) é:

$$
\mathbf{P}=\frac{F}{S} \rightarrow F=\mathbb{E} \tilde{\boldsymbol{\epsilon}} S \rightarrow F=247,80
$$

A $1^{\text {a }}$ tensão de Piola-Kirchhoff (parcelas elástica e viscosa) obtida na barra $1 \mathrm{com}$ o programa desenvolvido está ilustrada na Figura 22, onde as parcelas de tensão elástica e viscosa são calculadas conforme a Equação 3.149 e a Equação 3.150.

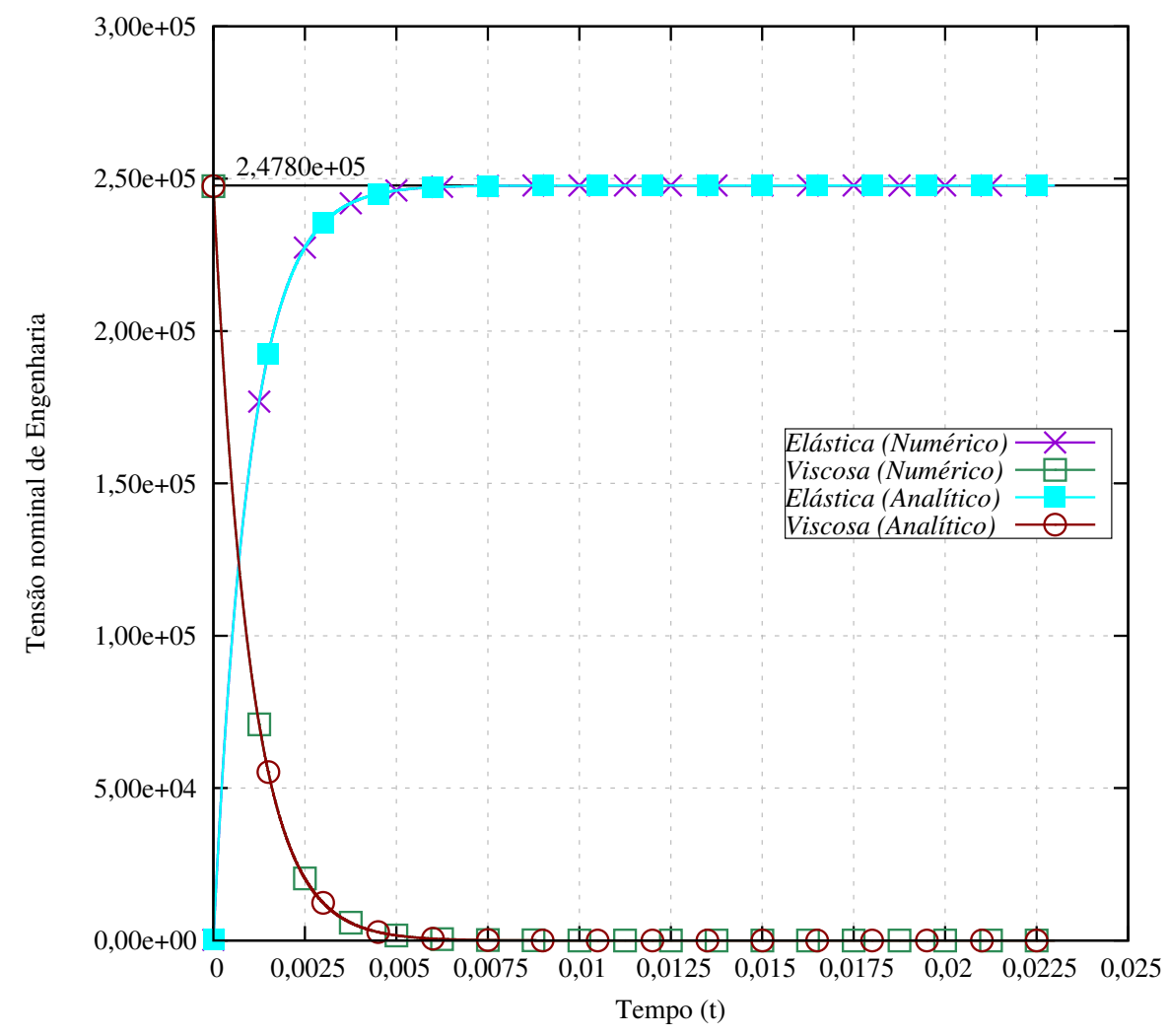

Figura 22 - Tensões viscosa e elástica no elemento de barra 1

O gráfico da Figura 22 condiz com o resultado esperado, isto é, a tensão viscosa parte da tensão inicialmente aplicada $\mathbf{P}=247,80 / 1,0 \times 10^{-3}=2,47 \times 10^{5}$ e tende a zero. Por outro lado, a tensão elástica parte de zero e tende a $2,478 \times 10^{5}$, que é a tensão aplicada. Como a área permanece inalterada, a tensão de Cauchy viscosa inicial e a tensão de Cauchy elástica final coincidem. A $1^{\text {a }}$ tensão de Piola-Kirchhoff (elástica) obtida nas barras ao longo dos 23.000 passos de tempo foram as seguintes: 


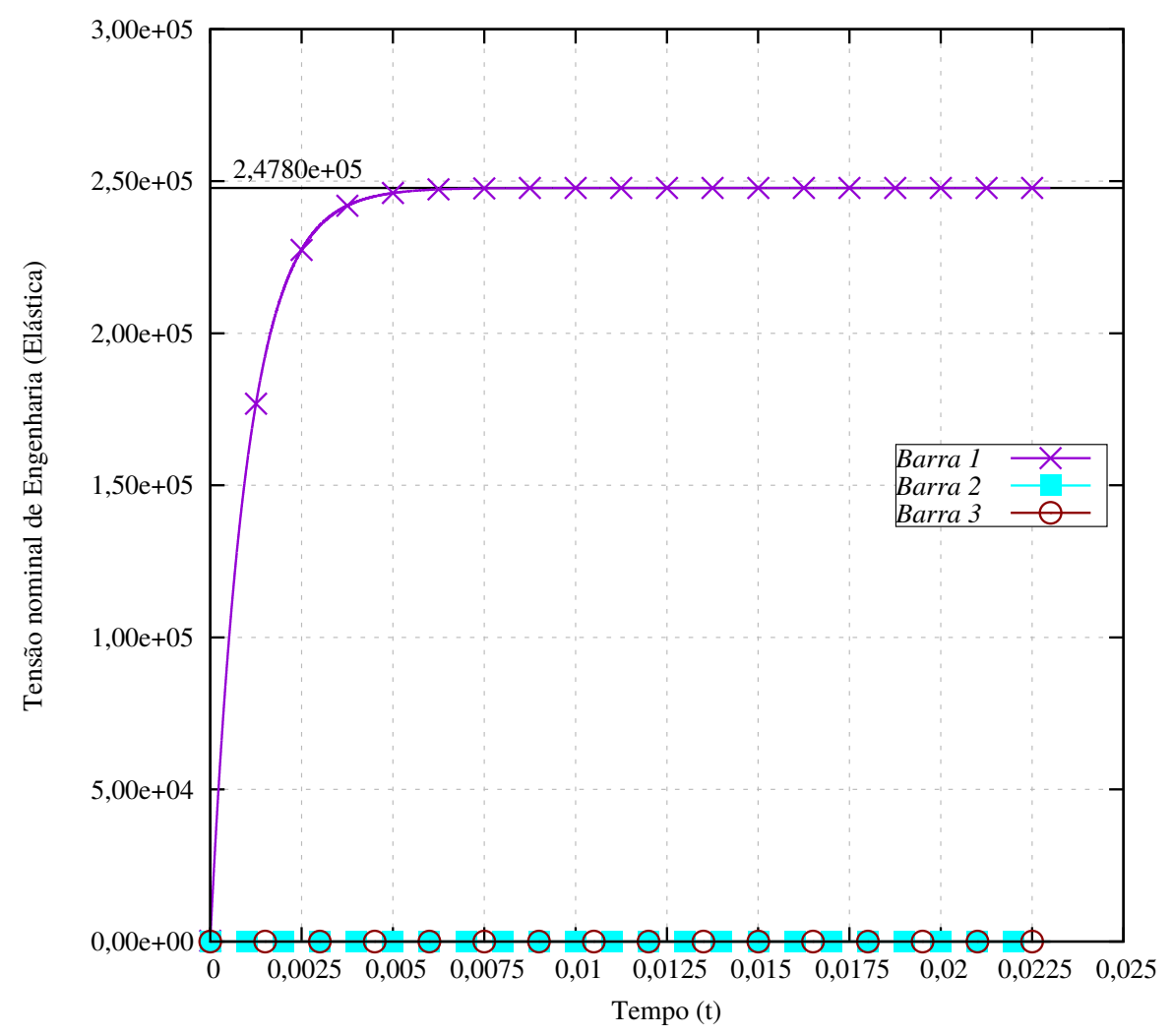

Figura 23 - Tensões elásticas nos elementos de barra

Logo, verifica-se na Figura 23 que as barras 2 e 3 estão livres de tensões durante todo o processo, pois apresentam movimento puro de corpo rígido. Os deslocamentos dos nós nas direções horizontal $(x)$ e vertical $(y)$ são apresentados na Figura 24:

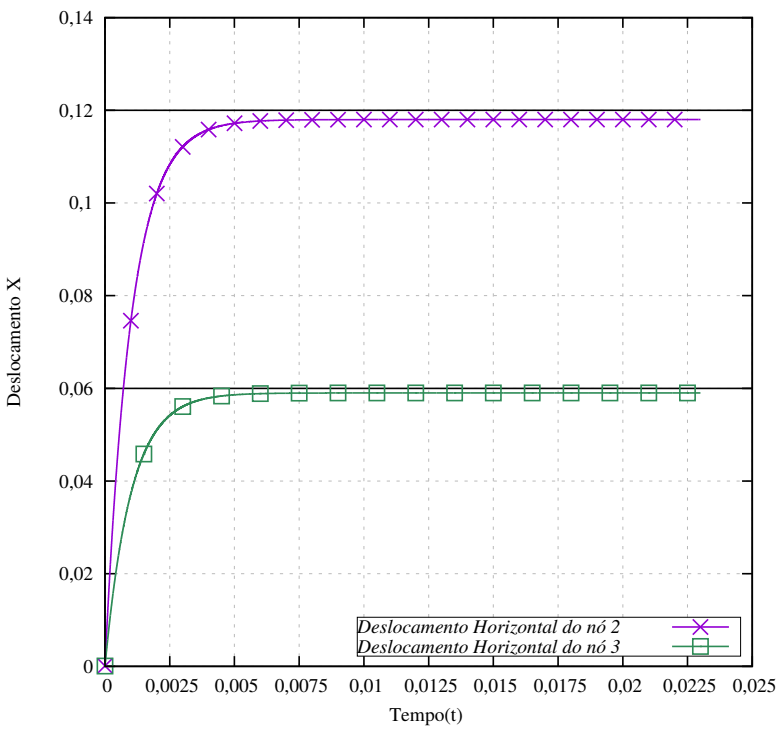

(a) Deslocamento na direção x

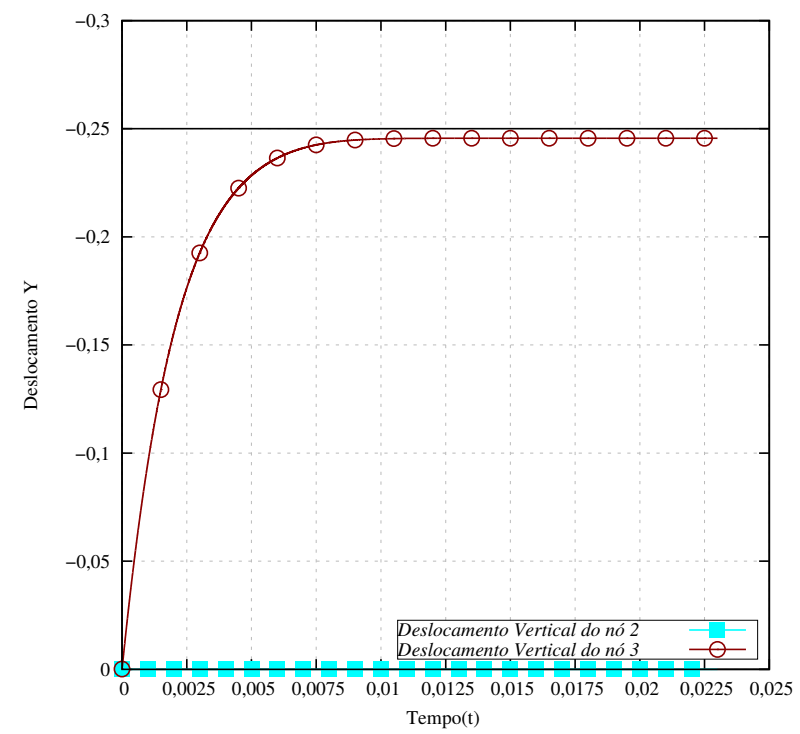

(b) Deslocamento na direção y

Figura 24 - Deslocamentos dos nós 2 e 3

Assim, como era de se esperar, verifica-se que o deslocamento horizontal do nó 3 é a 
metade do deslocamento horizontal do nó 2 . O deslocamento vertical observado no nó 3 foi de 0,245 (para baixo), o que corresponde a um valor $2 \%$ abaixo do previsto de 0,25 . Observe que parte desse erro é devido ao arredondamento do alongamento e da força calculados nas Equações 4.8 e 4.9, respectivamente. Nota-se também que, assim como a tensão elástica, e devido ao comportamento viscoelástico, os deslocamentos nos nós acontecem de forma gradual. Aplicando a força de 247,80 calculada na Equação 4.8 na estrutura da Figura 20, a deformação elástica (não linear de engenharia) final da barra 1 obtida pelo programa foi de 0,118 , ou seja, exatamente o valor esperado de $\tilde{\boldsymbol{\epsilon}}=\lambda-1=1,118-1=0,118$.

Introduzindo-se agora uma contração na barra 1 de 0,118 no $8.001^{\circ}$ passo de tempo, de tal forma que a estrutura retorne à posição inicial dada na Figura 20. Essa contração será então removida no $15.001^{\circ}$ passo de tempo, de modo que a estrutura volte à configuração da Figura 21. Muito provavelmente, o deslocamento de 0,245, levemente abaixo dos exatos 0,25, foi o que garantiu que a estrutura voltasse à posição da Figura 20 com o nó 3 na posição y positiva de 0,25 e não de forma invertida (com a posição y do nó 2 em -0,25).

Mesmo ativando e desativando o elemento de barra 1, as tensões obtidas nas barras foram exatamente as da Figura 23. A contração do elemento de barra, portanto, não altera nem as tensões elásticas atuantes nem interfere no comportamento exponencial característicos de materiais viscoelásticos ou vice versa, estando assim em conformidade com o modelo proposto na Figura 7. O deslocamentos obtidos nos nós 2 e 3 foram os seguintes:

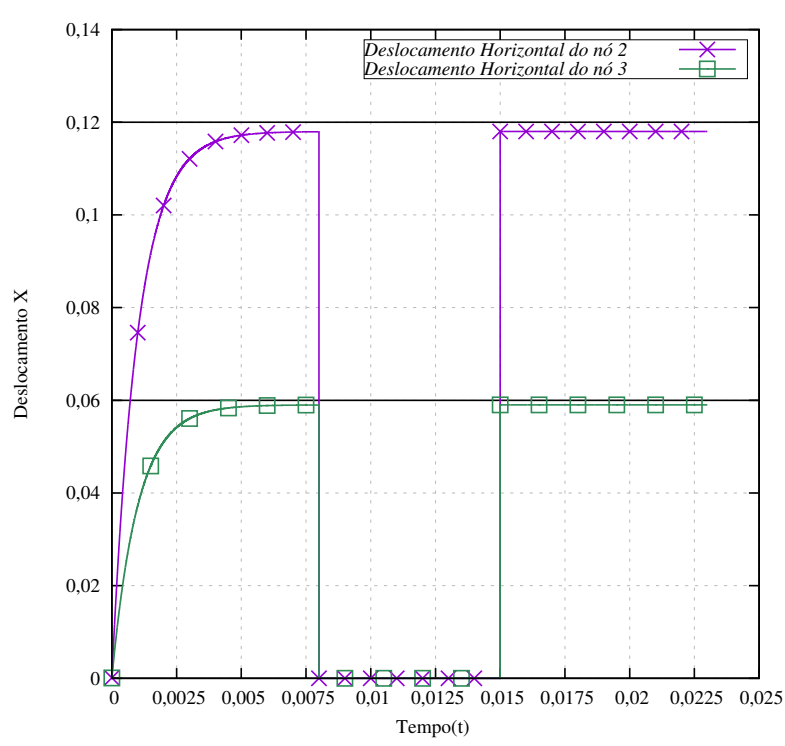

(a) Deslocamento na direção $x$

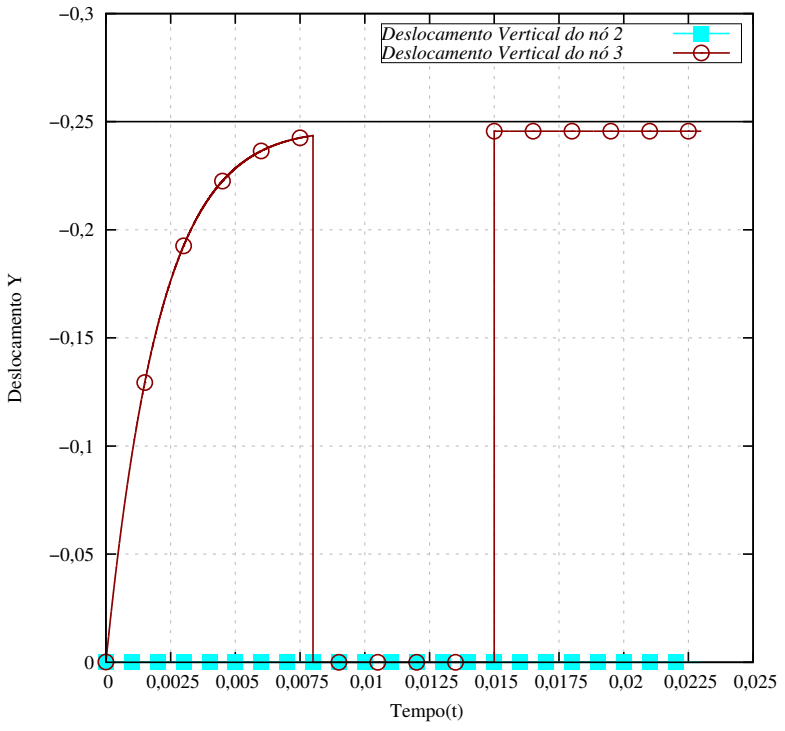

(b) Deslocamento na direção y

Figura 25 - Deslocamentos dos nós 2 e 3

A Figura 25 reforça mais uma vez que a contração aplicada no elemento é imediata. Pode-se dizer, portanto, que os deslocamentos induzidos pela contração do elemento são "rígidos" e imediatos, o que está de acordo com o modelo proposto na Figura 7. 
Para um único elemento de barra, a Equação 3.150 proposta para o modelo é imediatamente programável em planilhas eletrônicas, permitindo inclusive considerar o comportamento ativo. Utilizando os mesmos parâmetros do presente exemplo tanto considerando quanto desconsiderando a ativação do elemento de barra, os deslocamentos e tensões observados com a Equação 3.150 programada em uma planilha foram os mesmos observados para o elemento de barra 1 deste exemplo, o que valida as implementações realizadas para o modelo.

\subsection{Matriz reforçada com Fibras}

Este exemplo foi proposto para validação da implementação do modelo de acoplamento entre fibra e matriz. A Figura 26 consiste em um quadrado de lados unitários onde se encontram distribuídos 150 elementos de barra (50 elementos distribuídos na direção vertical e, cada um desses 50 elementos, divididos em outros 3 elementos de tamanhos iguais) com 2 nós cada, totalizando 200 nós de elementos de barra. Esses elementos de barra estão distribuídos de forma igualmente espaçada em uma matriz discretizada em 200 elementos de chapa de 10 nós cada, totalizando 961 nós de elementos de chapa.

Na Figura 26, as duas faces horizontais estão impedidas de se movimentarem na direção $y$, enquanto que a face vertical esquerda está impedida de se movimentar na direção $x$. Na face vertical direita é aplicado um deslocamento de $1,0 \times 10^{-3}$.

O objetivo deste exemplo é calcular a força horizontal $F$ na face da direita necessária para causar o deslocamento prescrito de 1,0 $\times 10^{-3}$ e comparar com o resultado analítico.

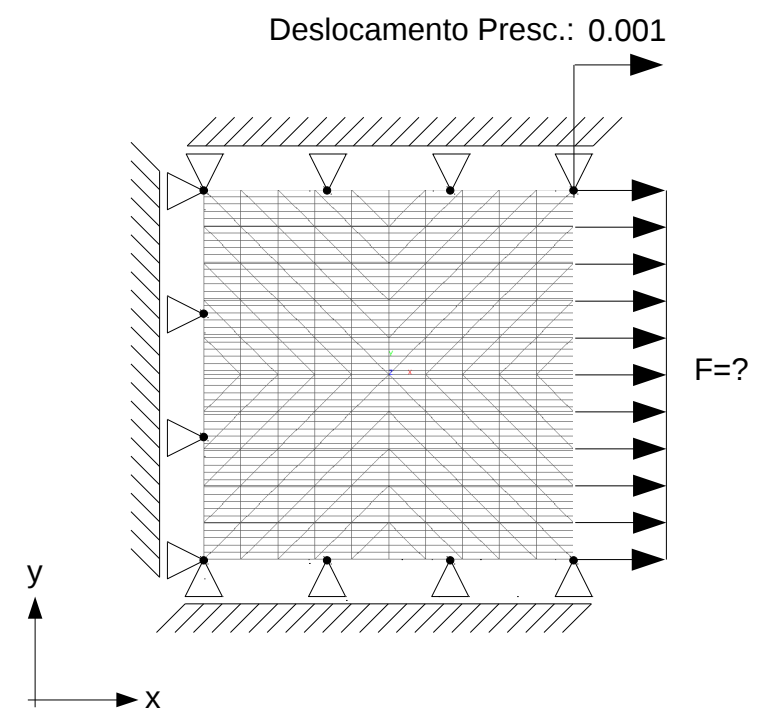

Figura 26 - Exemplo numérico 3

O modelo constitutivo escolhido foi o de Saint Venant-Kirchhoff na forma $u_{e}=$ 
$c_{10}(\operatorname{tr}(\mathbf{E}))^{2}+c_{20} \operatorname{tr}\left(\mathbf{E}^{2}\right)$ (ver Apêndice D) tanto para a matriz quanto para as fibras. Logo, a relação entre tensão e deformação é linear conforme a Equação D.13. Como neste exemplo o estado plano adotado é o de deformações, a terceira, quinta e sexta linhas e colunas na Equação D.13 são eliminadas.

As propriedades admitidas para todos os elementos de barra são as seguintes: módulo de elasticidade $\mathbb{E}=1,05 \times 10^{11}$ e área da secção transversal $\mathrm{A}_{f}=0,4 \times 10^{-3}$. As propriedades utilizadas para o material da matriz (elementos de chapa) foram escolhidas de forma arbitrária. São elas:

$$
\mathbb{E}=2,1 \times 10^{11} \quad \nu=0,0 \quad G=\frac{\mathbb{E}}{2(1+\nu)} \quad k=\frac{\mathbb{E}}{3(1-2 \nu)}
$$

Os parâmetros $c_{10}, c_{20}$ do modelo de Saint Venant-Kirchhoff são as constante de Lamé, as quais podem ser escritas em função do módulo de elasticidade ao cisalhamento $G$ :

$$
c_{10}=\frac{G \nu}{1-2 \nu} \quad c_{20}=G
$$

Observe que, assim como no caso unidimensional, o único deslocamento possível é ao longo do eixo horizontal, portanto, o deslocamento da extremidade pode ser calculado como se fosse um único elemento de barra simples. Sendo então $\delta$ o deslocamento prescrito na extremidade da direita, $L$ o comprimento das barras, $A_{f}$ a área da secção transversal das barras, $n_{f}$ o número de barras, $E_{f}$ o módulo de elasticidade das barras, $A_{m}$ a área da secção transversal da matriz e $E_{m}$ o módulo de elasticidade da matriz, as forças normais nas barras $N_{f}$ e na matriz $N_{m}$ podem ser calculadas, respectivamente, considerando que o deslocamento nas barras é o mesmo da matriz:

$$
\begin{gathered}
\delta=\frac{N_{f} L}{A_{f} E_{f}} \rightarrow \frac{N_{f} L}{n_{f} A_{f} E_{f}}=10^{-3} \rightarrow N_{f}=2,1 \times 10^{6} \\
\delta=\frac{N_{m} L}{A_{m} E_{m}} \rightarrow \frac{N_{m} L}{A_{m} E_{m}}=10^{-3} \rightarrow N_{m}=2,1 \times 10^{6}
\end{gathered}
$$

onde $A_{m}=1,0 \times 10^{-2}$. Como o deslocamento prescrito é muito pequeno, as deformações resultantes também são pequenas. Assim, os pequenos deslocamentos e deformações envolvidos no problema devem ser insuficiente para que as não linearidades se manifestem. Além disso, para pequenos deslocamentos e deformações, também vale a superposição dos efeitos e, por isso, a força total aplicada é a soma das forças normais na matriz e nas barras.

$$
N=N_{f}+N_{m}=4,2 \times 10^{6}
$$

O resultado numérico obtido foi de $4,13964 \times 10^{6}$, o que significa uma diferença inferior a $2 \%$ com relação ao calculado de forma analítica. A Figura 27 ilustra os deslocamentos e as tensões obtidas para o presente exemplo. 


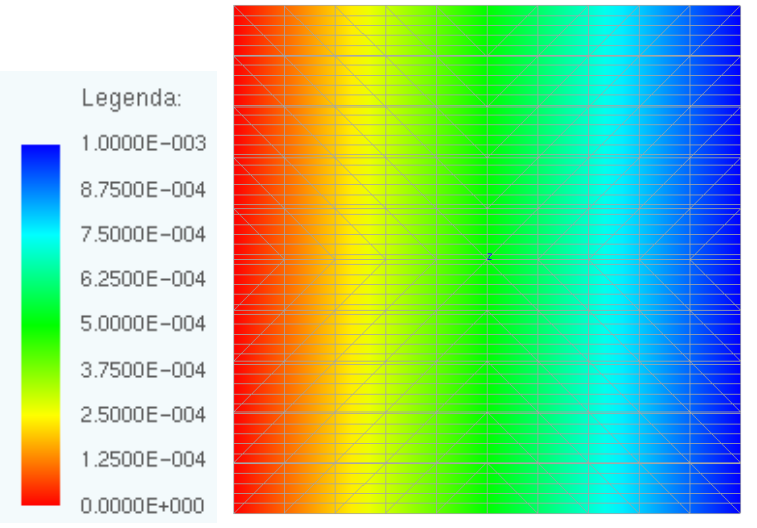

(a) Deslocamento na direção $\mathrm{x}$

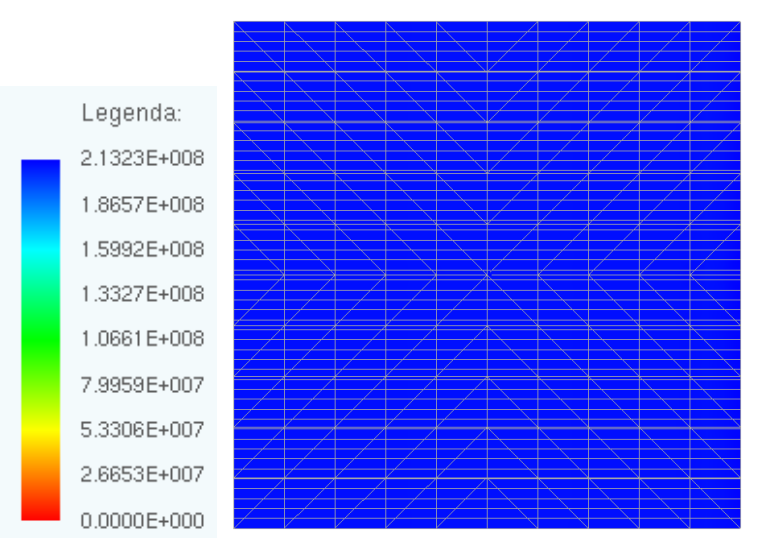

(c) Tensão de Cauchy na direção x

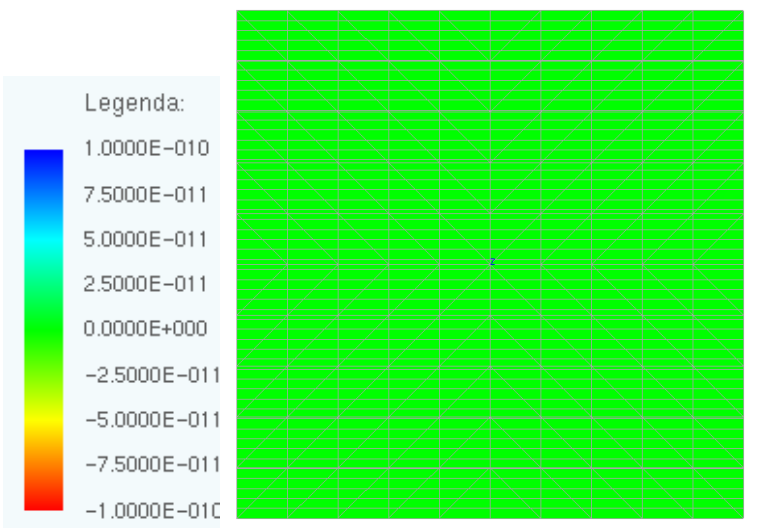

(b) Deslocamento na direção y

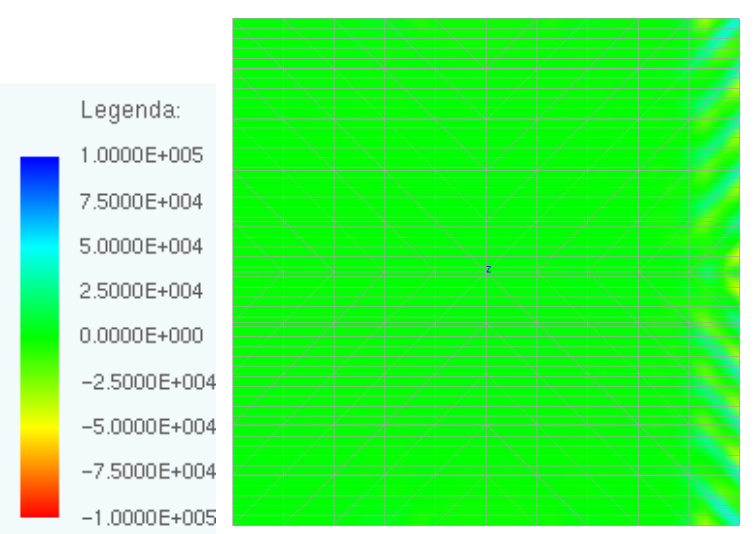

(d) Tensão de Cauchy na direção y

Figura 27 - Tensões e deslocamentos

Na Figura 27 observam-se deslocamentos crescentes ao longo do eixo $x$, além de deslocamentos praticamente nulos na direção y (da ordem de $10^{-10}$ unidades de comprimento), uma vez que a constante de Poisson $\nu$ foi adotada com valor igual a zero, não existindo, portanto, um "acoplamento" entre as direções $x$ e $y$. Além disso, a tensão normal ao longo do eixo $x$ varia entre $1,8657 \times 10^{8}$ e $2,1323 \times 10^{8}$, enquanto que as tensões obtidas na direção $y$ foram da ordem de $10^{4}$. Assim, as tensões na direção $y$ podem ser consideradas nulas se comparadas com a magnitude das tensões na direção do eixo $x$.

A Figura 28 ilustra a tensão de Cauchy obtida nos elementos de barra simples. Em se tratando de um elemento de barra simples com aproximação linear para as posições, a tensão é constante ao longo do mesmo. 


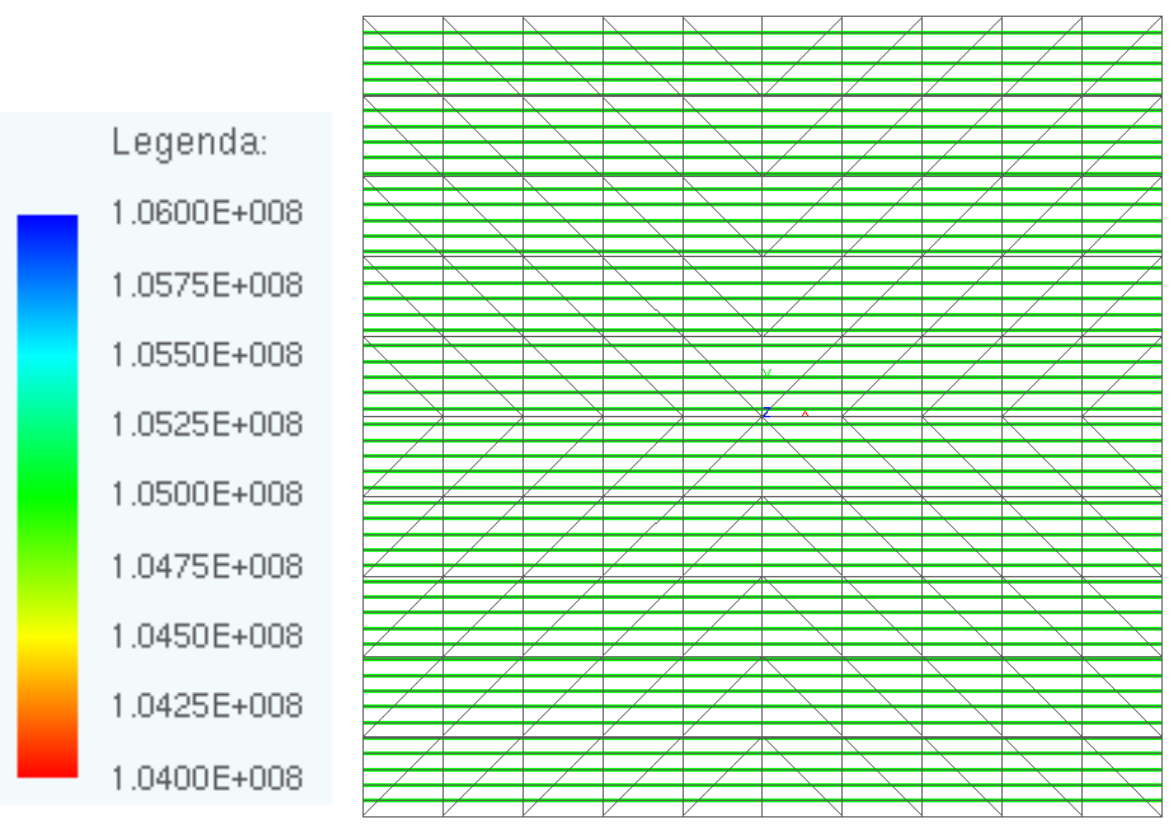

Figura 28 - Tensão nominal de engenharia nos elementos de barra simples

Estando os resultados apresentados em concordância com o comportamento esperado, tudo indica que procedimento de imersão das fibras tenha sido implementado de forma correta.

\subsection{Modelo de contração das Fibras}

Este exemplo ilustra o funcionamento do modelo de contração das fibras imersas na matriz. A Figura 29 consiste de um quadrado de lados unitários onde se encontram distribuídos 3 elementos de barra de 2 nós cada, totalizando 6 nós de elementos de barra. Esses elementos de barra estão distribuídos de forma igualmente espaçadas em uma matriz discretizada em 4 elementos de chapa de 10 nós cada, totalizando 25 nós de elemento de chapa. Em cada um dos 3 elementos de barra é aplicada deformação de contração de $40 \%$. A medida de deformação utilizada para os elementos de barra é a não linear de engenharia conforme proposto na subseção 3.2.4.

Na Figura 29, as duas faces horizontais estão impedidas de se movimentarem na direção y, enquanto que a face vertical esquerda está impedida de se movimentar na direção $\mathrm{x}$.

O objetivo deste exemplo é demonstrar que, durante a contração dos elementos de barra, tanto a rigidez da matriz quanto a rigidez das barras interferem nos deslocamentos finais da estrutura e, portanto, os deslocamentos finais não estão diretamente relacionados apenas com as contrações impostas nos elementos de barra. 


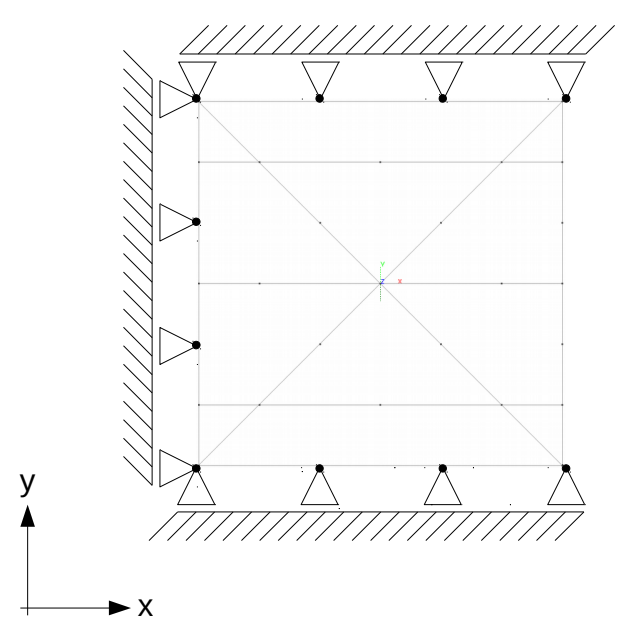

Figura 29 - Exemplo numérico 4

Para a matriz, o modelo constitutivo escolhido foi o de Saint Venant-Kirchhoff na forma $u_{e}=c_{10}(\operatorname{tr}(\mathbf{E}))^{2}+c_{20} \operatorname{tr}\left(\mathbf{E}^{2}\right)$ (ver Apêndice D). Para as barras foi escolhido um modelo consitutivo linear e unidimensional na forma $\tilde{\mathbf{P}}=\mathbb{E} \tilde{\boldsymbol{\epsilon}}$, onde $\tilde{\mathbf{P}}$ é a $1^{\text {a }}$ tensão de Piola-Kirchhoff e $\tilde{\boldsymbol{\epsilon}}$ é a deformação não linear de engenharia.

As propriedades adotadas para todos os elementos de barra são as seguintes: módulo de elasticidade $\mathbb{E}=2,1 \times 10^{6}$ e área da secção transversal $\mathrm{S}=1,0$. As propriedades utilizadas para o material da matriz (elementos de chapa) foram escolhidas de forma arbitrária. São elas:

$$
\mathbb{E}=2,1 \times 10^{6} \quad \nu=0,0 \quad G=\frac{\mathbb{E}}{2(1+\nu)} \quad k=\frac{\mathbb{E}}{3(1-2 \nu)}
$$

Os parâmetros $c_{10}, c_{20}$ do modelo de Saint Venant-Kirchhoff são as constante de Lamé, as quais podem ser escritas em função do módulo de elasticidade ao cisalhamento $G$ :

$$
c_{10}=\frac{G \nu}{1-2 \nu} \quad c_{20}=G
$$

A espessura adotada para todos os elementos de chapa foi de 1,0. A Figura 30 e a Figura 31 apresentam os deslocamentos e as tensões obtidas, respectivamente, na matriz e nos elementos de barra: 


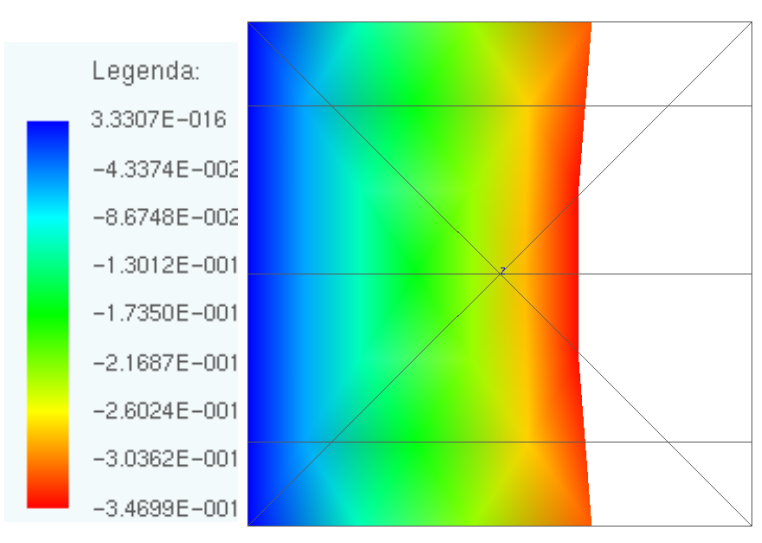

(a) Deslocamento na direção $\mathrm{x}$

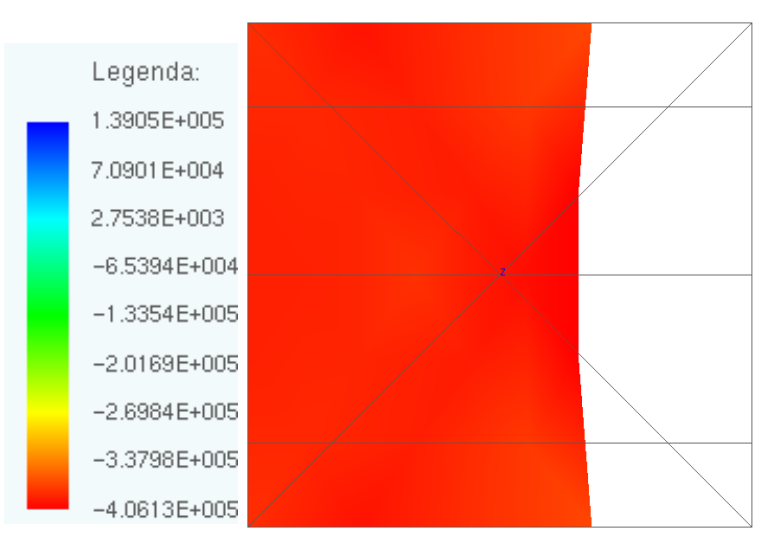

(c) Tensão de Cauchy na direção x

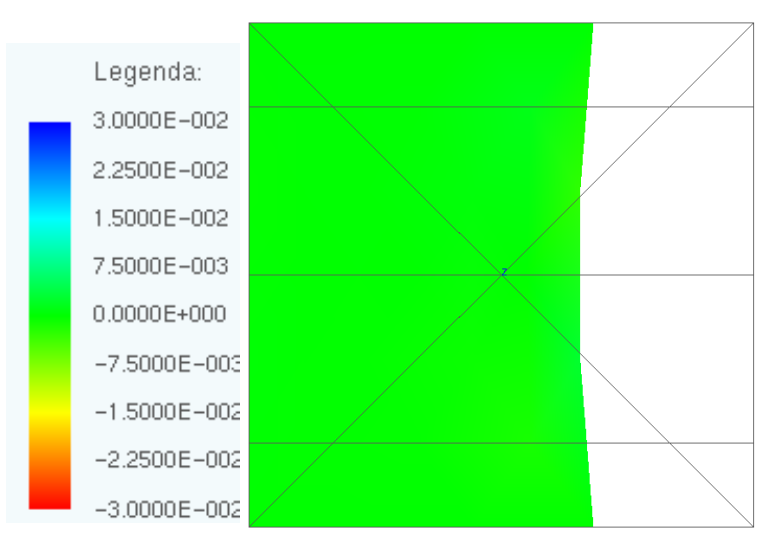

(b) Deslocamento na direção y

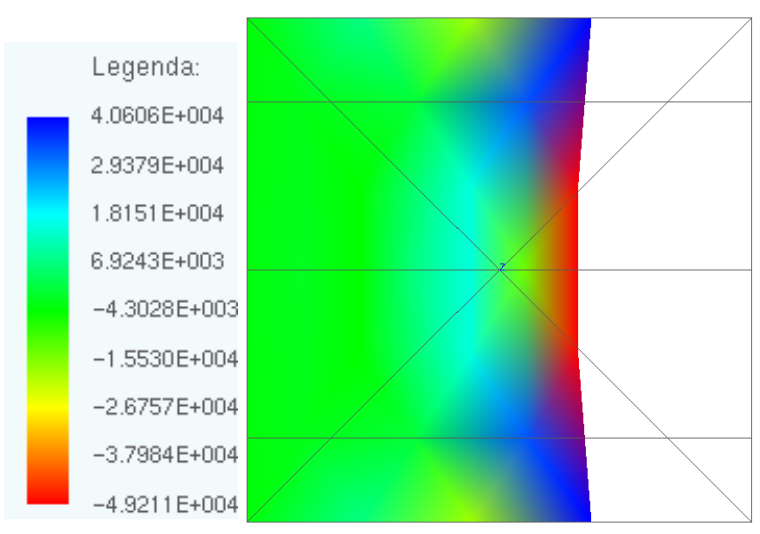

(d) Tensão de Cauchy na direção y

Figura 30 - Tensões e deslocamentos devido à contração das fibras

Na Figura 30 observam-se deslocamentos crescentes ao longo do eixo $x$, sendo $3,4699 \times 10^{-1}$ o valor máximo na face vertical direita. A tensão normal ao longo do eixo $x$ é de $4,0613 \times 10^{5}$ (compressão e praticamente constante), enquanto que as tensões obtidas na direção $y$ podem ser consideradas nulas se comparadas com a magnitude das tensões na direção do eixo $x$, já que a constante de Poisson $\nu$ foi adotada com valor igual a zero, não existindo, portanto, um "acoplamento" entre as direções $x$ e $y$. Devido às condições de contorno impostas, os deslocamentos obtidos na direção y são praticamente nulos. 


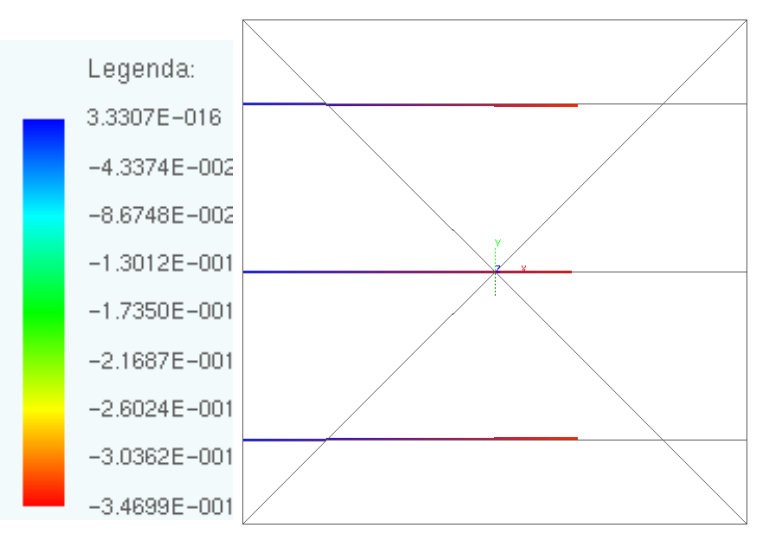

(a) Deslocamento na direção $\mathrm{x}$

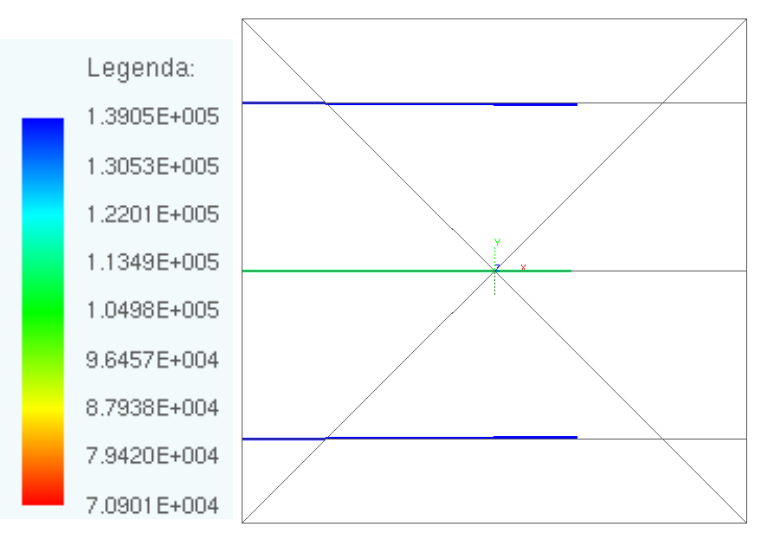

(b) Tensão de engenharia nas barras

Figura 31 - Tensões e deslocamentos nos elementos finitos de barra simples devido à contração das fibras

Na Figura 31 observam-se deslocamentos crescentes ao longo do eixo das barras, sendo $3,4699 \times 10^{-1}$ o valor máximo do deslocamento na extremidade da barra do centro e 3,3379 $\times 10^{-1}$ para as demais. Esse valor está de acordo com os deslocamentos obtidos para a matriz. Ao contrario do que foi obtido na Figura 30 para a matriz, a tensão normal nas barras é de tração e vale $1,11317 \times 10^{5}$ para a barra do centro e $1,39049 \times 10^{5}$ para as demais.

Observe que o deslocamento (encurtamento) horizontal obtido não foi exatamente a contração de 0,4 imposta nos elementos de barra. Isso acontece porque a contração imposta nos elementos de barra também contrai a matriz, a qual devido a sua rigidez, gera uma força oposta nos elementos de barra. Como essas barras também têm uma determinada rigidez, estas (as barras) tendem a se alongar, fazendo, portanto, com que o deslocamento (encurtamento) final da estrutura seja menor que a contração imposta. Logo, o deslocamento (encurtamento) final depende da relação entre as rigidezes da matriz e das barras.

Sendo a barra 1 a barra do centro e as barras 2 e 3, respectivamente, as barras acima e abaixo do eixo $x$ de referência, tem-se a seguinte situação: inicialmente as barras se contraem em 40\%, passando a ter um comprimento final de 0,6. A matriz se contrai e responde com uma força oposta proporcional a sua rigidez. Essa força então alonga a barra 1 em 0,4-0,34699 =0,05301 e as barras 2 e 3 em 0,4-0,333794 =0,06620, de tal forma que a $1^{\text {a }}$ tensão de Piola-Kirchhoff passa então a ser $\tilde{\mathbf{P}}=2,1 \times 10^{6} \times 0,05301=1,1132 \times 10^{5}$ na barra 1 e $\tilde{\mathbf{P}}=2,1 \times 10^{6} \times 0,06620=1,3902 \times 10^{5}$ nas barras 2 e 3 , conforme indicado na Figura 31.

Note ainda que o número de fibras e a área da secção transversal das barras bem como da matriz também influenciam nos deslocamentos finais, uma vez que existe entre a matriz e as barras um equilíbrio em forças. Isso pôde ser verificado no programa desenvolvido observando que, para o presente exemplo, um aumento (diminuição) da rigidez 
das barras ou diminuição (aumento) da rigidez da matriz reduz (aumenta) o alongamento das barras devido à força interna de reação gerada pela contração da matriz em oposição à contração das barras, fazendo, portanto, com que o deslocamento final fique mais próximo (longe) da contração imposta.

Da mesma forma, o mesmo vale para a área, ou seja, um aumento (diminuição) da área da seção transversal das barras ou diminuição (aumento) da área da seção transversal da matriz reduz (aumenta) o alongamento das barras devido à força interna de reação gerada pela contração da matriz em oposição à contração das barras, fazendo, portanto, com que o deslocamento final fique mais próximo (longe) da contração imposta.

Constatou-se também no programa desenvolvido que, um aumento do número de barras reduz o alongamento das barras devido à força interna de reação gerada pela contração da matriz em oposição à contração das barras, fazendo, portanto, com que o deslocamento final fique mais próximo da contração imposta.

Por exemplo, aumentando o número de elementos de barra distribuídos horizontalmente no presente exemplo de 3 para 10, o deslocamento final passa a ser de 0,38575 contra os 0,346699 originais com apenas 3 barras, ou seja, mais próximo da contração aplicada de 0,4. Isso acontece porque a força gerada pelas barras deve ser a mesma, no entanto, como existem um maior número de barras "disponíveis", a deformação adicional (sofrida depois da contração das mesmas devido à rigidez da matriz) de cada uma delas passa a ser menor.

Finalmente, observe que a contração final experimentada não pode ser controlada, pois, as contrações final e imposta na barra não são as mesmas. No entanto, um procedimento iterativo (entre os passos de tempo e o método de Newton-Raphson utilizado na solução do sistema não linear) pode ser adotado a fim de garantir uma contração final desejada nas barras. Seja $\epsilon_{f}$ a contração final desejada para a barra, tem-se a partir da Figura 7:

$$
\begin{aligned}
& \boldsymbol{\epsilon}_{t+1}=\boldsymbol{\epsilon}_{t+1}^{c}+\boldsymbol{\epsilon}_{t+1}^{v e} \rightarrow \boldsymbol{\epsilon}_{f}=\boldsymbol{\epsilon}_{t+1}^{c}+\boldsymbol{\epsilon}_{t+1}^{v e} \rightarrow \boldsymbol{\epsilon}_{t+1}^{c} \simeq \boldsymbol{\epsilon}_{f}-\boldsymbol{\epsilon}_{t}^{v e} \\
& \boldsymbol{\epsilon}_{t+1}^{c} \simeq \boldsymbol{\epsilon}_{f}-\left(\boldsymbol{\epsilon}_{t}-\boldsymbol{\epsilon}_{t}^{c}\right)
\end{aligned}
$$

Através desse procedimento iterativo verifica-se para o presente exemplo que para uma contração final nas barras de $\epsilon_{f}=0,35$ é necessário que a contração imposta nas barras seja de $\epsilon^{c}=-0,40304157$ (esse valor foi encontrado com 6 iterações do procedimento). A Figura 32 ilustra o resultado obtido aplicando-se uma contração de $\epsilon^{c}=-0,40304157$ nas barras: 


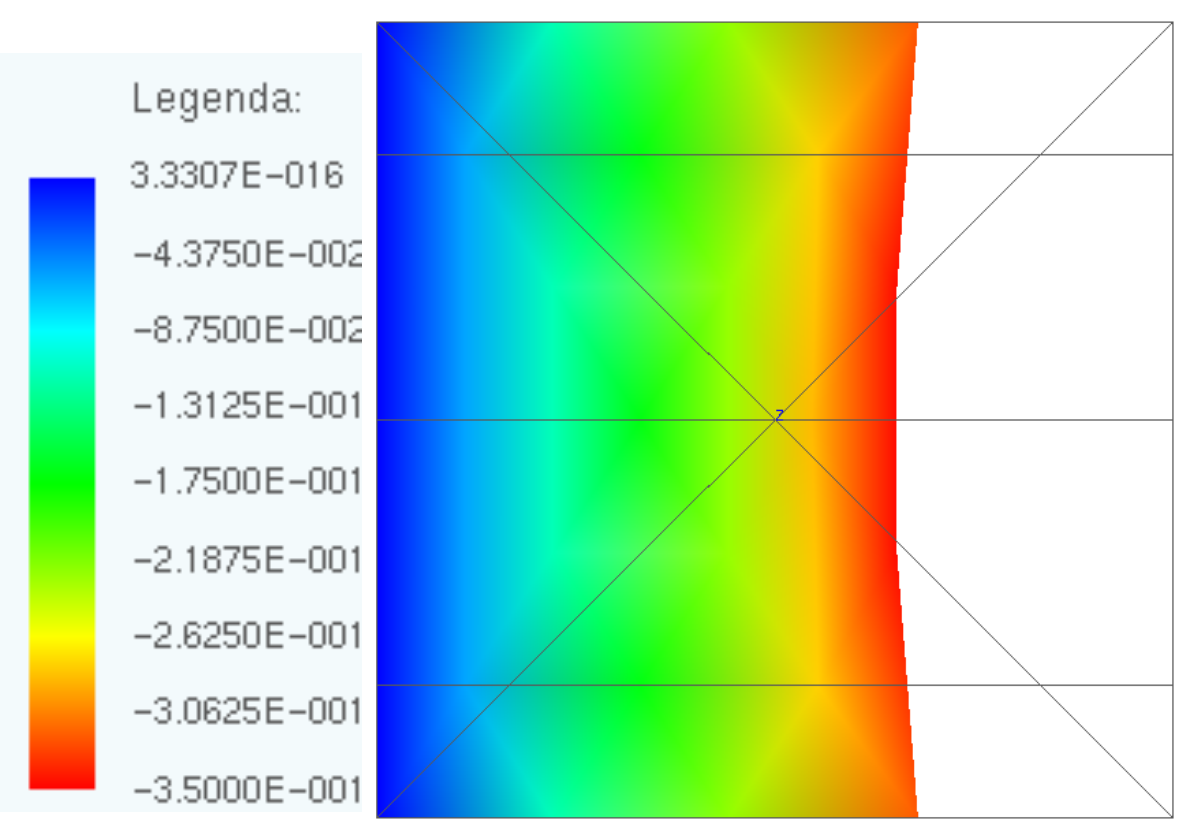

Figura 32 - Deslocamento na direção x com procedimento iterativo de contração das fibras

Verificou-se também que a formulação proposta funciona tanto para encurtamento ( $\epsilon^{c}$ negativo) quanto alongamento das barras ( $\epsilon^{c}$ positivo). A Figura 33 ilustra a resposta obtida para um alongamento de 0,52361808 imposto nas barras, o que resulta em um alongamento final de 0,35 e tensão de tração entre $1,0420 \times 10^{6}$ e 1,1909 × $10^{6}$ na direção $x$ na matriz.

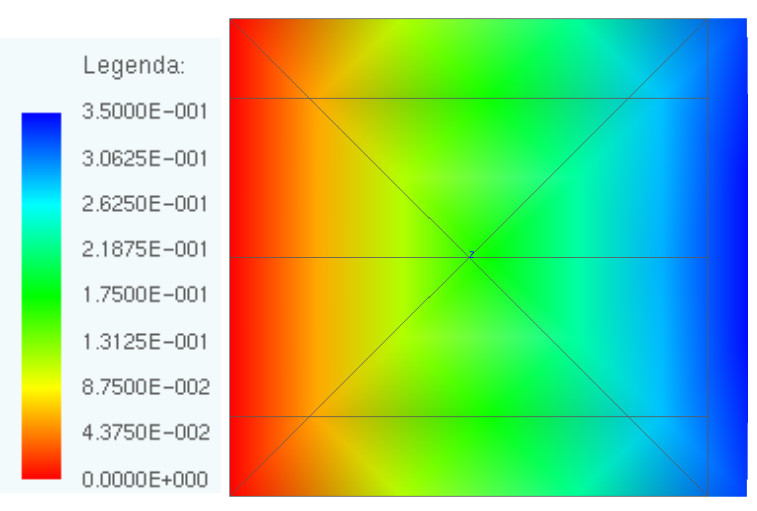

(a) Deslocamento na direção $\mathrm{x}$

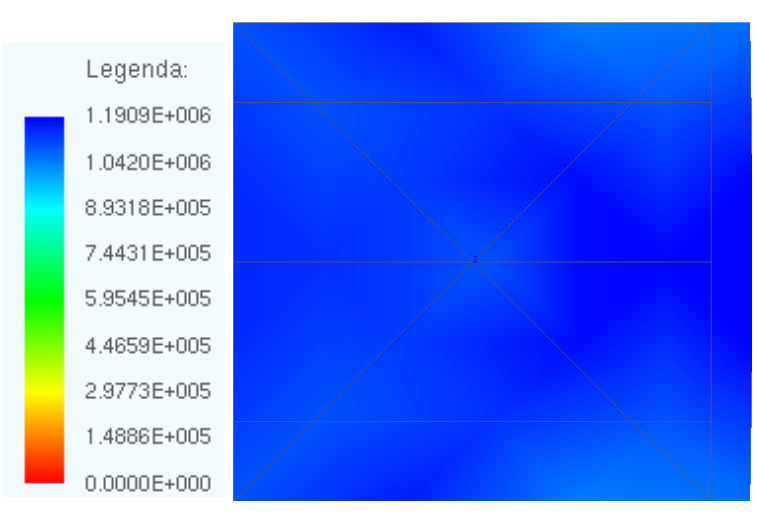

(b) Tensão de Cauchy na direção x

Figura 33 - Tensões e deslocamentos com procedimento iterativo de alongamento das fibras

A Figura 34 ilustra, conforme esperado, tensão de compressão para as barras. Os valores são de $-3,6460 \times 10^{5}$ para barra do centro e $-3,8446 \times 10^{5}$ para as demais. 


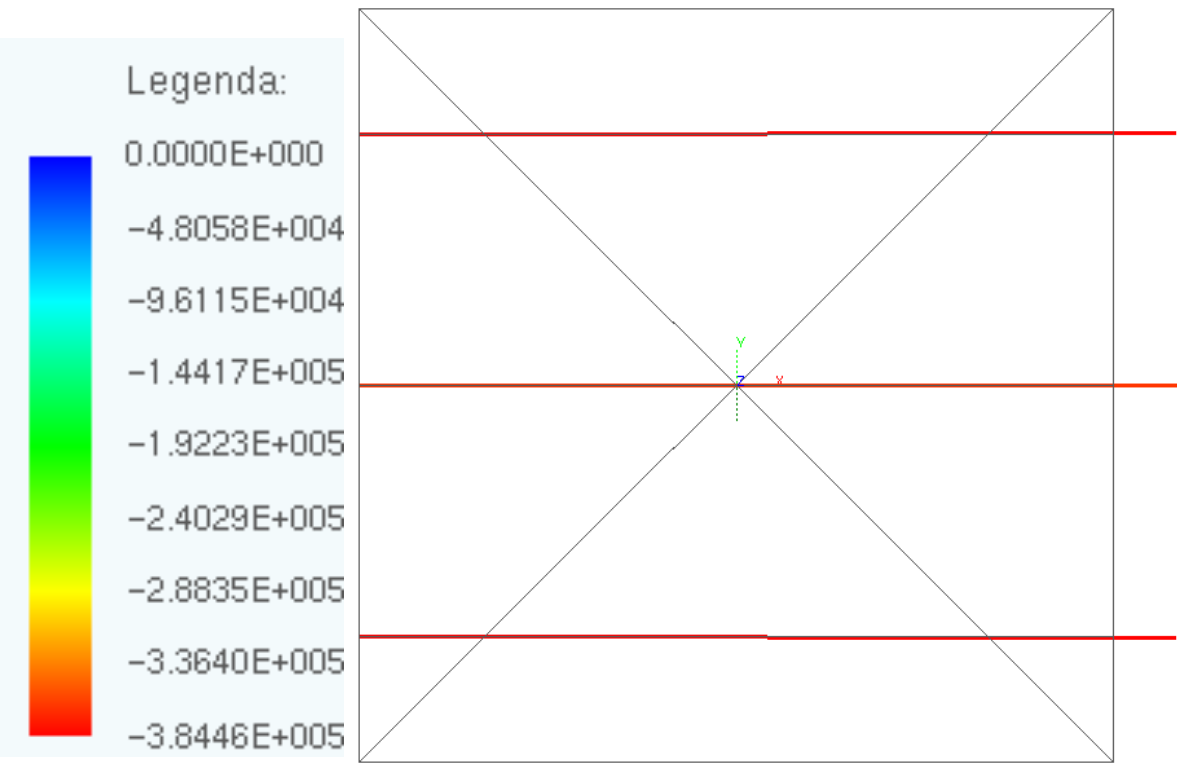

Figura 34 - Tensão nominal de engenharia nos elementos de barra simples com procedimento iterativo de alongamento das fibras

O encurtamento da barra do centro provocado pela força gerada pela matriz foi de $0,52361808-0,35=0,17361808$, o que gera a tensão compressiva de $-0,17361808 \times 2,1 \times$ $10^{6}=-3,64597 \times 10^{5}$ observada para esta barra.

A Figura 35 ilustra o mesmo exemplo da Figura 30, agora com os nós da face horizontal superior livres na direção $y$ e coeficiente de Poisson $\nu=0,49$. Conforme constatado utilizando-se o programa desenvolvido, se o coeficiente de Poisson adotado fosse zero, não existiria acoplamento entre as direções $x$ e $y$, e o deslocamento vertical na direção $y$ seria zero.

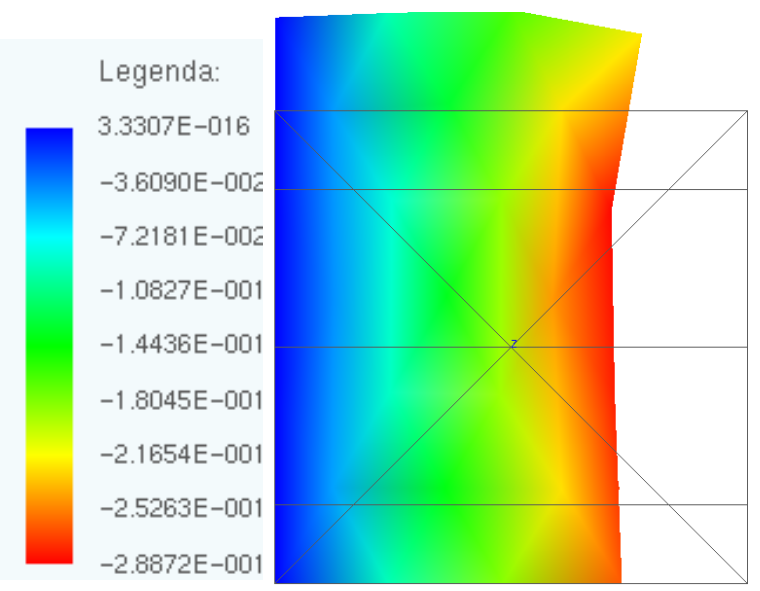

(a) Deslocamento na direção $\mathrm{x}$

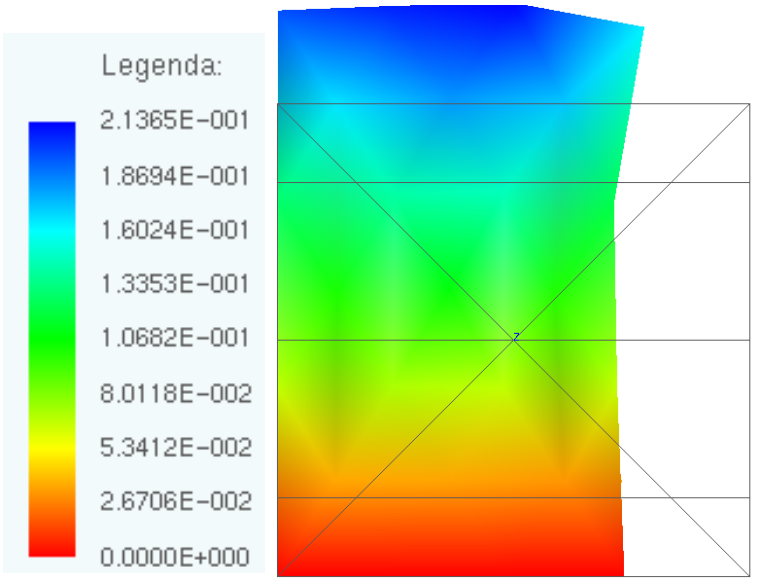

(b) Deslocamento na direção y

Figura 35 - Deslocamentos com coeficiente de Poisson diferente de zero e devido à contração das fibras 


\subsubsection{A contração como variação de temperatura}

A situação ilustrada na Figura 36, além de demonstrar a aplicabilidade do mecanismo de contração das fibras na solução de problemas envolvendo variação de temperatura, também constitui uma analogia interessante a cerca da interação que ocorre entre as fibras e a matriz. Essa analogia não só ilustra o funcionamento do mecanismo de contração, como também explica o porquê das contrações impostas na fibra não serem as contrações finais observadas para o conjunto fibras e matriz.

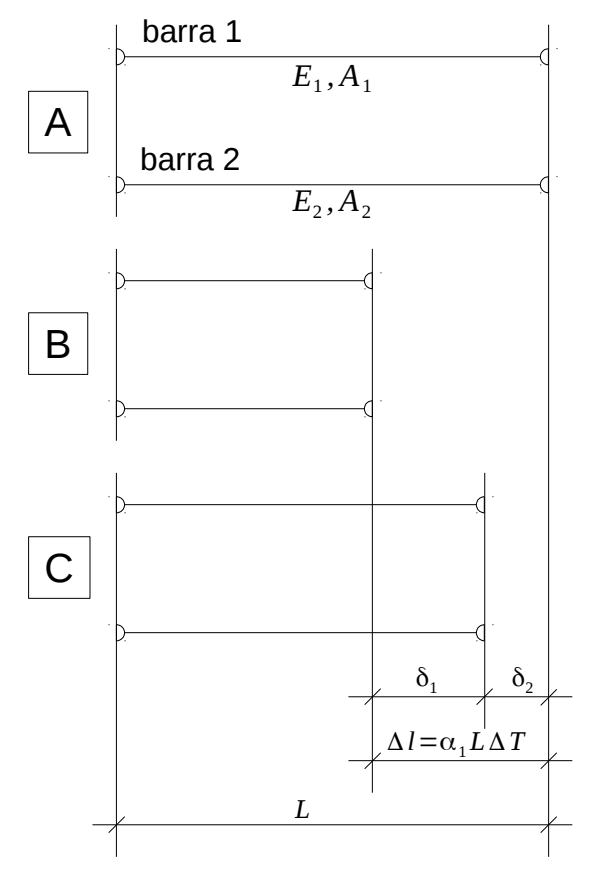

Figura 36 - Barras paralelas e sujeitas a variação de temperatura

Na Figura 36 têm-se, inicialmente e na ausência de forças externas, duas barras paralelas (1 e 2), respectivamente, com módulo de elasticidade $E_{1}$ e $E_{2}$ e área da seção transversal $A_{1}$ e $A_{2}$, em completo repouso (condição A). Aplicando-se uma variação de temperatura apenas na barra 1 e, considerando que as duas barras estejam "ligadas", ambas se alongam (ou encurtam) em $\Delta l=\alpha_{1} L \Delta T$ (condição B).

No entanto, uma vez tendo somente a barra 1 sido submetida à variação de temperatura, a barra 2 resiste ao encurtamento provocado pela varição de temperatura na barra 1 , fazendo com que ambas barras recuem $\delta_{1}$, de tal maneira que o alongamento final na barra 1 devido à resistência imposta pela barra 2 seja de $\delta_{1}$ e o encurtamento final da barra 2 provocado pela variação de temperatura da barra 1 seja de $\delta_{2}$ (condição C), demonstrando assim a existência de uma iteração entre as duas barras. A equação de equilíbrio das barras resulta em:

$$
N_{1}+N_{2}=0 \rightarrow N_{1}=-N_{2}
$$


Por outro lado, a equação de compatibilidade dos deslocamentos das barras fornece:

$$
\delta_{1}+\left(-\delta_{2}\right)=\alpha_{1} L \Delta T
$$

Considerando que as barras 1 e 2 sejam elementos "equivalentes" que representam, respectivamente, os elementos de fibra imersos e a matriz, e, combinando as Equações 4.18 e 4.19, obtém-se a força normal na barra $N_{1}$ :

$$
\begin{gathered}
\frac{N_{1} L}{n_{f} A_{1} E_{1}}-\frac{N_{2} L}{A_{2} E_{2}}=\alpha_{1} L \Delta T \rightarrow \frac{N_{1}}{n_{f} A_{1} E_{1}}+\frac{N_{1}}{A_{2} E_{2}}=\alpha_{1} \Delta T \\
N_{1}=\alpha_{1} \Delta T\left(\frac{1}{n_{f} A_{1} E_{1}}+\frac{1}{A_{2} E_{2}}\right)^{-1}
\end{gathered}
$$

Onde $n_{f}$ é a quantidade de elementos de barra simples. Considerando os seguintes valores numéricos:

$$
\begin{gathered}
\mathbb{E}_{1}=1,05 \times 10^{11} \quad A_{1}=0,4 \times 10^{-2} \quad \alpha_{1} \Delta T=1,0 \times 10^{-3} \quad n_{f}=50 \\
\mathbb{E}_{2}=2,10 \times 10^{11} \quad A_{2}=1,0 \times 10^{-2}
\end{gathered}
$$

Obtém-se uma força normal $N_{1}$ na barra 1 como sendo de:

$$
\begin{gathered}
N_{1}=10^{-3} \times\left(\frac{1}{50 \times 0,4 \times 10^{-3} \times 1,05 \times 10^{11}}+\frac{1}{1,0 \times 10^{-2} \times 2,1 \times 10^{11}}\right)^{-1} \\
N_{1}=1,05 \times 10^{6}
\end{gathered}
$$

A partir de onde conclui-se que o encurtamento $\delta_{2}$ final so conjunto é:

$$
\delta_{2}=\frac{N_{2} L}{A_{2} \mathbb{E}_{2}}=\frac{-N_{1} L}{A_{2} \mathbb{E}_{2}}=-\frac{1,05 \times 10^{6}}{1,0 \times 10^{-2} \times 2,1 \times 10^{11}} \rightarrow \quad \delta_{2}=-0,5 \times 10^{-3}
$$

De onde resultam as seguintes tensões nas barras $\left(\sigma_{1}\right)$ e na matriz $\left(\sigma_{2}\right)$ :

$$
\begin{gathered}
\sigma_{1}=\frac{\delta_{1} \mathbb{E}_{1}}{L}=\frac{0,5 \times 10^{-3}}{1,0} \times 1,05 \times 10^{11} \rightarrow \sigma_{1}=5,25 \times 10^{7} \\
\sigma_{2}=\frac{\delta_{2} \mathbb{E}_{2}}{L}=\frac{-0,5 \times 10^{-3}}{1,0} \times 2,1 \times 10^{11} \rightarrow \sigma_{2}=-1,05 \times 10^{8}
\end{gathered}
$$

Resolve-se agora o problema ilustrado na Figura 36 utilizando o programa desenvolvido conforme ilustrado na Figura 37. Nesse caso, as duas faces horizontais estão impedidas de se movimentarem na direção y, enquanto que a face vertical esquerda está impedida de se movimentar na direção x.

O esquema da Figura 37 consiste de um quadrado de lados unitários onde se encontram distribuídos 2500 elementos de barra (50 elementos distribuídos na direção 
vertical e, cada um desses 50 elementos, divididos em outros 50 elementos de tamanhos iguais) com 2 nós cada, totalizando 2550 nós de elementos de barra. Esses elementos de barra estão distribuídos na direção vertical de forma igualmente espaçadas em uma matriz discretizada em 200 elementos de chapa de 10 nós cada, totalizando 961 nós de elementos de chapa. Em cada um dos 2500 elementos de barra é aplicada uma deformação de contração de $1,0 \times 10^{-3}$, equivalente a $\alpha_{1} \Delta T=1,0 \times 10^{-3}$ das Equações 4.21. A medida de deformação utilizada para os elementos de barra é a não linear de engenharia conforme proposto na subseção 3.2.4.

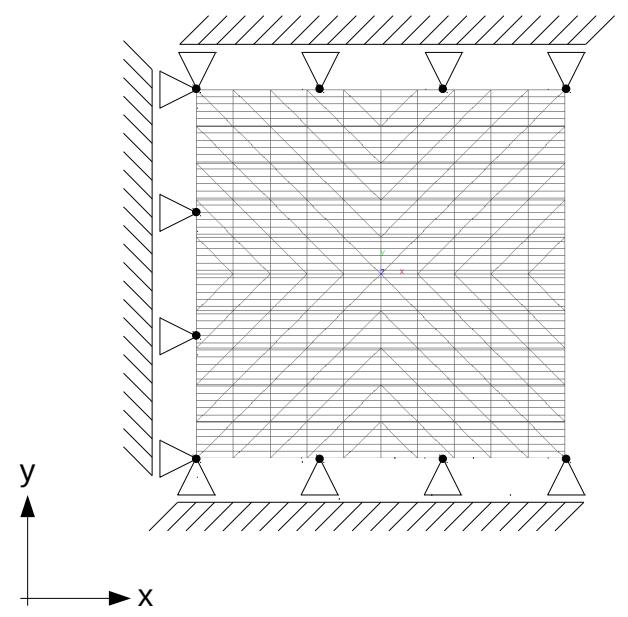

Figura 37 - Modelo de barras paralelas sujeitas a variação de temperatura

Assim, a quantidade de fibras é, portanto, $n_{f}=50$. O módulo de elasticidade e a área da seção transversal adotadas são, respectivamente, $\mathbb{E}_{1}$ e $A_{1}$ para a fibra e, $\mathbb{E}_{2}$ e $A_{2}$ para a matriz (Equação 4.21). Os deslocamentos obtidos no conjunto, bem como a tensão nos elementos de chapa são apresentadas na Figura 38.

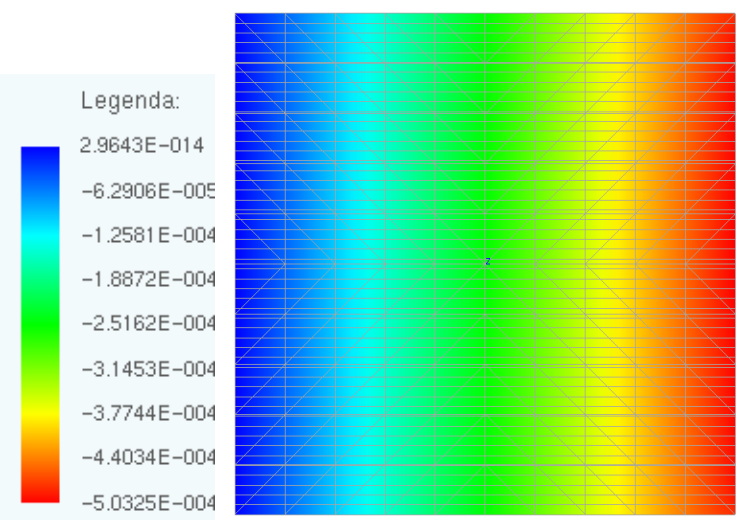

(a) Deslocamento na direção $x$

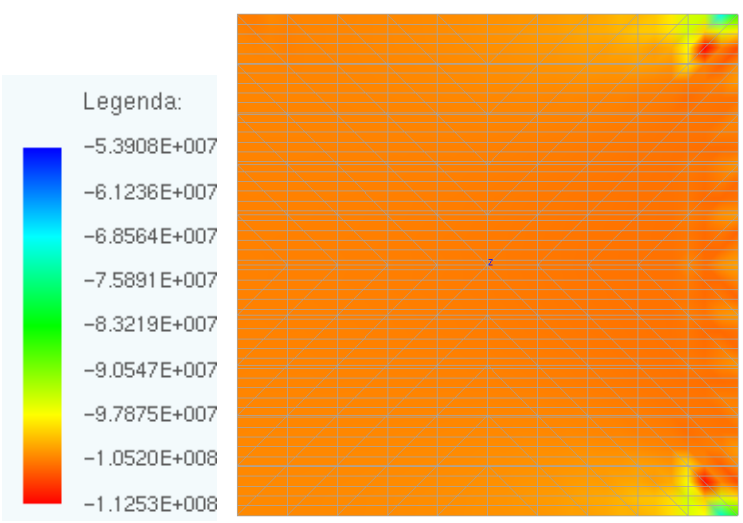

(b) Tensão de Cauchy na direção $\mathrm{x}$

Figura 38 - Tensões e deslocamentos devido ao encurtamento das fibras

O deslocamento obtido para o conjunto é menor do que $1 \%$ superior ao obtido 
na Equação 4.23 e, conforme o esperado, notam-se tensões compressivas na matriz com valores muito próximos daqueles obtidos na Equação 4.24. Por outro lado, a tensão de engenharia (Força/Área inicial) obtida nos elementos de barra são de tração e também estão próximas dos valores obtidos na Equação 4.24, conforme observa-se na Figura 39.
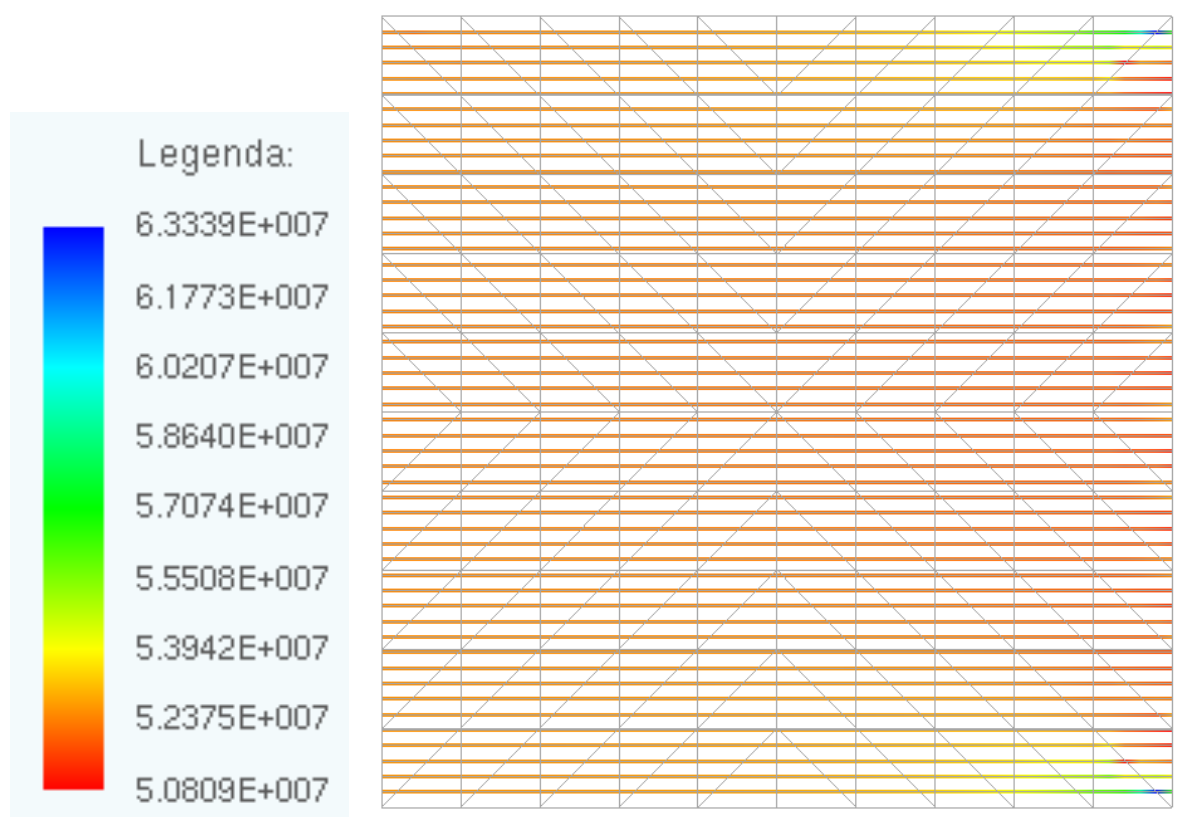

Figura 39 - Tensão nominal de engenharia nos elementos de barra simples devido ao encurtamento das fibras

\subsubsection{Tempos de processamento}

A Tabela 1 ilustra os tempos de processamento do esquema da Figura 37, obtidos durante as 8 iterações do método de Newton-Raphson que foram necessárias para atingir uma convergência em deslocamentos de $1 \times 10^{-10}$. Na referida tabela, exceto o procedimento de cálculo do vetor de forças internas das fibras chamado apenas de "Força interna fibras" e "Outros", todas as demais rotinas foram paralelizadas em linguagem OpenMP. 
Tabela 1 - Tempo de Processamento (em segundos)

\begin{tabular}{lcccccc}
\hline $\mathrm{N}^{\circ}$ de Threads & $1^{\dagger}$ & $1^{\ddagger}$ & $1^{\S}$ & 2 & 3 & 4 \\
\hline \hline Resolver sistema & 193,3689 & 0,8798 & 0,2338 & 0,1950 & 0,2129 & 0,2034 \\
\hline Força interna matriz & 1,1073 & 1,1964 & 1,1272 & 0,6239 & 0,7298 & 0,5956 \\
\hline Hessiana matriz & 1,5613 & 1,5540 & 1,5204 & 0,9028 & 1,1010 & 0,8850 \\
\hline Encontrar os nós das fibras & 0,6333 & 0,6480 & 0,6250 & 0,5977 & 0,4320 & 0,3890 \\
\hline Força interna fibras & 0,1541 & 0,1573 & 0,1573 & 0,1950 & 0,2464 & 0,1919 \\
\hline Hessiana fibras & 0,2013 & 0,1950 & 0,1856 & 0,1342 & 0,1447 & 0,1017 \\
\hline Tempo total & 197,0264 & 4,6305 & 3,8493 & 2,6487 & 2,8668 & 2,3666 \\
\hline \hline Outros & 0,8053 & 0,8137 & 0,8221 & 0,8965 & 0,9227 & 0,9070 \\
\hline
\end{tabular}

Nota: $\dagger$ - Solução do sistema linear resultante utilizando o método de decomposição LU

$\ddagger$ - Solução do sistema linear resultante utilizando o solver MA28 ${ }^{1}$

$\S$ - Solução do sistema linear resultante utilizando o solver HSL_86 ${ }^{2}$

onde na Tabela 1 "Outros" são as tarefas não relacionadas diretamente aos procedimentos paralelizados (resolver sistema, força interna matriz, hessiana matriz, encontrar os nós das fibras e hessiana fibras), tais como: leitura do arquivo de entrada, montagem do vetor de forças internas global da matriz, montagem da hessiana global da matriz, cálculo do vetor de forças internas das fibras, espalhamento do vetor de forças internas das fibras no vetor de forças internas da matriz, espalhamento da hessiana das fibras na hessiana da matriz, aplicação das condições de contorno e escrita dos arquivos de saída. "Tempo Total" é a soma das 6 tarefas anteriores da Tabela 1.

Na Tabela 2 estão apresentados os ganhos obtidos com as paralelizações com relação aos tempos da $3^{\text {a }}$ coluna da Tabela 1.

Tabela 2 - Ganhos obtidos com a paralelização

\begin{tabular}{lcccc}
\hline & 1 Thread & 2 Threads & 3 Threads & 4 Threads \\
\hline \hline Speedup & 1,0000 & 1,3177 & 1,2327 & 1,4270 \\
\hline Eficiência da Paralelização & $100,0000 \%$ & $65,8834 \%$ & $41,0907 \%$ & $35,6748 \%$ \\
\hline
\end{tabular}

onde "Speedup" é o tempo de execução sequencial dividido pelo tempo de execução em paralelo $($ Ex: $(3,8493+0,8221) /(2,6487+0,8965)=1,3177)$ e representa uma medida da aceleração obtida com a paralelização. Já a "Eficiência da Paralelização" é o "Speedup" dividido pelo número de threads utilizados (Ex: 1,3177/2 =65,8834\%) e pode ser entendida como uma medida da utilização ou ocupação média dos threads, ou seja, uma eficiência de $35,6748 \%$ significa que, na média, os threads estão $35,6748 \%$ do tempo de execução do

\footnotetext{
${ }^{1}$ STFC Rutherford Appleton Laboratory (2015b)
}

${ }^{2}$ STFC Rutherford Appleton Laboratory (2015a) 
programa trabalhando e 64,3252\% do tempo parados. Esses conceitos são detalhados em Chapman, Jost e Pas (2008).

O levantamento dos tempos foi feito em um notebook Samsung modelo NP270E5G - XD1BR com processador Intel i5-3230M @ 2.60GHz × 4, 7,7 GiB de memória RAM, sistema operacional Linux Ubuntu versão 15.10 e compilador GNU Fortran versão 5.2.1.

\subsection{Braço Biomecânico}

Este exemplo demonstra a aplicabilidade da formulação posicional do método dos elementos finitos conforme a subseção 3.2 .3 e da técnica de imersão de fibras apresentada na subseção 3.2.5 na modelagem de estruturas biológicas. O presente exemplo atesta o potencial do modelo viscoelástico ativo (contração/alongamento) para elementos de barra simples que utilizam a medida de deformação não linear de engenharia, conforme desenvolvido na subseção 3.2.4.

A fim de comprovar a superioridade de outros modelos hiperelásticos com relação ao modelo hiperelástico de Saint Venant-Kirchhoff, expõe-se aqui uma limitação do modelo de Saint Venant-Kirchhoff. Dessa forma, pretende-se ilustrar de forma bastante clara a melhoria na qualidade das análises que pode ser obtida com a utilização de leis constitutivas hiperelásticas (subseção 3.1.10) em um código de elementos finitos posicional (subseção 3.2.3)

A Figura 40 apresenta um modelo de um braço onde se encontram imersos 7350 elementos de barra de 2 nós cada, totalizando 7420 nós de elementos de barra. Esses elementos de barra estão distribuídos em uma matriz discretizada em 640 elementos de chapa de 10 nós cada, totalizando 3031 nós de elemento de chapa. Os elementos de chapa em azul (elementos de número 1-200) representam tecido duro, enquanto que os elementos de chapa em vermelho (elementos de número 201 - 640) representam a tecido mole. Os 7350 elementos de barra simples são igualmente distribuídos em 3675 fibras superiores (elementos de número 1 - 3675) e 3675 fibras inferiores (elementos de número 3676 - 7350). Na Figura 40, a face vertical esquerda esta impedida de se movimentar tanto na direção $x$ quanto na direção $y$. O modelo da Figura 40 é o mesmo utilizado em Baiocco, Coda e Paccola (2013).

O objetivo deste exemplo é englobar todos os conceitos estudados ao longo desse trabalho e demonstrar a aplicabilidade das formulações desenvolvidas. 


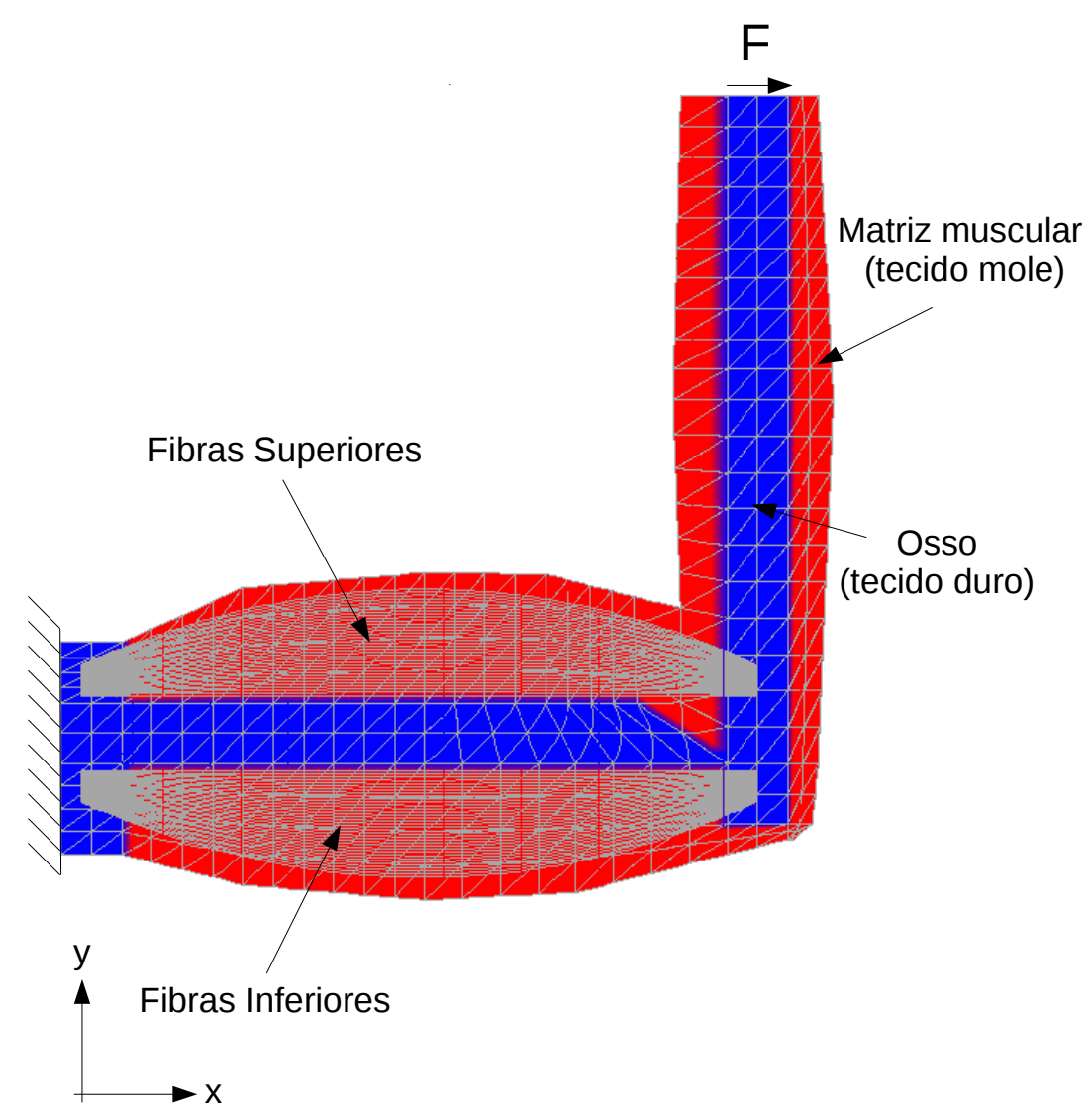

Figura 40 - Exemplo numérico 5

Inicialmente o modelo constitutivo escolhido foi o de Saint Venant-Kirchhoff na forma $u_{e}=c_{10}(t r(\mathbf{E}))^{2}+c_{20} t r\left(\mathbf{E}^{2}\right)$ (ver Apêndice D), tanto para o tecido mole (elementos em vermelho) quanto para tecido duro (elementos em azul). Logo, a relação entre tensão e deformação é linear conforme a Equação D.13. Como neste exemplo o estado plano adotado é o de deformações, a terceira, quinta e sexta linhas e colunas na Equação D.13 são eliminadas.

O módulo de elasticidade adotado para as fibras superiores é $\mathbb{E}=0,3 \times 10^{6}$ e para as fibras inferiores é de $\mathbb{E}=0,3 \times 10^{3}$. A área da secção transversal de todas as fibras é $\mathrm{S}=1,0 \times 10^{-1}$. As propriedades utilizadas para tecido duro (elementos em azul) são:

$$
\mathbb{E}=1,5 \times 10^{8} \quad \nu=0,0 \quad G=\frac{\mathbb{E}}{2(1+\nu)} \quad k=\frac{\mathbb{E}}{3(1-2 \nu)}
$$

As propriedades utilizadas para o tecido mole (elementos em vermelho) são:

$$
\mathbb{E}=0,3 \times 10^{3} \quad \nu=0,0 \quad G=\frac{\mathbb{E}}{2(1+\nu)} \quad k=\frac{\mathbb{E}}{3(1-2 \nu)}
$$

Os parâmetros $c_{10}, c_{20}$ do modelo de Saint Venant-Kirchhoff são as constante de Lamé, as quais podem ser escritas em função do módulo de elasticidade ao cisalhamento 
$G$ :

$$
c_{10}=\frac{G \nu}{1-2 \nu} \quad c_{20}=G
$$

A força horizontal $F$ da Figura 40, que é de 320, está uniformemente distribuída na face dos dois elementos de tecido duro na extremidade do antebraço. Na Figura 41 são apresentados os resultados obtidos com fibras formuladas a partir de elementos de barra simples que utilizam a deformação de Green-Lagrange e o $2^{\circ}$ tensor de tensões de Piola-Kirchhoff e elementos de barra simples que utilizam a deformação não linear de engenharia e o $1^{\circ}$ tensor de tensões de Piola-Kirchhoff.

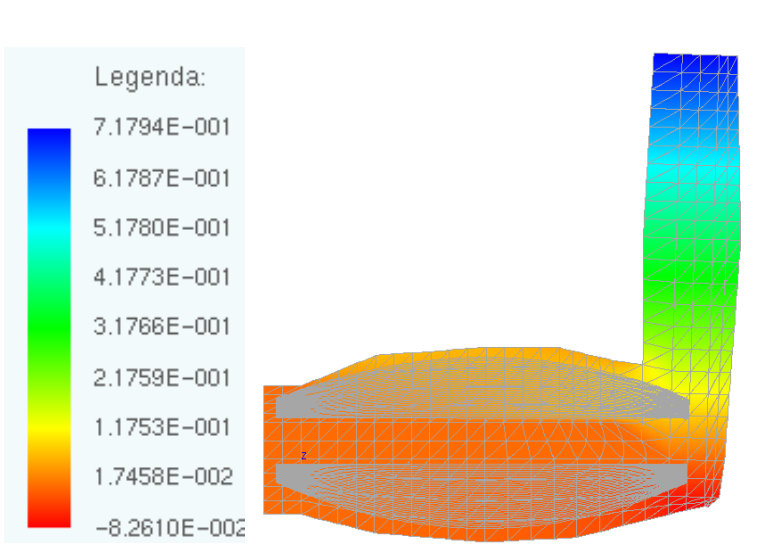

(a) Fibras com deformação de Green-Lagrange

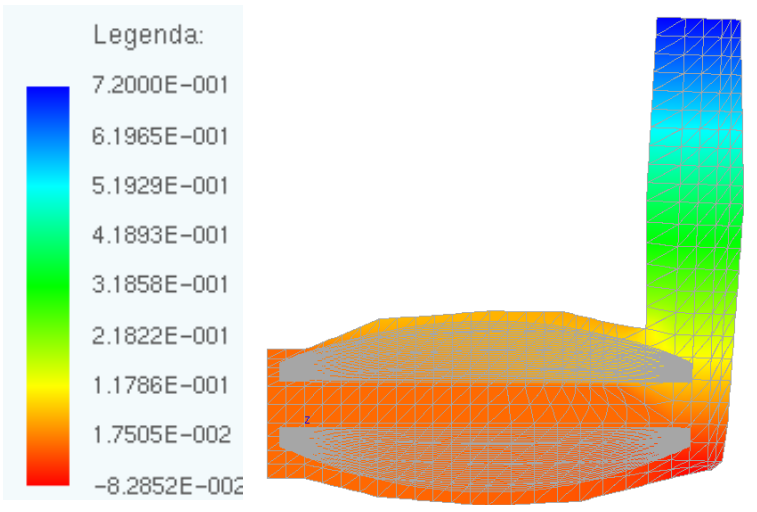

(b) Fibras com deformação não linear de engenharia

Figura 41 - Deslocamentos na direção x

O resultado obtido utilizando elementos de barra simples com deformação de GreenLagrange e o $2^{\circ}$ tensor de tensões de Piola-Kirchhoff para as fibras é praticamente idêntico ao obtido por Baiocco, Coda e Paccola (2013). Em se tratando de pequenos deslocamentos, esse resultado é próximo da solução obtida com elementos de barra simples que utilizam deformação não linear de engenharia e o $1^{\circ}$ tensor de tensões de Piola-Kirchhoff (cerca de $0.2 \%$ menor), conforme verifica-se na Figura 41, pois, em regime de pequenos deslocamentos (e deformações), tais medidas de deformação e tensão se confundem.

\subsubsection{Modelo neo-hookeno}

Com o propósito de se observar grandes deslocamentos e deformações moderadas, o módulo de elasticidade $\mathbb{E}$ das fibras superiores é reduzido de $\mathbb{E}=0,3 \times 10^{6}$ para $\mathbb{E}=0,3 \times 10^{4}$ e as propriedades dos elementos de chapa em azul (tecido duro) e vermelho (tecido mole) mantidas as mesmas de 4.25 e 4.26 , respectivamente.

Baseado na parcela de energia de deformação $\frac{1}{2} \mathbb{E} \epsilon^{2}$, propõe-se um modelo hiperelástico neo-hookeano da forma:

$$
u_{e}=c_{10}\left(\bar{I}_{1}-3\right)+\frac{1}{2} k(J-1)^{2} \quad \text { onde } \quad c_{10}=\frac{G}{2}
$$


Os resultados obtidos com a lei constitutiva hiperelástica de Saint Venant-Kirchhoff e com o modelo hiperelástico neo-hookeano proposto na Equação 4.28 são comparados na Figura 42. Em ambos os casos as fibras são consideradas elementos de barra simples formulados a partir da deformação não linear de engenharia e do $1^{\circ}$ tensor de tensões de Piola-Kirchhoff.

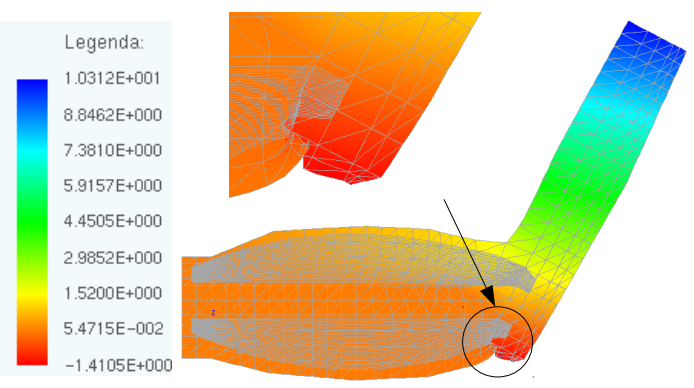

(a) Modelo hiperelástico de Saint VenantKirchhoff

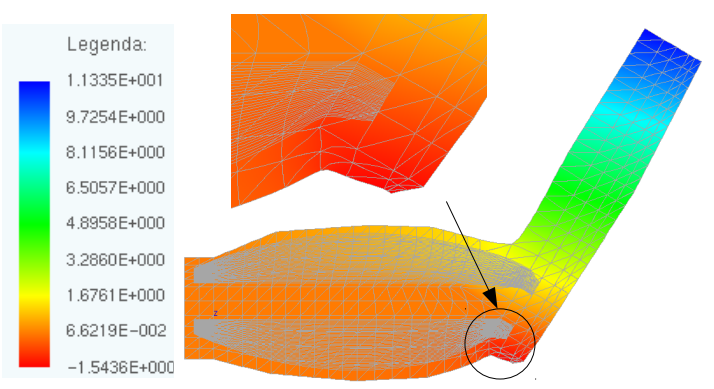

(b) Modelo hiperelástico neo-hookeano

Figura 42 - Deslocamentos na direção x

Na Figura 42 observa-se que a lei constitutiva de Saint Venant-Kirchhoff permite a auto-intersecção de material, ao passo que a lei constutiva hiperelástica neo-hookeana proposta, embora simples, é fisicamente mais consistente (mesmo que o deslocamento seja cerca de $9 \%$ maior). A auto intersecção no modelo de Saint Venant-Kirchhoff atrapalha a convergência do programa, sendo portanto notável a maior facilidade de convergência do modelo neo-hookeano. Para a Figura 42, a tolerância em deslocamentos de 1,0 × 10 com o modelo de Saint Venant-Kirchhoff foi atingida em 13 iterações do método de Newton-Raphson contra 8 iterações do modelo neo-hookeano proposto.

A Figura 43 apresenta as tensões de Cauchy nas direções $x$ e $y$ para o modelo hiperelástico neo-hookeano.

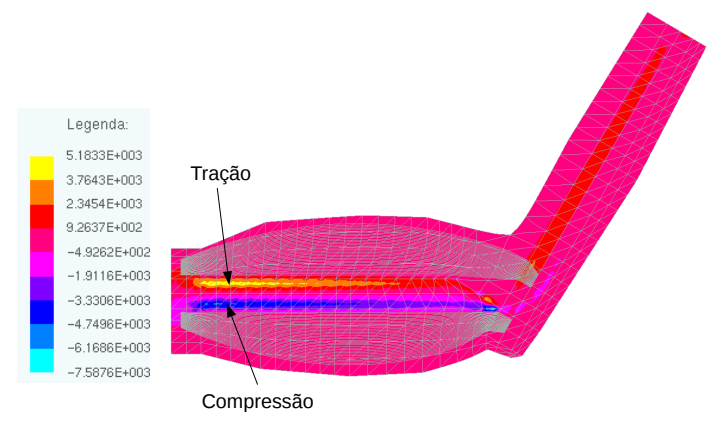

(a) Tensão de Cauchy na direção x

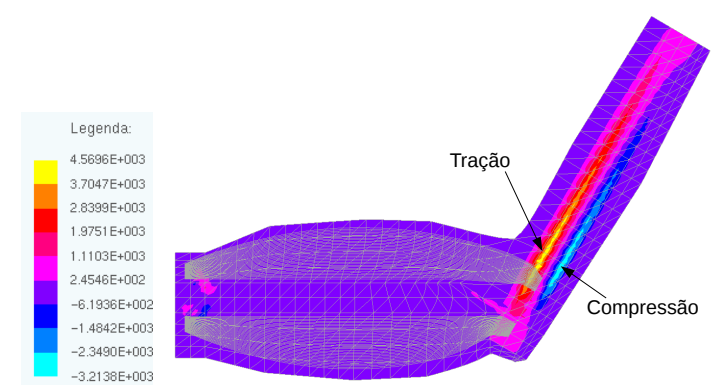

(b) Tensão de Cauchy na direção y

Figura 43 - Tensões de Cauchy nas direções x e y

Na Figura 43 notam-se tensões de compressão e tração no osso, respectivamente, nas porções inferior e superior do bíceps, bem como do lado esquerdo e direito do antebraço. 
Esses resultados estão de acordo com os deslocamentos calculados e o sentido da carga aplicada. Observe ainda que, sendo a rigidez do tecido mole menor que a rigidez do tecido duro, as tensões na matriz muscular são bem menores que as tensões no osso.

\subsubsection{Viscoelasticidade}

Mantendo o módulo de elasticidade das fibras superiores em $\mathbb{E}=0,3 \times 10^{4}$ e das fibras inferiores em $\mathbb{E}=0,3 \times 10^{3}$ e, adotando as propriedades para os elementos de chapa em azul (tecido duro) e vermelho (tecido mole), respectivamente, conforme 4.25 e 4.26 , determinam-se os deslocamentos da estrutura da Figura 40 sob a ação da força horizontal $F$ de 320 ao longo de 500 passos de tempo utilizando um passo de tempo $\Delta t=0,5 \times 10^{-4} \mathrm{e}$ um coeficiente de viscosidade $c$ de 15 para os elementos de fibra. A lei constitutiva adotada para todos os elementos de chapa é a neo-hookena proposta na Equação 4.28. As fibras são consideradas elementos de barra simples formulados a partir da deformação não linear de engenharia e do $1^{\circ}$ tensor de tensões de Piola-Kirchhoff.

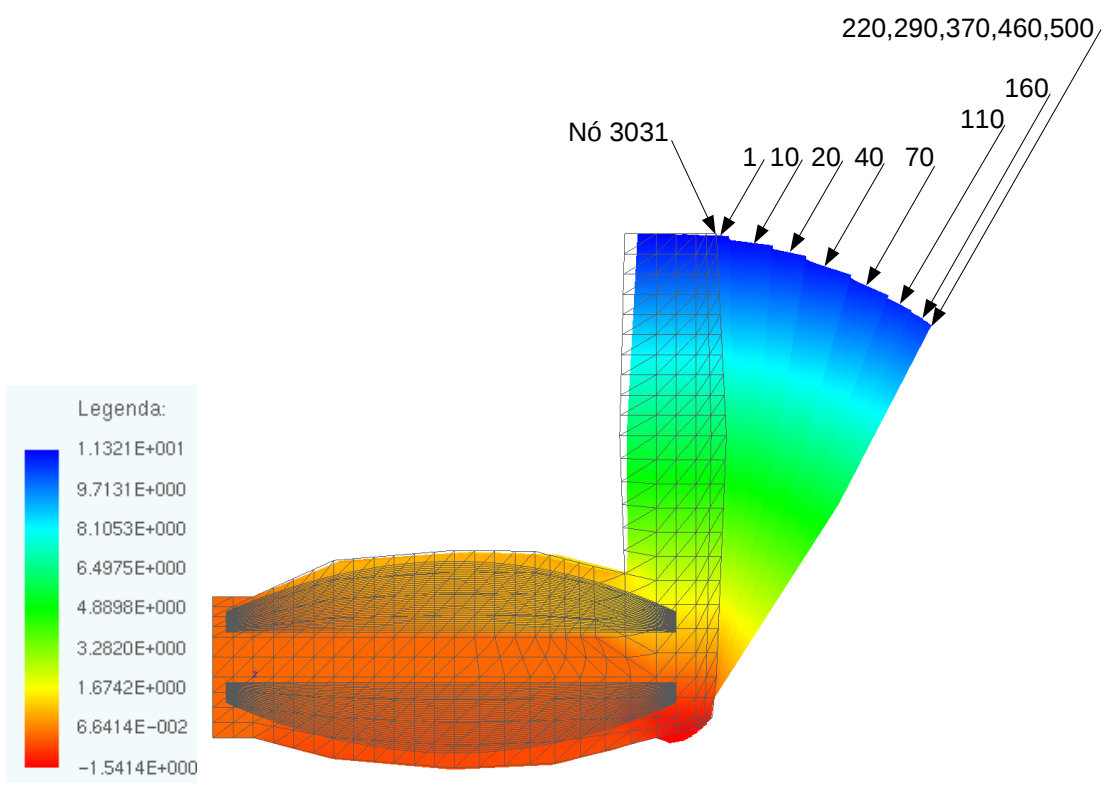

Figura 44 - Deslocamentos na direção x

$\mathrm{Na}$ Figura 44 nota-se que foi possível introduzir um efeito viscoso na estrutura a partir da consideração de fibras formuladas a partir de elementos de barra simples viscoelásticos, conforme a subseção 3.2.4. Ao final dos 500 passos de tempo, os deslocamentos na direção $x$ são os apresentados na legenda da Figura 44, estando estes em conformidade com os obtidos na Figura 42. Os deslocamentos ilustrados na Figura 44 referem-se aos passos de tempo 1, 10, 20, 40, 70, 110, 160, 220, 290, 370, 460, 500. A Figura 45 apresenta os deslocamentos (em módulo) na direção $x$ e $y$ do nó 3031 na extremidade do braço. 


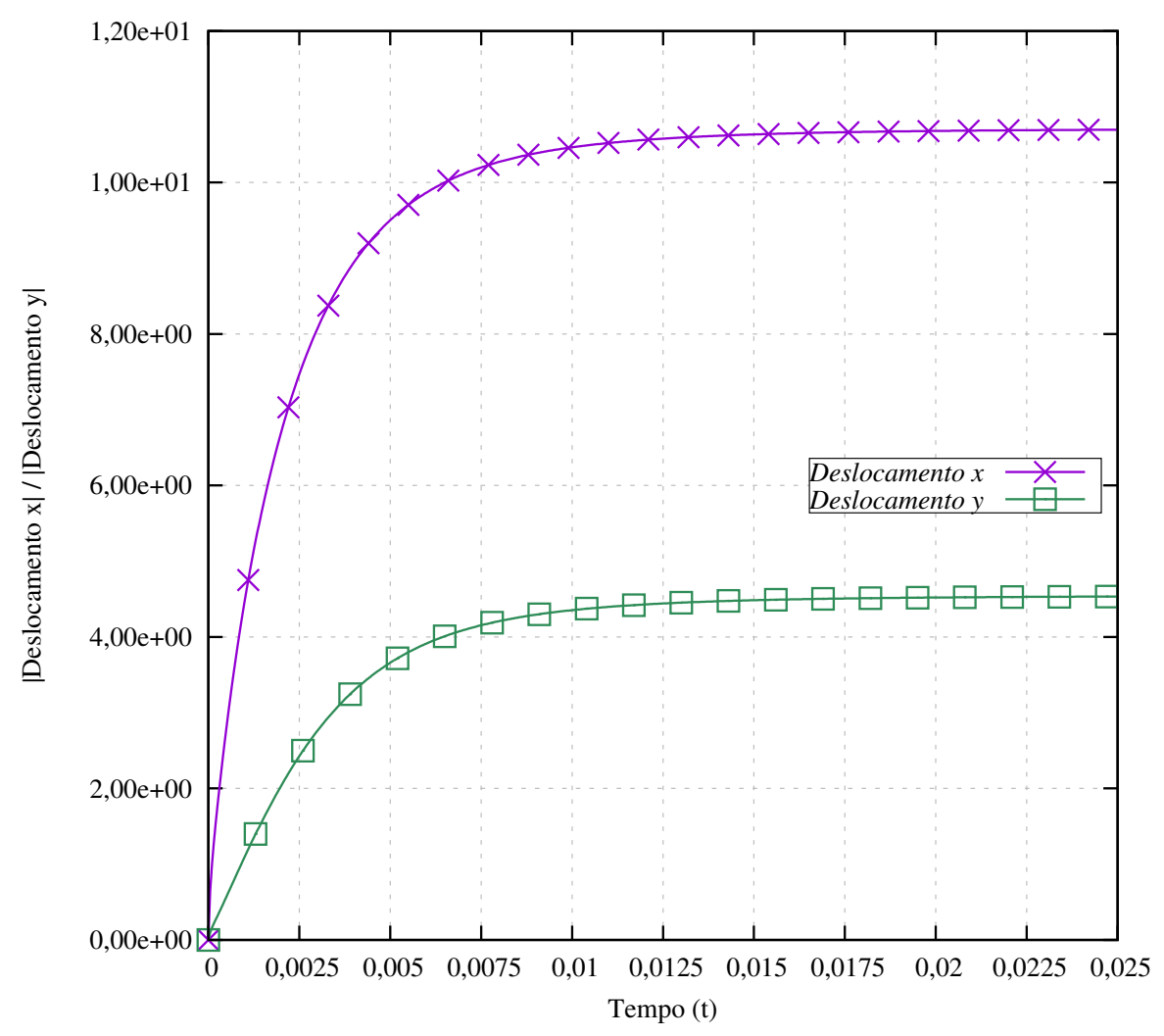

Figura 45 - Deslocamentos nas direções x e y do nó 3031

Observe na Figura 44 e na Figura 45 que no passo de tempo 160 (tempo $290 \times$ $0,5 \times 10^{-4}=0,0145$ na Figura 45), a estrutura praticamente já atingiu a configuração final de equilíbrio, não havendo, portanto, mais mudança de posição a partir deste ponto.

\subsubsection{Tempos de processamento}

Da mesma forma que na subseção 4.4.2, a Tabela 3 e a Tabela 4 apresentam os ganhos de tempo obtidos na execução do problema da subseção 4.5.2 em paralelo utilizando a biblioteca OpenMP. 
Tabela 3 - Tempo de Processamento (em segundos)

\begin{tabular}{lccccc}
\hline $\mathrm{N}^{\circ}$ de Threads & 1 & 2 & 3 & 4 & $24^{\dagger}$ \\
\hline \hline Resolver sistema & 269,5176 & 228,9922 & 223,1789 & 221,7015 & 85,0940 \\
\hline Força interna matriz & 371,1655 & 193,1288 & 137,6277 & 105,7132 & 28,1857 \\
\hline Hessiana matriz & 398,5040 & 224,7004 & 153,8806 & 123,1332 & 40,5338 \\
\hline Encontrar os nós das fibras & 7,3437 & 4,2100 & 3,8913 & 2,1957 & 1,8790 \\
\hline Força interna fibras & 36,1151 & 44,3527 & 44,8738 & 44,0716 & 27,6489 \\
\hline Hessiana fibras & 44,4481 & 29,7366 & 20,8373 & 16,5056 & 6,4425 \\
\hline Tempo total & 1127,0940 & 725,1207 & 584,2896 & 513,3208 & 189,7839 \\
\hline \hline Outros & 276,0188 & 255,1426 & 275,5511 & 259,0706 & 223,6067 \\
\hline No:
\end{tabular}

Nota: $†$ - Utilizando o cluster Intel Xeon X5660

Solução dos sistema lineares resultantes utilizando o solver HSL_ $86^{3}$

As rotinas paralelizadas bem como o significado dos termos que constam na Tabela 3 e na Tabela 4 são idênticos aos da subseção 4.4.2. O computador utilizado no levantamento dos tempos foi um desktop com processador Intel@ Core i5-2500 CPU @ 3.30GHz $\times 4$, 3,8 GiB de memória RAM, sistema operacional Linux Ubuntu versão 15.10 e compilador GNU Fortran versão 5.2.1.

Tabela 4 - Ganhos obtidos com a paralelização

\begin{tabular}{lccccc}
\hline & 1 Thread & 2 Threads & 3 Threads & 4 Threads & 24 Threads \\
\hline \hline Speedup & 1,0000 & 1,4314 & 1,6318 & 1,8166 & 3,3942 \\
\hline Eficiência da Paralelização & $100,00 \%$ & $71,57 \%$ & $54,39 \%$ & $45,41 \%$ & $14,14 \%$ \\
\hline
\end{tabular}

Observa-se na Tabela 4 um aumento do speedup com o aumento do número de threads utilizados e, assim como na subseção 4.4.2, nota-se que esse aumento do speedup também vem acompanhado de uma redução na eficiência da paralelização. Logo, tudo indica como sendo 2 o número ótimo de threads a ser adotado na resolução dos problemas em questão com o computador utilizado.

\subsubsection{Contração das fibras}

Considerando o módulo de elasticidade das fibras superiores e inferiores $\mathbb{E}=0,3 \times 10^{3}$ e, adotando um modelo constitutivo neo-hookeano para todos os elementos de chapa com propriedades para tecido duro (elementos em azul) e para a tecido mole (elementos em vermelho), respectivamente, de acordo com 4.25 e 4.26, o mecanismo de contração das fibras formuladas a partir de elementos de barra simples que utilizam a deformação não

\footnotetext{
${ }^{3}$ STFC Rutherford Appleton Laboratory (2015a)
} 
linear de engenharia e o $1^{\circ}$ tensor de tensões de Piola-Kirchhoff apresentado na 3.2.4 é demonstrado em 4 passos de tempo e na ausência de cargas externas da seguinte forma:

1. Todas as fibras superiores (elementos de barra simples número 1-3675) são contraídas em $50 \%$, enquanto que as fibras inferiores são deixadas livres para se alongarem ou se contraírem;

2. A contração imposta nos elementos de fibra superiores é retirada e todas as fibras são deixadas livres para se alongarem ou se contraírem;

3. Todas as fibras inferiores (elementos de barra simples número 3676 - 7350) são contraídas em 90\%, enquanto que as fibras superiores são deixadas livres para se alongarem ou se contraírem;

4. A contração imposta nos elementos de fibra inferiores é retirada e todas as fibras são deixadas livres para se alongarem ou se contraírem;

Como era se esperar, a Figura 46 demonstra que a contração das fibras superiores correspondentes ao bíceps desloca o braço para a esquerda, ao passo que a contração das fibras inferiores correspondentes ao tríceps desloca o braço para a direita.

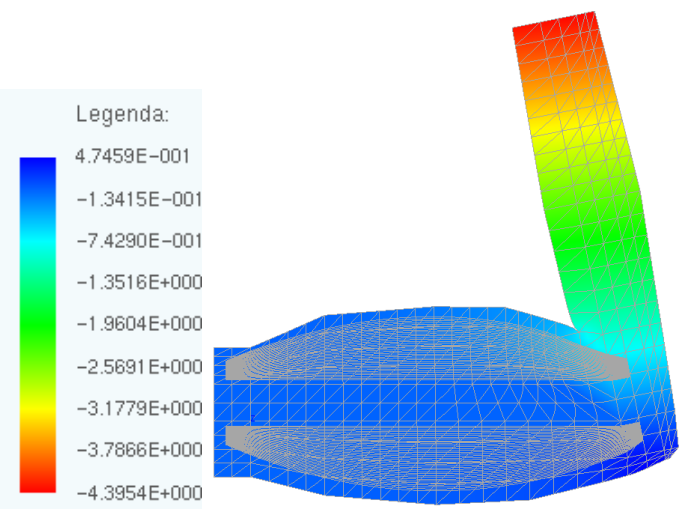

(a) Contração das fibras superiores (bíceps)

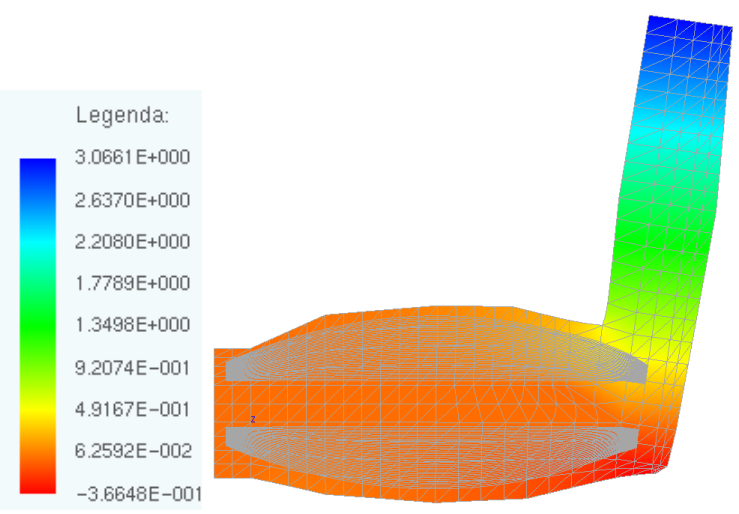

(b) Contração das fibras inferiores (tríceps)

Figura 46 - Deslocamentos na direção x devido a contração das fibras

Ao retirar as contrações nas fibras nos passos 2 e 4 o braço retorna à configuração inicial de repouso da Figura 47. 


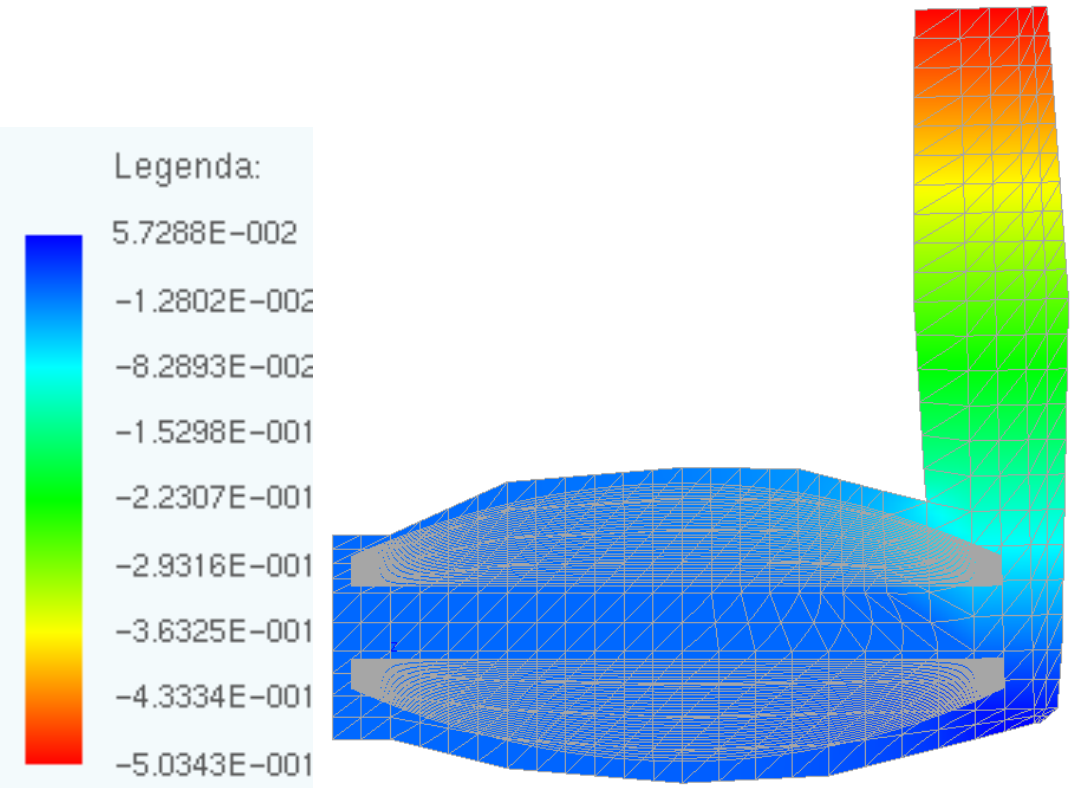

Figura 47 - Deslocamento na direção x sem contração das fibras

Atente para o fato de que, devido ao mecanismo de interação entre as fibras e a matriz discutida na seção 4.4 e nesse caso também devido à rigidez das fibras inferiores (superiores), a contração das fibras superiores (inferiores) não é exatamente a contração imposta. Uma contração final desejada poderia ser forçada através da Equação 4.17, no entanto, isso implicaria em um músculo com força infinita.

Para ilustrar essa ideia imagine que o braço da Figura 40 tenta levantar um peso maior que sua capacidade muscular. Nesse caso, por mais que as fibras desse músculo se contraiam, o peso não sai do lugar, as fibras não conseguem se mexer e o braço não se movimenta. No entanto, se uma contração final desejada fosse imposta de forma forçada nas fibras, o braço seria capaz de levantar qualquer peso. Não impor uma contração final desejada no elemento de fibra permite limitar a força muscular e é, portanto, fisicamente mais consistente.

Assim, é possível também englobar o caso em que o braço, mesmo com as fibras tentando se contrair, não resiste e cede na direção da carga. A ideia é então contrair as fibras e "deixar" que qualquer uma das três situações abaixo ocorram:

- Se a carga atuante for menor que a capacidade muscular, o músculo se contrai e a carga se movimenta em sentido contrário ao de atuação. Nesse caso, o deslocamento final da carga em sentido contrário ao de atuação não corresponde à contração imposta nas fibras;

- Se a carga atuante for igual à capacidade muscular, o comprimento do músculo permanece inalterado;

- Se a capacidade muscular for menor que a carga atuante, o músculo se alonga e a carga se movimenta no seu sentido de atuação. Embora nesse caso a carga se desloque em 
seu sentido de atuação, esse deslocamento é menor do que se não houvesse a contração das fibras, uma vez que a atividade muscular, embora insuficiente para movimentar a carga em sentido contrário ao de atuação, representa uma resistência adicional ao deslocamento da carga;

A Figura 48 retrata as tensões nominais de engenharia ao longo do eixo das fibras. Observe que as fibras ativas, ou seja, aquelas que foram contraídas, são as que apresentam as maiores tensões normais.
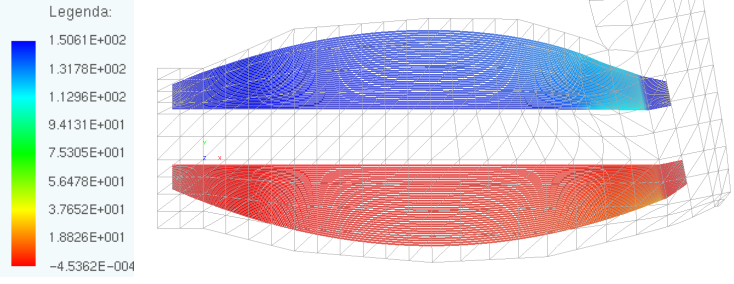

(a) Contração das fibras superiores
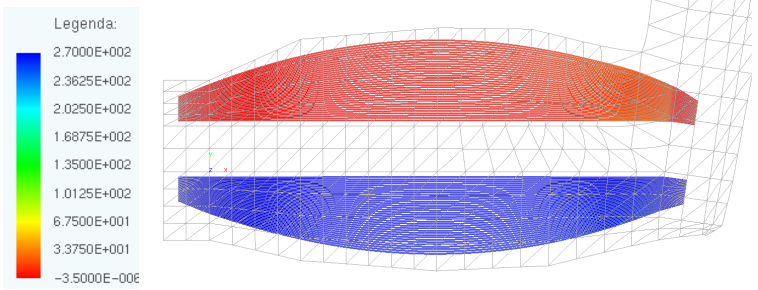

(b) Contração das fibras inferiores

Figura 48 - Tensões nominais de engenharia nos elementos de barra simples devido a contração das fibras

Na sequência, mantendo-se o módulo de elasticidade e área da seção transversal para todas as fibras, respectivamente, iguais a $\mathbb{E}=0,3 \times 10^{3}$ e $\mathrm{S}=1,0 \times 10^{-1}$ e, considerando as propriedades para os elementos de chapa conforme 4.25 e a 4.26 , aplica-se uma contração em todas as fibras superiores igual a $50 \%$ se a lei constitutiva adotada para os elementos de chapa é a de Saint Venant-Kirchhoff conforme o Apêndice D. Quando a lei constitutiva admitida é o modelo hiperelástico neo-hookeano proposto na Equação 4.28, a contração imposta nas fibras é igual a 99,99\%. As fibras são consideradas elementos de barra simples formulados a partir da deformação não linear de engenharia e do $1^{\circ}$ tensor de tensões de Piola-Kirchhoff.

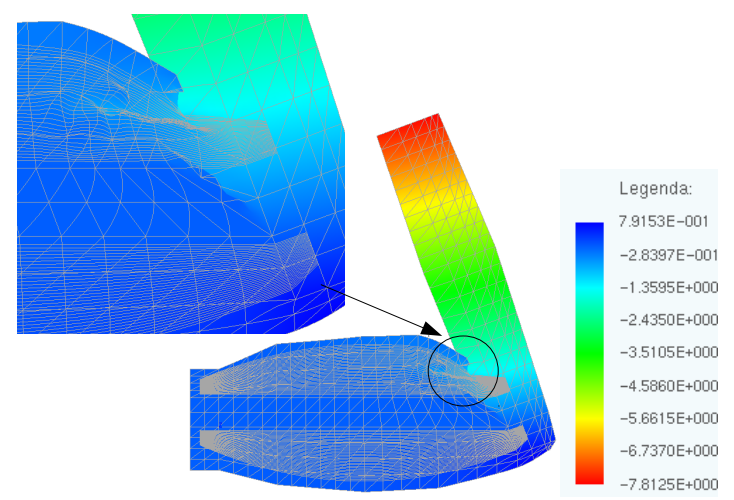

(a) Contração de 50,0\% das fibras superiores e modelo hiperelástico de Saint VenantKirchhoff para os elementos de chapa

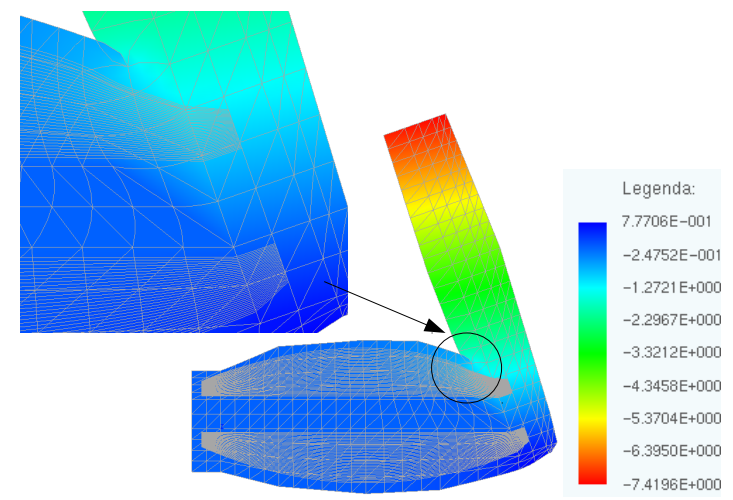

(b) Contração de 99,9\% das fibras superiores e modelo hiperelástico neo-hookeano para os elementos de chapa

Figura 49 - Deslocamentos na direção x devido a contração das fibras 
Apesar das contrações impostas nas fibras serem praticamente o dobro para o modelo hiperelástico neo-hookeno do que para o modelo de Saint Venant-Kirchhoff, nota-se na Figura 49 que o resultado obtido com o modelo neo-hookeano ainda sim é melhor do que o obtido com o modelo de Saint Venant-Kirchhoff na região submetida a compressão localizada entre o braço e o ante-braço (O modelo de Saint Venant-Kirchhoff novamente permitiu a auto-intersecção de material).

Assumindo agora a força $F$ da Figura 40 igual e 256, tomando o módulo de elasticidade e área da seção transversal de todas as fibras, respectivamente, iguais a $\mathbb{E}=0,3 \times 10^{3}$ e $\mathrm{S}=1,0 \times 10^{-1}$ e, considerando as propriedades para os elementos de chapa conforme 4.25 e 4.26, obtém-se utilizando o modelo neo-hookeno os deslocamentos na direção $x$ da estrutura da Figura 40. Nesse caso as fibras também são consideradas sem contração e formuladas por elementos de barra simples formulados a partir da deformação não linear de engenharia e do $1^{\circ}$ tensor de tensões de Piola-Kirchhoff.

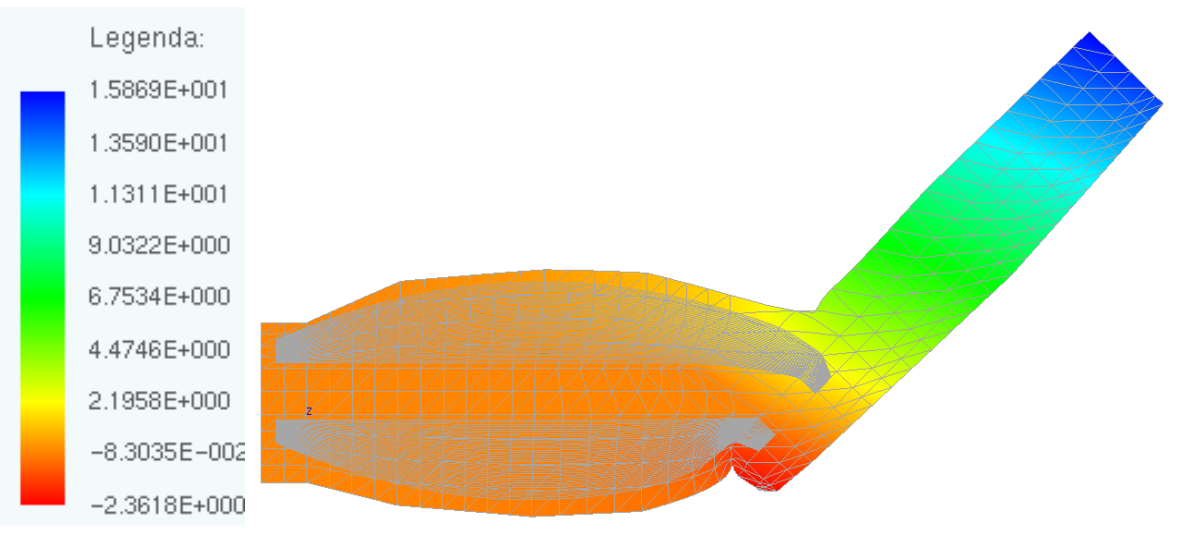

Figura 50 - Deslocamento na direção x sem a contração das fibras

Semelhantemente ao que já foi observado na Figura 42, observa-se na Figura 50 a qualidade da resposta obtida com o modelo neo-hookeno na região correspondente ao cotovelo.

Mantendo-se agora a força de 256 aplicada na extremidade do braço conforme esquematizado na Figura 40, todas as fibras superiores são inicialmente contraídas em $40 \%$ e, em seguida, contraídas em 90\%. A Figura 51 ilustra os deslocamentos na direção $x$ devido à contração das fibras superiores. As fibras inferiores são deixadas livres para se contraírem ou alongarem. 


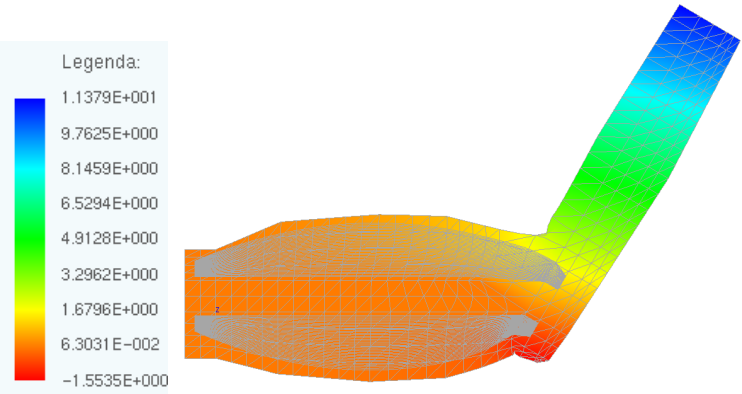

(a) Contração de 40,0\% das fibras superiores

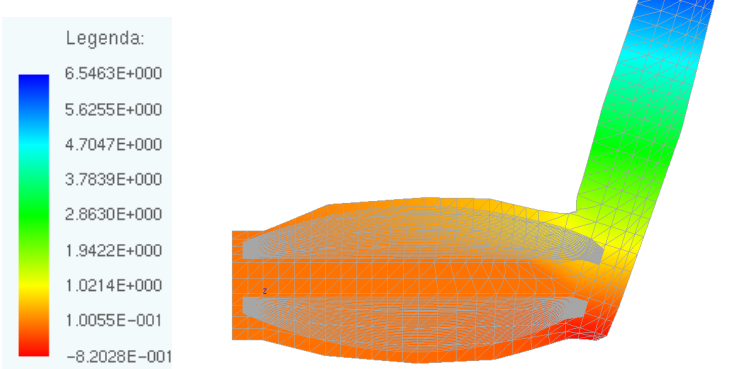

(b) Contração de 90,0\% das fibras superiores

Figura 51 - Deslocamentos na direção x devido a contração das fibras

A Figura 51 claramente demonstra que foi possível movimentar o braço através da imposição de contrações nas fibras imersas. Também observa-se na Figura 51 que uma maior contração resultou em menor deslocamento final do braço para a mesma força aplicada. A Figura 52 ilustra as tensões normais de engenharia nas fibras superiores e inferiores na situação da Figura 50, ou seja, sem contração dos elementos de barra simples imersos.

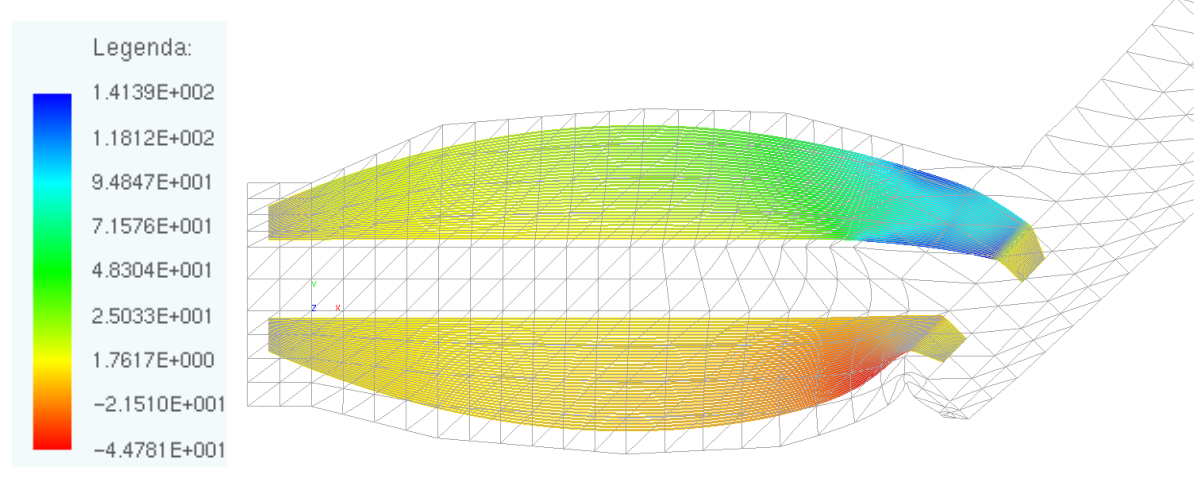

Figura 52 - Tensão nominal de engenharia nos elementos de barra simples sem a contração das fibras

Na Figura 53 são retratadas as tensões normais de engenharia nas fibras superiores e inferiores nas situações apresentadas na Figura 51, ou seja, com contração de 40\% e 90\% dos elementos de barra simples imersos. 


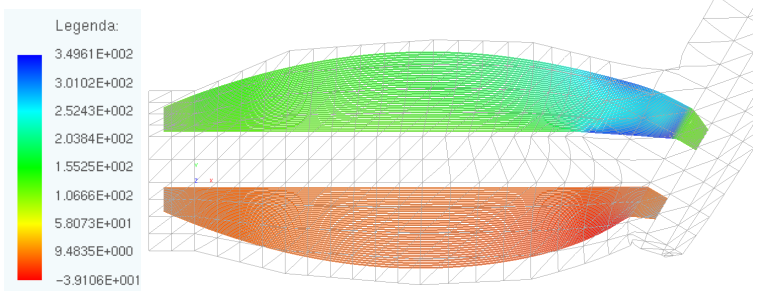

(a) Contração de 40,0\% das fibras superiores

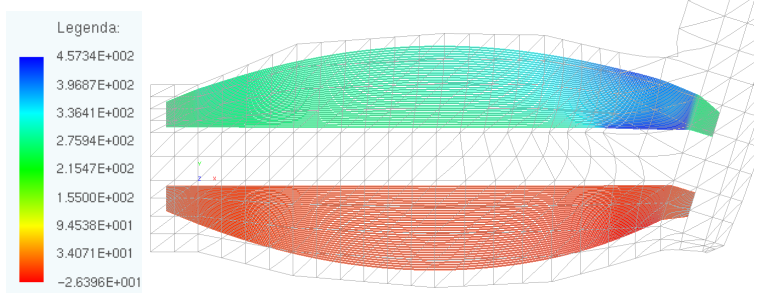

(b) Contração de 90,0\% das fibras superiores

Figura 53 - Tensões nominais de engenharia nos elementos de barra simples devido a contração das fibras

As Figuras 52 e 53 demonstram que a contração das fibras superiores geram tensões trativas nas mesmas ao mesmo tempo em que aliviam as tensões compressivas das fibras inferiores. Note ainda na Figura 53 que, quanto maior a contração imposta nas fibras, maiores são tensões trativas nas fibras contraídas e menores são as tensões compressivas nas fibras livres. Isso indica que, quanto maior a capacidade muscular, maior é o poder de contração das fibras musculares e maiores são as tensões trativas desenvolvidas.

Considere agora a situação onde ao mesmo tempo em que as fibras superiores são contraídas em $90 \%$, elas também têm seu módulo de elasticidade dobrado, ou seja, aumentado de $\mathbb{E}=0,3 \times 10^{3}$ para $\mathbb{E}=0,6 \times 10^{3}$. A Figura 54 ilustra os deslocamentos resultantes para essa situação. Esse efeito é análogo ao efeito de aplicação de variação de temperatura em estruturas, pois neste caso, as fibras desenvolvem tensões trativas ao mesmo tempo em que experimentam uma diminuição no seu comprimento.

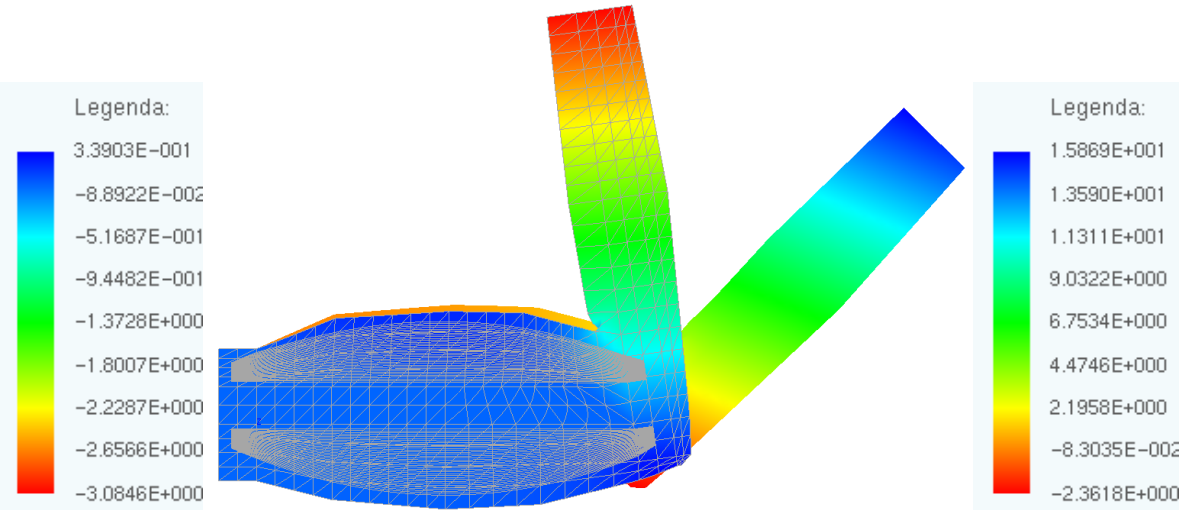

Figura 54 - Deslocamentos na direção x devido à contração das fibras e aumento do módulo de elasticidade

$\mathrm{Na}$ legenda à direita da Figura 54 notam-se inicialmente os mesmos deslocamentos da Figura 50, mas, como a rigidez das fibras superiores é aumentada durante a contração, elas "cedem" menos do que no caso da Figura 51, resultando assim em uma maior capacidade de contração conforme verificado na legenda à esquerda da Figura 54. A Figura 55 ilustra as tensões nominais de engenharia nos elementos de barra simples imersos. 


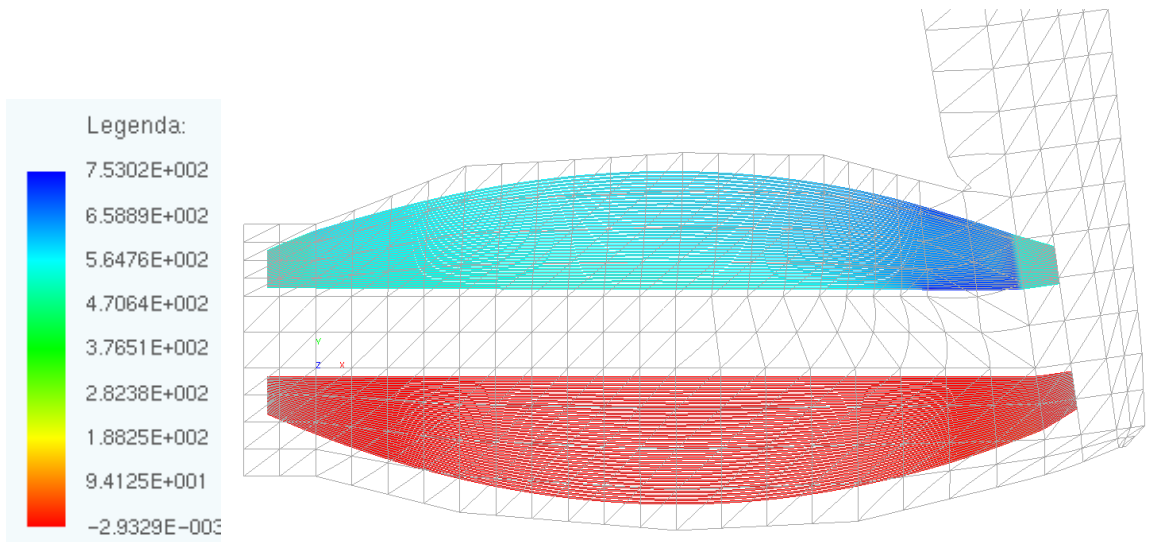

Figura 55 - Tensão nominal de engenharia nos elementos finitos de barra simples devido à contração das fibras e aumento do módulo de elasticidade

Observe na Figura 55 que as tensões trativas nas fibras superiores são maiores e as tensões compressivas nas fibras inferiores são menores do que nos casos da Figura 53, estando, portanto, a capacidade muscular também diretamente relacionada com a rigidez das fibras musculares. Logo e conforme já comentado, não faz sentido forçar que as contrações atinjam determinados valores desejados através da Equação 4.17. Conforme bem observado na Figura 51 e na Figura 54, a capacidade de contração muscular deve depender tanto do poder de contração das fibras musculares (magnitude das contrações, por exemplo $40 \%$ ou $90 \%$ ) bem como da rigidez das fibras musculares (módulo de elasticidade, por exemplo $\mathbb{E}=0,3 \times 10^{3}$ ou $\mathbb{E}=0,6 \times 10^{3}$ ). Dessa forma é possível considerar diferentes músculos com diferentes capacidades musculares.

Um aspecto importante e que deve ser mencionado é de que em todos os casos dessa seção 4.5, as contrações sempre foram impostas em único passo.

Este exemplo demonstra através da Figura 41 que tanto a técnica de imersão das fibras apresentado por Sampaio, Paccola e Coda (2013) como a formulação posicional do método dos elementos finitos foram implementadas de forma correta, conforme verifica-se em Baiocco, Coda e Paccola (2013).

Por se tratar de pequenos deslocamentos (e deformações), a Figura 41 também é um indicativo de que o elemento de barra simples formulado a partir da deformação não linear de engenharia e do $1^{\circ}$ tensor de tensões de Piola-Kirchhoff tenha sido desenvolvido de forma correta.

Dada a facilidade de se considerar leis constitutivas hiperelásticas dentro da formulação posicional do método dos elementos finitos, as Figuras 42 e 50 destacam o potencial desse método na solução de problemas envolvendo grandes deslocamentos e deformações.

A Figura 44 não só valida a formulação de um elemento de barra simples com comportamento viscoelástico, como também atesta a consistência da técnica de imersão das fibras ao demonstrar que tal comportamento é transferido para a estrutura como um 
todo.

Por fim, este exemplo também certifica a validade do comportamento ativo introduzido no elemento de barra simples proposto e apresenta nas Figuras 46, 48, 49, 51, 53, 54 e 55 umas das possíveis aplicações desse elemento quando combinado com a técnica de imersão das fibras apresentada na 3.2.5, legitimando ainda sua utilização para casos envolvendo a imposição de grandes deformações de contração (Figura 49), bem como na ausência (Figuras 46, 48, 49) e na presença (Figuras 51, 53, 54 e 55) de cargas externas. As Figuras 50 e 52 ilustram o potencial do método dos elementos finitos posicional e da técnica de imersão de fibras na modelagem de estruturas biológicas e, por fim, as Figuras 54, 55 comprovam a maleabilidade da combinação do elemento de barra simples proposto com o método dos elementos finitos posicional e a técnica de imersão de fibras, elucidando para novas possibilidades de desenvolvimentos futuros. 

CAPÍTULO

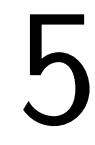

CONCLUSÕES

Os exemplos numéricos apresentados claramente demonstram as potencialidades do elemento de barra simples proposto com propriedades viscoelásticas e comportamento ativo (com capacidade de contração/alongamento). A utilização da deformação não linear de engenharia e do $1^{\circ}$ tensor de tensões de Piola-Kirchhoff na formulação desse elemento, além de facilitar a interpretação física dos resultados obtidos das simulações numéricas, também simplifica a introdução das propriedades viscoelásticas e a consideração do comportamento ativo do mesmo.

Demonstrou-se também que esse elemento proposto pode ser imerso em elementos de chapa através da estratégia apresentada por Vanalli, Paccola e Coda (2008), Sampaio, Paccola e Coda (2013) e Sampaio (2014) para simulação de materiais compósitos reforçados com fibras. Essa estratégia de imersão permitiu que as propriedades viscoelásticas e o comportamento ativo presentes nos elementos de barra simples imersos se manifestassem na estrutura plana como um todo e não só nos próprios elementos de barra.

A modelagem de estruturas biológicas ou a simulação de materiais compósitos reforçados com fibras e sujeitos a variação de temperatura com diferentes coeficientes de dilatação para as fibras e a matriz são algumas das possíveis aplicações desse elemento proposto.

Como todo o desenvolvimento desse trabalho foi realizado utilizando a formulação posicional do método dos elementos finitos, as formulações propostas já são automaticamente adequadas para simulações envolvendo grandes deslocamentos e, como a formulação posicional do método dos elementos finitos permite adotar leis constitutivas hiperelásticas de uma forma imediata, também é possível considerar grandes deformações, relações não lineares entre tensões e deformações, incluir comportamento de incompressibilidade, além de propor leis constitutivas fisicamente consistentes, como por exemplo que não permitem degeneração ou auto intersecção de material. 
Por fim, conclui-se também que a biblioteca OpenMP pode ser utilizada para ganhos de tempo de processamento de até $240 \%{ }^{1}$ com esforço de implementação muito pequeno quando comparado com o ganho alcançado.

\subsection{Sugestão para trabalhos futuros}

Para trabalhos futuros sugere-se a busca de leis constitutivas hiperelásticas mais adequadas para simulação de tecidos musculares e que sejam baseadas em resultados experimentais. Estando essas leis constitutivas de acordo com resultados experimentais, elas poderão ser implementadas de forma imediata e direta através das equações do Apêndice E.

A expansão do programa desenvolvido para o caso tridimensional também é outro ponto interessante. Ademais, embora no programa desenvolvido e devido ao efeito viscoelástico o equilíbrio da estrutura possa evoluir gradativamente ao longo do tempo, efeitos de inércia e amortecimento não são, no entanto, considerados. Assim, considerar a inércia e o amortecimento também se caracteriza como uma proposta para desenvolvimentos futuros.

Por fim, como nas análises apresentadas os alongamentos ou as contrações impostas nas fibras foram todas iguais, avaliar situações com fibras com diferentes contrações ou alongamentos (na forma de um "gradiente de contração", por exemplo) também é outro aspecto a ser considerado.

\footnotetext{
${ }^{1}$ estima-se que ganhos ainda maiores podem ser obtidos em problemas maiores
} 


\section{REFERÊNCIAS BIBLIOGRÁFICAS}

ALVES FILHO, A. Elementos finitos - a base da tecnologia CAE: análise não linear. São Paulo: Editora Érica, 2012.

ALVES FILHO, A. Elementos finitos - a base da tecnologia CAE: análise estática. São Paulo: Editora Érica, 2013.

ASSAN, A. E. Método dos elementos finitos. Campinas: Editora Unicamp, 2003.

BAIOCCO, M. H. Uma iniciação à mecânica dos sólidos não linear com aplicações à biomecânica via método dos elementos finitos. São Carlos, 2012. Relatório de Iniciação Científica.

BAIOCCO, M. H.; CODA, H. B.; PACCOLA, R. R. A simple way to model skeletal muscles by FEM. In: 22nd INTERNATIONAL CONGRESS OF MECHANICAL ENGINEERING (COBEM 2013), Ribeirão Preto, 2013. Anais do COBEM. Rio de Janeiro: Associação Brasileira de Ciências Mecânicas, 2013.

BLEMKER, S. S.; PINSKY, P. M.; DELP, S. L. A 3d model of muscle reveals the causes of nonuniform strains in the biceps brachii. Journal of Biomechanics, v. 38, n. 4, p. 657-665, 2005.

BÖL, M. et al. A new approach for the validation of skeletal muscle modelling using MRI data. Computational Mechanics, v. 47, n. 5, p. 591-601, 2011.

BONET, J. et al. Finite element analysis of air supported membrane structures. Computer Methods in Applied Mechanics and Engineering, v. 190, n. 5-7, p. 579-595, 2000.

BOSBOOM, E. M. H. et al. Passive transverse mechanical properties of skeletal muscle under in vivo compression. Journal of Biomechanics, v. 34, n. 10, p. 1365-1368, 2001.

CALVO, B. et al. Passive nonlinear elastic behaviour of skeletal muscle: experimental results and model formulation. Journal of Biomechanics, v. 43, n. 2, p. 318-325, 2010.

CAVALCANTI, G. C. M. dos S. Estudo e desenvolvimento de código computacional baseado no método dos elementos finitos para análise dinâmica não linear geométrica de sólidos bidimensionais. Dissertação (Mestrado) — Universidade de São Paulo, São Carlos, 2006.

CENTENO, O. J. Finite element modeling of rubber bushing for crash simulation: experimental tests and validation. Dissertação (Mestrado) — Lund University, Lund, Suécia, 2009.

CHAGNON, G.; REBOUAH, M.; FAVIER, D. Hyperelastic energy densities for soft biological tissues: a review. Journal of Elasticity, v. 120, n. 2, p. 129-160, 2015. ISSN 0374-3535. 
CHAPMAN, B.; JOST, G.; PAS, R. van der. Using OpenMP: portable shared memory programming. Estados Unidos da America: The MIT Press, 2008.

CODA, H. B. Análise não linear de geométrica de sólidos e estruturas: uma formulação posicional baseada no MEF. São Carlos, 2003. Tese para concurso de professor titular.

CODA, H. B. SET5854 - Introdução à dinâmica não linear das estruturas. 2014. Universidade de São Paulo (aulas).

CODA, H. B. SET5876 - Fundamentos da mecânica dos materiais e das estruturas. 2014. Universidade de São Paulo (aulas).

COMMUNITY RESEARCH AND DEVELOPMENT INFORMATION SERVICE.

Humos (Human Model for Safety). 2015. Disponível em: < http://cordis.europa.eu/ project/rcn/38788_en.html>. Acesso em: 17 dez. 2015.

DESSAULT SYSTEMES. Solidworks 2016 Help: Recommendations for hyperelastic materials. [S.l.], 2016. Disponível em: <http://help.solidworks.com/2016/English/ SolidWorks/cworks/r_Recommendations_Hyperelastic_Materials.htm>. Acesso em: 09 set. 2015 .

FUNG, Y. C. Elasticity of soft tissues in simple elongation. American Journal of Physiology, v. 28, p. 1532-1544, 1967.

FUNG, Y. C. Biorheology of soft tissues. Biorheology, v. 10, p. 139-155, 1973.

FUNG, Y. C. Biomechanics: mechanical properties of living tissues. [S.l.]: Springer Verlag, 1993.

GORDON, A. M.; HUXLEY, A. F.; JULIAN, F. J. The variation in isometric tension with sarcomere length in vertebrate muscle fibres. The Journal of Physiology, v. 184, p. 170-192, 1966.

GURTIN, M. E.; FRIED, E.; ANAND, L. The mechanics and thermodynamics of continua. New York: Cambridge University Press, 2010.

HILL, A. V. The heart shortening and the dynamic constants of muscle. Proceedings of the Royal Society of London. Series B, Biological Sciences, v. 126, p. 136-195, 1938.

HOLZAPFEL, G. A. Nonlinear solid mechanics a continuum approach for engineering. Chichester: John Wiley \& Sons Ltd., 2000.

HOSS, L. Modelos constitutivos hiperelásticos para elastômeros incompressíveis: ajuste, comparação de desempenho e proposta de um novo modelo. Dissertação (Mestrado) - Universidade Federal do Rio Grande do Sul, Porto Alegre, 2009.

HOSS, L.; MARCZAK, R. J. A new constitutive model for rubber-like materials. In: IX ARGENTINIAN CONGRESS ON COMPUTATIONAL MECHANICS, Buenos Aires, 2010. Mecánica Computacional. Güemes: Asociación Argentina de Mecánica Computacional, 2010. v. 29, p. 2759-2773. 
HUMPHREY, J. D. Review paper: continuum biomechanics of soft biological tissues. Proceedings of the Royal Society of London A: Mathematical, Physical and Engineering Sciences, v. 459, n. 2029, p. 3-46, 2003.

HUMPHREY, J. D.; YIN, F. C. P. On constitutive relations and finite deformations of passive cardiac tissue: I. a pseudostrain-energy function. Journal of biomechanical engineering, v. 109, p. 298-304, 1987.

HUXLEY, A. F. Muscle structure and theories of contraction. Progress in Biophysics and Biophysical Chemistry, v. 7, p. 257-318, 1957.

JOHANSSON, T.; MEIER, P.; BLICKHAN, R. A finite-element model for the mechanical analysis of skeletal muscles. Journal of Theoretical Biology, v. 206, n. 1, p. 131-149, 2000 .

LEVEQUE, R. J. High performance scientific computing. 2015. University of Washington (curso on-line). Disponível em: <https://www.coursera.org/course/scicomp > . Acesso em: 21 jun. 2015.

LU, Y. et al. A visco-hyperelastic model for skeletal muscle tissue under high strain rates. Journal of Biomechanics, v. 43, n. 13, p. 2629-2632, 2010.

MARSDEN, J. E.; HUGHES, T. J. R. Mathematical Foundations of Elasticity. Englewood Cliffs, N. J.: Prentice Hall, 1983.

MARTINS, J. A. C. et al. A numerical model of passive and active behavior of skeletal muscles. Computer Methods in Applied Mechanics and Engineering, v. 151, n. 3-4, p. 419-433, 1998.

MATTSON, T. Introduction to OpenMP. 2015. Disponível em: <https: //www.youtube.com/playlist?list=PLLX-Q6B8xqZ8n8bwjGdzBJ25X2utwnoEG >. Acesso em: 09 nov. 2015.

MOERMAN, K. M. et al. Digital image correlation and finite element modelling as a method to determine mechanical properties of human soft tissue in vivo. Journal of Biomechanics, v. 42, n. 8, p. 1150-1153, 2009.

MOONEY, M. A theory of large elastic deformation. Journal of Applied Physics, v. 11, p. 582-592, 1940.

MUGGENTHALER, H. Einfluss der muskelaktivität auf die kinematik des menschlichen körpers und die deformationseigenschaften des muskels. Tese (Doutorado) — LMU München, München, 2006.

MUGGENTHALER, H. et al. Experimental tests for the validation of active numerical human models. Forensic Science International, v. 177, n. 2-3, p. 184-191, 2008.

MUKHERJEE, S. et al. Finite element crash simulations of the human body: passive and active muscle modelling. Sadhana Academy Proceedings in Engineering Sciences, v. 32, n. 4, p. 409-426, 2007.

NOVOZHILOV, V. V. Foundations of the nonlinear theory of elasticity. Fourth printing, february 1971. New York: Graylock press, 1953. Translated from the first russian edition (1948). 
OGDEN, R. W. Large deformation isotropic elasticity -on the correlation of theory and experiment for incompressible rubberlike solids. Philosophical Transactions of the Royal Society of London A: Mathematical, Physical and Engineering Sciences, v. 326, n. 1567, p. 565-584, 1972.

OGDEN, R. W. Large deformation isotropic elasticity: on the correlation of theory and experiment for compressible rubberlike solids. Philosophical Transactions of the Royal Society of London A: Mathematical, Physical and Engineering Sciences, v. 328, n. 1575 , p. 567-583, 1972.

OGDEN, R. W. Non linear elastic deformations. New York: Dover Publications, 1997.

OTTOSEN, N.; RISTINMAA, M. The mechanics of constitutive modeling. Reino Unido: Elsevier, 2005.

PAIVA, J. B. SET0601 - Introdução ao método dos elementos finitos. 2012. Universidade de São Paulo (notas de aula).

PASCON, J. P. Modelos constitutivos para materiais hiperelásticos: estudo e implementação computacional. Dissertação (Mestrado) - Universidade de São Paulo, São Carlos, 2008.

PASCON, J. P. Sobre modelos constitutivos não lineares para materiais com gradação funcional exibindo grandes deformações implementação numérica em formulação não linear geométrica. Tese (Doutorado) - Universidade de São Paulo, São Carlos, 2012.

PROENÇA, S. P. SET5875 Introdução aos métodos numéricos. 2010. Universidade de São Paulo (notas de aula).

PROENÇA, S. P. Análise não Linear de estruturas. 2013. Universidade de São Paulo (notas de aula).

RIVLIN, R. S.; SAUNDERS, D. W. Large elastic deformations of isotropic materials. VII. experiments on the deformation of rubber. Philosophical Transactions of the Royal Society of London A: Mathematical, Physical and Engineering Sciences, v. 243, n. 865, p. 251-288, 1951.

SAMPAIO, M. do S. M. Análise não linear geométrica de cascas laminadas reforçadas com fibras. Tese (Doutorado) - Universidade de São Paulo, São Carlos, 2014.

SAMPAIO, M. do S. M.; PACCOLA, R. R.; CODA, H. B. Fully adherent fiber-matrix FEM formulation for geometrically nonlinear 2d solid analysis. Finite Elements in Analysis and Design, v. 66, n. 0, p. 12 - 25, 2013.

SAVASSI, W. Introdução ao método dos elementos finitos em análise linear de estruturas. São Carlos: Serviço gráfico - EESC, 1996.

SORIANO, H. L. Método dos elementos finitos em análise de estruturas. São Paulo: Edusp - Editora da Universidade de São Paulo, 2003. 
STFC RUTHERFORD APPLETON LABORATORY. Sparse solver for real and complex indefinite matrices using OpenMP. 2015. Disponível em: <http://www.hsl.rl.ac.uk/catalogue/hsl_ma86.html>. Acesso em: 10 nov. 2015.

STFC RUTHERFORD APPLETON LABORATORY. Sparse solver MA28. 2015. Disponível em: <http://www.hsl.rl.ac.uk/archive/specs/ma28.pdf>. Acesso em: 09 dez. 2015.

TANG, C. Y.; ZHANG, G.; TSUI, C. P. A 3d skeletal muscle model coupled with active contraction of muscle fibres and hyperelastic behaviour. Journal of Biomechanics, v. 42, n. 7, p. 865-872, 2009.

THE ARCHITECTURE REVIEW BOARD - ARB. OpenMP. 2015. Disponível em: $<$ http://openmp.org/wp/>. Acesso em: 09 nov. 2015.

TRELOAR, L. R. G. The elasticity and related properties of rubbers. Reports on Progress in Physics, v. 36, n. 7, p. 755-826, 1973.

VANALLI, L. O MEC e o MEF aplicados à análise de problemas viscoplásticos em meios anisotrópicos e compostos. Tese (Doutorado) — Universidade de São Paulo, São Carlos, 2004.

VANALLI, L.; PACCOLA, R. R.; CODA, H. B. A simple way to introduce fibers into FEM models. Communications in Numerical Methods in Engineering, John Wiley \& Sons Ltd., v. 24, n. 7, p. 585-603, 2008.

VANLEUWEN, J. L. Mechanics of animal locomotion. [S.l.]: Springer Verlag, 1992.

VANNAH, W. M.; CHILDRESS, D. S. Indentor tests and finite element modeling of bulk muscular tissue in vivo. Journal of Rehabilitation Research and Development, 1996.

VAZ, L. E. Método dos elementos finitos em análise de estruturas. Rio de Janeiro: Editora Elsevier, 2010.

WEICHERT, F. et al. Finite element simulation of skeletal muscular structures obtained from images of histological serial sections. Journal of Biomechanics, v. 43, n. 8, p. 1483-1487, 2010.

WEISS, J. A.; MAKER, B. N.; GOVINDJEE, S. Finite element implementation of incompressible, transversely isotropic hyperelasticity. Computer Methods in Applied Mechanics and Engineering, v. 135, n. 1-2, p. 107-128, 1996.

ZAJAC, F. Muscle and tendon: properties, models, scaling, and application to biomechanics and motor control. Critical Reviews in Biomedical Engineering, v. 17, p. 359-411, 1989. 

APÊNDICES 

APÊNDICE

\section{A}

NOTAÇÕES

Noções de Álgebra Tensorial são imprescindíveis para um bom entendimento da Teoria da Elasticidade Não Linear e da Mecânica do Contínuo, ambos temas principais deste trabalho. As diferentes notações utilizadas sempre levam a mal entendidos. Por isso, faz-se necessário esclarecer a notação aqui utilizada para o bom entendimento deste trabalho. Noções básicas sobre Álgebra Tensorial podem ser encontradas em Holzapfel (2000).

Sempre que possível, neste trabalho, optou-se por utilizar a notação indicial. Isto porque as expressões em notação indicial são diretamente e imediatamente programáveis e, além disso, apesar da notação diádica ser mais elegante e compacta, em notação indicial tem-se a certeza de se estar sempre trabalhando com escalares. Sendo assim, todos os cálculos tensoriais se reduzem a três operações básicas, a saber: multiplicação, soma e subtração de escalares. Dessa forma, algumas regras do cálculo diferencial e integral, tal como a regra da cadeia, são diretamente aplicáveis. Portanto, a notação indicial certamente facilita o entendimento em uma primeira abordagem.

\section{A.1 Vetores ou Tensores de ordem 1}

Exceto quando explicitamente indicado, tensores de ordem 1 são sempre representados apenas por letras maiúsculas em negrito $\mathbf{X}$... quando referentes à configuração inicial indeformada e letras minúsculas em negrito quando quando referentes à configuração atual deformada $\boldsymbol{x} . .$. em notação diádica, $X_{i} \mathbf{e}_{i}$ em notação indicial ou ainda mesmo (pseudo)matricialmente por $\{X\}$ ou $\left\{X_{i}\right\}$. Na notação indicial, $\mathbf{e}_{i}$ se refere a uma componente qualquer de uma base qualquer do espaço vetorial e, portanto, $X_{i}$ é uma componente qualquer do vetor. É importante destacar que, por exemplo, a notação $\left\{X_{\alpha}^{\beta}\right\}$ tem o mesmo significado que $\{X\}$, isto é, $\alpha$ e $\beta$ são apenas índices utilizados como intuito 
de separar as componentes:

$$
\left\{X_{\alpha}^{\beta}\right\}=\left(\begin{array}{c}
X_{\alpha}^{1} \\
X_{\alpha}^{2} \\
X_{\alpha}^{3} \\
\vdots
\end{array}\right)=\left(\begin{array}{c}
X_{1}^{1} \\
X_{2}^{1} \\
\vdots \\
X_{\alpha}^{1} \\
X_{1}^{2} \\
X_{2}^{2} \\
\vdots \\
X_{\alpha}^{\beta}
\end{array}\right)
$$

\section{A.2 Tensores de ordem 2}

Exceto quando explicitamente indicado, tensores de ordem 2 são sempre representados apenas por letras maiúsculas em negrito F, E... quando referentes à configuração inicial indeformada e letras minúsculas em negrito quando quando referentes à configuração atual deformada $\boldsymbol{\sigma} \ldots$ em notação diádica, $F_{i j}\left(\mathbf{e}_{i} \otimes \mathbf{e}_{j}\right)$ em notação indicial ou ainda mesmo (pseudo)matricialmente por $[\mathrm{F}]$. Na notação indicial, $\mathbf{e}_{i} \otimes \mathbf{e}_{j}$ é chamado de base tensorial quando $\mathbf{e}_{i}$ e $\mathbf{e}_{j}$ são duas componentes quaisquer de uma base qualquer do espaço vetorial e, portanto, $F_{i j}$ é uma componente qualquer do tensor.

\section{A.3 Tensores de ordem 4}

Exceto quando explicitamente indicado, tensores de ordem 4 são sempre representados apenas por letras maiúsculas do tipo $\mathbb{C}, \mathbb{N}, \mathbb{R} \ldots$ em notação diádica, $\mathbb{C}_{i j k l}\left(\mathbf{e}_{i} \otimes\right.$ $\mathbf{e}_{j} \otimes \mathbf{e}_{k} \otimes \mathbf{e}_{l}$ ) em notação indicial ou ainda (pseudo)matricialmente por [ $\left.\mathbb{C}\right]$. Na notação indicial, $\mathbf{e}_{i} \otimes \mathbf{e}_{j} \otimes \mathbf{e}_{k} \otimes \mathbf{e}_{l}$ é chamado de base tensorial quando $\mathbf{e}_{i}, \mathbf{e}_{j}, \mathbf{e}_{k}$ e $\mathbf{e}_{l}$ são quatro componentes quaisquer de uma base qualquer do espaço vetorial e, portanto, $\mathbb{C}_{i j k l}$ é uma componente qualquer do tensor.

\section{A.4 Escalares}

Exceto quando explicitamente indicado, escalares são sempre representados por letras tais como $\nu, \rho, c_{10}, v, J, V \ldots$ e, sempre que fizer sentido, as letras maiúsculas referemse a configuração inicial indeformada e as letras minúsculas referem-se a configuração atual deformada. As componentes de um tensor $\mathbb{C}_{i j k l}, S_{k l}, E_{i j} \ldots$ são sempre escalares. 


\section{A.5 Notação indicial}

A notação indicial consiste na atribuição de índices com significado implícito de somatório nas componentes dos tensores, o que permite explicitar os tensores e suas componentes de uma forma compacta. Por exemplo, escrever o tensor de deformações de Green-Lagrange da maneira "vetorial" usual como tradicionalmente, este ficaria sendo:

$$
\begin{aligned}
\mathbf{E} & =E_{11}\left(\mathbf{e}_{1} \otimes \mathbf{e}_{1}\right)+E_{12}\left(\mathbf{e}_{1} \otimes \mathbf{e}_{2}\right)+E_{13}\left(\mathbf{e}_{1} \otimes \mathbf{e}_{3}\right) \\
& +E_{21}\left(\mathbf{e}_{2} \otimes \mathbf{e}_{1}\right)+E_{22}\left(\mathbf{e}_{2} \otimes \mathbf{e}_{2}\right)+E_{23}\left(\mathbf{e}_{2} \otimes \mathbf{e}_{3}\right) \\
& +E_{31}\left(\mathbf{e}_{3} \otimes \mathbf{e}_{1}\right)+E_{32}\left(\mathbf{e}_{3} \otimes \mathbf{e}_{2}\right)+E_{33}\left(\mathbf{e}_{3} \otimes \mathbf{e}_{3}\right)
\end{aligned}
$$

Dessa forma, toda toda vez que se utilizasse esse tensor de deformações em algum cálculo, seria necessário carregar todos os termos da equação Equação A.2. A situação se complicaria ainda mais se o cálculo envolvesse, por exemplo, o tensor constitutivo $\mathbb{C}$, que no caso tem 81 componentes e não simplesmente 9 como para o tensor de ordem 2 da Equação A.2. É por isso que Einstein propôs representar o tensor de deformações de Green-Lagrange apenas por:

$$
\mathbf{E}=\sum_{j=1}^{3} \sum_{i=1}^{3} E_{i j}\left(\mathbf{e}_{i} \otimes \mathbf{e}_{j}\right)=E_{i j}\left(\mathbf{e}_{i} \otimes \mathbf{e}_{j}\right)
$$

Neste trabalho e assim como na Equação A.3, o fato dos índices (i,j,k,l,m,n,o,p...) das componentes dos tensores variarem de 1 a 3 já deve estar subentendido, uma vez que estes se referem as três direções em um espaço 3D. Isso também porque aparentemente não há sentido físico algum em considerar espaços de dimensões maiores que 3 em Mecânica do Contínuo.

Uma outra convenção útil na notação indicial é a seguinte:

$$
\begin{aligned}
C_{i j k l} E_{k l} & =C_{i j 11} E_{11}+C_{i j 12} E_{12}+C_{i j 13} E_{13} \\
& +C_{i j 21} E_{21}+C_{i j 22} E_{22}+C_{i j 23} E_{23} \\
& +C_{i j 31} E_{31}+C_{i j 32} E_{32}+C_{i j 33} E_{33}
\end{aligned}
$$

ou seja, índices repetidos indicam somatório sobre esse índice. No entanto, também convenciona-se que isso não seja válido para termos que aparecem em lados diferentes da igualdade. Assim, a seguinte afirmação não é verdadeira:

$$
\begin{aligned}
\epsilon_{i j}= & \frac{\gamma_{i j}}{2} \\
\epsilon_{11}+\epsilon_{12}+\epsilon_{13} & \frac{\gamma_{11}}{2}+\frac{\gamma_{12}}{2}+\frac{\gamma_{13}}{2} \\
+\epsilon_{21}+\epsilon_{22}+\epsilon_{23}= & +\frac{\gamma_{21}}{2}+\frac{\gamma_{22}}{2}+\frac{\gamma_{23}}{2} \\
+\epsilon_{31}+\epsilon_{32}+\epsilon_{33} & +\frac{\gamma_{31}}{2}+\frac{\gamma_{32}}{2}+\frac{\gamma_{33}}{2}
\end{aligned}
$$


Uma outra convenção utilizada é que, por exemplo, índices escritos dentro de parênteses não são considerados repetidos. Logo, a seguinte igualdade não é válida:

$$
u_{i(i)}=u_{1(1)}+u_{2(2)}+u_{3(3)}
$$

Nesse caso, $u_{i(i)}$ se refere apenas a um, e somente um, dos termos $u_{11}, u_{22}$ ou $u_{33}$ e não ao somatório deles. Por fim, uma última notação utilizada é de que uma vírgula (,) entre os índices denota uma operação de derivada entre esses índices. Assim, se uma vírgula aparecer entre dois índices, isto quer dizer que deve-se tomar a derivada em relação ao índice imediatamente após a vírgula, exemplo:

$$
u_{1,1}=\frac{\partial u_{1}}{\partial x_{1}}
$$

onde ja se sabe de antemão implicitamente pelo contexto ou pelo problema que u é somente função de $\mathbf{x}$.

Em notação indicial, as direções $x, y$ e $z$ são indicadas, respectivamente, através dos números 1,2 e 3 .

\section{A.6 Operador tensorial ( )}

Um tensor é um operador linear de um espaço vetorial. Sendo assim, a notação $\mathbf{v}=$ Au indica que o tensor A "opera" sobre o vetor (ou tensor de ordem 1) u, "transformando" $\mathbf{u}$ em outro elemento $\mathbf{v}$ do mesmo espaço vetorial de $\mathbf{u}$. Portanto, v é o resultado da aplicação de $\mathbf{A}$ sobre $\mathbf{u}$. Sejam $\left(\mathbf{e}_{i}, \mathbf{e}_{j}, \mathbf{e}_{k}\right)$ componentes quaisquer de uma base qualquer do espaço vetorial, tem-se que a operação de um tensor de $2^{\mathrm{a}}$ ordem $\mathbf{A}$ sobre um vetor (ou tensor de ordem 1) u é um vetor (ou tensor de ordem 1):

$$
\mathbf{A u}=A_{i j}\left(\mathbf{e}_{i} \otimes \mathbf{e}_{j}\right) u_{k} \mathbf{e}_{k}=A_{i j} u_{k} \delta_{j k} \mathbf{e}_{i}=A_{i j} u_{j} \mathbf{e}_{i}=A_{i 1} u_{1} \mathbf{e}_{i}+A_{i 2} u_{2} \mathbf{e}_{i}+A_{i 3} u_{3} \mathbf{e}_{i}
$$

O tensor de tensões $\boldsymbol{\sigma}$ é um exemplo de tensor que "opera" sobre um vetor normal $\mathbf{n}$, "transformando" $\mathbf{n}$ em um vetor de forças de superfície $\mathbf{t}$ contido no mesmo espaço vetorial de dimensão 1 de $\mathbf{n}$ através da seguinte operação $\mathbf{t}=\boldsymbol{\sigma} \mathbf{n}$.

A aplicação de um tensor de ordem 2 A sobre outro tensor de ordem 2 B resulta em um outro tensor também de ordem 2 C, contido no mesmo espaço de $\mathbf{A}$ e $\mathbf{B}$. Sendo assim:

$$
\begin{aligned}
(\mathbf{A B})_{i j} & =\mathbf{e}_{i} \cdot(\mathbf{A B}) \mathbf{e}_{j}=\mathbf{e}_{i} \cdot A_{k l}\left(\mathbf{e}_{k} \otimes \mathbf{e}_{l}\right) B_{m n}\left(\mathbf{e}_{m} \otimes \mathbf{e}_{n}\right) \mathbf{e}_{j} \\
& =A_{k l} B_{m n} \delta_{j n} \mathbf{e}_{i} \cdot\left(\mathbf{e}_{k} \otimes \mathbf{e}_{l}\right) \mathbf{e}_{m}=A_{k l} B_{m n} \delta_{j n} \delta_{l m} \mathbf{e}_{i} \cdot \mathbf{e}_{k} \\
& =A_{k l} B_{m n} \delta_{j n} \delta_{l m} \delta_{i k}=A_{i l} B_{l j} \\
\therefore \mathbf{C}=\mathbf{A B} & =A_{i l} B_{l j}\left(\mathbf{e}_{i} \otimes \mathbf{e}_{j}\right) \\
& =A_{i 1} B_{1 j}\left(\mathbf{e}_{i} \otimes \mathbf{e}_{j}\right)+A_{i 2} B_{12}\left(\mathbf{e}_{i} \otimes \mathbf{e}_{j}\right)+A_{i 3} B_{3 j}\left(\mathbf{e}_{i} \otimes \mathbf{e}_{j}\right)
\end{aligned}
$$




\section{A.7 Produto vetorial $(x)$}

O símbolo " $\mathrm{x}$ " representa o produto vetorial entre dois vetores, sendo definido da seguinte forma para uma base $\left(\mathbf{e}_{i}, \mathbf{e}_{j}, \mathbf{e}_{k}\right)$ qualquer do espaço vetorial :

$$
\mathbf{e}_{i} \mathrm{x} \mathbf{e}_{j}=\epsilon_{i j k} \mathbf{e}_{k}
$$

onde $\epsilon_{i j k}$ é o permutador cíclico de Levi - Cevita

\section{A.8 Produto escalar (.)}

Sejam $\left(\mathbf{e}_{i}, \mathbf{e}_{j}, \mathbf{e}_{k}\right)$ componentes quaisquer de uma base qualquer do espaço vetorial, tem-se que o produto escalar entre dois vetores ( $\mathbf{u}$ e $\mathbf{v}$ ) ou tensores de ordem 1 é um escalar:

$$
u_{i} \mathbf{e}_{i} \cdot v_{j} \mathbf{e}_{j}=u_{i} v_{j} \delta_{i j}=u_{i} v_{i}=u_{1} v_{1}+u_{2} v_{2}+u_{3} v_{3}
$$

onde $\delta_{i j}$ é o delta de Kronecker.

\section{A.9 Contração (:)}

Sejam $\left(\mathbf{e}_{i}, \mathbf{e}_{j}, \mathbf{e}_{k} \ldots\right)$ componentes quaisquer de uma base qualquer do espaço vetorial, têm-se que a contração de dois tensores (A e B) de ordem 2 é um escalar:

$$
\begin{aligned}
& A_{i j}\left(\mathbf{e}_{i} \otimes \mathbf{e}_{j}\right): B_{k l}\left(\mathbf{e}_{k} \otimes \mathbf{e}_{l}\right)=A_{i j} B_{k l} \delta_{i k} \delta_{j l}=A_{i j} B_{i j} \\
& =A_{1 j} B_{1 j}+A_{2 j} B_{2 j}+A_{3 j} B_{3 j} \\
& =A_{11} B_{11}+A_{12} B_{12}+A_{13} B_{13} \\
& +A_{21} B_{21}+A_{22} B_{22}+A_{23} B_{23} \\
& +A_{31} B_{31}+A_{32} B_{32}+A_{33} B_{33}
\end{aligned}
$$

A contração de um tensor de ordem $4(\mathbb{C})$ com um tensor de ordem $2(\mathbf{A})$ é um tensor de ordem 2 :

$$
\begin{aligned}
& \mathbb{C}\left(\mathbf{e}_{i} \otimes \mathbf{e}_{j} \otimes \mathbf{e}_{k} \otimes \mathbf{e}_{l}\right): A_{m n}\left(\mathbf{e}_{m} \otimes \mathbf{e}_{n}\right)=\mathbb{C}_{i j k l} A_{m n} \delta_{k m} \delta_{l n}\left(\mathbf{e}_{i} \otimes \mathbf{e}_{j}\right) \\
& =\mathbb{C}_{i j k l} A_{k n}\left(\mathbf{e}_{i} \otimes \mathbf{e}_{j}\right) \\
& =\mathbb{C}_{i j 1 l} B_{1 l}\left(\mathbf{e}_{i} \otimes \mathbf{e}_{j}\right)+\mathbb{C}_{i j 2 l} B_{2 l}\left(\mathbf{e}_{i} \otimes \mathbf{e}_{j}\right)+\mathbb{C}_{i j 3 l} B_{3 l}\left(\mathbf{e}_{i} \otimes \mathbf{e}_{j}\right) \\
& =\mathbb{C}_{i j 11} B_{11}\left(\mathbf{e}_{i} \otimes \mathbf{e}_{j}\right)+\mathbb{C}_{i j 12} B_{12}\left(\mathbf{e}_{i} \otimes \mathbf{e}_{j}\right)+\mathbb{C}_{i j 13} B_{13}\left(\mathbf{e}_{i} \otimes \mathbf{e}_{j}\right) \\
& +\mathbb{C}_{i j 21} B_{21}\left(\mathbf{e}_{i} \otimes \mathbf{e}_{j}\right)+\mathbb{C}_{i j 22} B_{22}\left(\mathbf{e}_{i} \otimes \mathbf{e}_{j}\right)+\mathbb{C}_{i j 23} B_{23}\left(\mathbf{e}_{i} \otimes \mathbf{e}_{j}\right) \\
& +\mathbb{C}_{i j 31} B_{31}\left(\mathbf{e}_{i} \otimes \mathbf{e}_{j}\right)+\mathbb{C}_{i j 32} B_{32}\left(\mathbf{e}_{i} \otimes \mathbf{e}_{j}\right)+\mathbb{C}_{i j 33} B_{33}\left(\mathbf{e}_{i} \otimes \mathbf{e}_{j}\right)
\end{aligned}
$$



APÊNDICE

B

\section{DEFORMAÇÕES DE ENGENHARIA}

\section{B.1 Deformação não linear de Engenharia}

Seja $l_{0}$ o comprimento inicial de uma fibra de material e $l$ o comprimento final dessa mesma fibra na configuração deformada e, considere também $u$ e $v$ como sendo dois vetores diretores quaisquer, $\Theta$ o ângulo inicial entre esses dois vetores e $\theta$ o ângulo final entre esses mesmos dois vetores, definem-se a seguir 3 grandezas matemáticas orientadas conforme esses dois vetores diretores.

Deformação longitudinal na direção $u$ :

$$
\epsilon_{u}=\left(\frac{l-l_{0}}{l_{0}}\right)
$$

Distorção entre $u$ e $v$ :

$$
\gamma_{u v}=\Theta-\theta
$$

Alongamento na direção $u$ :

$$
\lambda_{u}=\frac{l}{l_{0}}
$$

Adotando o gradiente da função mudança de configuração dado por $\mathbf{F}$, concluiu-se que a deformação longitudinal e a distorção não linear de engenharia valem respectivamente:

$$
\begin{gathered}
\epsilon_{u}=\sqrt{\mathbf{u}^{T} \mathbf{F}^{T} \mathbf{F u}}-1 \\
\gamma_{u v}=\Theta-\arccos \left(\frac{\mathbf{v}^{t} \mathbf{F}^{T} \mathbf{F u}}{\lambda_{u} \lambda_{v}}\right)
\end{gathered}
$$

O resultado da multiplicação $\mathbf{F}^{T} \mathbf{F}$ pode ser agrupado em um único tensor $\mathbf{C}$, 
conhecido como tensor de alongamento à direita de Cauchy-Green:

$$
\mathbf{C}=\mathbf{F}^{T} \mathbf{F}=\left[\begin{array}{lll}
C_{11} & C_{12} & C_{13} \\
C_{21} & C_{22} & C_{23} \\
C_{31} & C_{32} & C_{33}
\end{array}\right]
$$

Note que por sua própria definição $\mathbf{C}$ é simétrico.

Utilizando a notação indicial e, sendo ainda os vetores $u$ e $v$ ortonormais em um espaço 3D definido por $\mathbf{e}_{i}, \mathbf{e}_{j}, \mathbf{e}_{k}$ tem-se que:

$$
\begin{gathered}
\epsilon_{i j}=\frac{1}{2}\left(\frac{\pi}{2}-\arccos \left(\frac{C_{i j}}{\lambda_{(i)} \lambda_{(j)}}\right)\right) \\
\epsilon_{i(i)}=\sqrt{C_{i(i)}}-1
\end{gathered}
$$

\section{B.2 Deformação linear de Engenharia}

Para os casos de pequenos deslocamentos e pequenas rotações é razoável desprezar o produto entre as derivadas dos deslocamentos, isto é, $U_{i, j} U_{k, l} \simeq 0$, quaisquer que sejam as direções $i, j, k, l$ orientadas de acordo com o conjunto de vetores diretores $\mathbf{e}_{i}, \mathbf{e}_{j}, \mathbf{e}_{k}$ que formam uma base ortonormal qualquer do espaço 3D. Assim, a deformação linear de engenharia pode ser entendida como uma simplificação da medida não linear de engenharia, conforme será demonstrado a seguir.

Adotando vetores diretores ortonormais, a deformação longitudinal passa então a ser dada por:

$$
\epsilon_{i(i)}=\sqrt{\left(\mathbf{F}^{T} \mathbf{F}\right)_{i(i)}}-1=\sqrt{x_{i,(i)}^{2}+x_{j, i}^{2}+x_{k, i}^{2}}-1=\sqrt{\left(U_{i,(i)}+1\right)^{2}+U_{j, i}^{2}+U_{k, i}^{2}}-1
$$

O resultando da Equação B.9 anterior é coerente com o apresentado em Novozhilov (1953, p. 15). Porém, em regime de pequenos deslocamento e rotações, desprezam-se os produtos entre as derivadas dos deslocamentos:

$$
\epsilon_{i(i)} \simeq \sqrt{\left(U_{i,(i)}+1\right)^{2}}-1 \simeq U_{i,(i)}
$$

Que é a medida de deformação longitudinal linear de engenharia. Por sua vez, a deformação angular vale:

$$
\epsilon_{i j}=\frac{1}{2}\left(\frac{\pi}{2}-\arccos \left(\frac{\left(\mathbf{F}^{T} \mathbf{F}\right)_{i j}}{\lambda_{(i)} \lambda_{(j)}}\right)\right) \quad \forall i \neq j
$$

Ou então quantificando essa deformação cisalhante em termos da distorção angular $\gamma$ :

$$
\gamma_{i j}=\frac{\pi}{2}-\arccos \left(\frac{x_{(i), i} x_{(i), j}+x_{(j), i} x_{j,(j)}+x_{(k), i} x_{(k), j}}{\sqrt{x_{i,(i)}^{2}+x_{j, i}^{2}+x_{k, i}^{2}} \sqrt{x_{i, j}^{2}+x_{j,(j)}^{2}+x_{k, j}^{2}}}\right)=\frac{\pi}{2}-\arccos (\theta)
$$


Introduzindo uma simplificação trigonométrica tal que:

$$
\begin{aligned}
\sin \left(\gamma_{i j}\right) & =\sin \left(\frac{\pi}{2}-\arccos (\theta)\right) \\
& =\sin \left(\frac{\pi}{2}\right) \cos (\arccos (\theta))-\cos \left(\frac{\pi}{2}\right) \sin (\arccos (\theta)) \\
& =\sin \left(\frac{\pi}{2}\right) \cos (\arccos (\theta)) \rightarrow \sin \left(\gamma_{i j}\right)=\theta
\end{aligned}
$$

Logo:

$$
\begin{aligned}
\sin \left(\gamma_{i j}\right)=\theta \rightarrow \sin \left(\gamma_{i j}\right) & =\frac{x_{(i), i} x_{(i), j}+x_{(j), i} x_{(j), j}+x_{(k), i} x_{(k), j}}{\sqrt{x_{i,(i)}^{2}+x_{j, i}^{2}+x_{k, i}^{2}} \sqrt{x_{i, j}^{2}+x_{j,(j)}^{2}+x_{k, j}^{2}}} \\
& =\frac{x_{(i), i} x_{(i), j}+x_{(j), i} x_{(j), j}+x_{(k), i} x_{(k), j}}{\sqrt{\left(x_{i,(i)}^{2}+x_{j, i}^{2}+x_{k, i}^{2}\right)\left(x_{i, j}^{2}+x_{j,(j)}^{2}+x_{k, j}^{2}\right)}}
\end{aligned}
$$

Substituindo a função mudança de configuração $\mathbf{x}(\mathbf{X})=\mathbf{X}+\mathbf{U}(\mathbf{X})$ na Equação B.14 acima em notação indicial:

$$
\sin \left(\gamma_{i j}\right)=\frac{\left(U_{(i), i}+1\right) U_{(i), j}+U_{(j), i}\left(U_{(j), j}+1\right)+U_{(k), i} U_{(k), j}}{\sqrt{\left(1+2 U_{i,(i)}+U_{i,(i)}^{2}+U_{j, i}^{2}+U_{k, i}^{2}\right)\left(1+2 U_{j,(j)}+U_{i, j}^{2}+U_{j,(j)}^{2}+U_{k, j}^{2}\right)}}
$$

O resultando encontrado na Equação B.15 anterior é o mesmo do apresentado em Novozhilov (1953, p. 16). Novamente simplificando para os casos de pequenos deslocamentos e rotações, tem-se a seguinte medida de distorção:

$$
\sin \left(\gamma_{i j}\right)=\frac{U_{(j), i}+U_{(i), j}}{1}
$$

Pois, para pequenos deslocamentos e rotações, os termos $U_{(i), i}+1, U_{(j), j}+1$, $1+2 U_{i,(i)}+U_{i,(i)}^{2}+U_{j, i}^{2}+U_{k, i}^{2}$ e $1+2 U_{j,(j)}+U_{i, j}^{2}+U_{j,(j)}^{2}+U_{k, j}^{2}$ praticamente se reduzem a 1, uma vez que as derivadas dos deslocamentos são praticamente desprezíveis se comparadas com a unidade. Além disso, como em regimes de pequenas rotações tem-se $\sin \left(\gamma_{i j}\right) \simeq \gamma_{i j}$, conclui-se finalmente que a deformação angular linear de engenharia é dada por:

$$
\gamma_{i j}=\frac{U_{(j), i}+U_{(i), j}}{1}
$$

Por fim, ressalta-se novamente que o caminho adotado na referência Novozhilov (1953) para estabelecer as medidas não lineares de deformação (Equações B.9 e B.15) é muito diferente da estratégia adotada no presente trabalho, o que, no entanto, não impediu que os resultados finais obtidos fossem exatamente iguais.

A hipótese de pequenos deslocamentos e pequenas rotações utilizada na Equação B.10 automaticamente implica também em pequenas deformações. Tomando novamente 
a Equação B.9, porém agora somente com a hipótese de pequenas deformações:

$$
\begin{aligned}
& \epsilon_{i(i)}=\sqrt{\left(U_{i,(i)}+1\right)^{2}+U_{j, i}^{2}+U_{k, i}^{2}}-1 \\
& \left(\epsilon_{i(i)}+1\right)^{2}=\left(\sqrt{\left(U_{i,(i)}+1\right)^{2}+U_{j, i}^{2}+U_{k, i}^{2}}\right)^{2} \\
& \epsilon_{i(i)}^{2}+2 \epsilon_{i(i)}+1=U_{i,(i)}^{2}+2 U_{i,(i)}+1+U_{j, i}^{2}+U_{k, i}^{2} \\
& 2 \epsilon_{i(i)} \simeq 2 U_{i,(i)}+U_{i,(i)}^{2}+U_{j, i}^{2}+U_{k, i}^{2} \\
& \epsilon_{i(i)} \simeq U_{i,(i)}+\frac{1}{2}\left(U_{i,(i)}^{2}+U_{j, i}^{2}+U_{k, i}^{2}\right)
\end{aligned}
$$

Que é uma medida de deformação que pode ser utilizada para pequenas deformações e grandes rotações. 
APÊNDICE
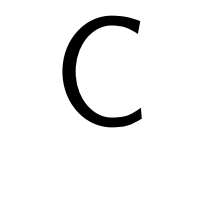

\section{TENSORES CONSTITUTIVOS}

Um tensor constitutivo de ordem 4 pode ser expresso através da seguinte equação $\mathbb{C}=\mathbb{C}_{i j k l}\left(\mathbf{e}_{i} \otimes \mathbf{e}_{j} \otimes \mathbf{e}_{k} \otimes \mathbf{e}_{l}\right)$. Nesta notação, o termo $\mathbb{C}_{i j k l}$ representa cada uma das componentes do tensor constitutivo $\mathbb{C}$ enquanto $\left(\mathbf{e}_{i} \otimes \mathbf{e}_{j} \otimes \mathbf{e}_{k} \otimes \mathbf{e}_{l}\right)$ é uma base qualquer do espaço dos tensores de ordem 4 . Por sua vez, os índices $i, j, k, l$ variam de 1 a 3 e são cada uma das direções do espaço 3D. Assim como qualquer outro tensor, o tensor constitutivo também pode ser organizado na forma de uma "matriz de matrizes" da seguinte forma:

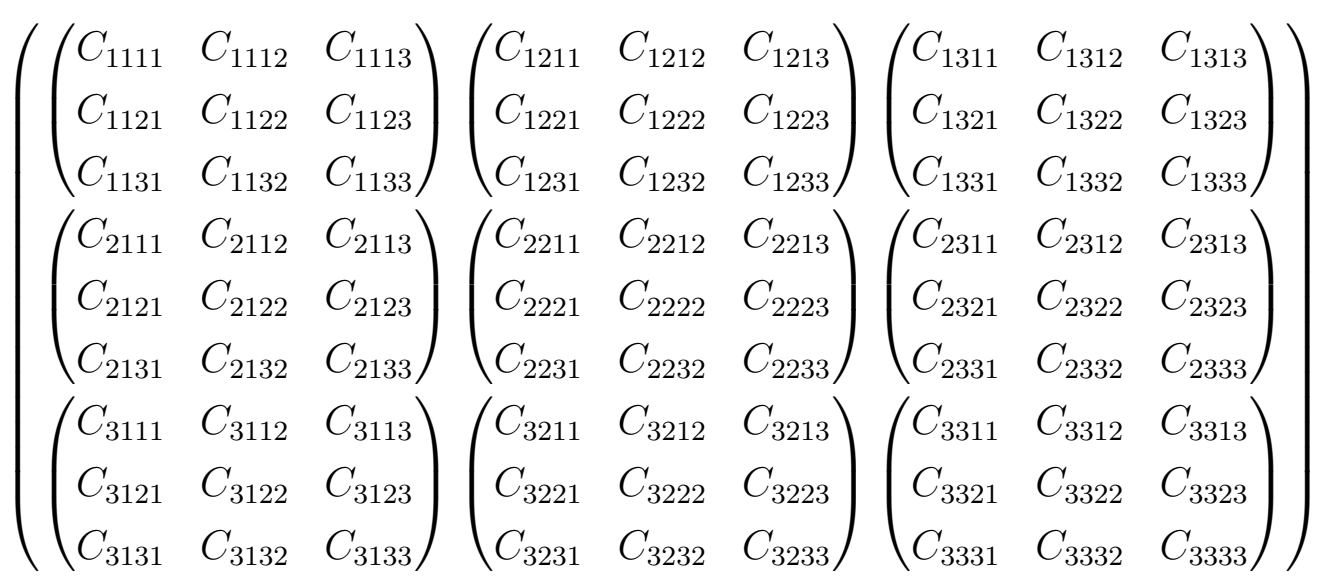

Note que na representação da Equação C.1, cada uma das componentes $\mathbb{C}_{i j k l}$ do tensor $\mathbb{C}$ ocupa uma certa linha $k$ e uma certa coluna $l$ em uma determinada submatriz. Cada submatriz, por sua vez, ocupa uma certa linha $i$ e uma certa coluna $j$ de uma matriz maior e mais externa.

Analisando a forma matricial da Equação C.1 com um pouco mais de cuidado, verifica-se no entanto que um tensor de ordem 4 também pode ser organizado matricialmente em uma única matriz. Isto é feito reduzindo-se o número de índices de 4 para 2 por meio de uma compactação desses índices, como por exemplo, da seguinte forma $\mathbb{C}_{i j k l}=$ $\mathbb{C}_{3(i-1)+j, 3(k-1)+l}$. O tensor constitutivo reorganizado de uma forma mais compacta em 
uma única matriz assume então o seguinte formato:

$$
\left(\begin{array}{lllllllll}
C_{1111} & C_{1112} & C_{1113} & C_{1121} & C_{1122} & C_{1123} & C_{1131} & C_{1132} & C_{1133} \\
C_{1211} & C_{1212} & C_{1213} & C_{1221} & C_{1222} & C_{1223} & C_{1231} & C_{1232} & C_{1233} \\
C_{1311} & C_{1312} & C_{1313} & C_{1321} & C_{1322} & C_{1323} & C_{1331} & C_{1332} & C_{1333} \\
C_{2111} & C_{2112} & C_{2113} & C_{2121} & C_{2122} & C_{2123} & C_{2131} & C_{2132} & C_{2133} \\
C_{2211} & C_{2212} & C_{2213} & C_{2221} & C_{2222} & C_{2223} & C_{2231} & C_{2232} & C_{2233} \\
C_{2311} & C_{2312} & C_{2313} & C_{2321} & C_{2322} & C_{2323} & C_{2331} & C_{2332} & C_{2333} \\
C_{3111} & C_{3112} & C_{3113} & C_{3121} & C_{3122} & C_{3123} & C_{3131} & C_{3132} & C_{3133} \\
C_{3211} & C_{3212} & C_{3213} & C_{321} & C_{3222} & C_{3223} & C_{3231} & C_{3232} & C_{3233} \\
C_{3311} & C_{3312} & C_{3313} & C_{3321} & C_{3322} & C_{3323} & C_{3331} & C_{3332} & C_{3333}
\end{array}\right)
$$

Uma vez conhecido o tensor constitutivo e sendo este constante, poder-se-ia também pensar em obter o $2^{\circ}$ tensor de tensões de Piola-Kirchhoff $(\mathbf{S})$ diretamente através de uma contração tensorial dupla ao invés de derivar a energia específica de deformação. Isto é:

$$
\begin{aligned}
\mathbf{S} & =\mathbb{C}: \mathbf{E}=\mathbb{C}_{i j k l}\left(\mathbf{e}_{i} \otimes \mathbf{e}_{j} \otimes \mathbf{e}_{k} \otimes \mathbf{e}_{l}\right): E_{m n}\left(\mathbf{e}_{m} \otimes \mathbf{e}_{n}\right) \\
& =\mathbb{C}_{i j k l} E_{m n} \delta_{k m} \delta_{l n}\left(\mathbf{e}_{i} \otimes \mathbf{e}_{j}\right)=\mathbb{C}_{i j k l} E_{k l}\left(\mathbf{e}_{i} \otimes \mathbf{e}_{j}\right) \\
\therefore S_{i j} & =\mathbb{C}_{i j k l} E_{k l}\left(\mathbf{e}_{i} \otimes \mathbf{e}_{j}\right)
\end{aligned}
$$

Contrações do tipo $\mathbb{C}_{i j k l}=\mathbb{C}_{3(i-1)+j, 3(k-1)+l}, S_{i j}=S_{3(i-1)+j}$ e $E_{k l}=E_{3(k-1)+l}$, respectivamente, nos índices dos tensores constitutivo $\mathbb{C}$, de $2^{\text {a }}$ tensão de Piola-Kirchhoff $\mathbf{S}$ e de deformação de Green-Lagrange $\mathbf{E}$, apenas aparentemente reduzem a ordem desses tensores de 4 para 2 e de 2 para 1 . A contração desses índices permite então reorganizar a operação de contração da Equação C.3 em uma notação matricial visual e compreensiva:

$$
\left(\begin{array}{l}
S_{11} \\
S_{12} \\
S_{13} \\
S_{12} \\
S_{22} \\
S_{21} \\
S_{31} \\
S_{32} \\
S_{33}
\end{array}\right)=\left(\begin{array}{lllllllll}
C_{1111} & C_{1112} & C_{1113} & C_{1121} & C_{1122} & C_{1123} & C_{1131} & C_{1132} & C_{1133} \\
C_{1211} & C_{1212} & C_{1213} & C_{1221} & C_{1222} & C_{1223} & C_{1231} & C_{1232} & C_{1233} \\
C_{1311} & C_{1312} & C_{1313} & C_{1321} & C_{1322} & C_{1323} & C_{1331} & C_{1332} & C_{1333} \\
C_{2111} & C_{2112} & C_{2113} & C_{2121} & C_{2122} & C_{2123} & C_{2131} & C_{2132} & C_{2133} \\
C_{2211} & C_{2212} & C_{2213} & C_{2221} & C_{2222} & C_{2223} & C_{2231} & C_{2232} & C_{2233} \\
C_{2311} & C_{2312} & C_{2313} & C_{2321} & C_{2322} & C_{2323} & C_{2331} & C_{2332} & C_{2333} \\
C_{3111} & C_{3112} & C_{3113} & C_{3121} & C_{3122} & C_{3123} & C_{3131} & C_{3132} & C_{3133} \\
C_{3211} & C_{3212} & C_{3213} & C_{3221} & C_{3222} & C_{3223} & C_{3231} & C_{3232} & C_{3233} \\
C_{3311} & C_{3312} & C_{3313} & C_{3321} & C_{3322} & C_{3323} & C_{3331} & C_{3332} & C_{3333}
\end{array}\right)\left(\begin{array}{l}
E_{11} \\
E_{12} \\
E_{13} \\
E_{21} \\
E_{22} \\
E_{23} \\
E_{31} \\
E_{32} \\
E_{33}
\end{array}\right)
$$

Agora observe que, conhecendo $E_{12}, E_{13}$ e $E_{23}$, automaticamente também são conhecido $E_{21}, E_{31}$ e $E_{32}$ e, uma vez calculado $S_{12}, S_{13}$ e $S_{23}$, não é necessário calcular $S_{21}, S_{31}$ e $S_{32}$, já que tanto o $2^{\circ}$ tensor de tensões de Piola-Kirchhoff $\mathbf{S}$ quanto o tensor de deformações de Green-Lagrange E são simétricos. Assim, eliminado as linhas e as colunas referentes aos termos simétricos, é possível, portanto, compactar a notação da C.4 um 
pouco:

$$
\left(\begin{array}{l}
S_{11} \\
S_{12} \\
S_{13} \\
S_{22} \\
S_{23} \\
S_{33}
\end{array}\right)=\left(\begin{array}{llllll}
C_{1111} & C_{1112} & C_{1113} & C_{1122} & C_{1123} & C_{1133} \\
C_{1211} & C_{1212} & C_{1213} & C_{1222} & C_{1223} & C_{1233} \\
C_{1311} & C_{1312} & C_{1313} & C_{1322} & C_{1323} & C_{1333} \\
C_{2211} & C_{2212} & C_{2213} & C_{2222} & C_{2223} & C_{2233} \\
C_{2311} & C_{2312} & C_{2313} & C_{2322} & C_{2323} & C_{2333} \\
C_{3311} & C_{3312} & C_{3313} & C_{3322} & C_{3323} & C_{3333}
\end{array}\right)\left(\begin{array}{c}
E_{11} \\
E_{12} \\
E_{13} \\
E_{22} \\
E_{23} \\
E_{33}
\end{array}\right)
$$

que é a "pseudo-matrix 6x6" da subseção 3.1.10 para materiais elásticos. Considerando agora a outra simetria do tensor constitutivo já verificada na subseção 3.1 .10 através da expressão para a energia específica de deformação:

$$
\begin{gathered}
u_{E}=\mathbf{E}: \mathbb{C}: \mathbf{E}=E_{i j}\left(\mathbf{e}_{i} \otimes \mathbf{e}_{j}\right): \mathbb{C}_{m n o p}\left(\mathbf{e}_{m} \otimes \mathbf{e}_{n} \otimes \mathbf{e}_{o} \otimes \mathbf{e}_{p}\right): E_{k l}\left(\mathbf{e}_{k} \otimes \mathbf{e}_{l}\right) \\
=E_{k l}\left(\mathbf{e}_{k} \otimes \mathbf{e}_{l}\right): \mathbb{C}_{m n o p}\left(\mathbf{e}_{m} \otimes \mathbf{e}_{n} \otimes \mathbf{e}_{o} \otimes \mathbf{e}_{p}\right): E_{i j}\left(\mathbf{e}_{i} \otimes \mathbf{e}_{j}\right) \\
=E_{i j} \mathbb{C}_{i j k l} E_{k l}=E_{k l} \mathbb{C}_{k l i j} E_{i j} \\
\therefore \mathbb{C}_{i j k l}=\mathbb{C}_{k l i j}
\end{gathered}
$$

Isto quer dizer que, uma deformação em uma direção j qualquer causa um efeito (tensão) em uma direção i também qualquer diferente de j. Uma mesma deformação em módulo agora nessa direção i, deve causar o mesmo efeito nessa outra direção j diferente de i. Assim, o tensor constitutivo mais geral para os materiais com propriedades mecânicas constantes se reduz a uma "pseudo-matriz 6x6" simétrica e tem, portanto, 21 constantes distintas $(6+5+4+3+2+1=21)$.

Se ainda as propriedades do material forem tais que $\mathbb{C}_{i j k l}=0$ para todo $i \neq j$ ou todo $k \neq l$ quando $i \neq k$ ou $j \neq l$, tem-se nesse caso que:

$$
\left(\begin{array}{l}
S_{11} \\
S_{12} \\
S_{13} \\
S_{22} \\
S_{23} \\
S_{33}
\end{array}\right)=\left(\begin{array}{cccccc}
C_{1111} & 0 & 0 & C_{1122} & 0 & C_{1133} \\
0 & C_{1212} & 0 & 0 & 0 & 0 \\
0 & 0 & C_{1313} & 0 & 0 & 0 \\
C_{2211} & 0 & 0 & C_{2222} & 0 & C_{2233} \\
0 & 0 & 0 & 0 & C_{2323} & 0 \\
C_{3311} & 0 & 0 & C_{3322} & 0 & C_{3333}
\end{array}\right)\left(\begin{array}{l}
E_{11} \\
E_{12} \\
E_{13} \\
E_{22} \\
E_{23} \\
E_{33}
\end{array}\right)
$$

Note na Equação C.7 que para esse tipo de material, distorções $\left(E_{12}, E_{13}, E_{23}\right)$ não geram tensões normais $\left(S_{11}, S_{22}, S_{33}\right)$, bem como deformações normais $\left(E_{11}, E_{22}, E_{33}\right)$ também não causam tensões cisalhantes $\left(S_{12}, S_{13}, S_{23}\right)$. Neste caso, o material é dito ortotrópico. Reorganizando convenientemente a operação matricial da C.7 de modo a separar as deformações/tensões normais das deformações/tensões cisalhantes, obtém-se a 
seguinte forma matricial final:

$$
\left(\begin{array}{l}
S_{11} \\
S_{22} \\
S_{33} \\
S_{12} \\
S_{13} \\
S_{23}
\end{array}\right)=\left(\begin{array}{cccccc}
C_{1111} & C_{1122} & C_{1133} & 0 & 0 & 0 \\
C_{2211} & C_{2222} & C_{2233} & 0 & 0 & 0 \\
C_{3311} & C_{3322} & C_{3333} & 0 & 0 & 0 \\
0 & 0 & 0 & C_{1212} & 0 & 0 \\
0 & 0 & 0 & 0 & C_{1313} & 0 \\
0 & 0 & 0 & 0 & 0 & C_{2323}
\end{array}\right)\left(\begin{array}{c}
E_{11} \\
E_{22} \\
E_{33} \\
E_{12} \\
E_{13} \\
E_{23}
\end{array}\right)
$$

Em se tratando de materiais hiperelásticos, a "pseudo-matriz" da Equação C.8 é simétrica e, portanto, tem-se sempre que $C_{1122}=C_{2211}, C_{1133}=C_{3311}$ e $C_{2233}=C_{3322}$. Sendo assim, são $9(3+2+1+1+1+1=9)$ o número de constantes de um material hiperelástico e ortotrópico. Se, além disso, o material também for isotrópico, o número de constante se reduz para 3 , uma vez que também se tem adicionalmente que $C_{1111}=$ $C_{2222}=C_{3333}, C_{1122}=C_{1133}=C_{2233}$ e $C_{1212}=C_{1313}=C_{2323}$.

Por último, relembrando alguns aspectos importantes que frenquentemente causam dúvidas:

1. Dado um tensor, este existe e independe da base. A base serve apenas como uma espécie de referência, o que permite escrever de maneira explicita cada um dos termos ou componentes de um determinado tensor. Mudando-se a base, mudam-se também as componentes ou termos do tensor, mas o tensor em si, no entanto, permanece essencialmente o mesmo.

2. Da mesma forma que as formulações em elementos finitos, os tensores também não nasceram na forma matricial. Assim como feito anteriormente onde as operações e os tensores foram sendo constantemente organizados e reorganizados, as matrizes servem apenas como uma ferramenta que facilita a manipulação e organização dos termos dos tensores e dos cálculos em elementos finitos. Isto pode ser verificado observando-se que aparentemente as Equações C.7 e C.8 são diferentes. No entanto, neste caso, apenas a representação foi alterada, enquanto que, a operação em si e o tensor permaneceram essencialmente os mesmos. Tensores portanto não são matrizes.

3. O desenvolvimento aqui apresentado vale para modelos constitutivos lineares onde o tensor constitutivo $\mathbb{C}$ é constante. O mesmo desenvolvimento pode ser feito para modelos constitutivos não lineares considerando-se variações de tensões $\delta \mathbf{S}$ e variações de deformações $\delta \mathbf{E}$ ao invés das tensões $\mathbf{S}$ e deformações $\mathbf{E}$ propriamente ditas. 
APÊNDICE

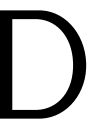

D

\section{MODELOS CONSTITUTIVOS}

Neste item são apresentados os cálculos do $2^{\circ}$ tensor de tensões de Piola-Kirchhoff $\mathbf{S}$ e do tensor constitutivo $(\mathbb{C})$ das leis constitutivas adotadas na seção 4.1.

Uma dedução bem detalhada das expressões foi feita para o modelo de Saint Venant-Kirchhoff, enquanto que para o modelo de Yeoh são apresentadas somente as expressões finais. Seguindo o mesmo caminho de cálculo apresentado para o modelo de Saint Venant-Kirchhoff, é possível com ajuda do Apêndice E, detalhar todos os cálculos de qualquer modelo constitutivo hiperelástico e, dessa forma, também verificar propriedades tensoriais tais como isotropia, simetria e ortotropia do respectivo tensor constitutivo envolvido.

Além disso, poder-se-ia inclusive organizar as expressões e os tensores em forma matricial, assim como feito para o modelo de Saint Venant-Kirchhoff e também no Apêndice C. Vale relembrar que os modelos constitutivos hiperelásticos com relações não lineares entre tensão e deformação são variacionais, ou seja, $\mathbb{C}$ relaciona variações de tensões com variações de deformações conforme a Equação 3.65 ao invés de relacionar as tensões e deformações propriamente ditas.

\section{D.1 Modelo de Saint Venant-Kirchhoff}

Segundo Holzapfel (2000), a expressão a energia de deformação no modelo de Saint Venant-Kirchhoff é dada pela seguinte equação:

$$
u_{e}=c_{10}(t r(\mathbf{E}))^{2}+c_{20} t r\left(\mathbf{E}^{2}\right)=c_{10} E_{m m} E_{n n}+c_{20} E_{m n} E_{n m}
$$

Esse modelo hiperelástico de Saint Venant-Kirchhoff é não linear e compressível. 


\section{D.1.1 Tensão de Piola-Kirchhoff (S)}

Utilizando a expressão da energia de deformação dada pela Equação D.1, é possível obter a segunda tensão de Piola para o modelo de Saint Venant-Kirchhoff em função das deformações de Green-Lagrange em notação indicial:

$$
\begin{aligned}
S_{i j} & =\frac{\partial u}{\partial E_{i j}}=\frac{\partial}{\partial E_{i j}}\left(c_{10} E_{m m} E_{n n}+c_{20} E_{m n} E_{n m}\right) \\
& =c_{10}\left(\frac{\partial E_{m m}}{\partial E_{i j}} E_{n n}+\frac{\partial E_{n n}}{\partial E_{i j}} E_{m m}\right)+c_{20}\left(\frac{\partial E_{m n}}{\partial E_{i j}} E_{n m}+\frac{\partial E_{n m}}{\partial E_{i j}} E_{m n}\right) \\
& =c_{10}\left(\delta_{i m} \delta_{j m} E_{n n}+\delta_{i n} \delta_{j n} E_{m m}\right)+c_{20}\left(\delta_{i m} \delta_{j n} E_{n m}+\delta_{i n} \delta_{j m} E_{m n}\right) \\
& =c_{10}\left(\delta_{i j} E_{n n}+\delta_{i j} E_{m m}\right)+c_{20}\left(\delta_{i m} \delta_{j n}+\delta_{i n} \delta_{j m}\right) E_{m n} \\
& =2 c_{10}\left(\delta_{i j} E_{n n}\right)+c_{20}\left(\delta_{i m} \delta_{j n}+\delta_{i n} \delta_{j m}\right) E_{m n} \\
& =2 c_{10}\left(\delta_{i j} E_{n n}\right)+c_{20}\left(E_{i j}+E_{j i}\right) \\
\therefore S_{i j} & =2 c_{10} \delta_{i j} E_{n n}+2 c_{20} E_{i j}
\end{aligned}
$$

\section{D.1.2 Tensor constitutivo $(\mathbb{C})$}

Através da Equação D.2 obtém-se o tensor constitutivo de ordem 4 para o modelo de Saint Venant-Kirchhoff em notação indicial:

$$
\begin{aligned}
\mathbb{C}_{i j k l} & =\frac{\partial S_{i j}}{\partial E_{k l}}=\frac{\partial}{\partial E_{k l}}\left[c_{10}\left(\delta_{i j} E_{n n}+\delta_{i j} E_{m m}\right)+c_{20}\left(\delta_{i m} \delta_{j n}+\delta_{i n} \delta_{j m}\right) E_{m n}\right] \\
& =c_{10}\left(\delta_{i j} \frac{\partial E_{n n}}{\partial E_{k l}}+\delta_{i j} \frac{\partial E_{m m}}{\partial E_{k l}}\right)+c_{20}\left(\delta_{i m} \delta_{j n}+\delta_{i n} \delta_{j m}\right) \frac{\partial E_{m n}}{\partial E_{k l}} \\
& =c_{10}\left(\delta_{i j} \delta_{k n} \delta_{l n}+\delta_{i j} \delta_{k m} \delta_{l m}\right)+c_{20}\left(\delta_{i m} \delta_{j n}+\delta_{i n} \delta_{j m}\right) \delta_{k m} \delta_{l n} \\
\therefore \mathbb{C}_{i j k l} & =2 c_{10}\left(\delta_{i j} \delta_{k l}\right)+c_{20}\left(\delta_{i k} \delta_{j l}+\delta_{i l} \delta_{j k}\right)
\end{aligned}
$$

Observe que para a lei constitutiva de Saint Venant-Kirchhoff, o tensor constitutivo $\mathbb{C}$ é de fato constante, assim como assumido na subseção 3.1.10.

Como qualquer outro tensor, o tensor constitutivo de Saint Venant-Kirchhoff dado pela Equação D.3 também pode ser organizado na forma de uma "matriz de matrizes" da 
seguinte forma e conforme já feito no Apêndice C:

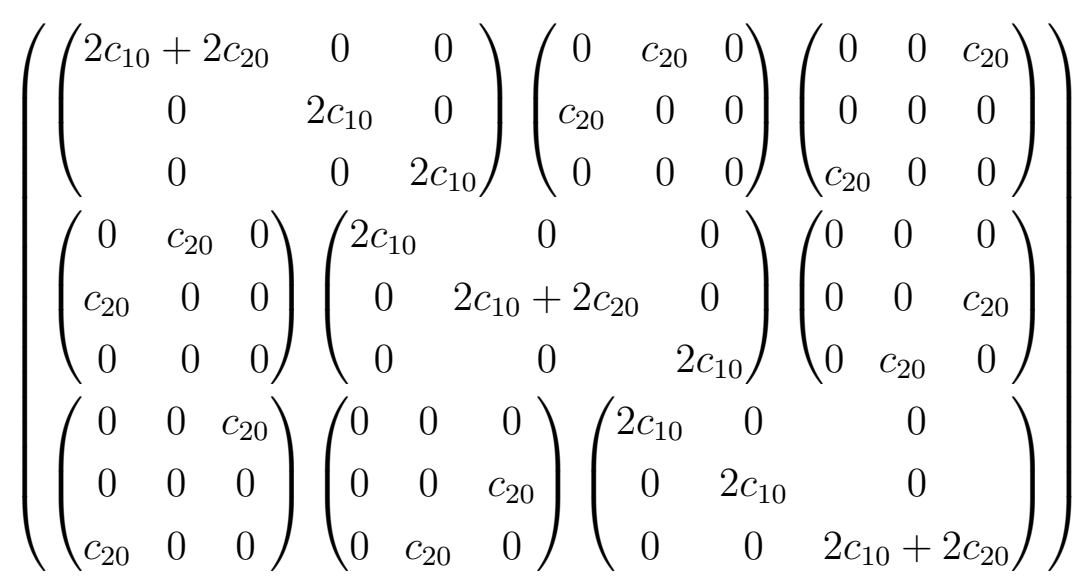

No entanto, analisando a forma matricial da Equação D.4 com um pouco mais de cuidado, verifica-se que esse tensor constitutivo de Saint Venant-Kirchhoff de ordem 4 também pode ser organizado matricialmente em uma única matriz. Isto é feito reduzindo-se o número de índices de 4 para 2 por meio de uma compactação desses índices, como por exemplo, da seguinte forma $\mathbb{C}_{i j k l}=\mathbb{C}_{3(i-1)+j, 3(k-1)+l}$. O tensor constitutivo reorganizado de uma forma mais compacta em uma única matriz assume então o seguinte formato:

$$
\left(\begin{array}{ccccccccc}
2 c_{10}+2 c_{20} & 0 & 0 & 0 & 2 c_{10} & 0 & 0 & 0 & 2 c_{10} \\
0 & c_{20} & 0 & c_{20} & 0 & 0 & 0 & 0 & 0 \\
0 & 0 & c_{20} & 0 & 0 & 0 & c_{20} & 0 & 0 \\
0 & c_{20} & 0 & c_{20} & 0 & 0 & 0 & 0 & 0 \\
2 c_{10} & 0 & 0 & 0 & 2 c_{10}+2 c_{20} & 0 & 0 & 0 & 2 c_{10} \\
0 & 0 & 0 & 0 & 0 & c_{20} & 0 & c_{20} & 0 \\
0 & 0 & c_{20} & 0 & 0 & 0 & c_{20} & 0 & 0 \\
0 & 0 & 0 & 0 & 0 & c_{20} & 0 & c_{20} & 0 \\
2 c_{10} & 0 & 0 & 0 & 2 c_{10} & 0 & 0 & 0 & 2 c_{10}+2 c_{20}
\end{array}\right)
$$

Agora, se as constantes do material fossem tais que:

$$
\begin{gathered}
c_{10}=\frac{G \nu}{1-2 \nu} \\
c_{20}=G
\end{gathered}
$$

então ver-se-ia que esse tensor constitutivo dado pela Equação D.3 em notação matricial 
ficaria sendo:

$$
\left(\begin{array}{ccccccccc}
\frac{2 G(1-\nu)}{1-2 \nu} & 0 & 0 & 0 & \frac{2 G \nu}{1-2 \nu} & 0 & 0 & 0 & \frac{2 G \nu}{1-2 \nu} \\
0 & 2 G & 0 & 2 G & 0 & 0 & 0 & 0 & 0 \\
0 & 0 & 2 G & 0 & 0 & 0 & 2 G & 0 & 0 \\
0 & 2 G & 0 & 2 G & 0 & 0 & 0 & 0 & 0 \\
\frac{2 G \nu}{1-2 \nu} & 0 & 0 & 0 & \frac{2 G(1-\nu)}{1-2 \nu} & 0 & 0 & 0 & \frac{2 G \nu}{1-2 \nu} \\
0 & 0 & 0 & 0 & 0 & 2 G & 0 & 2 G & 0 \\
0 & 0 & 2 G & 0 & 0 & 0 & 2 G & 0 & 0 \\
0 & 0 & 0 & 0 & 0 & 2 G & 0 & 2 G & 0 \\
\frac{2 G \nu}{1-2 \nu} & 0 & 0 & 0 & \frac{2 G \nu}{1-2 \nu} & 0 & 0 & 0 & \frac{2 G(1-\nu)}{1-2 \nu}
\end{array}\right)
$$

Esse tensor constitutivo da lei de Saint Venant-Kirchhoff dado pela Equação D.7 é dito isotrópico. Isto quer dizer que uma vez adotada uma matriz de rotação $Q_{i j}$ composta por versores unitários e ortogonais entre si, como por exemplo:

$$
Q=\left(\begin{array}{ccc}
\frac{\sqrt{3}}{3} & -\frac{\sqrt{2}}{2} & -\frac{\sqrt{6}}{6} \\
\frac{\sqrt{3}}{3} & \frac{\sqrt{2}}{2} & -\frac{\sqrt{6}}{6} \\
\frac{\sqrt{3}}{3} & 0 & \frac{\sqrt{6}}{3}
\end{array}\right)
$$

a aplicação uma operação de rotação nesse tensor, ou seja:

$$
\tilde{\mathbb{C}}_{i j k l}=Q_{m i} Q_{n j} Q_{o k} Q_{p l} \mathbb{C}_{m n o p}
$$

mantém o tensor constitutivo inalterado, isto é, $\widetilde{\mathbb{C}}=\mathbb{C}$.

Uma vez conhecido o tensor constitutivo de Saint Venant-Kirchhoff e sendo este constante, poder-se-ia também pensar em obter o $2^{\circ}$ tensor de tensões de Piola-Kirchhoff diretamente através de uma contração tensorial dupla ao invés de derivar a energia específica de deformação. Isto é:

$$
\begin{aligned}
S & =\mathbb{C}: E=\mathbb{C}_{i j k l}\left(\mathbf{e}_{i} \otimes \mathbf{e}_{j} \otimes \mathbf{e}_{k} \otimes \mathbf{e}_{l}\right): E_{m n}\left(\mathbf{e}_{m} \otimes \mathbf{e}_{n}\right) \\
& =\left[\mathbb{C}_{i j k l} E_{m n} \delta_{k m} \delta_{l n}\right]\left(\mathbf{e}_{i} \otimes \mathbf{e}_{j}\right)=\left[\mathbb{C}_{i j k l} E_{k l}\right]\left(\mathbf{e}_{i} \otimes \mathbf{e}_{j}\right) \\
& =\left\{\left[2 c_{10}\left(\delta_{i j} \delta_{k l}\right)+c_{20}\left(\delta_{i k} \delta_{j l}+\delta_{i l} \delta_{j k}\right)\right] E_{k l}\right\}\left(\mathbf{e}_{i} \otimes \mathbf{e}_{j}\right) \\
& =\left[2 c_{10} \delta_{i j} \delta_{k l} E_{k l}+c_{20}\left(\delta_{i k} \delta_{j l}+\delta_{i l} \delta_{j k}\right) E_{k l}\right]\left(\mathbf{e}_{i} \otimes \mathbf{e}_{j}\right) \\
& =\left[2 c_{10} \delta_{i j} E_{k k}+c_{20}\left(E_{i j}+E_{j i}\right)\right]\left(\mathbf{e}_{i} \otimes \mathbf{e}_{j}\right) \\
\therefore S_{i j} & =2 c_{10} \delta_{i j} E_{k k}+2 c_{20} E_{i j}
\end{aligned}
$$

que é o mesmo resultado obtido na Equação D.2. 
Contrações do tipo $\mathbb{C}_{i j k l}=\mathbb{C}_{3(i-1)+j, 3(k-1)+l}, S_{i j}=S_{3(i-1)+j}, E_{k l}=E_{3(k-1)+l}$, respectivamente, nos índices dos tensores constitutivo $\mathbb{C}$, de $2^{\text {a }}$ tensão de Piola-Kirchhoff $\mathbf{S}$ e de deformação de Green-Lagrange $\mathbf{E}$, apenas aparentemente reduzem a ordem desses tensores de 4 para 2 e de 2 para 1 . A contração desses índices permite então reorganizar a operação anterior em uma notação matricial visual e compreensiva:

$$
\left(\begin{array}{l}
S_{11} \\
S_{12} \\
S_{13} \\
S_{21} \\
S_{22} \\
S_{23} \\
S_{31} \\
S_{32} \\
S_{33}
\end{array}\right)=\left(\begin{array}{ccccccccc}
\frac{2 G(1-\nu)}{1-2 \nu} & 0 & 0 & 0 & \frac{2 G \nu}{1-2 \nu} & 0 & 0 & 0 & \frac{2 G \nu}{1-2 \nu} \\
0 & 2 G & 0 & 2 G & 0 & 0 & 0 & 0 & 0 \\
0 & 0 & 2 G & 0 & 0 & 0 & 2 G & 0 & 0 \\
0 & 2 G & 0 & 2 G & 0 & 0 & 0 & 0 & 0 \\
\frac{2 G \nu}{1-2 \nu} & 0 & 0 & 0 & \frac{2 G(1-\nu)}{1-2 \nu} & 0 & 0 & 0 & \frac{2 G \nu}{1-2 \nu} \\
0 & 0 & 0 & 0 & 0 & 2 G & 0 & 2 G & 0 \\
0 & 0 & 2 G & 0 & 0 & 0 & 2 G & 0 & 0 \\
0 & 0 & 0 & 0 & 0 & 2 G & 0 & 2 G & 0 \\
\frac{2 G \nu}{1-2 \nu} & 0 & 0 & 0 & \frac{2 G \nu}{1-2 \nu} & 0 & 0 & 0 & \frac{2 G(1-\nu)}{1-2 \nu}
\end{array}\right)\left(\begin{array}{l}
E_{11} \\
E_{12} \\
E_{13} \\
E_{21} \\
E_{22} \\
E_{23} \\
E_{31} \\
E_{32} \\
E_{33}
\end{array}\right)
$$

Agora observe que, conhecendo $E_{12}, E_{13}$ e $E_{23}$, automaticamente também são conhecido $E_{21}, E_{31}$ e $E_{32}$ e, uma vez calculado $S_{12}, S_{13}$ e $S_{23}$, não é necessário calcular $S_{21}, S_{31}$ e $S_{32}$, já que tanto o $2^{\circ}$ tensor de tensões de Piola-Kirchhoff $\mathbf{S}$ quanto o tensor de deformações de Green-Lagrange $\mathbf{E}$ são simétricos. Assim, eliminado as linhas e as colunas referentes aos termos simétricos, é possível, portanto, compactar a notação da D.11 um pouco:

$$
\left(\begin{array}{l}
S_{11} \\
S_{12} \\
S_{13} \\
S_{22} \\
S_{23} \\
S_{33}
\end{array}\right)=\left(\begin{array}{cccccc}
\frac{2 G(1-\nu)}{1-2 \nu} & 0 & 0 & \frac{2 G \nu}{1-2 \nu} & 0 & \frac{2 G \nu}{1-2 \nu} \\
0 & 2 G & 0 & 0 & 0 & 0 \\
0 & 0 & 2 G & 0 & 0 & 0 \\
\frac{2 G \nu}{1-2 \nu} & 0 & 0 & \frac{2 G(1-\nu)}{1-2 \nu} & 0 & \frac{2 G}{1-2 \nu} \\
0 & 0 & 0 & 0 & 2 G & 0 \\
\frac{2 G \nu}{1-2 \nu} & 0 & 0 & \frac{2 G \nu}{1-2 \nu} & 0 & \frac{2 G(1-\nu)}{1-2 \nu}
\end{array}\right)\left(\begin{array}{l}
E_{11} \\
E_{12} \\
E_{13} \\
E_{22} \\
E_{23} \\
E_{33}
\end{array}\right)
$$

Note na D.12 que na lei constitutiva de Saint Venant-Kirchhoff, distorções $\left(E_{12}, E_{13}, E_{23}\right)$ não geram tensões normais $\left(S_{11}, S_{22}, S_{33}\right)$, bem como deformações normais $\left(E_{11}, E_{22}, E_{33}\right)$ também não causam tensões cisalhantes $\left(S_{12}, S_{13}, S_{23}\right)$. Neste caso, o material é dito ortotrópico. Reorganizando convenientemente a operação matricial da Equação D.12 de modo a separar as deformações/tensões normais das deformações/tensões cisalhantes, obtém-se 
a seguinte forma matricial final:

$$
\left(\begin{array}{l}
S_{11} \\
S_{22} \\
S_{33} \\
S_{12} \\
S_{21} \\
S_{23}
\end{array}\right)=\left(\begin{array}{cccccc}
\frac{2 G(1-\nu)}{1-2 \nu} & \frac{2 G \nu}{1-2 \nu} & \frac{2 G \nu}{1-2 \nu} & 0 & 0 & 0 \\
\frac{2 G}{1-2 \nu} & \frac{2 G(1-\nu)}{1-2 \nu} & \frac{2 G \nu}{1-2 \nu} & 0 & 0 & 0 \\
\frac{2 G}{1-2 \nu} & \frac{2 G \nu}{1-2 \nu} & \frac{2 G(1-\nu)}{1-2 \nu} & 0 & 0 & 0 \\
0 & 0 & 0 & 2 G & 0 & 0 \\
0 & 0 & 0 & 0 & 2 G & 0 \\
0 & 0 & 0 & 0 & 0 & 2 G
\end{array}\right)\left(\begin{array}{l}
E_{11} \\
E_{22} \\
E_{33} \\
E_{12} \\
E_{13} \\
E_{23}
\end{array}\right)
$$

que é a fórmula frequentemente apresentada com 3 constantes distintas $\left(G, \frac{2 G(1-\nu)}{1-2 \nu}\right.$ e $\left.\frac{2 G \nu}{1-2 \nu}\right)$ para material elástico, ortotrópico e isotrópico.

\section{D.2 Modelo de Yeoh}

O modelo de Yeoh utilizado é composto de uma parcela de energia de deformação isovolumétrica e uma parcela de energia de deformação volumétrica. A expressão da energia específica de deformação adotada para esse modelo é a seguinte:

$$
u_{e}\left(\bar{I}_{1}, J\right)=c_{10}\left(\bar{I}_{1}-3\right)+c_{20}\left(\bar{I}_{1}-3\right)^{2}+c_{30}\left(\bar{I}_{1}-3\right)^{3}+k\left(J^{2}+J^{-2}-2\right)
$$

As derivadas da Equação D.14, respectivamente, em relação ao primeiro invariante a volume constante $\left(\bar{I}_{1}=J^{-\frac{2}{3}} I_{1}\right)$ e ao Jacobiano $(J)$ são:

$$
\begin{aligned}
\frac{\partial u_{i s o}}{\partial \bar{I}_{1}} & =c_{10}+2 c_{20}\left(\bar{I}_{1}-3\right)+3 c_{30}\left(\bar{I}_{1}-3\right)^{2} \\
\frac{\partial^{2} u_{i s o}}{\partial \bar{I}_{1}^{2}} & =2 c_{20}+6 c_{30}\left(\bar{I}_{1}-3\right) \\
\frac{\partial u_{v o l}}{\partial J} & =k\left(2 J-2 J^{-3}\right) \\
\frac{\partial^{2} u_{v o l}}{\partial J^{2}} & =k\left(2+6 J^{-4}\right)
\end{aligned}
$$

\section{D.2.1 Tensão de Piola-Kirchhoff (S)}

Substituindo as derivadas da energia específica de deformação encontradas na Equação D.15, Equação D.16, Equação D.17 e Equação D.18 nas equações do Apêndice E, calcula-se o segundo tensor de Piola-Kirchhoff:

$$
\begin{aligned}
S_{i j} & =2\left[c_{10}+2 c_{20}\left(\bar{I}_{1}-3\right)+3 c_{30}\left(\bar{I}_{1}-3\right)^{2}\right] J^{-\frac{2}{3}}\left(\delta_{i j}-\frac{1}{3} I_{1} C_{i j}^{-1}\right) \\
& +k J\left(2 J-2 J^{-3}\right) C_{i j}^{-1}
\end{aligned}
$$




\section{D.2.2 Tensor constitutivo ( $\mathbb{C}$ )}

Substituindo as derivadas da energia específica de deformação encontradas nas Equação D.15, Equação D.16, Equação D.17, Equação D.18 nas equações do Apêndice E, calcula-se também o tensor constitutivo:

$$
\begin{aligned}
\mathbb{C}_{i j k l} & =4\left(2 c_{20}+6 c_{30}\left(\bar{I}_{1}-3\right)\right) \delta_{i j} \delta_{k l} \\
& +\frac{4}{3}\left(c_{10}+2 c_{20}\left(\bar{I}_{1}-3\right)+3 c_{30}\left(\bar{I}_{1}-3\right)^{2}\right) J^{-\frac{2}{3}} \\
& I_{1}\left(\frac{1}{3} C_{k l}^{-1} C_{i j}^{-1}+\frac{1}{2} C_{k j}^{-1} C_{l i}^{-1}+\frac{1}{2} C_{k i}^{-1} C_{l j}^{-1}\right) \\
& -\frac{4}{3}\left(c_{10}+2 c_{20}\left(\bar{I}_{1}-3\right)+3 c_{30}\left(\bar{I}_{1}-3\right)^{2}\right) J^{-\frac{2}{3}}\left(C_{i j}^{-1} \delta_{k l}+C_{k l}^{-1} \delta_{i j}\right) \\
& +2 k\left(J^{2}+3 J^{-2}\right)\left(C_{i j}^{-1} C_{k l}^{-1}\right) \\
& +2 k\left(J^{2}-J^{-2}\right)\left(C_{i j}^{-1} C_{k l}^{-1}-C_{k j}^{-1} C_{l i}^{-1}-C_{k i}^{-1} C_{l j}^{-1}\right)
\end{aligned}
$$

\section{D.2.3 Modelo uniaxial de deformações}

Utilizando as Equações 4.4 e 4.5, a equação da $2^{\text {a }}$ tensão de Piola-Kirchhoff (Equação D.19) fornece para o modelo de Yeoh:

$$
\begin{aligned}
S_{11} & =\left(4 c_{30}\right) \lambda^{2}+\left(\frac{8 c_{20}}{3}-24 c_{30}\right) \lambda^{2 / 3} \\
& +\left(\frac{4 c_{10}}{3}-8 c_{20}+36 c_{30}\right) \lambda^{-2 / 3} \\
& +\left(\frac{8 c_{20}}{3}-24 c_{30}\right) \lambda^{-4 / 3} \\
& -\left(\frac{4 c_{10}}{3}-8 c_{20}+36 c_{30}\right) \lambda^{-8 / 3} \\
& +\left(48 c_{30}-\frac{16 c_{20}}{3}\right) \lambda^{-10 / 3}-\left(16 c_{30}+2 k\right) \lambda^{-4}
\end{aligned}
$$

Portanto, conforme a Equação 4.5 e, considerando que a $1^{\mathrm{a}}$ tensão de Piola-Kirchhoff é referente a área inicial $\mathrm{S}$ da configuração inicial indeformada, tem-se que a força $F$ aplicada vale:

$$
F=S_{11} \lambda S
$$





\section{APÊNDICE}

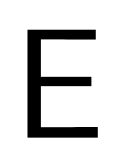

DERIVADAS

\section{E.1 Jacobiano $(J)$}

$J^{2}=\operatorname{det}(C)$

$\frac{\partial J}{\partial J^{2}}=\frac{1}{2} J^{-1}$

$\frac{\partial^{2} J}{\partial J^{2} \partial J^{2}}=-\frac{1}{4} J^{-3}$

$\frac{\partial J}{\partial C_{i j}}=\frac{1}{2} J C_{j i}^{-1}=\frac{1}{2} J C_{i j}^{-1}$

$\frac{\partial J^{2}}{\partial C_{i j}}=J^{2} C_{i j}^{-1}$

$\frac{\partial^{2} J}{\partial C_{i j} \partial C_{k l}}=\frac{1}{4} J C_{i j}^{-1} C_{k l}^{-1}-\frac{1}{4} J C_{k j}^{-1} C_{l i}^{-1}-\frac{1}{4} J C_{k i}^{-1} C_{l j}^{-1}$

$\frac{\partial^{2} J^{2}}{\partial C_{i j} \partial C_{k l}}=J^{2} C_{i j}^{-1} C_{k l}^{-1}-\frac{1}{2} J^{2} C_{k j}^{-1} C_{l i}^{-1}-\frac{1}{2} J^{2} C_{k i}^{-1} C_{l j}^{-1}$

$\frac{\partial J^{-\frac{2}{3}}}{\partial C_{i j}}=-\frac{1}{3} J^{-\frac{2}{3}} C_{i j}^{-1}$ 


\section{E.2 Alongamento de Cauchy (C)}

$\bar{C}_{i j}=J^{-\frac{2}{3}} C_{i j}$

$\frac{\partial C_{k l}}{\partial C_{i j}}=\delta_{i k} \delta_{j l}$

$\frac{\partial C_{k l}^{-1}}{\partial C_{i j}}=-\frac{1}{2}\left(C_{k j}^{-1} C_{l i}^{-1}+C_{k i}^{-1} C_{l j}^{-1}\right)$

$\frac{\partial C_{k l}^{2}}{\partial C_{i j}}=C_{j l} \delta_{i k}+C_{k i} \delta_{j l}$

$\frac{\partial^{2} C_{m n}^{2}}{\partial C_{i j} \partial C_{k l}}=\delta_{i m} \delta_{j k} \delta_{l n}+\delta_{k m} \delta_{i l} \delta_{j n}$

$\frac{\partial \bar{C}_{k l}}{\partial C_{i j}}=-\frac{1}{3} J^{-\frac{2}{3}} C_{k l} C_{i j}^{-1}+J^{-\frac{2}{3}} \delta_{i k} \delta_{j l}$

\section{E.3 Primeiro invariante $\left(I_{1}\right)$}

$$
\begin{aligned}
& I_{1}=C_{i i} \\
& \bar{I}_{1}=J^{-\frac{2}{3}} I_{1} \\
& \frac{\partial I_{1}}{\partial C_{i j}}=\delta_{i j} \\
& \frac{\partial I_{1}}{\partial C_{i j} \partial C_{k l}}=0 \\
& \frac{\partial \bar{I}_{1}}{\partial C_{i j}}=-\frac{1}{3} J^{-\frac{2}{3}} I_{1} C_{i j}^{-1}+J^{-\frac{2}{3}} \delta_{i j} \\
& \frac{\partial \bar{I}_{1}}{\partial C_{i j} \partial C_{k l}}=\frac{1}{3} J^{-\frac{2}{3}} I_{1}\left(\frac{1}{3} C_{k l}^{-1} C_{i j}^{-1}+\frac{1}{2} C_{k j}^{-1} C_{l i}^{-1}+\frac{1}{2} C_{k i}^{-1} C_{l j}^{-1}\right) \\
& \quad-\frac{1}{3} J^{-\frac{2}{3}}\left(C_{i j}^{-1} \delta_{k l}+C_{k l}^{-1} \delta_{i j}\right)
\end{aligned}
$$




\section{E.4 Segundo invariante $\left(I_{2}\right)$}

$$
\begin{aligned}
& I_{2}=C_{i i} C_{j j}-C_{i j} C_{j i} \\
& \bar{I}_{2}=J^{-\frac{4}{3}} I_{2} \\
& \frac{\partial I_{2}}{\partial C_{i j}}=I_{1} \delta_{i j}-C_{i j} \\
& \frac{\partial I_{2}}{\partial C_{i j} \partial C_{k l}}=\delta_{i j} \delta_{k l}-\delta_{i k} \delta_{j l} \\
& \frac{\partial \bar{I}_{2}}{\partial C_{i j}}=-\frac{2}{3} J^{-\frac{4}{3}} I_{2} C_{i j}^{-1}+J^{-\frac{4}{3}} I_{1} \delta_{i j}-J^{-\frac{4}{3}} C_{i j} \\
& \frac{\partial \bar{I}_{2}}{\partial C_{i j} \partial C_{k l}}=\frac{1}{3} J^{-\frac{4}{3}} I_{2}\left(\frac{4}{3} C_{k l}^{-1} C_{i j}^{-1}+C_{k j}^{-1} C_{l i}^{-1}+C_{k i}^{-1} C_{l j}^{-1}\right) \\
& \quad-\frac{2}{3} J^{-\frac{4}{3}} I_{1}\left(C_{k l}^{-1} \delta_{i j}+C_{i j}^{-1} \delta_{k l}\right) \\
& \quad+\frac{2}{3} J^{-\frac{4}{3}}\left(C_{k l}^{-1} C_{i j}+C_{i j}^{-1} C_{k l}\right)+J^{-\frac{4}{3}}\left(\delta_{k l} \delta_{i j}-\delta_{i k} \delta_{j l}\right)
\end{aligned}
$$

\section{E.5 Tensão de Piola-Kirchhoff ( $S$ )}

$$
\begin{aligned}
S_{i j}=2 & \left(\frac{\partial u_{i s o}}{\partial C_{i j}}+\frac{\partial u_{v o l}}{\partial C_{i j}}\right) \\
\frac{\partial u_{i s o}}{\partial C_{i j}} & =\frac{\partial u_{i s o}}{\partial \bar{I}_{1}} \frac{\partial \bar{I}_{1}}{\partial C_{i j}}+\frac{\partial u_{i s o}}{\partial \bar{I}_{2}} \frac{\partial \bar{I}_{2}}{\partial C_{i j}} \\
& =\frac{\partial u_{i s o}}{\partial \bar{I}_{1}}\left(J^{-\frac{2}{3}} \delta_{i j}-\frac{1}{3} J^{-\frac{2}{3}} I_{1} C_{i j}^{-1}\right) \\
& +\frac{\partial u_{i s o}}{\partial \bar{I}_{2}}\left(-\frac{2}{3} J^{-\frac{4}{3}} I_{2} C_{i j}^{-1}+J^{-\frac{4}{3}} I_{1} \delta_{i j}-J^{-\frac{4}{3}} C_{i j}\right) \\
\frac{\partial u_{i s o}}{\partial C_{i j}} & =\frac{\partial u_{i s o}}{\partial \bar{I}_{1}} J^{-\frac{2}{3}}\left(\delta_{i j}-\frac{1}{3} I_{1} C_{i j}^{-1}\right) \\
& +\frac{\partial u_{i s o}}{\partial \bar{I}_{2}} J^{-\frac{4}{3}}\left(I_{1} \delta_{i j}-\frac{2}{3} I_{2} C_{i j}^{-1}-C_{i j}\right) \\
\frac{\partial u_{v o l}}{\partial C_{i j}}= & \frac{\partial u_{v o l}}{\partial J} \frac{\partial J}{\partial C_{i j}}=\frac{\partial u_{v o l}}{\partial J} \frac{1}{2} J C_{i j}^{-1}
\end{aligned}
$$




\section{E.6 Tensor constitutivo $(\mathbb{C})$}

$$
\begin{aligned}
& \mathbb{C}_{i j k l}=4\left(\frac{\partial^{2} u_{i s o}}{\partial C_{i j} \partial C_{k l}}+\frac{\partial^{2} u_{v o l}}{\partial C_{i j} \partial C_{k l}}\right) \\
& \frac{\partial^{2} u_{i s o}}{\partial C_{i j} \partial C_{k l}}=\frac{\partial^{2} u_{i s o}}{\partial \bar{I}_{1}^{2}} \frac{\partial \bar{I}_{1}}{\partial C_{i j}} \frac{\partial \bar{I}_{1}}{\partial C_{k l}}+\frac{\partial u_{i s o}}{\partial \bar{I}_{1}} \frac{\partial^{2} \bar{I}_{1}}{\partial C_{i j} \partial C_{k l}} \\
& +\frac{\partial^{2} u_{i s o}}{\partial \bar{I}_{2}^{2}} \frac{\partial \bar{I}_{2}}{\partial C_{i j}} \frac{\partial \bar{I}_{2}}{\partial C_{k l}}+\frac{\partial u_{i s o}}{\partial \bar{I}_{2}} \frac{\partial^{2} \bar{I}_{2}}{\partial C_{i j} \partial C_{k l}} \\
& \frac{\partial^{2} u_{i s o}}{\partial C_{i j} \partial C_{k l}}=\frac{\partial^{2} u_{i s o}}{\partial \bar{I}_{1}^{2}} \delta_{i j} \delta_{k l} \\
& +\frac{\partial u_{i s o}}{\partial \bar{I}_{1}} \frac{1}{3} J^{-\frac{2}{3}} I_{1}\left(\frac{1}{3} C_{k l}^{-1} C_{i j}^{-1}+\frac{1}{2} C_{k j}^{-1} C_{l i}^{-1}+\frac{1}{2} C_{k i}^{-1} C_{l j}^{-1}\right) \\
& -\frac{\partial u_{i s o}}{\partial \bar{I}_{1}} \frac{1}{3} J^{-\frac{2}{3}}\left(C_{i j}^{-1} \delta_{k l}+C_{k l}^{-1} \delta_{i j}\right) \\
& +\frac{\partial^{2} u_{i s o}}{\partial I_{2}^{2}} J^{-\frac{8}{3}}\left(I_{1} \delta_{i j}-\frac{2}{3} I_{2} C_{i j}^{-1}-C_{i j}\right)\left(I_{1} \delta_{k l}-\frac{2}{3} I_{2} C_{k l}^{-1}-C_{k l}\right) \\
& +\frac{\partial u_{i s o}}{\partial \bar{I}_{2}} \frac{1}{3} J^{-\frac{4}{3}} I_{2}\left(\frac{4}{3} C_{k l}^{-1} C_{i j}^{-1}+C_{k j}^{-1} C_{l i}^{-1}+C_{k i}^{-1} C_{l j}^{-1}\right) \\
& -\frac{\partial u_{i s o}}{\partial \bar{I}_{2}} \frac{2}{3} J^{-\frac{4}{3}} I_{1}\left(C_{k l}^{-1} \delta_{i j}+C_{i j}^{-1} \delta_{k l}\right) \\
& +\frac{\partial u_{i s o}}{\partial \bar{I}_{2}} \frac{2}{3} J^{-\frac{4}{3}}\left(C_{k l}^{-1} C_{i j}+C_{i j}^{-1} C_{k l}\right) \\
& +\frac{\partial u_{i s o}}{\partial \bar{I}_{2}} J^{-\frac{4}{3}}\left(\delta_{k l} \delta_{i j}-\delta_{i k} \delta_{j l}\right) \\
& \frac{\partial^{2} u_{v o l}}{\partial C_{i j} \partial C_{k l}}=\frac{\partial^{2} u_{v o l}}{\partial J^{2}} \frac{\partial J}{\partial C_{i j}} \frac{\partial J}{\partial C_{k l}}+\frac{\partial u_{v o l}}{\partial J} \frac{\partial^{2} J}{\partial C_{i j} \partial C_{k l}} \\
& =\frac{\partial^{2} u_{v o l}}{\partial J^{2}} \frac{1}{4} J^{2} C_{i j}^{-1} C_{k l}^{-1} \\
& +\frac{\partial u_{v o l}}{\partial J} \frac{1}{4} J\left(C_{i j}^{-1} C_{k l}^{-1}-C_{k j}^{-1} C_{l i}^{-1}-C_{k i}^{-1} C_{l j}^{-1}\right)
\end{aligned}
$$




\section{APÊNDICE}

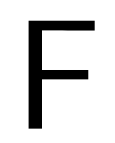

\section{PROPRIEDADES TENSORIAIS}

$$
\begin{aligned}
\frac{\operatorname{div}\left(\mathbf{A}^{T} \mathbf{u}\right)}{} & =\operatorname{div}(\mathbf{A}) \cdot \mathbf{u}+\mathbf{A}: \operatorname{grad}(\mathbf{u}) \\
\operatorname{div}\left(\mathbf{A}^{T} \mathbf{u}\right) & =\operatorname{div}\left(A_{i j}\left(\mathbf{e}_{j} \otimes \mathbf{e}_{i}\right) u_{k} \mathbf{e}_{k}\right)=\operatorname{div}\left(A_{i j} u_{k} \delta_{i k} \mathbf{e}_{j}\right)=\operatorname{div}\left(A_{i j} u_{i} \mathbf{e}_{j}\right) \\
& =\frac{\partial A_{i j}}{\partial x_{k}} u_{i} \mathbf{e}_{j} \cdot \mathbf{e}_{k}+A_{i j} \frac{\partial u_{i}}{\partial x_{k}} \mathbf{e}_{j} \cdot \mathbf{e}_{k}=\frac{\partial A_{i j}}{\partial x_{j}} u_{i}+A_{i j} \frac{\partial u_{i}}{\partial x_{j}} \\
& =\operatorname{div}(\mathbf{A}) \cdot \mathbf{u}+\mathbf{A}: \operatorname{grad}(\mathbf{u})
\end{aligned}
$$

$\underline{\mathbf{A}:(\mathbf{B C})=\mathbf{C}:\left(\mathbf{B}^{T} \mathbf{A}\right)=\mathbf{B}:\left(\mathbf{A} \mathbf{C}^{T}\right)}$

$\mathbf{A}:(\mathbf{B C})=A_{i j}\left(\mathbf{e}_{i} \otimes \mathbf{e}_{j}\right): B_{k l} C_{l m}\left(\mathbf{e}_{k} \otimes \mathbf{e}_{m}\right)=A_{i j} B_{k l} C_{l m} \delta_{i k} \delta_{j m}=A_{i j} B_{i l} C_{l j}$

$$
\begin{aligned}
& =C_{l j} B_{l i}^{T} A_{i j}=C_{m n}\left(\mathbf{e}_{m} \otimes \mathbf{e}_{n}\right): B_{l i}^{T} A_{i j}\left(\mathbf{e}_{l} \otimes \mathbf{e}_{j}\right)=\mathbf{C}: \mathbf{B}^{T} \mathbf{A} \\
& =B_{i l} A_{i j} C_{j l}^{T}=B_{m n}\left(\mathbf{e}_{m} \otimes \mathbf{e}_{n}\right): A_{i j} C_{j l}^{T}\left(\mathbf{e}_{i} \otimes \mathbf{e}_{l}\right)=\mathbf{B}: \mathbf{A C}^{T}
\end{aligned}
$$

$$
\begin{aligned}
& \frac{\delta \mathbf{E}=\frac{\partial \mathbf{E}}{\partial \mathbf{F}}:}{\delta \mathbf{F}}=\frac{1}{2}\left(\mathbf{F}^{T} \delta \mathbf{F}+\delta \mathbf{F}^{T} \mathbf{F}\right) \\
& \mathbf{E}(\mathbf{F}+\delta \mathbf{F})=\mathbf{E}+\frac{\partial \mathbf{E}}{\partial F}: \delta \mathbf{F}+o^{2} \\
&=\frac{1}{2}\left((\mathbf{F}+\delta \mathbf{F})^{T}(\mathbf{F}+\delta \mathbf{F})-\mathbf{I}\right)=\frac{1}{2}\left(\mathbf{F}^{T} \mathbf{F}+\mathbf{F}^{T} \delta \mathbf{F}+\delta \mathbf{F}^{T} \mathbf{F}-\mathbf{I}+o^{2}\right) \\
&=\mathbf{E}+\frac{1}{2}\left(\mathbf{F}^{T} \delta \mathbf{F}+\delta \mathbf{F}^{T} \mathbf{F}+o^{2}\right)=\mathbf{E}+\frac{\partial \mathbf{E}}{\partial F}: \delta \mathbf{F}+o^{2} \\
& \therefore \frac{\partial \mathbf{E}}{\partial F}: \delta \mathbf{F}=\frac{1}{2}\left(\mathbf{F}^{T} \delta \mathbf{F}+\delta \mathbf{F}^{T} \mathbf{F}\right)
\end{aligned}
$$


$\frac{\partial(\alpha \mathbf{A})}{\partial \mathbf{B}}=\alpha \frac{\partial \mathbf{A}}{\partial \mathbf{B}}+\mathbf{A} \otimes \frac{\partial \alpha}{\partial \mathbf{B}}$

$\alpha(\mathbf{B}+d \mathbf{B}) \mathbf{A}(\mathbf{B}+d \mathbf{B})=\alpha \mathbf{A}+\frac{\partial(\alpha \mathbf{A})}{\partial \mathbf{B}}: d \mathbf{B}+\mathrm{o}^{2}$

$\left(\alpha+\frac{\partial \alpha}{\partial \mathbf{B}}: d \mathbf{B}+o^{2}\right)\left(\mathbf{A}+\frac{\partial \mathbf{A}}{\partial \mathbf{B}}: d \mathbf{B}+o^{2}\right)=\alpha \mathbf{A}+\alpha \frac{\partial \mathbf{A}}{\partial \mathbf{B}}: d \mathbf{B}+\left(\frac{\partial \alpha}{\partial \mathbf{B}}: d \mathbf{B}\right) \mathbf{A}+o^{2}$

$=\alpha \mathbf{A}+\alpha \frac{\partial \mathbf{A}}{\partial \mathbf{B}}: d \mathbf{B}+\left(\mathbf{A} \otimes \frac{\partial \alpha}{\partial \mathbf{B}}\right): d \mathbf{B}+\mathrm{o}^{2}$

$\therefore \frac{\partial(\alpha \mathbf{A})}{\partial \mathbf{B}}: d \mathbf{B}=\alpha \frac{\partial \mathbf{A}}{\partial \mathbf{B}}: d \mathbf{B}+\left(\mathbf{A} \otimes \frac{\partial \alpha}{\partial \mathbf{B}}\right): d \mathbf{B}$ 
APÊNDICE

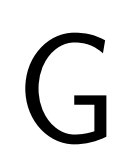

\section{O ELEMENTO FINITO DE BARRA SIMPLES}

\section{G.1 Modelo constitutivo hiperelástico incompressível}

Considere escrever a energia específica de deformação através de uma expressão que é função do primeiro invariante $I_{1}$ e do terceiro invariante $I_{3}$ do tensor de alongamento à direita de Cauchy-Green C. Seja ainda essa uma função estritamente positiva que obedece aos critérios de normalização, policonvexidade, condição de crescimento e objetividade.

$$
u_{e}\left(I_{1}, I_{3}\right)=u_{e}\left(I_{1}\right)-\frac{1}{2} p\left(I_{3}-1\right)
$$

Na Equação G.1, p é um multiplicador de Lagrange que introduz a hipótese de incompressibilidade na lei constitutiva. Pela $2^{\mathrm{a}}$ lei da termodinâmica, têm-se que o $2^{\circ}$ tensor de tensões de Piola-Kirchhoff $\mathbf{S}$ é o conjugado energético da deformação de Green Lagrange $\mathbf{E}$, portanto, aplicando a regra da cadeia e fazendo $I_{3}=1$ devido a hipótese de incompressibilidade adotada:

$$
\begin{aligned}
& \mathbf{S}=2 \frac{\partial u_{e}}{\partial \mathbf{C}}=2\left(\frac{\partial u_{e}}{\partial I_{1}} \frac{\partial I_{1}}{\partial \mathbf{C}}+\frac{\partial u_{e}}{\partial I_{3}} \frac{\partial I_{3}}{\partial \mathbf{C}}\right)=2\left(\frac{\partial u_{e}}{\partial I_{1}} \mathbf{I}+I_{3} \frac{\partial u_{e}}{\partial I_{3}} \mathbf{C}^{-1}\right) \\
& \mathbf{S}=-p \mathbf{C}^{-1}+2 \frac{\partial u_{e}}{\partial I_{1}} \mathbf{I}
\end{aligned}
$$

que na forma indicial é:

$$
S_{i j}=-p C_{i j}^{-1}+2 \frac{\partial u_{e}}{\partial I_{1}} \delta_{i j}
$$

O tensor constitutivo elástico $\mathbb{C}$, que por sua vez é obtido através de uma linearização de $\mathbf{S}$, fica sendo:

$$
\mathbb{C}=2 \frac{\partial \mathbf{S}}{\partial \mathbf{C}}=4\left[\frac{\partial}{\partial \mathbf{C}}\left(\frac{\partial u_{e}}{\partial I_{1}} \mathbf{I}\right)+\frac{\partial}{\partial \mathbf{C}}\left(I_{3} \frac{\partial u_{e}}{\partial I_{3}} \mathbf{C}^{-1}\right)\right]
$$

Tomando $I_{3}=1$ devido a hipótese de incompressibilidade adotada e sendo ainda $\alpha$ e A, respectivamente, um escalar e um tensor de ordem 2 escritos em função do tensor $\mathbf{B}$ 
também de ordem 2 (ver Apêndice F):

$$
\frac{\partial(\alpha \mathbf{A})}{\partial \mathbf{B}}=\alpha \frac{\partial \mathbf{A}}{\partial \mathbf{B}}+\mathbf{A} \otimes \frac{\partial \alpha}{\partial \mathbf{B}}
$$

Tem-se através da regra da cadeia que:

$$
\begin{aligned}
\mathbb{C} & =2 \frac{\partial \mathbf{S}}{\partial \mathbf{C}} \\
& =4\left[\frac{\partial u_{e}}{\partial I_{1}} \frac{\partial \mathbf{I}}{\partial \mathbf{C}}+\mathbf{I} \otimes \frac{\partial^{2} u_{e}}{\partial \mathbf{C} \partial I_{1}}+I_{3} \frac{\partial u_{e}}{\partial I_{3}} \frac{\partial \mathbf{C}^{-1}}{\partial \mathbf{C}}+\mathbf{C}^{-1} \otimes \frac{\partial}{\partial \mathbf{C}}\left(I_{3} \frac{\partial u_{e}}{\partial I_{3}}\right)\right] \\
& =4\left[\mathbf{I} \otimes\left(\frac{\partial^{2} u_{e}}{\partial I_{1} \partial I_{1}} \frac{\partial I_{1}}{\partial \mathbf{C}}+\frac{\partial^{2} u_{e}}{\partial I_{3} \partial I_{1}} \frac{\partial I_{3}}{\partial \mathbf{C}}\right)+I_{3} \frac{\partial u_{e}}{\partial I_{3}} \frac{\partial \mathbf{C}^{-1}}{\partial \mathbf{C}}\right. \\
& =4\left[\mathbf{I} \otimes\left(\frac{\partial^{2} u_{e}}{\partial I_{1} \partial I_{1}} \mathbf{I}\right)+I_{3} \frac{\partial u_{e}}{\partial I_{3}} \frac{\partial \mathbf{C}^{-1}}{\partial \mathbf{C}^{-1}} \otimes\left(\frac{\partial u_{e}}{\partial I_{3}} \frac{\partial I_{3}}{\partial \mathbf{C}}+I_{3} \frac{\partial^{2} u_{e}}{\partial \mathbf{C} \partial I_{3}}\right)\right] \\
& \left.+\mathbf{C}^{-1} \otimes\left(I_{3} \frac{\partial u_{e}}{\partial I_{3}} \mathbf{C}^{-1}+I_{3} \frac{\partial^{2} u_{e}}{\partial I_{1} \partial I_{3}} \frac{\partial I_{1}}{\partial \mathbf{C}}+I_{3} \frac{\partial^{2} u_{e}}{\partial I_{3} \partial I_{3}} \frac{\partial I_{3}}{\partial \mathbf{C}}\right)\right] \\
\mathbb{C} & =4\left(\frac{\partial^{2} u_{e}}{\partial I_{1} \partial I_{1}}\right) \mathbf{I} \otimes \mathbf{I}+4\left(I_{3} \frac{\partial u_{e}}{\partial I_{3}}\right) \mathbf{C}^{-1} \otimes \mathbf{C}^{-1}+4\left(I_{3} \frac{\partial u_{e}}{\partial I_{3}}\right) \frac{\partial \mathbf{C}^{-1}}{\partial \mathbf{C}} \\
& =4\left(\frac{\partial^{2} u_{e}}{\partial I_{1} \partial I_{1}}\right) \mathbf{I} \otimes \mathbf{I}+4\left(-\frac{1}{2} p\right) \mathbf{C}^{-1} \otimes \mathbf{C}^{-1}+4\left(-\frac{1}{2} p\right) \frac{\partial \mathbf{C}^{-1}}{\partial \mathbf{C}}
\end{aligned}
$$

que escrito na forma indicial utilizando a derivada $\partial \mathbf{C}^{-1} / \partial \mathbf{C}$ do anexo E é:

$$
\mathbb{C}_{i j k l}=4\left(\frac{\partial u_{e}}{\partial I_{1} \partial I_{1}}\right) \delta_{i j} \delta_{k l}-p\left(2 C_{i j}^{-1} C_{k l}^{-1}-C_{i k}^{-1} C_{j l}^{-1}-C_{i l}^{-1} C_{j k}^{-1}\right)
$$

O tensor de alongamento à direita de Cauchy-Green $\mathbf{C}$ para um elemento de barra simples incompressível $(\operatorname{det}(\mathbf{C})=1)$ é:

$$
\mathbf{C}=\left(\begin{array}{ccc}
\lambda^{2} & 0 & 0 \\
0 & 1 / \lambda & 0 \\
0 & 0 & 1 / \lambda
\end{array}\right) ; \quad \mathbf{C}^{-1}=\left(\begin{array}{ccc}
1 / \lambda^{2} & 0 & 0 \\
0 & \lambda & 0 \\
0 & 0 & \lambda
\end{array}\right)
$$

onde $\lambda$ é o alongamento e, portanto, nesse caso existe deformação na seção transversal da barra. Logo, apesar do elemento de barra simples ser um elemento com 1 grau de liberdade (axial), o problema é aqui abordado de forma tridimensional. Isso é possível porque a hipótese de incompressibilidade permite relacionar as deformações entre si, "eliminando" assim graus de liberdade, ou seja, conhecendo a deformação axial $\left(C_{11}\right)$, determinam-se as outras duas deformações $\left(C_{22}\right.$ e $\left.C_{33}\right)$ na seção transversal de forma direta. Na Equação G.8, admite-se também uma resposta igual nas duas direções da seção transversal da barra 
$\left(C_{22}=C_{33}\right)$. Adotando um estado uniaxial de tensões, isto é, $S_{22}=S_{33}=0$, é possível determinar de forma explícita o valor de $p$ :

$$
S_{22}=S_{33}=-p \lambda+2 \frac{\partial u_{e}}{\partial I_{1}}=0 \rightarrow p=\frac{2}{\lambda} \frac{\partial u_{e}}{\partial I_{1}}
$$

Portanto, conhecendo o segundo tensor de tensões de Piola Kirchhof $\mathbf{S}$ e o tensor elástico constitutivo $\mathbb{C}$, respectivamente, através das Equações G.3 e, G.7 e estando $p$ determinado pela Equação G.9, calcula-se o vetor de força interna e a hessiana do elemento de barra simples conforme, respectivamente, as Equações 3.144 e 3.138 da subseção 3.2.4. 

ANEXOS 

ANEXO

A

\section{HISTÓRICO DOS MODELOS CONSTITUTIVOS}

Apresenta-se neste item um histórico do desenvolvimento dos modelos constitutivos hiperelásticos conforme (HOSS, 2009).

1940 Mooney - Mooney (1940) propõe um modelo com dependência linear do primeiro e segundo invariante de deformação.

$$
\psi=c_{1}\left(I_{1}-3\right)+c_{2}\left(I_{2}-3\right)
$$

1943 Neo Hookeano - Treloar (1943) propõe um modelo que consiste na primeira parcela do modelo de Mooney.

$$
\psi=\frac{c_{1}}{2}\left(I_{1}-3\right)
$$

1951 Mooney Rivlin - Rivlin e Saunders (1951) generalizam o modelo inicialmente proposto por Mooney (1940) em termos de $I_{1}$ e $I_{2}$.

$$
\psi=\sum_{i+j=1}^{3} c_{i j}\left(I_{1}-3\right)^{i}\left(I_{2}-3\right)^{j}
$$

1958 Gent Thomas - Gent e Thomas (1958) modificam o modelo de Rivlin e Saunders (1951) considerando um termo logarítmico dependente de $I_{2}$.

$$
\psi=c_{1}\left(I_{1}-3\right)+3 c_{2} \ln \left(I_{2}\right)
$$

1966 Hart Smith - Smith et al. (1966) propõem uma nova família de modelos mesclando uma base exponencial com uma logarítmica.

$$
\psi=\frac{c_{1} e^{c_{3}\left(I_{1}-3\right)^{c_{4}}}}{c_{4}}+3 c_{2} \ln \left(I_{2}\right)
$$


1967 Fung - Fung (1967) introduz uma relação constitutiva exponencial para a modelagem de tecidos biológicos.

$$
\psi=\frac{c_{1}}{2 c_{2}}\left(e^{c_{2}\left(I_{1}-3\right)}-1\right)
$$

1968 Alexander - Alexander (1968) propõe uma expressão para a energia de deformação combinando as relações constitutivas dos modelos Hart - Smith e Rivlin - Sauders.

1970 Veronda Westmann - Veronda e Westmann (1970) modificaram o modelo de Fung (1967) adicionando um termo linear função de $I_{2}$.

$$
\psi=c_{1}\left[e^{c_{3}\left(I_{1}-3\right)}-1\right]-c_{2}\left(I_{2}-3\right)
$$

1972 Ogden - Ogden (1972) introduz um novo conceito, propondo uma expressão para a energia de deformação baseada diretamente nos alongamentos principais $\left(\lambda_{i}\right)$.

$$
\psi=\sum_{i=1}^{N} \frac{c_{i}}{d_{i}}\left(\lambda_{1}^{d_{i}}+\lambda_{2}^{d_{i}}+\lambda_{3}^{d_{i}}-3\right)
$$

1972 Peng Landel - Peng e Landel (1972) simplificam o modelo de Ogden (1972) utilizando uma única constante constitutiva.

$$
\psi=\sum_{i=1}^{3} c_{1}\left[\lambda_{i}-1-\ln \left(\lambda_{i}\right)-\frac{1}{6} \ln \left(\lambda_{i}\right)^{2}+\frac{1}{18} \ln \left(\lambda_{i}\right)^{3}-\frac{1}{216} \ln \left(\lambda_{i}\right)^{4}\right]
$$

1977 Knowles - Knowles (1977) propõe uma família de modelos baseada em termos de potências dos invariantes.

$$
\psi=\frac{c_{1}}{c_{2}}\left[\left(1+\frac{c_{2}\left(I_{1}-3\right)}{2 c_{3}}\right)^{c_{3}}-1\right]
$$

1981 Killian - Kilian (1981) propõe uma expressão com base logarítmica para a energia de deformação.

$$
\psi=-c_{1} c_{2}\left[\ln \left(1-\sqrt{\frac{I_{1}-3}{c_{2}}}\right)+\sqrt{\frac{I_{1}-3}{c_{2}}}\right]
$$

1981 Van der Waals - Kilian (1981) modifica o modelo proposto por Kilian (1981) através da consideração da contribuição do $I_{2}$.

$$
\begin{array}{r}
\psi=c_{1}\left[-\left(\lambda_{m}^{2}-3\right)(\ln (1-\eta)+\eta)-\frac{2}{3} c_{2}\left(\frac{1}{2} I_{1}^{\prime}-\frac{3}{2}\right)^{\frac{3}{2}}\right] \\
\eta=\sqrt{\frac{I_{1}^{\prime}-3}{\lambda_{m}^{2}-3}} \quad I_{1}^{\prime}=\left(1-c_{4}\right) I_{1}+c_{4} I_{2}
\end{array}
$$


1987 Humprey Yin - Humphrey e Yin (1987) propõem uma relação constitutiva de base exponencial, cuja versão isotrópica é função apenas de $I_{1}$.

$$
\psi=c_{1}\left(e^{c_{2}\left(I_{1}-3\right)}-3\right)
$$

1987 Edwards Vilgis - Edwards e Vilgis (1987) e Takamizawa e Hayashi (1987) propõem uma família limiting chain extensibility.

$$
\psi=\frac{c_{1}}{2}\left[\frac{\left(c_{2}+2\right)\left(c_{2}-3\right)\left(I_{1}-2\right)}{c_{2}\left(c_{2}-I_{1}+3\right)}+\ln \left(1-\frac{I_{1}-3}{c_{2}}\right)\right]
$$

1990 Yeoh - Yeoh (1990) propõe uma forma polinomial correspondente a uma forma truncada do modelo de Mooney-Rivlin.

$$
\psi=\sum_{i=1}^{N} c_{i 0}\left(I_{1}-3\right)^{i}
$$

1993 Yeoh Modified - Yeoh (1993) propõe uma modificação no modelo proposto de Yeoh(1990) através da adição de um termo exponencial.

$$
\psi=c_{10}\left(I_{1}-3\right)^{1}+c_{20}\left(I_{1}-3\right)^{2}+c_{30}\left(I_{1}-3\right)^{3}+\frac{c_{4}}{c_{5}}\left(1-e^{-c_{5}\left(I_{1}-3\right)}\right)
$$

1993 Arruda e Boyce - Arruda e Boyce (1993) propõem um modelo com potências de alta ordem de $I_{1}$, mostrando que a energia de deformação pode ser escrita como uma função apenas do primeiro invariante de deformação.

$$
\begin{aligned}
\psi= & c_{1}\left(\frac{1}{2}\left(I_{1}-3\right)+\frac{1}{20 c_{2}{ }^{2}}\left(I_{1}{ }^{2}-3^{2}\right)+\frac{11}{1050 * c_{2}{ }^{4}}\left(I_{1}{ }^{3}-3^{3}\right)+\right. \\
& \left.\frac{19}{7050 c_{2}{ }^{6}}\left(I_{1}{ }^{4}-3^{4}\right)+\frac{519}{673750 c_{2}{ }^{8}}\left(I_{1}^{5}-3^{5}\right)\right)
\end{aligned}
$$

1993 / 2002 - Yamashita e Kawabata (1993) seguidos por Davis et al., (1994), Gregory (1997) e Amin et al.(2002) propuseram uma função polinomial de potências a ajustar.

$$
\begin{gathered}
\psi=c_{1}\left(I_{1}-3\right)^{1}+\frac{c_{3}}{c_{2}+1}\left(I_{1}-3\right)^{c_{2}+1} \\
\psi=\frac{c_{1}}{2\left(1-c_{2} / 2\right)}\left(I_{1}-3+c_{3}^{2}\right)^{1-c_{2} / 2}+c_{4}\left(I_{1}-3\right)^{2} \\
\psi=\frac{c_{1}}{2-c_{2}}\left(I_{1}-3+c_{3}^{2}\right)^{1-c_{2} / 2}+\frac{c_{4}}{2+c_{5}}\left(I_{1}-3+c_{3}^{2}\right)^{1+c_{5} / 2} \\
\psi=c_{1}\left(I_{1}-3\right)+\frac{c_{2}}{c_{3}+1}\left(I_{1}-3\right)^{c_{3}+1}+\frac{c_{4}}{c_{5}+1}\left(I_{1}-3\right)^{c_{5}+1}
\end{gathered}
$$


1996 Gent - Gent (1996) propõe uma relação constitutiva de base logarítmica baseada no modelo de Takamizawa e Hayashi (1987).

$$
\psi=-\frac{c_{1}}{2}\left(c_{2}-3\right) \ln \left(1-\frac{I_{1}-3}{c_{2}-3}\right)
$$

1997 Yeoh e Fleming - Yeoh e Fleming (1997) mesclam os modelos propostos por Yeoh (1990) e Gent (1996).

$$
\psi=\frac{c_{1}}{c_{2}}\left(1-e^{c_{2}\left(I_{1}-3\right)}\right)-c_{3}\left(c_{4}-3\right) \ln \left(1-\frac{I_{1}-3}{c_{4}-3}\right)
$$

1998 Martins - Martins (1998) utiliza o modelo proposto por Humphrey (1987) para propor um modelo constitutivo para modelagem do comportamento passivo de tecidos musculares considerando duas parcelas para a energia de deformação: uma referente $\left(I_{1}\right)$ a matriz e outra as fibras $\left(\lambda_{f}\right)$.

$$
\psi=c_{1}\left(e^{c_{2}\left(I_{1}-3\right)}-1\right)+c_{3}\left(e^{c_{4}\left(\lambda_{f}-1\right)^{2}}-1\right)
$$

19993 Parameters Gent - Gent (1999) incorpora à expressão original proposta em Gent (1996) a participação do termo $I_{2}$.

$$
\psi=\frac{c_{1}}{2}\left[-c_{3}\left(c_{2}-3\right) \ln \left(1-\frac{I_{1}-3}{c_{2}-3}\right)+\left(1-c_{3}\right)\left(I_{2}-3\right)\right]
$$

2002 Pucci Saccomandi - Pucci e Saccomandi (2002) também incorporam a participação do termo $I_{2}$ no modelo inicialmente proposto por Gent (1996).

$$
\psi=-\frac{1}{2} c_{1} c_{3} \ln \left(1-\frac{I_{1}-3}{c_{3}}\right)+c_{2} \ln \left(\frac{1}{3} I_{2}\right)
$$

2003 Hartmann Neff - Hartmann e Neff (2003) propuseram uma função policonvexa para a energia de deformação em termos dos invariantes $I_{1}$ e $I_{2}$.

$$
\psi=c_{1}\left(I_{1}^{3}-3^{3}\right)+\sum_{i=1}^{N} c_{i}\left(I_{1}-3\right)^{i}+\sum_{j=1}^{m} c_{j}\left(I_{2}{ }^{3 / 2}-3 \sqrt{3}\right)^{j}
$$

2004 Horgan Saccomandi - Horgan e Saccomandi (2004) propõem um modelo capaz de descrever o feito de Mullins dos elastômeros.

$$
\psi=-\frac{c_{1}}{2} c_{3} \ln \left[\frac{\left(1-\frac{\lambda_{1}^{2}}{c_{2}}\right)\left(1-\frac{\lambda_{2}^{2}}{c_{2}}\right)\left(1-\frac{\lambda_{3}^{2}}{c_{2}}\right)}{\left(1-\frac{1}{c_{2}}\right)^{3}}\right]
$$

2005 Bechir - Bechir et al., (2005) adicionam ao modelo Neo Hookeano um novo conjunto de invariantes.

$$
\psi=\sum_{n=1}^{\infty} \sum_{r=1}^{\infty}{c_{n}}^{r}\left(\lambda_{1}^{2 n}+\lambda_{2}^{2 n}+\lambda_{3}^{2 n}-3\right)
$$


ANEXO

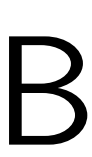

\section{PONTOS E PESOS DE HAMMER}

Tabela 5 - Pontos e pesos de Hammer

\begin{tabular}{ccccc}
\hline$i h$ & $\xi_{1}$ & $\xi_{2}$ & $\xi_{3}$ & $w_{i h}$ \\
\hline \hline 1 & $1 / 3$ & $1 / 3$ & $1 / 3$ & 0,11250 \\
\hline 2 & 0,797426985353087 & 0,101286507323456 & 0,101286507323456 & $0,125939180544827 / 2$ \\
\hline 3 & 0,101286507323456 & 0,797426985353087 & 0,101286507323456 & $0,125939180544827 / 2$ \\
\hline 4 & 0,101286507323456 & 0,101286507323456 & 0,797426985353087 & $0,125939180544827 / 2$ \\
\hline 5 & 0,470142064105115 & 0,470142064105115 & 0,059715871789770 & $0,132394152788506 / 2$ \\
\hline 6 & 0,059715871789770 & 0,470142064105115 & 0,470142064105115 & $0,132394152788506 / 2$ \\
\hline 7 & 0,470142064105115 & 0,059715871789770 & 0,470142064105115 & $0,132394152788506 / 2$ \\
\hline Fonte: Assan, 2000 & & &
\end{tabular}

